\title{
Earthquake-induced hydrogeological changes in New Zealand
}

By

Konrad Cedd Weaver

\author{
A thesis submitted to \\ Victoria University of Wellington \\ in fulfilment of the requirements \\ for the degree of \\ Doctor of Philosophy in Geophysics
}

Victoria University of Wellington

2018 


\section{Abstract}

Earthquakes redistribute fluids and change associated flow paths in the subsurface. Earthquake hydrology is an evolving discipline that studies such phenomena, providing novel information on crustal processes, natural hazards and water resources. This thesis uses the internationally significant New Zealand "hydroseismicity" dataset, in a regional-scale multi-site multi-earthquake study which includes the occurrence and the absence of responses, spanning a decade. Earthquake-induced groundwater level and tidal behaviour changes were examined in a range of aquifers, rock types and hydrogeological settings. Monitoring wells were within one (near-field) to several (intermediatefield) ruptured fault lengths of a variety of earthquakes that had a range of shaking intensities. This thesis presents three studies on the seismic and hydrogeological controls on earthquake-induced groundwater level changes.

Water level changes were recorded New Zealand-wide within compositionally diverse, young shallow aquifers, in 433 monitoring wells at distances between 4 and 850 $\mathrm{km}$ from the $2016 \mathrm{M}_{\mathrm{w}} 7.8$ Kaikōura earthquake epicentre. Water level changes are inconsistent with static stress changes, but do correlate with peak ground acceleration (PGA). At PGAs exceeding $\sim 2 \mathrm{~m} / \mathrm{s}^{2}$, water level changes predominantly increased persistently, which may have resulted from shear-induced consolidation. At lower PGAs there were approximately equal numbers of persistent water level increases and decreases, which are thought to have resulted from permeability enhancement. Water level changes also occurred more frequently north of the epicentre, due to the northward directivity of the Kaiköura earthquake rupture. Local hydrogeological conditions also contributed to the observed responses, with larger water level changes occurring in deeper wells and in well-consolidated rocks at equivalent PGA levels.

Earthquakes have previously been inferred to induce hydrological changes in aquifers on the basis of changes to well tidal behaviour and water level, but the relationship between these changes have been unclear. Earthquake-induced changes to tidal behaviour and groundwater levels were quantified in 161 monitoring wells screened in gravel aquifers in Canterbury, New Zealand. In the near-field of the Canterbury earthquake sequence of 2010 and 2011, permeability reduction detected by tidal behaviour changes and increased water levels supports the hypothesis of shear-induced consolidation. Water level changes that occurred with no change in tidal behaviour re-equilibrated at a new post-seismic level within $\sim 50$ minutes possibly due to high permeability, good well-aquifer coupling, and/or small permeability changes in the local aquifer. Water 
level changes that occurred with tidal behaviour changes took from $\sim 240$ minutes to $\sim 10$ days to re-equilibrate, thought to represent permeability changes on a larger scale.

Recent studies commonly utilise a general metric for earthquake-induced hydrological responses based on epicentral distance, earthquake magnitude and seismic energy density. A logistic regression model with random effects was applied to a dataset of binary responses of 495 monitoring well water levels to $11 \mathrm{M}_{\mathrm{w}} 5.4$ or larger earthquakes. Within the model, earthquake shaking (represented by peak ground velocity), degree of confinement (depth) and rock strength (site average shear wave velocity in the shallow subsurface) were incorporated. For practical applications, the probabilistic framework was converted into the Modified Mercalli (MM) intensity scale. The model shows that water level changes are unlikely below MM intensity VI. At an MM intensity VII, water level changes are about as likely as not to very likely. At MM intensity VIII, the likelihood rises to very likely to virtually certain. This study was the first attempt we are aware of worldwide at incorporating both seismic and hydrogeological factors into a probabilistic framework for earthquake-induced groundwater level changes. The framework is a novel and more universal approach in quantifying responses than previous metrics using epicentral distance, magnitude and seismic energy density. It has potential to enable better comparison of international studies and inform practitioners making decisions around investment to mitigate risk to, and to increase the resilience of, water supply infrastructure. 


\section{Acknowledgements}

Firstly, I'd like to thank my primary supervisor Simon Cox, for being incredibly supportive and providing guidance throughout my PhD at Victoria University of Wellington. I'd also like to thank my secondary supervisor John Townend for his advice with my research. Mai-Linh Doan, Caroline Holden, Richard Arnold, Ian Hamling and Helen Rutter have also provided invaluable support with projects within my PhD.

I'm grateful for the major funding source of this PhD, which was obtained by Simon Cox from the Royal Society of New Zealand Marsden Fund "Earthquake Hydrology: seismic pumps or broken pipes?" (12-GNS-003). Funding was also provided by Victoria University of Wellington, the New Zealand Hydrological Society, and Geoscience Society of New Zealand. Thought-provoking discussions have been had with collaborators and colleagues in New Zealand and abroad: Chi-Yuen Wang, Michael Manga, Xin Liao, Julian Weir, Michael Friedel, Charles Williams, Robert Holdsworth, Jon Gluyas, Adrian Butler, Mohammed Hoque, and Paul Younger. Past earthquake hydrology students Anton Gulley, Annabel Cohen and Grant O'Brien have shown me the numerous pathways that can be explored within the earthquake hydrology discipline.

This PhD would not have come to fruition if it weren't for the first-rate work by New Zealand's regional councils who install, manage, and maintain the dense monitoring hydrological networks and provide access to their databases. It has been a privilege to work with: Susie Osbaliston, Sandrine Le Gars, Alan Bee, Andrew Lester, Nicholas Holwerda, Diane Harvey, Brent Hutchby, Matthew McGill-Brown, Simon Harper, John Hughey, Jane Harvey, Fiona Jansma, Regan Phipps, Stephen Collins, Brent Watson, Sheree Tidswell, Doug Mzila, Mike Thompson, Peter Davidson, Joseph Thomas, Monique Harvey, Shaun Thomsen, Andrew Egan, Nineva Vaitupu and Michael Killick. Hydrological data from industry were also provided by Neil Whitford, Ross Hector, Erik Van Nieuwkerk, Nic Conland and Steve Easthope. Working with datasets from GeoNet, the National Institute of Water and Atmospheric Research and Land Information New Zealand has been a great benefit.

It has been a privilege to be a part of the VUW SGEES post-grad community. I'd like to especially thank my past and present office mates Pegah Faegh Lashgary, Holly Godfrey, Lucie Janků-Čápová and Hubert Zal who have provided insightful scientific discussions and good humour. Thank you to other past and present SGEES post-grad students: Rachel Heckels, Jesse-Lee Dimech, Laura-May Baratin, Dominic Evanzia,

Katie Jacobs, Lucas Janků, Kenny Graham, Clement Roussel, Chet Hopp, Cecile Mas- 
siot, Konstantinos Michailos, Francesco Civilini, Steven Sewell, Calum Chamberlain, Emily Warren-Smith, Georgia Grant, Abhijith Ulayottil Venugopal, Marcel Mizera, Jurgen Osterle, Leo Pure, Elliot Swallow, Lucek Luc, Tom Womack and many others. I am also indebted to staff members within the School of Geography, Environment and Earth Sciences and the Antarctic Research Centre such as Dez Tessler, Adrian Benson, Alec Beliaev, Darcy Mandeno, Miranda Voke, Monika Hanson, Emma Fisher, Euan Smith, Simon Lamb, Martha Savage, Rupert Sutherland, Tim Stern, Tim Little, Carolyn Boulton, Jim McGregor, Rewi Newnham and Bethanna Jackson. Getting to know the Deep Fault Drilling Project Science team, scientists at GNS Science, Aqualinc Research Ltd and the numerous conferences has broadened my knowledge. Post-graduate students from the University of Otago have also been great to work with including Jack Williams, Kat Sauer and many others.

Outside of work, sailing has kept me refreshed with special thanks to Paul and Suellen Davies who have kept me distracted when I needed a break. It's been an honour to get to know Nikki Carey and my New Zealand relatives, especially Alan, Ronnie and the Harrison family. Furthermore, the Cox family (Simon, Anna, Charlie, Katy, Judy, Bar and Brian) took me in when I first arrived in New Zealand, and helped with the transition overseas.

Most importantly, I'd like to express gratitude to my family and friends for their endless support. My friends Ben, Brad, Peter, Oli, Thea, and many others have kept me sane through the journey and put a smile on my face. My uncles, aunts and cousins have kept encouraging me. My granddads Larry and Stanisław, and my brother Bart have given me strength when I needed it. Finally, Mum and Dad have experienced this $\mathrm{PhD}$ as much as I have. I am eternally gratefully for their support and am forever indebted to them both. 


\section{Contents}

Abstract iii

Acknowledgements $\quad$ v

List of Figures $\quad$ xii

List of Tables $\quad$ xiii

1 Motivations and research questions 1

1.1 Motivations ......................... 2

1.2 Research questions . . . . . . . . . . . . . . . 5 5

1.3 Thesis content . . . . . . . . . . . . . . 7

1.4 Statement of contributions . . . . . . . . . . . . . . 9 9

2 Background and scientific approach $\quad 11$

2.1 Mechanisms of hydrological responses to earthquakes . . . . . . . . 11

Static stress changes . . . . . . . . . . . . . 15

Dynamic stress changes . . . . . . . . . . . . . 16

Hydrogeological factors . . . . . . . . . . . . . . . 19

Crustal stress state . . . . . . . . . . . . 21

2.2 New Zealand geological setting . . . . . . . . . . . . . . . . 21

Tectonics ..................... 21

Hydrogeology . . . . . . . . . . . . . . . . . 24

2.3 Previous earthquake hydrology research in New Zealand . . . . . . . . 24

2010-2011 Canterbury earthquake sequence . . . . . . . 24

Multi-earthquake studies . . . . . . . . . . . . . 26

2.4 Data sources . . . . . . . . . . . . . . . . . . 28

2.5 Scientific approach ..................... 32

3 Case study of the $2016 M_{w} 7.8$ Kaikōura earthquake 35

3.1 Abstract . . . . . . . . . . . . . . . . . 35

3.2 Introduction . . . . . . . . . . . . . . . 36

3.3 New Zealand hydrogeology . . . . . . . . . . . . . . . . 37

3.4 Hydrological and seismic data . . . . . . . . . . . . . 37

3.5 Groundwater-level changes induced by the Kaikōura earthquake . . . . 40 
3.6 The influence of earthquake driven factors on water-level changes . . . 40

Earthquake-induced static stress changes . . . . . . . . . . 40

Earthquake-induced dynamic shaking . . . . . . . . . . . 44

3.7 The influence of local hydrogeological factors on water-level changes . . 49

Depth ....................... 50

Shear wave velocity ................... 51

3.8 Discussion . . . . . . . . . . . . . . . . 54

Earthquake-induced static stress changes . . . . . . . . 54

Earthquake-induced dynamic shaking . . . . . . . . . 55

Local hydrogeological factors . . . . . . . . . . . . . 57

3.9 Conclusion . . . . . . . . . . . . . . . . . . 58

3.10 Acknowledgements . . . . . . . . . . . . . . . 60

4 Tidal behaviour and water-level changes to multiple earthquakes $\quad 61$

4.1 Abstract ........................ 61

4.2 Introduction . . . . . . . . . . . . . . . . 62

Tectonics and hydrogeological setting ......... 63

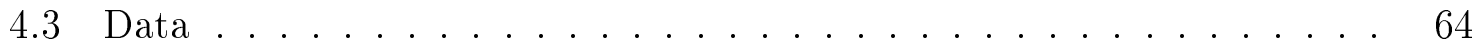

Seismic data . . . . . . . . . . . . . 64

Hydrological data . . . . . . . . . . . . . . . 64

4.4 Material and methods . . . . . . . . . . . . . . 66

Tidal computation ............... 66

Water-level fluctuations caused by earth and ocean tides . . . . 68

Earthquake-induced tidal behaviour changes . . . . . . . . 70

Earthquake-induced water-level changes . . . . . . . . 70

Stress changes . . . . . . . . . . . . . 71

Uncertainties and assumptions . . . . . . . . . . 72

4.5 Results . . . . . . . . . . . . . . . . . 73

Identification of the origin of the tides . . . . . . . 73

Earthquake-induced tidal behaviour changes . . . . . . . . 76

Earthquake-induced water-level changes . . . . . . . . 77

Comparison of tidal behaviour and water-level changes . . . . 78

4.6 Discussion . . . . . . . . . . . . . . . . . . . 81

Mechanisms for water-level and tidal behaviour change . . . . 81

Peak dynamic stress . . . . . . . . . . . . 83

Comparison of tidal behaviour and water-level changes . . . . 84

4.7 Conclusion . . . . . . . . . . . . . . . . . . 85

4.8 Acknowledgments . . . . . . . . . . . . . . . . 86 
$5 \quad$ Aquifer susceptibility to earthquake-induced water-level changes $\quad 87$

5.1 Abstract . . . . . . . . . . . . . . . . 87

5.2 Introduction . . . . . . . . . . . . . . 88

Previous studies ..................... 88

5.3 New Zealand tectonics and hydrogeology . . . . . . . . . . . . . 90

5.4 Seismic and hydrological monitoring, and the classification of data . . 91

5.5 Methods . . . . . . . . . . . . . . . . . . 94

Logistic regression analysis . . . . . . . . . . . . 94

Predictor selection . . . . . . . . . . . . 95

Jackknife variance estimation . . . . . . . . . . . . . 97

5.6 Results . . . . . . . . . . . . . . . . . . . 98

All seismic predictor model . . . . . . . . . . . 100

One seismic predictor model . . . . . . . . . . . 100

5.7 Discussion . . . . . . . . . . . . . . . 106

All seismic predictor model . . . . . . . . . . 106

One seismic predictor model . . . . . . . . . . . 107

Marginal probabilities . . . . . . . . . . . 107

Future work . . . . . . . . . . . . . 111

5.8 Conclusions . . . . . . . . . . . . . . . . . . . 112

5.9 Acknowledgements . . . . . . . . . . . . . . 113

6 Summary and directions for future research $\quad 115$

6.1 Key results of each study . . . . . . . . . . . . . . . 115

6.2 Research questions revisited . . . . . . . . . . . . . 117

6.3 Implications for future research . . . . . . . . . . . . . . . . 120

6.4 Discussion: New research avenues and ideas . . . . . . . . . . . 122

6.5 Concluding statement . . . . . . . . . . . . . . 128

$\begin{array}{lr}\text { Appendix } & 129\end{array}$

A Tidal analysis: Earth and ocean tidal responses 131

$\begin{array}{ll}\text { Bibliography } & 135\end{array}$ 


\section{List of Figures}

1.1 Well response induced by the $2004 \mathrm{M}_{\mathrm{w}} 9.2$ Sumatra earthquake . . . . 2

1.2 Damage to wells caused by the $2010 \mathrm{M}_{\mathrm{w}} 7.1$ Darfield earthquake . . . . 4

1.3 Damage after the $\mathrm{M}_{\mathrm{w}} 6.2$ Christchurch earthquake in February 2011 . . 5

2.1 Earthquake magnitudes and epicentral distances for international studies 12

2.2 Time-shifting and re-sampling a hydroseismogram response . . . . . . . 13

2.3 Example of groundwater response types . . . . . . . . . . . . . . . 14

2.4 Co-seismic static stress and water-level changes in Iceland . . . . . . 16

2.5 Groundwater-level changes to as a function of epicentral distance . . . 18

2.6 Flow chart relationship between earthquakes and hydrogeology . . . . . 19

2.7 Schematic crustal cross-section across New Zealand . . . . . . . . . . . 22

2.8 Geological map of New Zealand . . . . . . . . . . . . . . . . . . . 23

2.9 Water-level changes induced by the 2010 Darfield $\mathrm{M}_{\mathrm{w}} 7.1$ earthquake . 25

2.10 Step-drawdown tests pre- and post-Darfield earthquake . . . . . . . 26

2.11 Examples of hydrological data from Cromwell Gorge . . . . . . . . . . . 27

2.12 Spatial distribution of the 11 earthquakes studied in this thesis . . . . . 30

2.13 Spatial distribution of the seismic and hydrological datasets . . . . . . 31

2.14 Schematic comparison of datasets between international studies . . . . 33

3.1 Spatial distribution of the hydrological and seismic sites . . . . . . . . 39

3.2 Spatial distribution of water-level changes . . . . . . . . . . . . . 41

3.3 Magnitude v epicntral distance for New Zealand and international studies 42

3.4 Spatial distribution of water-level changes and mean static stress changes 43

3.5 Relationship between mean static stress changes and water-level changes 44

3.6 Spatial distribution of water-level changes, maximum PGV and PGA . 46

3.7 Water-level change amplitude as a function of PGV, and PGA . . . . . 48

3.8 Transect of Kaikōura earthquake responses, shaking and stress changes 49

3.9 WLC/PGA as a function of monitoring well depth. . . . . . . . . . 51

$3.10 \mathrm{WLC} / \mathrm{PGA}$ as a function of $\mathrm{Vs}_{30} \ldots \ldots \ldots \ldots \ldots$

4.1 Seismic and hydrological monitoring in Canterbury, New Zealand . . . 65

4.2 Monitoring well tides characterised by $\mathrm{M}_{2}$ amplitude and $B K_{u} \ldots \ldots$

4.3 Distribution of monitoring wells in Canterbury . . . . . . . . . . 75

4.4 A schematic of the coastal Canterbury plains aquifer system . . . . . 75 
4.5 Water-level and $\mathrm{M}_{2} \phi_{\text {lag }}$ time-series . . . . . . . . . . . 77

4.6 Table of tidal behaviour and water-level changes . . . . . . . . . . 79

4.7 Earthquake dynamic stresses, tidal behaviour and water-level changes . 80

4.8 Cross-plots comparing water-level and $\mathrm{M}_{2} \phi_{\text {lag }}$ changes . . . . . . . . 81

4.9 Box plots showing water-level change duration . . . . . . . . . . 82

5.1 Spatial distribution of earthquakes and seismic and hydrological sites . 93

5.2 Violin plots of predictors when responses and no responses occur . . . . 99

5.3 The receiver operating characteristic curve for the OSPM . . . . . . . . 104

5.4 Marginal probabilities of persistent water-level changes in the OSPM . 110

6.1 Seismic and hydrological response at DFDP-1A and DFDP-1B . . . . 123

6.2 Groundwater-level response above and below the PSZ in DFDP-1B . . 123

6.3 Time-series of turbidity, flow and rainfall . . . . . . . . . . . . 125

6.4 Turbidity decay constants before and after the Kaikōura earthquake . . 125

6.5 Lake Horowhenua water-level, groundwater-level, stream-flow . . . . . . 127

A.1 Map showing clustered wells in the Canterbury Plains monitoring system 133

A.2 Water-level changes that occurred nearby permeability changes . . . . . 134 


\section{List of Tables}

2.1 Major mechanisms that may explain groundwater-level changes . . . 15

2.2 Table of the 11 earthquakes studied in this thesis . . . . . . . . . 28

2.3 Table comparing datasets of international studies . . . . . . . . . 32

4.1 Table of the nine earthquakes that occurred between 2008 and 2015 . . 66

4.3 Table of the $\mathrm{M}_{2} \phi_{\text {lag }}$ changes . . . . . . . . . . . . . 76

4.5 Tally of the water-level changes . . . . . . . . . . 78

4.7 Combination tally of tidal behaviour and water-level changes . . . . . 79

5.1 Table of the 11 earthquakes that occurred between 2008 and 2017 . . 92

5.2 Table of the responses and no responses observed in the five datasets . 94

5.3 Pair analysis response combinations at a range of radii . . . . . . . . 99

5.4 Mixed effects logistic regression results from the ASPM . . . . . . . 101

5.5 Mixed effects logistic regression results from the OSPM . . . . . . . . . 102

5.6 Jackknife estimates (earthquake) for the OSPM . . . . . . . . . 105

5.7 Jackknife estimates (well) for the OSPM . . . . . . . . . . . 105

5.8 Akaike Information Criterion for the ASPM and OSPM . . . . . . . . 111

5.9 Probability of responses at different Modified Mercalli intensity scales . 112

A.1 Table of sea level sites, locations, physical and tidal properties . . . . 131

A.2 Table of earth tide boreholes, locations, physical and tidal properties - 131

A.3 Table of ocean tide borehole location, physical and tidal properties . . . 132 


\section{Motivations and research questions}

Earthquakes redistribute fluids and change associated flow paths in the subsurface. Earthquake hydrology is an evolving discipline that studies such phenomena, providing novel information on crustal processes, natural hazards and water resources. Although there are extensive networks for seismic and groundwater monitoring in New Zealand due to the high levels of seismic activity and heavy reliance on groundwater, there have been few investigations of earthquake-induced hydrological responses and their causes. This thesis focuses on contributing local observations of earthquake-induced changes to groundwater levels and tidal behaviour, providing locally important and internationally significant observations from New Zealand.

Earthquakes can influence the hydrological regime in surface waters (Montgomery et al., 2003; Montgomery and Manga, 2003) and groundwater (Roeloffs, 1998), affecting water quality (e.g. Manga and Rowland, 2009; Cox et al., 2015; Rutter et al., 2018) and quantity (Manga, 2001; Wang and Chia, 2008; Chen and Wang, 2009). Furthermore, earthquakes may affect hydrological processes in a variety of environments (Manga and Brodsky, 2006; Dykes et al., 2017) and seismic shaking may cause surface sediments to lose strength and liquefy (Galli, 2000; Berrill et al., 1994; Ambraseys, 1988). Earthquakes can affect fluid pressures thousands of kilometres from earthquake epicentres (Figure 1.1, Brodsky et al., 2003; Shi and Wang, 2014; Weingarten and Ge, 2014; Zhang et al., 2015), which may inturn trigger seismicity (e.g. Velasco et al., 2008). Since responses vary with distance from the earthquake epicentre, the following general expressions are commonly adopted (Wang and Manga, 2010a): near-field denotes one rupture fault length, intermediate-field represents one to ten rupture fault lengths and far-field includes greater distances. 


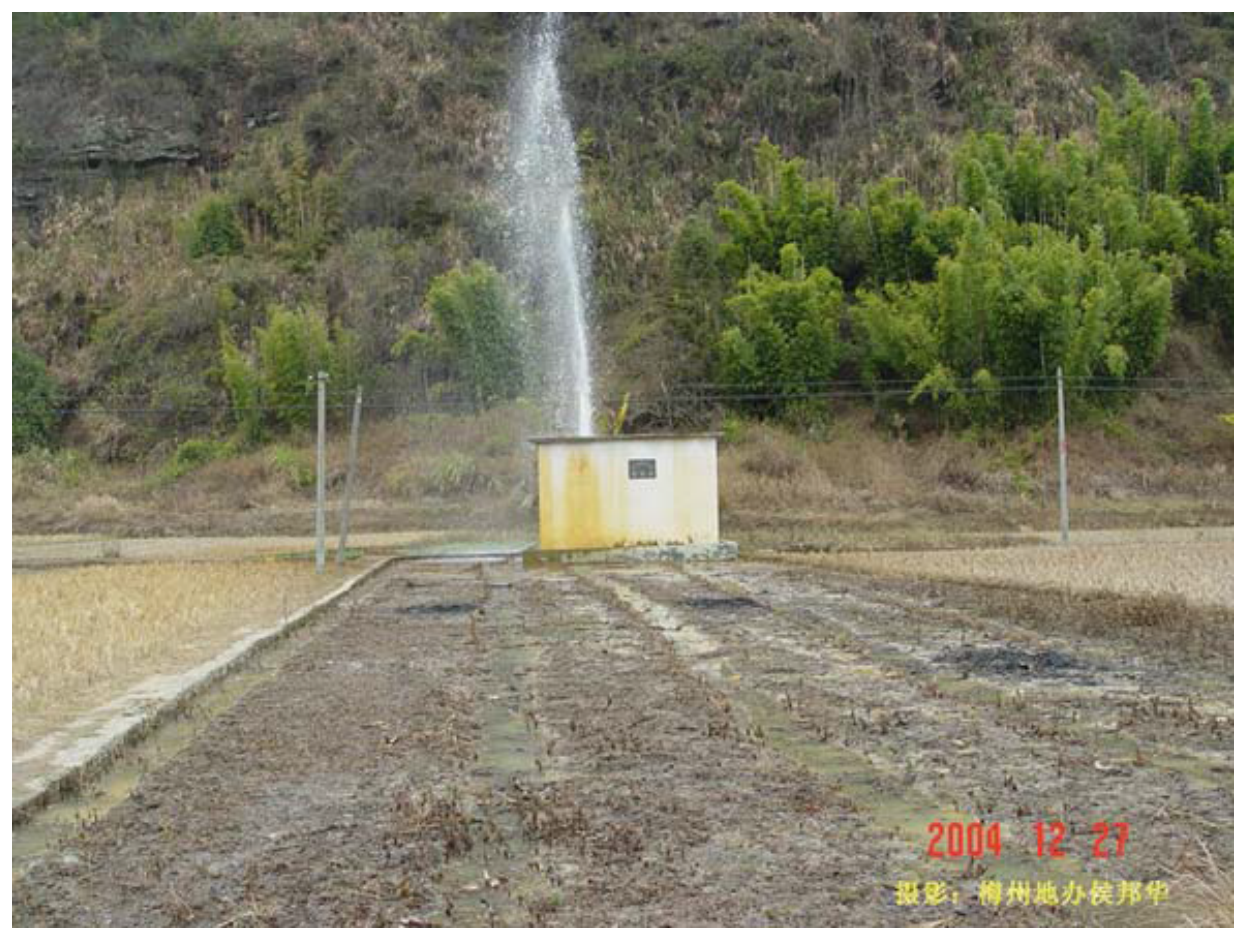

Figure 1.1: Photo of the response of a monitoring well in China taken two days after the $2004 \mathrm{M}_{\mathrm{w}} 9.2$ Sumatra earthquake $\sim 3200 \mathrm{~km}$ away. The fountain was $\sim 50$ to $60 \mathrm{~m}$ high one day after the earthquake. Photo taken by Hou Banghua, Earthquake Office of Meizhou County, Guangdong. From Wang and Manga (2010a).

\subsection{Motivations}

This thesis addresses the interaction between seismic and hydrogeological processes, and in doing so is motivated to provide internationally significant examples of crustal hydromechanics, assist in the mitigation and prediction of natural hazards and support infrastructural decision-making in the public and private sector.

In recent decades there been increasing recognition that fluids are mechanically involved within all stages of the earthquake cycle (Sibson, 1994; Faulkner et al., 2010) and that permeability fluctuations play a key role in the rupture-reactivation-cementation cycle (Dempsey et al., 2014; Sutherland et al., 2012; Boulton et al., 2017). In active tectonic environments, permeability appears to be dynamically self-regulating (cf. Townend and Zoback, 2000; Weis et al., 2012) and coupled with the structure and mechanics of fault zones (Faulkner et al., 2010; Bense et al., 2013). The self-regulating nature of permeability is achieved through competing processes that increase and decrease the connectivity and volume of voids and fractures (Rojstaczer et al., 1995). Permeability changes can be induced by earthquakes, both locally and distally, directly or indirectly through changes in static and dynamic stress (Wang and Manga, 2010a). Creep-related water-level change (e.g. Johnson et al., 1973; Mortensen et al., 
1977 ) could be related to fault plane permeability, propagation speed, slip distribution and hydraulic diffusivity of the reservoir rock (Roeloffs and Rudnicki, 1986; Rudnicki and Roeloffs, 1990; Wesson, 1981; Roeloffs and Rudnicki, 1984). On a larger-scale, it is postulated that high pore pressures partially contribute to the conditions required for slow slip earthquakes (SSEs; Saffer and Wallace, 2015). The impact fluids have on the occurrence of SSEs is important because SSEs may trigger potentially large earthquakes in the region surrounding aseismic slip (Ito et al., 2013; Kato et al., 2012). Water-level changes have additionally been assessed for precursory earthquake signals (Liu et al., 2013; Shi et al., 2013a).

Natural hazards may be influenced by the coupling of seismic and hydrological processes. Seismically-induced hydrological changes may contribute to the severity of droughts or floods (Chen and Wang, 2009), influence geothermal activity (Linde and Sacks, 1998; Manga and Brodsky, 2006; Bonini et al., 2016), or control the extent of liquefaction (Wang, 2007). Thresholds of stress (e.g. Seed and Idriss, 1967; Youd, 1972) and strain (e.g. Dobry et al., 1982; Vucetic, 1994) demonstrate that the incidence of consolidation-induced liquefaction (Terzaghi, 1925) may occur at distances up to $\sim 1$ ruptured fault length. However, liquefaction beyond these epicentral distances may be caused by dynamic shaking that generates and/or enhances pathways between sources and soil sites, which in turn may cause pore-pressure spreading (Wang, 2007). Landslides and lateral spreading may be triggered by pore-pressure increases. Thus, understanding the non-linear effects of fluid movement during seismic events may help determine liquefaction susceptibility (Wang, 2007), landslide occurrence (Seed, 1968) and land damage.

Natural hazards associated with earthquake-induced hydrological responses can also influence ecological systems. In many parts of the world biodiversity has been reduced in forests due to landslides (Allen et al., 1999), tsunamis (Jacoby et al., 1997) and groundwater fauna have been affected by changing groundwater-levels (Galassi et al., 2014). In some instances, increased water discharge at the surface temporarily promotes root-water-uptake (Mohr et al., 2015).

Boreholes and associated monitoring equipment are costly to install and maintain and can be subject to damage during earthquakes (Figure 1.2). Earthquake shaking may result in water-related damage to piezometers and data loggers rendering monitoring non-functional. Turbidity increases within well waters may cause screens to become clogged with sediment, reducing well productivity and increasing extraction costs (e.g. Zemansky et al., 2012; Rutter et al., 2016). Elucidating the controls on such problems may advise protocol for post-earthquake management of infrastructure. 

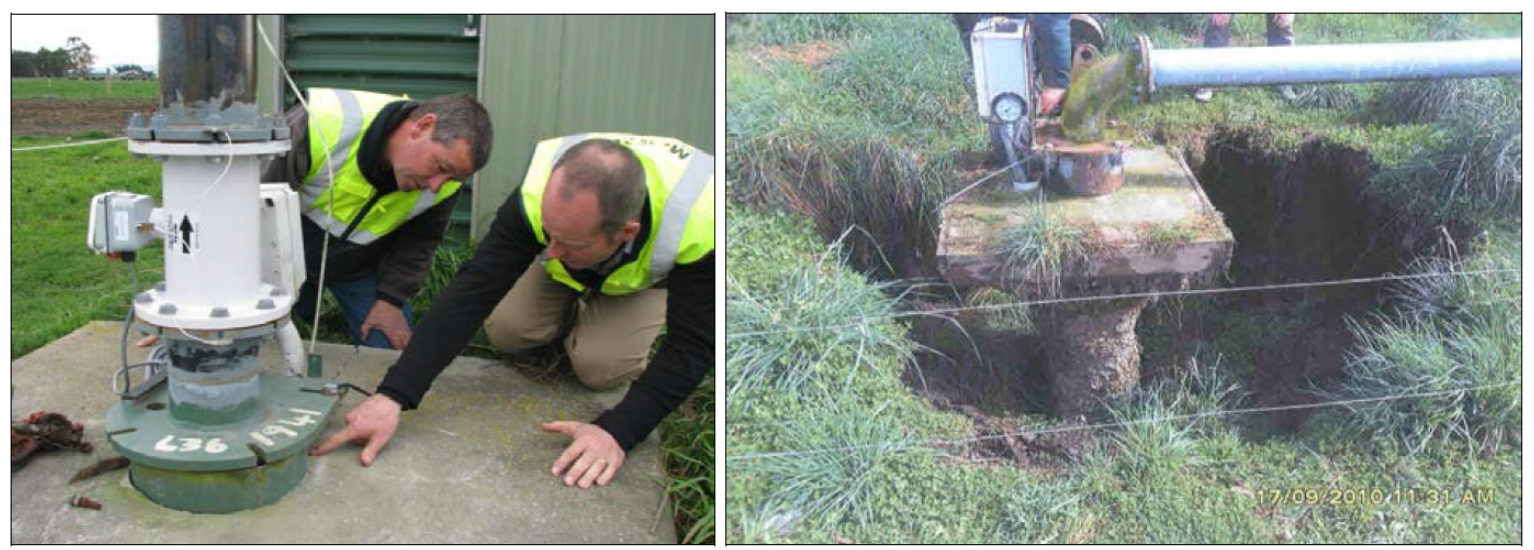

Figure 1.2: Example of damage to wells in the Canterbury Plains caused by the 2010 $\mathrm{M}_{\mathrm{w}} 7.1$ Darfield earthquake. Some well heads were affected by subsidence while others rose out of the ground. Photos from Zemansky et al. (2012).

The understanding of seismically induced fluid flow processes can aid industry with resource development and management, and advance extraction methods. Seismicityinduced flow may compromise the longevity of $\mathrm{CO}_{2}$ (Zoback and Gorelick, 2012; Gleeson and Ingebritsen, 2016), waste-water (Keranen et al., 2014) and nuclear waste (Carrigan et al., 1991) repositories. Furthermore, fluid injection can induce seismicity through hydraulic fracturing (e.g. Ellsworth, 2013; Keranen et al., 2014).

Earthquakes may cause permanent changes in aquifer permeability and/or storativity, altering an aquifer's capability to store and transport fluids. Permeability controls hydrocarbon migration (Gluyas and Swarbrick, 2013) and influences the advection of heat and solutes (Cox et al., 2015). Static stress changes may re-distribute and concentrate resources into economically viable units for extraction. Seismic pumps (Sibson et al., 1975) may provide an elegant way to transport large volumes of hydrocarbons (Burley et al., 1989), especially where buoyancy driven pathways are inadequate. Furthermore, seismic pumping and fluid pressure differentials are thought to control the distribution of mineral deposits, which are commonly found in fault jogs or other dilatational sites (Sibson, 1986). Yet, case-studies of real-time fluid flow around faults during fault-rupture (e.g Cox et al., 2012) are not consistent with the seismic pumping model.

The last decade in New Zealand has seen substantially more large-scale seismic activity (Kaiser et al., 2017) than in the four decades prior (Downes and Dowrick, 2015; Nicol et al., 2016). Furthermore, the Alpine Fault is thought to be late in its seismic cycle ( $\sim 300$ years $)$ and typically ruptures with large magnitude $\left(\sim \mathrm{M}_{\mathrm{w}} 8\right.$; Sutherland et al., 2007; Berryman et al., 2012; Howarth et al., 2014). With an increasing number of earthquakes in New Zealand in the last decade, there has been a realisation that the New Zealand "hydroseismicity" dataset is internationally significant and worthy 

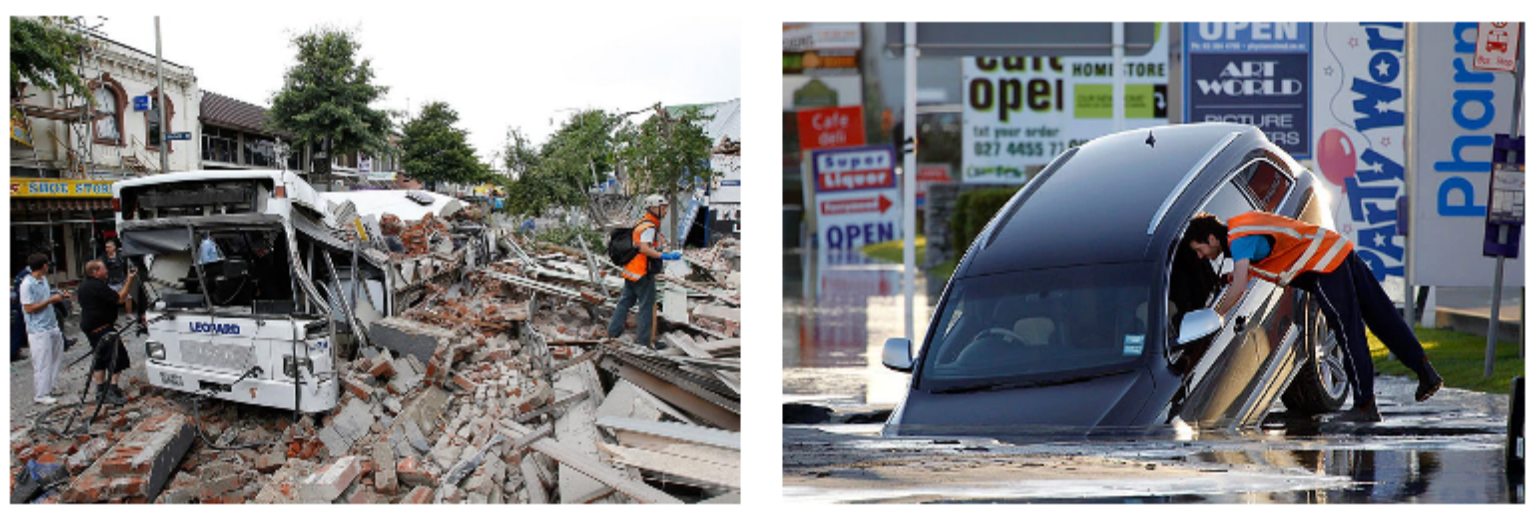

Figure 1.3: Damage after the devastating $\mathrm{M}_{\mathrm{w}}$ 6.2 Christchurch earthquake on 22 February 2011, which killed 185 people and injured thousands. (a - Left) Much of the central business district had severe damage to buildings and infrastructure, (b - Right) Liquefaction was widespread during the Canterbury earthquake sequence, causing $\sim \mathrm{NZ} \$ 15$ to 20 billion in infrastructure damage. Photos from https://www.stuff.co.nz.

of comparison to the responses recorded from the $1999 \mathrm{M}_{\mathrm{w}}$ 7.6 Chi-Chi earthquake (Taiwan), one of the most widely studied and cited events in earthquake hydrology (e.g Wong and Wang, 2007; Wang et al., 2004a). A series of studies have started to capitalise on the dataset, including in particular investigations of the groundwater response to the Canterbury earthquake sequence of 2010-2011 (Figure 1.3 Cox et al., 2012; Gulley et al., 2013; Dudley Ward, 2015; Rutter et al., 2016).

\subsection{Research questions}

A major contribution of this study has been to compile a national record of multiple monitoring sites, responding to multiple earthquakes in order to elucidate the causative factors. This thesis focuses on characterising and assessing earthquake-induced changes in groundwater level and tidal behaviour. As part of the Marsden project "Earthquake hydrology: Seismic pumps or broken pipes?" (12-GNS-003), this thesis aims to address the following questions:

\section{What is the relative importance of static and dynamic stress changes on groundwater level changes?}

The sign and amplitude of groundwater-level changes can be compared with those predicted from mechanistic models to provide insight into the causal mechanisms. To date, there is continued debate on the contribution of static and dynamic stresses to earthquake-induced water-level responses (Wang and Manga, 2010a). Both static and dynamic stresses increase with earthquake magnitude, but decay very differently with distance from the epicentre (Manga and Wang, 2007). Earthquake-induced static 
stress changes imposed on the surrounding crust cause volumetric strain changes within aquifer systems. Previous studies have suggested that volumetric strain changes cause water-level changes (e.g. Wakita, 1975; Quilty and Roeloffs, 1997; Jónsson et al., 2003; Akita and Matsumoto, 2004).

Dynamic stress changes may also induce a variety of mechanisms depending on the shaking intensity at the site of interest. Shear-induced dilatation, consolidation and liquefaction (Wang et al., 2001; Wang, 2007) are thought to occur at cyclic shear strains exceeding $\sim 10^{-4}$ (Dobry et al., 1982; Vucetic, 1994). At lower thresholds of dynamic shaking, earthquake-induced flow velocities may be strong enough to dislodge colloidal particles in preferential flow pathways (Wang et al., 2009) and enhance horizontal permeability (Matsumoto et al., 2003; Brodsky et al., 2003; Wang and Chia, 2008; Rutter et al., 2016). At low levels of dynamic shaking, pore spaces may dilate and compress leading to transient pulses of pore pressure (Roeloffs, 1998) and poroelastic deformation (e.g. Kano and Yanagidani, 2006). This thesis assesses the contribution of static and dynamic stress changes by comparing them to groundwater-level change characteristics

\section{What is the relative importance of each hydrogeological factor on ground- water level changes?}

Although information about the distance from the epicentre and earthquake-induced stress changes provides a rough approximation of how a monitoring well may respond to an earthquake, some monitoring wells respond with larger amplitudes of water-level changes than other wells with the same epicentral distance and similar degrees of stress change. Aquifer properties are likely to partly control earthquake-induced water-level changes. The degree to which hydrogeological factors contribute to earthquake-induced groundwater-level changes is still poorly understood. The temporal variation of seasonal water level fluctuations is controlled by hydrometeorological factors, but the spatial variation is governed by geological factors, such as: lithology; topography; slope; geological structures; fracture systems; weathered-zone thickness; drainage pattern; landforms; climatic patterns; and land use/cover (Mukherjee, 1996; Alley et al., 2002; Bhuiyan, 2010). Hydrological factors that affect seasonal water level fluctuations include transmissivity and storativity. As we are generally interested in the saturated zone, we collectively term these geological and hydrological factors as hydrogeological factors which also affect earthquake-induced groundwater level fluctuations.

Several studies show that the degree of confinement may influence the occurrence of responses (Stearns, 1928; Eaton and Takasaki, 1959; Roeloffs, 1996; Rutter et al., 2016), while rock type may determine the capability of an aquifer to respond hydrologically to teleseismic earthquakes (Brodsky et al., 2003; Shi and Wang, 2014; Weingarten and Ge, 2014; Zhang et al., 2015). Furthermore, variable permeability may contribute 
to the amplitude of water-level changes (Manga and Wang, 2007; Wang et al., 2009) and reequilibration time (Faoro et al., 2012). O'Brien et al. (2016) first showed the importance of local hydrological parameters, specifically how landslides respond, whereas this thesis builds on this work to examine to what extent hydrogeological factors are regionally important contributors to groundwater-level changes.

\section{Is there a more informative earthquake hydrology metric than epicentral distance and magnitude?}

Currently, the most universal earthquake hydrology metric is that of the earthquake's magnitude and the epicentral distance to hydrological responses (Wang and Manga, 2010b). The current metric does not consider hydrogeological factors. Furthermore, the terms seismic energy density (Wang, 2007), near-, intermediate-, and far-field (Wang and Manga, 2010a) and one fault rupture length (Wells and Coppersmith, 1994) do not take into account the directivity of an earthquake. This thesis incorporates seismic and hydrogeological factors in a probabilistic framework and is a fresh and more universal approach to earthquake hydrology metrics.

\subsection{Thesis content}

The body of this thesis is three self-contained studies (Chapter 3, 4, and 5), that have been prepared for publication in academic journals. The three studies are at various stages of preparation/submission and thus contain individual abstracts; introductions; methods and conclusion sections. As a result, there is some repetition of the discussion of processes and datasets presented. Also they have been written in the first person plural ("we"), as is common practice for publications involving several authors. This thesis is structured in the following way:

\section{Chapter 2: Background and scientific approach}

This chapter discusses the background of earthquake hydrology and the mechanisms that cause earthquake-induced hydrological responses. The New Zealand geological setting and a monitoring network of hydrogeology and seismology, collectively termed the "hydroseismicity" dataset are presented. Previous international and New Zealand studies are considered within the context of the scientific approach applied in this thesis.

\section{Chapter 3: Case study of the $2016 \mathrm{M}_{\mathrm{w}}$ 7.8 Kaikōura earthquake}

The $\mathrm{M}_{\mathrm{w}}$ 7.8 Kaiköura earthquake occurred on the 13th November 2016 23:02:56 (NZST) and induced groundwater-level changes throughout New Zealand. This study collates 
groundwater-level responses from 433 sites in compositionally diverse, young shallow aquifers, at distances of 4 to $850 \mathrm{~km}$ from the earthquake epicentre. The level to which earthquake-driven and local hydrogeological factors contributed to the national-scale groundwater level response has been assessed. This is the most extensive "hydroseismicity" dataset ever compiled in New Zealand, surpassing the collation made by Cox et al. (2012) for the $2010 \mathrm{M}_{\mathrm{w}} 7.1$ Darfield earthquake and is comparable to large case studies internationally such as the $1999 \mathrm{M}_{\mathrm{w}}$ 7.3 Chi-Chi (Chia et al., 2008), and the $2008 \mathrm{M}_{\mathrm{w}} 7.9$ Wenchuan earthquake (Shi et al., 2013b, 2015b).

\section{Chapter 4: Tidal behaviour and water-level changes to multiple earthquakes}

The relationship between tidal behaviour changes and water-level changes remains unclear (Elkhoury et al., 2006), with changes rarely occurring simultaneously (e.g. Shi et al., 2015b; Yan et al., 2014; Shi and Wang, 2015). In this study changes to tidal behaviour and water-level in a hydrological network, monitoring gravel aquifers in Canterbury, New Zealand, are quantified following response to nine $\mathrm{M}_{\mathrm{w}} 5.4$ or larger earthquakes in the period of 2008 to 2015. This study assesses the occurrence and absence of responses, their corresponding thresholds of seismic shaking and implications of scale and well-aquifer relations.

\section{Chapter 5: Aquifer susceptibility to earthquake-induced groundwater-level changes}

The first probabilistic model for groundwater response as a function of the Modified Mercalli (MM) intensity scale for earthquake shaking has been constructed by developing a catalogue that is comparable to international datasets. The occurrence and absence of persistent groundwater-level changes in 495 monitoring wells to one or more of 11 earthquakes larger than $M_{w} 5.4$, between 2008 and 2017 has been quantified. A binary logistic regression model with random effects has been applied to the dataset with three predictors: peak ground velocity (PGV), depth and site-average shear wave velocity. Marginal probabilities have been calculated as a function of PGV and the MM intensity scale, as well as the likelihood of persistent water-level changes for MM intensity II to VIII. The probabilistic framework determined here is proposed as an addition to the environmental response criteria of the New Zealand MM intensity scale.

\section{Chapter 6: Summary and directions for future research}

In the final chapter, the key results of the three studies are examined and reflected upon, with respect to the research questions outlined in Section 1.2. Implications for future research are discussed and preliminary analysis of possible research avenues are presented. 


\section{Appendix A: Monitoring well tidal responses, Canterbury, South Island, New Zealand}

This is an appendix for Chapter 4, containing monitoring well number, location and depth collected from Environment Canterbury. The earth and ocean tidal properties have been computed using Baytap08 for monitoring wells. The data include poroelastic properties and phase lag of the $\mathrm{M}_{2}$ waveform and the amplitudes of various waveforms. See Electronic appendices for further supplementary data relevant to the Chapter 4.

\section{Electronic appendices}

Electronic appendix 1: The seismic and hydrological data for each monitoring well in the $2016 \mathrm{M}_{\mathrm{w}} 7.8$ Kaikōura earthquake dataset is provided, together with the earthquakeinduced static stress changes, dynamic shaking parameters, associated hydrological response characterisation and hydrogeological properties. This appendix has been integrated into the supplementary material for the manuscript that has been submitted to the international journal Geofluids (Chapter 3).

Electronic appendix 2: Water-level data for the wells that showed tidal signals for the period $01 / 01 / 2008$ to $01 / 06 / 2016$ have been included in the same order as Appendix A. Furthermore, a .kml file shows the spatial distribution of tidal responses and water-level changes for each earthquake. This supplementary material, together with Appendix A, forms the supplementary material for the manuscript submitted and reviewed by the international journal Water Resources Research (Chapter 4).

Electronic appendix 3: The binary water-level responses to the 11 earthquakes that occurred between 2008 and 2017 are provided, together with the seismic properties and hydrogeological parameters. This appendix is integrated into the supplementary material for the manuscript that will be submitted to an international journal (Chapter $5)$.

\subsection{Statement of contributions}

The research described in this thesis has been conducted by me (Konrad Cedd Weaver), unless stated otherwise. Mai-Linh Doan (ISTerre, France) contributed knowledge on tidal analysis (Chapter 4), Caroline Holden (GNS Science) provided insights into seismic processing (Chapter 3, 4), Helen Rutter (Aqualinc Research Ltd) provided data collection support (Chapter 3), Ian J. Hamling (GNS Science) calculated static stress changes (Chapter 3) and Richard Arnold (Victoria University of Wellington) gave guidance on statistical analysis (Chapter 5). All results presented also benefited from collaboration with New Zealand regional Councils. The first person plural writing style 
used in Chapter 3, 4 and 5 reflects these contributions and the guidance and advice of my supervisors Simon C. Cox (GNS Science) and John Townend (Victoria University of Wellington) throughout the project. 


\section{Background and scientific approach}

\subsection{Mechanisms of hydrological responses to earthquakes}

A general reference used to study earthquake-induced groundwater-level changes takes into consideration the magnitude of the earthquake and the epicentral distance of the hydrological response. The use of this metric is particularly useful due to the many historic response documentations that lack any other hydrological or seismological characteristics (Figure 2.1, Wang and Manga, 2010b). The seismic energy density (e) parameter is defined from an empirical relationship of magnitude and epicentral distance (Equation 2.1).

Seismic energy density is defined as the maximum available seismic energy per unit volume of rock during seismic shaking (Wang and Manga, 2010a). The seismic energy density may be estimated from the particle velocity of the ground motion (Lay and Wallace, 1995) and thus may be simplified to $e \sim \mathrm{PGV}^{2}$ (peak ground velocity; Wang, 2007), which has been shown to be consistent with field observations (Wang et al., 2006). Considering PGV attenuation in southern California (Cua, 2004) and empirical relations between earthquake energy and magnitude (Bath, 1966), Wang (2007) derived a relation between seismic energy density $\left(e, \mathrm{~J} / \mathrm{m}^{3}\right)$, earthquake magnitude $(\mathrm{M})$ and epicentral distance $(r, \mathrm{~km})$ :

$$
M=2.7+0.69 \log (e)+2.1 \log (r)
$$

Although the relationship was derived in southern California, the metric of seismic energy density, earthquake magnitude and epicentral distance has been utilised for many types of hydrological responses around the globe (Wang and Manga, 2010b). In the absence of a comparable relationship for New Zealand and for comparison with previous literature this relationship is used in Chapters 3 and 5. 


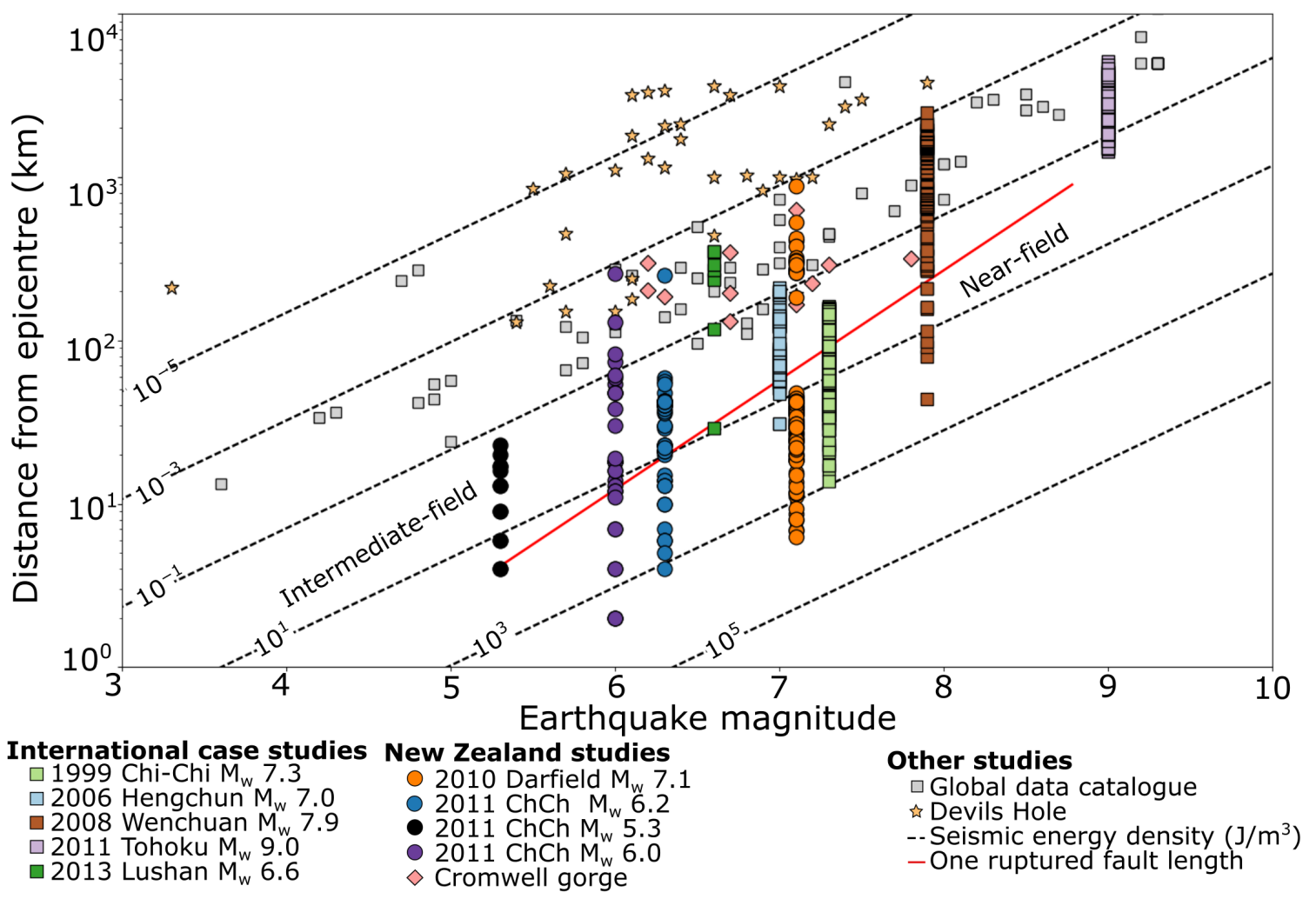

Figure 2.1: Earthquake magnitude as a function of distance from epicentre where groundwater-level responses were observed, collated from New Zealand and international case studies. New Zealand studies include: 2010 Darfield $\mathrm{M}_{\mathrm{w}} 7.1$ (Cox et al., 2012); 2011 Christchurch $\mathrm{M}_{\mathrm{w}}$ 6.2, 5.3, 6.0 (Gulley et al., 2013); and Cromwell Gorge (O'Brien et al., 2016). International studies include: 1999 Chi-Chi $\mathrm{M}_{\mathrm{w}} 7.3$ and 2006 Hengchun $\mathrm{M}_{\mathrm{w}} 7.0$ (Chia et al., 2008); 2008 Wenchuan $\mathrm{M}_{\mathrm{w}} 7.9$ (Shi et al., 2013b, 2015a); 2011 Tohoku $\mathrm{M}_{\mathrm{w}} 9.0$ (Yan et al., 2014); 2013 Lushan $\mathrm{M}_{\mathrm{w}} 6.6$ (Shi et al., 2014). Also included is a worldwide compilation of groundwater responses (Wang and Chia, 2008); responses from the Devils Hole (Weingarten and Ge, 2014); seismic energy density contours in $\mathrm{J} / \mathrm{m}^{3}$ (Wang, 2007); and the hypocentral distance equal to one ruptured fault length as a function of earthquake magnitude (Wells and Coppersmith, 1994). The one ruptured fault length defines the boundary between the near-field and intermediatefield. NB Christchurch has been shortened to $\mathrm{ChCh}$ in the key.

Earthquake-induced groundwater-level changes can be observed in both the coseismic and post-seismic domains. The capability of a site to record co-seismic and post-seismic groundwater-level changes is determined by the temporal resolution of the data collected by the instrument installed in the monitoring well. To record co-seismic fluctuations, groundwater-levels generally need to be sampled at least every minute. Furthermore, sampling must be continuous for an extended time period. The co-seismic oscillations are directly forced by the dynamic shaking, and the post-seismic oscillations are considered directly free from forcing as they attenuate as a function of the hydraulic properties and conditions of the surrounding aquifer (Cooper et al., 1965). 
The post-seismic free oscillations may persist for several minutes after the dynamic shaking has ceased (e.g. Brodsky et al., 2003). The free oscillations may be captured by 15 minute-sampled groundwater-level monitoring. The free oscillations of hydroseismograms can have an effect on the type of response observed at 15 minute intervals (Figure 2.2). As a result of time-shifting the hydroseismogram in one minute intervals, the re-sampled 15 minute response varies in the first 30 minutes after the earthquake, with positive or negative spikes observed before re-equilibration. Positive and negative spikes prior to re-equilibration have been identified in previous studies (Cox et al., 2012). The presence/absence of spikes and their polarity, may be partly a function of sample fidelity so care must be taken when interpreting changes immediately after, or during earthquakes. However, the 15 minute sampling interval is adequate for longerterm post-seismic responses as post-seismic water-level changes may still be detectable several hours after an earthquake. Characterisation of post-seismic groundwater-level changes varies between studies (e.g. Cox et al., 2012; Shi et al., 2015a), as responses vary in time, polarity, and amplitude, and can be transient (eventually returning to pre-earthquake levels) or sustained (Wang and Manga, 2010a).

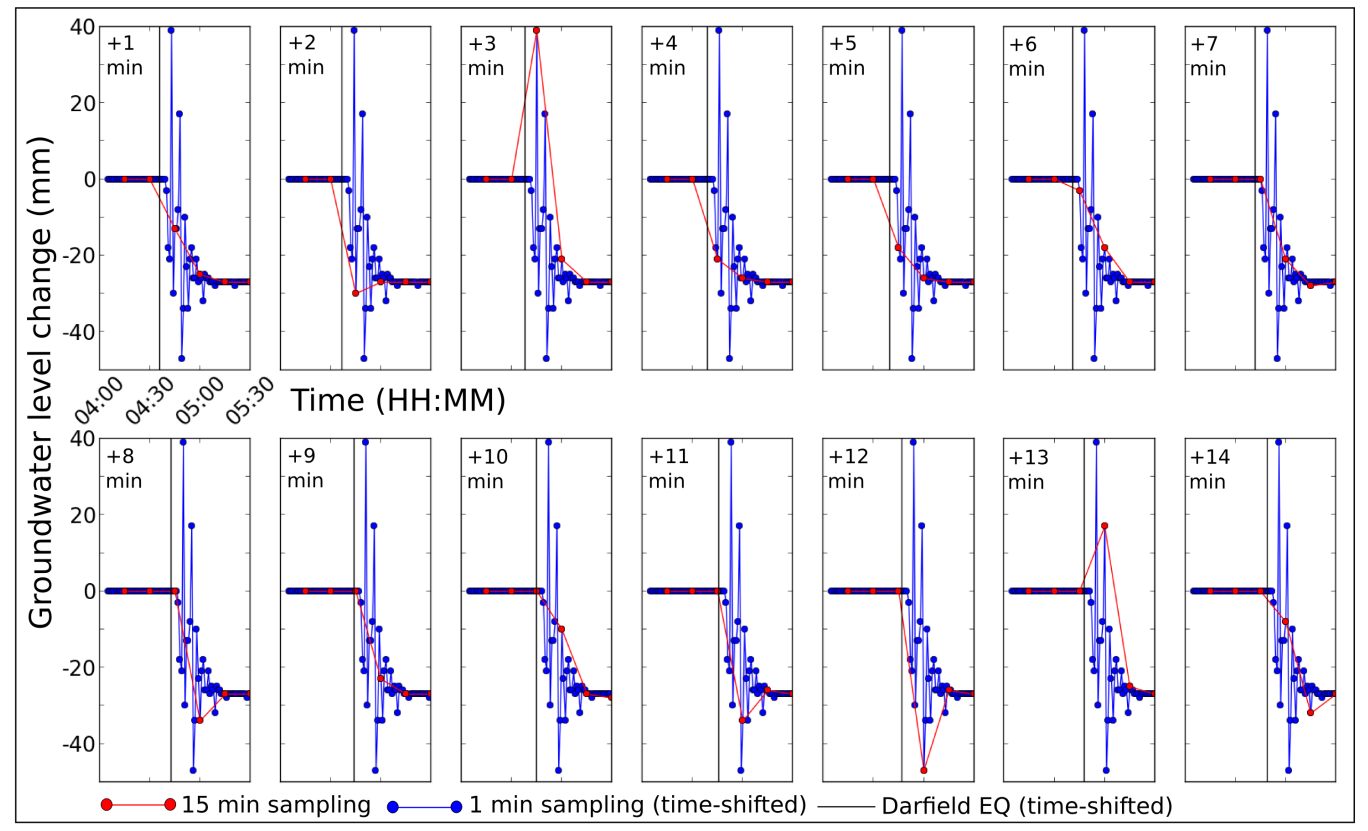

Figure 2.2: Time-shifting and re-sampling of the hydroseismogram response observed at Puriri Park, Whangarei, to the $2010 \mathrm{M}_{\mathrm{w}} 7.1$ Darfield earthquake. The hydrological response was first reported by Cox et al. (2012). The hydroseismogram is time-shifted and re-sampled at 15 minute intervals, as outlined by the red line and sample points. This diagram highlights the 15 minute sampling interval, most commonly adopted by regional council groundwater monitoring in New Zealand, is limited in its ability to characterise any co-seismic responses, but is quite adequate for longer-term, postseismic responses. 


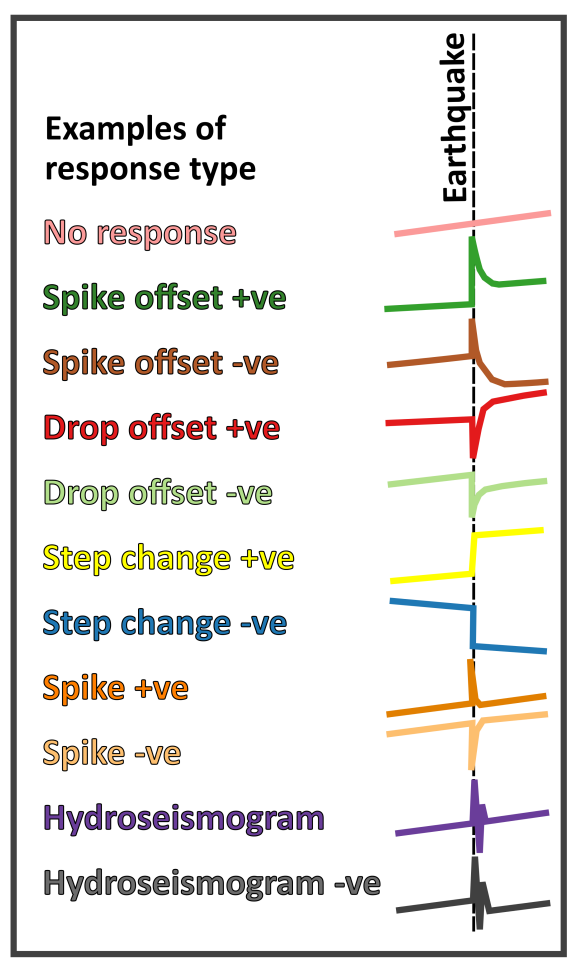

Figure 2.3: Examples of groundwater-level response type in monitoring wells. Figure adapted from Cox et al. (2012).

The principle of poroelasticity (Biot, 1941) dictates that resultant stresses deform porous solids and change fluid pressures. If gradients of fluid pressure $(\Delta p)$ exist, there will be Darcy fluid flux q:

$$
q=-\frac{k}{\mu} \Delta p
$$

where $k$ is permeability $\left(\mathrm{m}^{2}\right)$, and $\mu$ is fluid viscosity (Pas). The distance from the earthquake largely determines the magnitude of the stress changes and the type of response. When fault dislocation occurs, static and dynamic stresses are both applied to the current stress state in the crust, both decaying at different rates with distance from the fault zone (Wang and Manga, 2010a). Step-like changes (Figure 2.3) commonly occur in the near-field, with more gradual changes observed in the intermediate-field and transient oscillations in the far-field (Roeloffs, 1998).

The following sections discuss the effect of static and dynamic stress changes on groundwater-level changes (Figure 2.6), followed by hydrogeological factors. We consider the mechanisms that may cause groundwater-level changes (Table 2.1). 
Table 2.1: Major mechanisms presented in the literature to explain earthquake-induced groundwater-level changes.

\begin{tabular}{|c|c|c|c|}
\hline $\begin{array}{l}\text { Hydrogeological } \\
\text { factors }\end{array}$ & $\begin{array}{c}\text { Earthquake } \\
\text { stress }\end{array}$ & $\begin{array}{l}\text { Mechanism for } \\
\text { change }\end{array}$ & $\begin{array}{c}\text { Prediction of groundwater-level } \\
\text { changes }\end{array}$ \\
\hline \multirow{7}{*}{$\begin{array}{l}\text { Affected by } \\
\text { degree of } \\
\text { confinement, } \\
\text { rock type, flow } \\
\text { properties and } \\
\text { well } \\
\text { susceptibility }\end{array}$} & Static & $\begin{array}{l}\text { Contraction strain } \\
\text { change }\end{array}$ & $\begin{array}{l}\text { Step-like water-level increase with predictable } \\
\text { amplitude }\end{array}$ \\
\hline & Static & $\begin{array}{l}\text { Dilatation strain } \\
\text { change }\end{array}$ & $\begin{array}{l}\text { Step-like water-level decrease with } \\
\text { predictable amplitude }\end{array}$ \\
\hline & Dynamic & $\begin{array}{l}\text { Shear-induced } \\
\text { consolidation }\end{array}$ & $\begin{array}{l}\text { Step-like water-level increase (commonly }>1 \\
\text { m amplitude) }\end{array}$ \\
\hline & Dynamic & $\begin{array}{l}\text { Shear-induced } \\
\text { dilatation }\end{array}$ & $\begin{array}{c}\text { Step-like water-level decrease (commonly }>1 \\
\text { m amplitude) }\end{array}$ \\
\hline & Dynamic & $\begin{array}{c}\text { Horizontal } \\
\text { permeability } \\
\text { enhancement (unclog } \\
\text { fractures/pathways) }\end{array}$ & $\begin{array}{l}\text { Sustainted water-level change (increase or } \\
\text { decrease; commonly }<1 \mathrm{~m} \text { amplitude) }\end{array}$ \\
\hline & Dynamic & $\begin{array}{l}\text { Verical permeability } \\
\text { enhancement (unclog } \\
\text { fractures/pathways) }\end{array}$ & $\begin{array}{c}\text { Convergence of water-levels in stratified } \\
\text { aquifers }\end{array}$ \\
\hline & Dynamic & $\begin{array}{l}\text { Poro-elastic } \\
\text { deformation }\end{array}$ & $\begin{array}{c}\text { Transient water-level changes (increase } \\
\text { and/or decrease; hydroseismograms, }<1 \mathrm{~m} \\
\text { amplitude) }\end{array}$ \\
\hline
\end{tabular}

\section{Static stress changes}

Earthquake-induced static stress changes are permanent and decay rapidly with distance $(r)$ at $\sim 1 / r^{3}$, hence being most significant in the near-field (Lay and Wallace, 1995; Manga and Wang, 2007). Static stress changes cause volumetric static strain change, contraction and dilatation. The mean static stress change $\left(\sigma_{\mathrm{kk}}, \mathrm{GPa}\right)$ can be converted into volumetric strain change $\left(\epsilon_{\mathrm{kk}}\right)$, using the Bulk modulus (K, GPa) of the lithology:

$$
\epsilon_{\mathrm{kk}}=\sigma_{\mathrm{kk}} / \mathrm{K}
$$

This is related to the pore-pressure change $(p)$ in a monitored well (Roeloffs, 1996) by:

$$
p=-2 G B \frac{\left(1+v_{\mathrm{u}}\right)}{1-2 v_{\mathrm{u}}} \epsilon_{\mathrm{kk}}
$$

where $G$ is the shear modulus (GPa), $B$ is the Skempton's coefficent and $v_{\mathrm{u}}$ is the undrained poisson ratio. The spatial distribution of volumetric changes depends upon the faulting style of the earthquake. Volumetric strain changes within aquifer systems are thought to cause groundwater-level changes (Wakita, 1975; Quilty and Roeloffs, 1997; Jónsson et al., 2003; Akita and Matsumoto, 2004), with levels increasing in areas of contraction, and decreasing in areas of dilatation. The amplitude of such changes is predictable using poro-elastic theory (e.g. Roeloffs, 1996). It has been suggested that monitoring wells that don't respond to earth tides are not likely to respond to coseismic static strain (e.g. Quilty and Roeloffs, 1997). As static strain changes attenuate rapidly with distance, groundwater-level changes in the intermediate- and far-field are 
commonly larger than model predictions (Figure 2.4, Shi and Wang, 2015; Wang and Manga, 2010a), due to other factors.

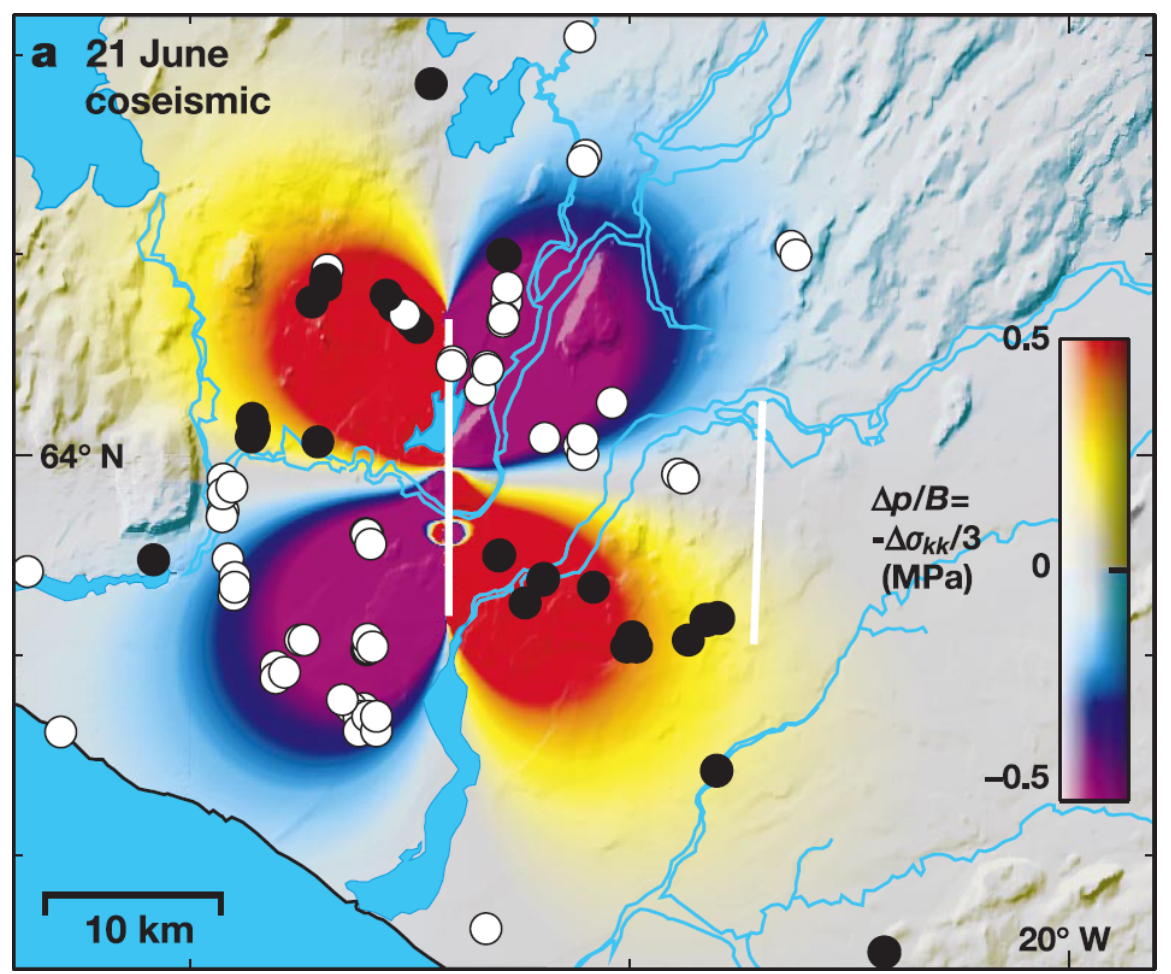

Figure 2.4: Co-seismic water-level increases (black dots) and decreases (white dots) observed following the 21st June 2000 M 6.5 earthquake in Iceland. Also included is the predicted co-seismic pore-pressure change at $0.5 \mathrm{~km}$ depth (colour map). From Jónsson et al. (2003)

\section{Dynamic stress changes}

Dynamic stress changes caused by the passage of seismic waves are short-lived, yet decay with distance $r$ at $\sim 1 / r^{1.66}$ and occur from the near- to far-field. (Lay and Wallace, 1995). Dynamic deformation depends on loading rates and cycles of forces (Manga and Wang, 2007). Commonly, shaking does not impose clear permanent deformation, thus, transient stresses must induce changes in the subsurface that persist after shaking has stopped (Manga et al., 2012).

Peak ground velocity (PGV) has been compared to groundwater-level changes (e.g. Elkhoury et al., 2006; Shi et al., 2015a) and has been invoked as a proxy for dynamic stress (Love, 1927; Elkhoury et al., 2006; Kano and Yanagidani, 2006). Peak dynamic stress $\left(\sigma_{\mathrm{D}}, \mathrm{GPa}\right)$ can be calculated (Jaeger and Cook, 1979) by:

$$
\sigma_{\mathrm{D}} \sim \frac{\mu_{\mathrm{s}} \mathrm{PGV}}{\mathrm{Vs}}
$$


with shear modulus $\left(\mu_{\mathrm{s}}, \mathrm{GPa}\right)$, shear-wave velocity at the monitoring well (Vs, m/s) and peak ground velocity $(\mathrm{PGV}, \mathrm{m} / \mathrm{s})$. Peak dynamic stress has been used in permeability enhancement experiments (e.g. Roberts, 2005; Elkhoury et al., 2011).

Earthquake-induced groundwater-level changes associated with dynamic stresses are often attributed to changes in horizontal or vertical permeability (Wang and Manga, 2010a), which may be permanent (e.g. Rutter et al., 2016) or transient (e.g. Elkhoury et al., 2006; Cox et al., 2015). Permeability reduction is mainly documented in the postearthquake environment, involving chemical processes such as fault healing (Gratier and Gueydan, 2007; Aben et al., 2017), cementation (Dempsey et al., 2014) and clay alteration (Menzies et al., 2016). Co-seismic reduction of permeability has been observed in the field as a result of the clogging of fractures with colloids (Shi et al., 2018; Yan et al., 2016) and can be associated with processes resulting from high levels of shaking (Vucetic, 1994): shear-induced consolidation (Rutter et al., 2016; Wang et al., 2001) and liquefaction (Wang, 2007).

Undrained dilatation and consolidation has been shown to be dominant in the nearfield (Wang and Manga, 2010a). Experimental engineering studies have subjected sediments to cyclic shearing in a range of saturated conditions and confining pressures (Seed and Lee, 1966; Ishihara, 1996; Hsu and Vucetic, 2004). If shear strains are significantly higher than $10^{-4}$, during earthquake-induced cyclic shearing, sediments begin to dilate, increasing porosity and decreasing pore pressure (Luong, 1980). Considering the high level of shaking required, groundwater level decreases associated with this process must occur in sedimentary aquifer systems close to the fault rupture (Figure 2.5; Wang et al., 2001; Wang and Chia, 2008).

At lower shear strains, still higher than $10^{-4}$ (Dobry et al., 1982; Vucetic, 1994), sediment consolidation within an aquifer decreases the porosity of the formation, resulting in groundwater-level increases (Wang et al., 2001). The threshold strain to induce undrained consolidation is equivalent in the laboratory and the field (Hazirbaba and Rathje, 2004). Therefore, it is reasonable to compare the laboratory based dissipated energy with field-based seismic energy density. Seismic energy densities larger than $\sim 10^{1} \mathrm{~J} / \mathrm{m}^{3}$ are above the threshold for undrained consolidation, with sensitive sites experiencing consolidation above $\sim 10^{-1} \mathrm{~J} / \mathrm{m}^{3}$ (Wang and Manga, 2010a). Shear-induced consolidation may also cause permeability reduction (Rutter et al., 2016) and liquefaction (Wang, 2007). Abrupt water-level changes may result in areas of shear-induced consolidation as pore pressures immediately change as a result of the undrained volumetric change (Wang and Manga, 2010a).

At lower thresholds of dynamic shaking, enhancement of horizontal permeability may occur as a result of the dislodging of colloidal particles from preferential flow pathways (Matsumoto et al., 2003; Brodsky et al., 2003; Wang and Chia, 2008; Rutter et al., 2016). Earthquake-induced groundwater flow velocities associated with shear and love waves may be sufficient to dislodge colloidal aggregates and enhance permeability 

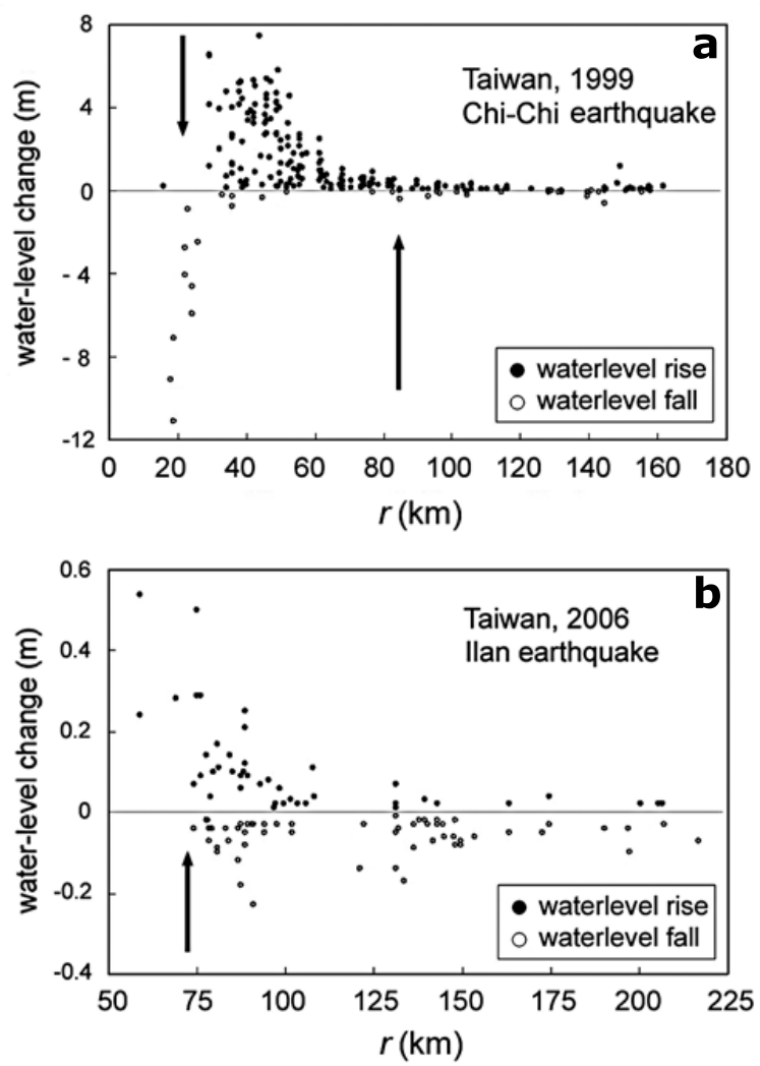

Figure 2.5: Groundwater-level changes to large magnitude earthquakes as a function of epicentral distance. The downward arrows shows where nine wells had a sudden decrease in water-level, in proximity $(<10 \mathrm{~km})$ to the surface rupture. The upward arrow shows the limit of the near-field. Water-level changes to the (a - Top) Chi-Chi $1999 \mathrm{M}_{\mathrm{w}} 7.5$ earthquake, and the (b - Bottom) Taiwan $2006 \mathrm{M}_{\mathrm{w}} 7$ earthquake. Note the scales of water-level changes are significantly different. From Wang and Chia (2008).

(Wang et al., 2009). Laboratory experiments on pore unclogging (Liu and Manga, 2009; Elkhoury et al., 2011) and observations of groundwater colour change (Prior and Lohmann, 2003) support dislodgement of colloidal particles.

Horizontal permeability enhancements could occur up or down hydraulic head gradient of a borehole, resulting in an increase or a decrease in the water-level. Therefore, horizontal permeability enhancement by dislodging of colloidal particles predicts a random distribution of response polarity (Figure 2.5, Wang and Chia, 2008). Gradual sustained water-level changes may result from dislodging colloidal particles, as the groundwater-level change re-equilibration time to the new post-earthquake level depends on the distance between the monitoring well and the source of the blockage (Roeloffs, 1998; Brodsky et al., 2003). Dislodgment of colloids may also occur within aquitards, re-distributing pore pressures and causing convergence of water-levels in stratified aquifers (Wang, 2007; Dudley Ward, 2015; Wang et al., 2016). For the Hengchun and Chi-Chi earthquakes the transition from consolidation to colloidal dislodgement was inferred at $\sim 10^{1} \mathrm{~J} / \mathrm{m}^{3}$ (Wang and Chia, 2008). 


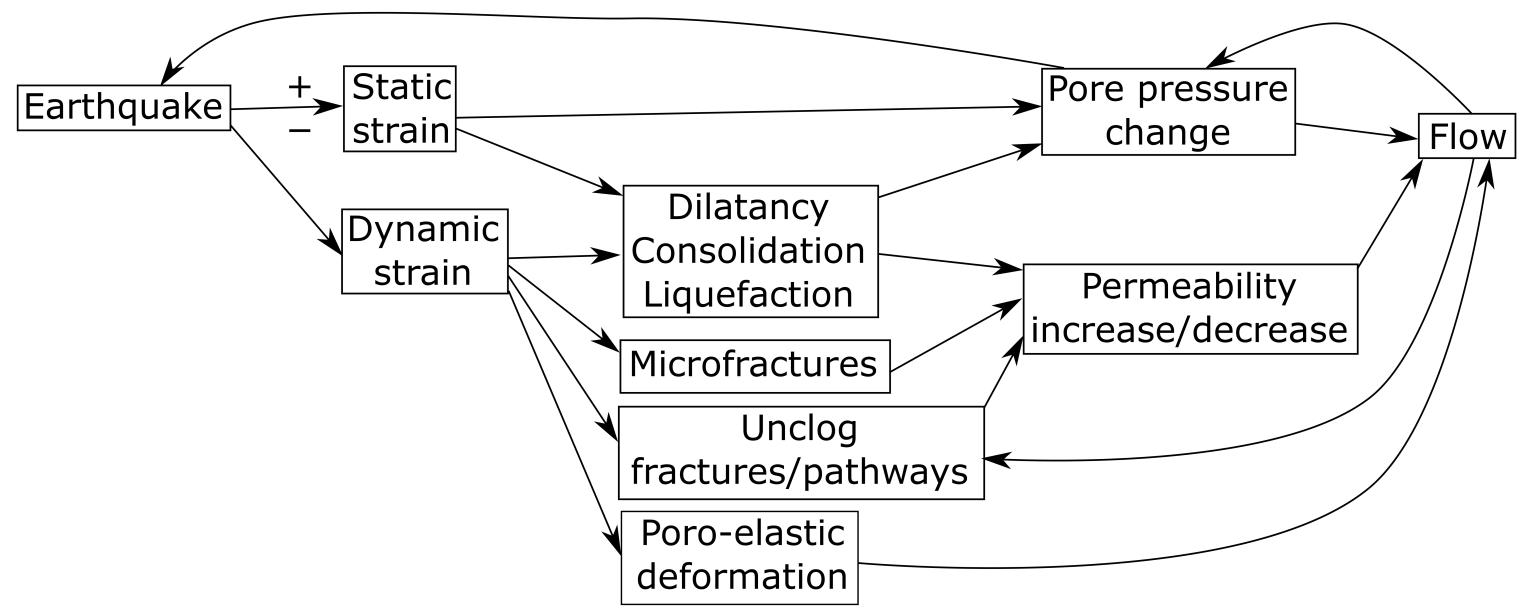

Figure 2.6: Flow chart of the relationship between earthquakes and hydrogeological responses. The flow chart is based on Manga and Wang (2007) and illustrations by David Mays.

The formation of sub-vertical fractures by dynamic shaking may also hydrologically connect stratified aquifers. Increased vertical permeability may permit rapid downward flow of water in topographic highs (Wang et al., 2004b) and release artesian pressure in confined aquifers into overlying unconfined aquifers (Wang, 2007; Cox et al., 2012; Liao et al., 2015; Wang et al., 2016).

Dynamic shaking can also cause poro-elastic deformation which causes groundwater level oscillations (termed hydroseismograms; Stearns, 1928). The motion induced by seismic waves causes aquifer pore space to dilate and compress, which translates to pore pressure oscillations. These aquifer pressure oscillations may induce fluid flow into and out of the well causing the oscillations observed. Hydroseismograms correlate with a suite of analytical solutions based upon well geometry, groundwater flow, and aquifer properties (Blanchard and Byerly, 1935; Bodvarsson, 1970; Cooper et al., 1965; Liu et al., 1989). Under open well conditions, wellbore storage effects cause a phase delay and reduction in sensitivity, resulting in the observation of Rayleigh waves in the well water-level (Blanchard and Byerly, 1935; Cooper et al., 1965; Ohno et al., 1997; Brodsky et al., 2003). In artesian wells, shear waves have been observed in hydroseismograms (Brodsky et al., 2003; Kano and Yanagidani, 2006). In anisotropic poroelastic media, it is expected that these shear waves generate volumetric strains (Wang, 2000; Kano and Yanagidani, 2006).

\section{Hydrogeological factors}

Although earthquake-induced stresses play a crucial role in causing groundwater-level changes, some monitoring wells have larger amplitude responses than others for similar static or dynamic stress changes. The architecture of hydrogeological settings and 
their recharge and discharge processes may play a role in groundwater-level changes, especially with variations in seasonality (Yan et al., 2014).

Darcy fluid flux occurs when fluid pressure gradients $(\Delta p)$ are induced by stresses deforming porous solids and changes in fluid pressures (Equation 2.2). Therefore, it is not surprising that the occurrence, polarity and/or amplitude of water-level changes are a function of flow properties (Faoro et al., 2012). For a monitoring well water-level to reflect the piezometric surface in the aquifer that it is screened in; the monitoring well and aquifer must be coupled (Doan and Brodsky, 2006). Considering pore pressure fluctuations induced by earthquakes are generally fast, high permeability is required for observable changes at wells to occur. If permeabilities are small, the monitoring well and aquifer are uncoupled and well water-levels may not respond to earthquakes. Matrix- and fracture-dominated flows may also play a role in the occurrence and characteristics of groundwater-level changes.

Earthquake-induced groundwater-level changes have been observed to be more pronounced in deeper confined aquifers compared to shallow unconfined aquifers (Stearns, 1928; Eaton and Takasaki, 1959; Roeloffs, 1996; Gulley et al., 2013; Rutter et al., 2016). This may be a result of the specific yield of unconfined aquifers being higher than the storativity of confined aquifers (Freeze and Cherry, 1979). Water-level changes in unconfined aquifers represent the (de)watering of pore spaces above/below the water-table, which forms the aquifers upper boundary. In confined aquifers, assuming undrained conditions (Kano and Yanagidani, 2006), changes in pore pressure ( $p$, GPa) are determined by the mean stress $\left(\sigma_{\mathrm{kk}}, \mathrm{GPa}\right)$, and rock compressibilitiy (Skempton's coefficient, B; Roeloffs, 1996; Wang, 2000), where:

$$
p=-B \sigma_{\mathrm{kk}} / 3
$$

At shear strains $>10^{-4}$ or $10^{-3}$, consolidated and unconsolidated media show permanent deformation, with failure occurring at shear strains on the order of $10^{-2}$. The deformation characteristics depend on the consolidation state of the rock. For unconsolidated deposits, shear deformation causes grains to move into pre-existing pores, reducing porosity and deposit volume. Shear deformation of consolidated deposits will create new porosity and increase the volume of the deposits (Manga and Wang, 2007).

Seismic waves attenuate and filter differently through different rock types with different efficiencies of dynamic shaking (Wang, 2007; Wang and Manga, 2010a). Consolidated/crystalline deposits amplify high frequency shaking more than low frequency shaking (Bradley, 2013). In contrast, unconsolidated deposits damp high frequency motions, while amplifying low frequencies (Popescu, 2002; Wong and Wang, 2007; Youd and Carter, 2005). Hydrogeological sites in crystalline or well consolidated rocks have responded to teleseismic earthquakes (motion caused by earthquakes at epicentral distances exceeding 1000 km; Brodsky et al., 2003; Shi and Wang, 2014; Weingarten and 
Ge, 2014; Zhang et al., 2015). At these distances, static and dynamic stress changes are insignificant, therefore, rock type must partly control the occurrence and/or characteristics of groundwater-level changes. Furthermore, rocks that are weakened and/or damaged by discontinuous tectonic deformation may also be sensitive to seismic-induced groundwater-level changes (King et al., 1999; Shi et al., 2015a).

Although most studies focus on monitoring wells that have earthquake-induced groundwater-level changes, there are a significant number of wells that experience similar levels of shaking that do not exhibit any observable water-level change. This demonstrates that hydrogeological factors do contribute to a monitoring wells susceptibility to respond. As well as considering hydrogeological factors independently, it must be acknowledged that the spatial distribution of fluids and degree of saturation within the crust affect the velocity and attenuation of seismic waves (Li et al., 2001). Therefore, there is an underlying coupling between seismic and hydrogeological factors.

\section{Crustal stress state}

The tectonic stress field can be influenced by earthquake-induced stress changes (e.g. Grapes, 1988; Stein et al., 1997; Freed, 2005; Cox et al., 2015) and crustal fluids (e.g. Townend and Zoback, 2000; Zoback and Townend, 2001; Zoback, 2010). The critically stressed crust can be subject to failure by fluid injection (e.g. Walsh and Zoback, 2015; Ellsworth, 2013; Weingarten et al., 2015), reservoir impoundment (e.g. Roeloffs, 1996) and other earthquakes (e.g. Stein et al., 1997). Pre-existing faults may be subject to failure, often as a result of small increases in pore pressure (Zoback and Gorelick, 2012). Furthermore, seismically induced transient stresses have the potential to interact with fluids and dynamically trigger seismicity at far-field distances (Cox et al., 2015). Triggered seismicity in-turn can induce groundwater (Wang et al., 2017) and surface water responses (Manga et al., 2016). Repeated accumulation and release of tectonic stresses may weaken and damage rocks that make up bulk aquifer material (e.g. Zhang et al., 2003), possibly resulting in larger co-seismic groundwater-level changes Shi et al. (2015a). Therefore, the crustal stress state should be considered when trying to understand the factors that may influence groundwater-level changes.

\subsection{New Zealand geological setting}

\section{Tectonics}

Paleozoic (Western Province) and Mesozoic terrane accretion (Eastern Province); and plutonism on the margin of Gondwana formed New Zealand's basement rocks (Landis and Coombs, 1967; Coombs et al., 1976). Subsequently, the cover sequences formed by late-Cretaceous Gondwana rifting and break-up, followed by Eocene-Quaternary 


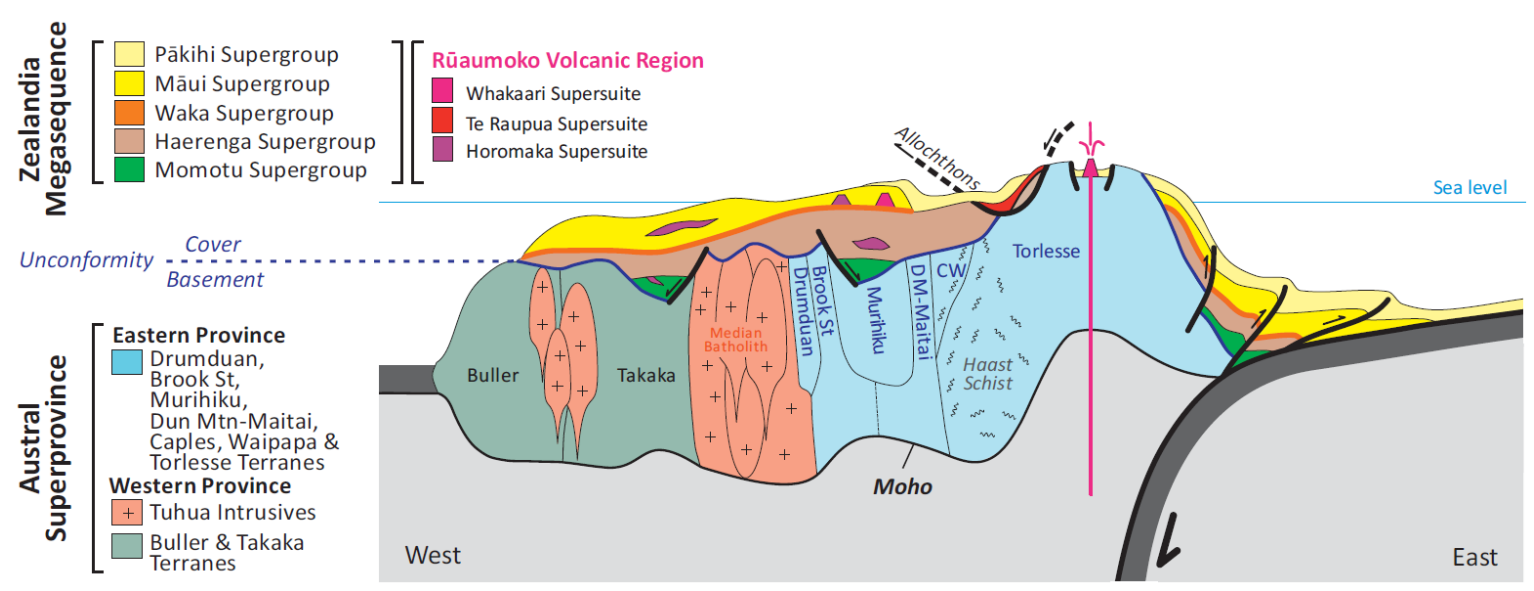

Figure 2.7: Schematic crustal cross-section across New Zealand showing the crustal basement (Austral Superprovince) and the late-Cretaceous-Holocene Zealandia cover (Zealandia Megasequence). From Mortimer et al. (2014).

evolution of the still-active plate boundary (Cox and Sutherland, 2007). The basement rocks are collectively termed the Austral Superprovince, and the Cretaceous-Holocene Zealandia cover is termed the Zealandia Megasequence (Figure 2.7; Mortimer et al., 2014)

Presently, oblique-convergent collision between the Australia and Pacific plates in southwest New Zealand occurs at $\sim 38 \mathrm{~mm} /$ year (DeMets et al., 2010) and earthquakes occur throughout the country along the plate boundary zone. In the central South Island, the majority of late Quaternary plate motion has been accommodated by slip on the Alpine Fault (Norris and Cooper, 2001). In the northern South Island, the Alpine Fault transitions into four major active strike slip faults, known as the Marlborough Fault System, that accommodates 80 to $100 \%$ of plate motion in the region (Holt and Haines, 1995). Northern progressive slip partitioning transfers kinematic motion to the Hikurangi Trough (Little and Jones, 1998), resulting in oblique subduction and the prolific arc of the Taupo Volcanic Zone (Rowland and Simmons, 2012). The Alpine Fault and Marlborough Fault System connect two subduction zones of opposite dip: the Puysegur trench to the South; and the Hikurangi trough to the North (Berryman et al., 1992).

The National Seismic Hazard Model (NSHM) for New Zealand provides a probabilistic estimate of the strength of earthquake shaking over a specific time period (Stirling et al., 2012). The NSHM utilises New Zealand's active fault database (Litchfield et al., 2014), a 180 year (1840-2018) historical earthquake catalogue, and Ground Motion Prediction Equations (e.g. McVerry et al., 2006) to estimate the hazard across a spectrum of site conditions (Destegul et al., 2008). The NSHM can be used to produce a range of metrics. With each earthquake forecast, the Modified Mercalli (MM) intensity can be predicted by the intensity prediction equation of Dowrick and Rhoades 
(2005).

Seismic hazard models have been formulated following the recovery of major earthquakes, notably the Canterbury Time-dependent Seismic Hazard Model (Gerstenberger et al., 2014). Ground motion prediction modelling has also been accomplished for specific large magnitude earthquakes such as Alpine Fault ruptures (Holden and Zhao, 2011; Bradley et al., 2017a), and earthquakes in the Wellington region (Benites and Olsen, 2005; Holden et al., 2013b). Site factors are important to consider with hazard modelling as they influence the spatial variation in seismic ground motions, by causing (de)amplification of ground motions. To account for local site conditions in seismic shaking estimates, amplification factors (Borcherdt, 1994) can be applied to the Site Class Maps of New Zealand (Destegul et al., 2008). Furthermore, ground motion modelling of local site effects (e.g. Kaiser et al., 2012b) elucidates site behaviour in large earthquakes. On the basis of these model predictions, collaborative susceptibility assessments of water supply infrastructure to earthquake-induced shaking could inform practitioners in decision-making processes for investment to mitigate risk to, and to increase the resilience of, water supply infrastructure.

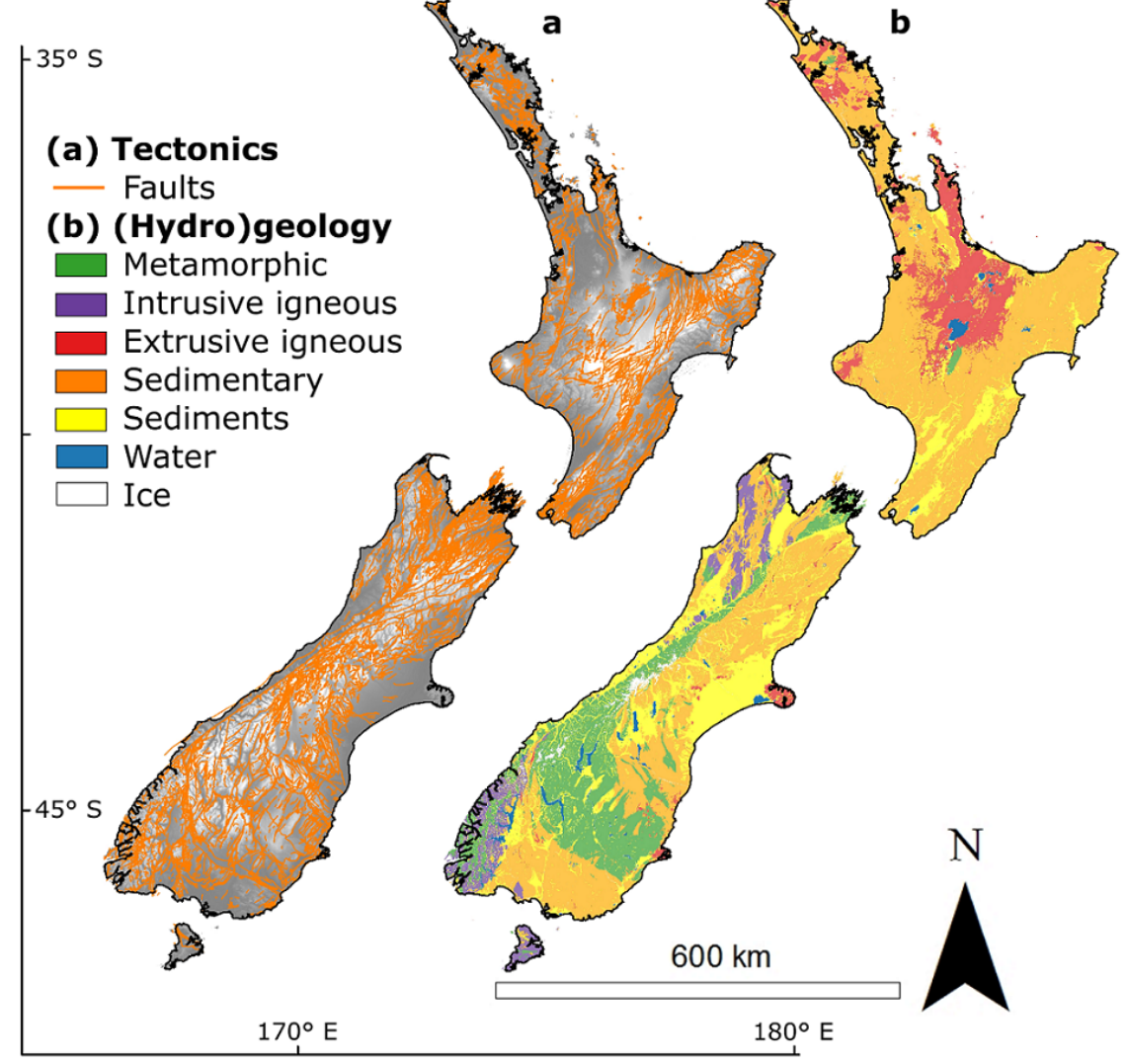

Figure 2.8: Geological map of New Zealand. (a - Left) Map showing all onshore faults (Langridge et al., 2016). (b - Right) Map showing the geology of New Zealand (Heron, 2014). 


\section{Hydrogeology}

There are a wide variety of compositionally diverse aquifers in New Zealand, formed in a range of depositional environments, primarily in the Tertiary and Quaternary periods. Sedimentary aquifers were formed from terrestrial (e.g. glacial, aeolian), shallow- (e.g. deltaic, carbonate) and deep-marine sedimentary deposits, with mixed clast compositions that reflect the varied source rock geology (White, 2001). There are also volcanic aquifers of ignimbrite and scoriaceous deposits formed in the central North Island caldera eruptions and basalt flows in the Taupo Volcanic Zone respectively. Groundwater is also stored in fractured Mesozoic-Cretaceous metamorphic bedrock that forms mountain ranges in both the North and South Islands, but is seldom utilised for water supplies due to the low permeability and yield of the bedrock (White, 2001).

\subsection{Previous earthquake hydrology research in New Zealand}

There are few previous studies of earthquake hydrological responses in New Zealand. The first scientific publication in New Zealand discussing earthquake-induced hydrological changes was by Brown and Weeber (1992), on the response of the Canterbury Plains aquifer system to the $1989 \mathrm{M}_{\mathrm{w}}$ 8.2 Macquarie Ridge earthquake. Brown and Weeber (1992) mapped liquefaction susceptibility as a function of sediment/soil type distribution and soil strength.

\section{0-2011 Canterbury earthquake sequence}

The first nation-wide collation of groundwater responses to a local seismic event was by Cox et al. (2012) for the Darfield $2010 \mathrm{M}_{\mathrm{w}} 7.1$ earthquake (Figure 2.9). Liquefaction caused by the Darfield earthquake (e.g. Allen et al., 2010) and Christchurch $\mathrm{M}_{\mathrm{w}}$ 6.2 aftershock on 22 February 2011 (e.g. Cubrinovski et al., 2011) were examined and compared (Orense et al., 2011). The characteristics of recurrent liquefaction from several earthquakes within the Canterbury earthquake sequence have also been evaluated (Quigley et al., 2013). 


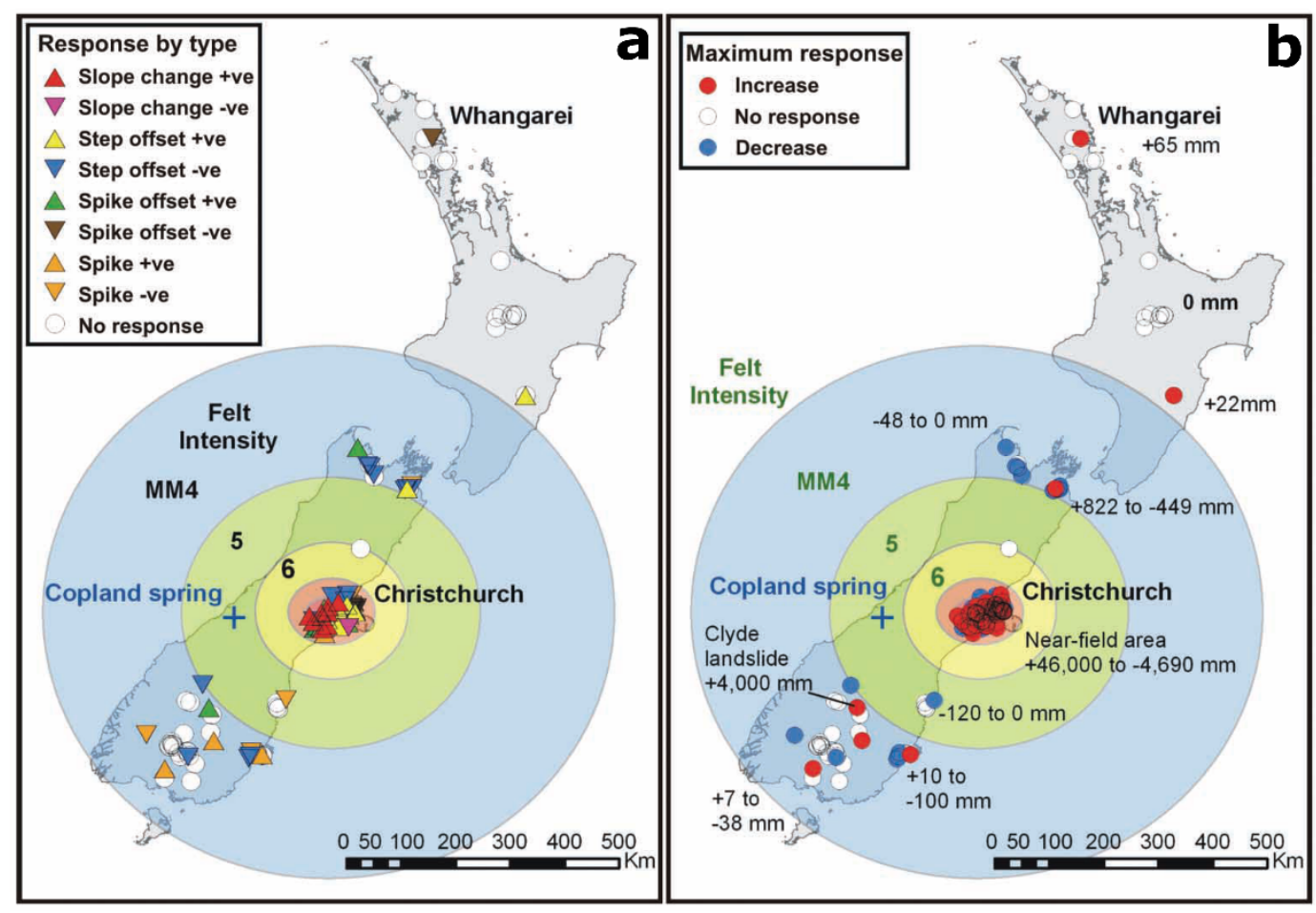

Figure 2.9: New Zealand-wide groundwater-level changes induced by the 2010 Darfield $\mathrm{M}_{\mathrm{w}} 7.1$ earthquake with an isoseismal map of shaking intensity. (a - Left) Spatial distribution of different response types outlined in Figure 2.3. (b - Right) Spatial distribution of overall water-level change. From Cox et al. (2012).

Rutter et al. (2016) was the first international study to repeat aquifer tests preand post-earthquake. The longer-term groundwater response to the 2010 Darfield $\mathrm{M}_{\mathrm{w}}$ 7.1 earthquake was assessed with step-drawdown tests within $15 \mathrm{~km}$ of the Greendale Fault (Figure 2.10). A reduction in transmissivity and an increase in well losses was observed, thought to result from sediment incursions into high-permeability open framework gravel lenses that accommodate the majority of groundwater flow. To further understand earthquake-induced aquifer change, this thesis uses tidal analysis to calculate pre- and post-earthquake aquifer properties on a continuous basis and assesses the extent to which dynamic stress changes contribute to aquifer changes.

Gulley et al. (2013) quantified groundwater-level responses to the $\mathrm{M}_{\mathrm{w}} 6.2$ earthquake of 22 February 2011, and the $\mathrm{M}_{\mathrm{w}} 6.0$ and $\mathrm{M}_{\mathrm{w}} 5.6$ aftershocks of 13 June 2011, showing that groundwater-level consistently dropped in deeper wells and rose in shallow wells. They interpreted this to be resulting from the vertical movement of water from confined to unconfined aquifers through the breaching of aquitards. Numerical modelling supports this hypothesis (Dudley Ward, 2015). 

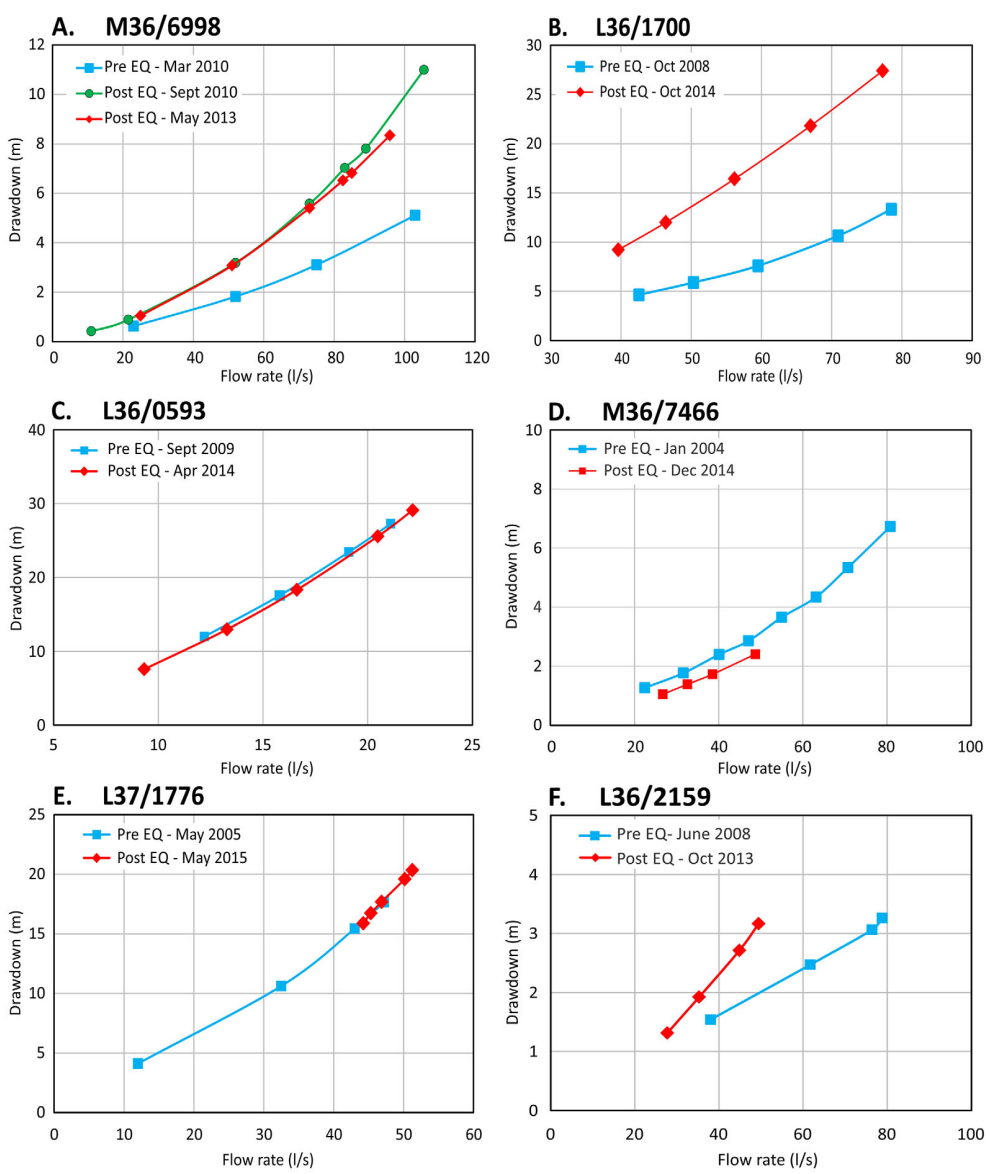

Figure 2.10: Step-drawdown tests on monitoring wells in the Canterbury plains before (blue) and after (red and green) the Darfield earthquake. Monitoring wells are within $15 \mathrm{~km}$ of the Greendale Fault. From Rutter et al. (2016).

\section{Multi-earthquake studies}

In a separate study, the temperature and fluid chemistry of the Copland hot spring in the Southern Alps was monitored over several large magnitude earthquakes, including the $2009 \mathrm{M}_{\mathrm{w}} 7.8$ Dusky Sound and $\mathrm{M}_{\mathrm{w}} 7.1$ Darfield earthquakes (Cox et al., 2015). Observed temperature and fluid chemistry responses were inferred to reflect subtle changes in the fracture permeability of the schist rock adjacent to Copland hot spring. Fracture generation or opening potentially enabled cool near-surface meteoric water to mix with warmer upwelling water. The dynamic stress associated with the passage of seismic waves through the mountains released a component of stored tectonic strain. Cox et al. (2015) highlights the potential role of triggered changes in local rock stress state in causing permeability change and that local hydrogeogical factors in an active tectonic setting are potentially important. This forms the basis for focussing on the extent to which hydrogeological factors contribute to groundwater-level changes in this thesis. 

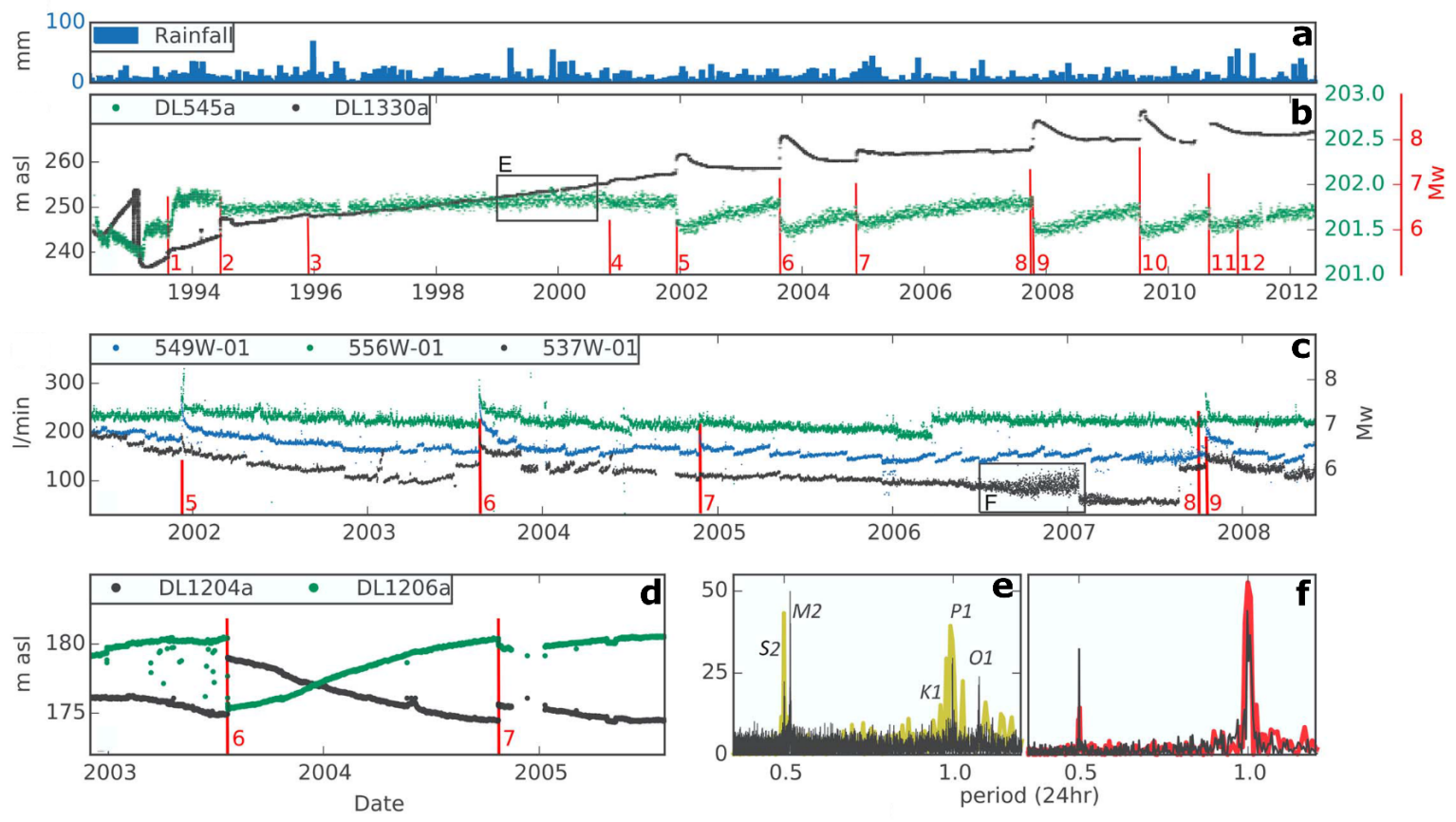

Figure 2.11: Examples of hydrological data from Cromwell Gorge. (a - Top) Rainfall, (b - Middle top) Groundwater-level data and 12 earthquakes studied, (c - Middle) Tunnel V notch weir flow rates, (d - Bottom left) Groundwater-level data from two wells in the same landslide that mirror each other, (e and $\mathrm{f}$ - Bottom right) Periodograms of tidal oscillations with (e) groundwater level and (f) discharge data. From O'Brien et al. (2016).

In a separate investigation by O'Brien et al. (2016), geoengineered groundwater systems within schist landslides in Cromwell Gorge were observed to have responded to $11 \mathrm{M}_{\mathrm{w}} 6.2$ or larger earthquakes from 1990 to 2013, at a variety of epicentral distances. The groundwater-level changes were systematic in terms of duration, polarity and amplitude for the earthquakes studied. A damped harmonic oscillator was implemented to characterise the ability of the aquifer system to resist and recover from hydrological change. By normalising site responses this paper was able to highlight the role different types of earthquake shaking have on the scale and duration of hydrological changes. O'Brien et al. (2016) was an early attempt at a multi-site multi-earthquake catalogue in which they normalised site responses in order to see effects of site shaking spectra. However, this was a local geoengineered situation and it remains unclear how well these lessons can be applied regionally/internationally, thus leading to the building of the largest New Zealand-wide catalogue in this thesis. 


\subsection{Data sources}

To address the research questions of this thesis, the groundwater-level responses to 11 $\mathrm{M}_{\mathrm{w}} 5.4$ or larger earthquakes that occurred between 2008 and 2017 in New Zealand have been examined (Table 2.2). These earthquakes were selected as they provided a mix of near-field and intermediate-field responses across the New Zealand groundwater monitoring network, in order to assess the seismic and hydrogeological controls. Lower-magnitude earthquakes were included to catalogue the occurrence and absence of responses.

The earthquakes selected for analysis have predominantly caused the greatest intensity of shaking to the New Zealand landmass over a period of a decade (2008 to 2018). As characterising hydrological responses is time-intensive, not all significant large earthquakes were used. The following earthquakes could be used to make a more complete onshore decadal catalogue: $2015 \mathrm{M}_{\mathrm{w}} 6$ Arthur's Pass earthquake; $2015 \mathrm{M}_{\mathrm{w}}$ 6.2 St Arnaud earthquake; $2015 \mathrm{M}_{\mathrm{w}} 5.8$ Wanaka earthquake; $2016 \mathrm{M}_{\mathrm{w}} 5.7$ Valentine's day earthquake; and the $2016 \mathrm{M}_{\mathrm{w}}$ 7.1 East Cape earthquake.

Table 2.2: Table of the 11 earthquakes studied in this thesis. See Figure 2.12 for the focal mechanisms of these event. Note that the time format is in $\mathrm{dd} / \mathrm{mm} / \mathrm{yy} \mathrm{HH}: \mathrm{MM}$ in New Zealand Standard Time. The datasets that each earthquake are in are included. Chap. = Thesis chapter containing results.

\begin{tabular}{cccccc}
\hline $\begin{array}{c}\text { Earthquake } \\
\text { location }\end{array}$ & $\begin{array}{c}\text { Epicentre } \\
\text { latitude, } \\
\text { longitude }\end{array}$ & Time and date & $\mathbf{M}_{\mathbf{w}}$ & $\begin{array}{c}\text { Depth } \\
(\mathbf{k m})\end{array}$ & Chap. \\
\hline Hastings & $-39.72,176.85$ & $25 / 08 / 0823: 25$ & 5.4 & 32 & 3,4 \\
Dusky Sound & $-45.77,166.59$ & $15 / 07 / 0921: 22$ & 7.8 & 12 & 3,4 \\
Darfield & $-43.53,172.17$ & $4 / 09 / 104: 35$ & 7.1 & 11 & 3,4 \\
Christchurch & $-43.58,172.68$ & $22 / 02 / 1111: 51$ & 6.2 & 5 & 3,4 \\
Christchurch & $-43.57,172.74$ & $13 / 06 / 1114: 12$ & 6.0 & 7 & 3,4 \\
Christchurch & $-43.52,172.75$ & $23 / 12 / 1115: 18$ & 5.9 & 7 & 3,4 \\
Opunake & $-40.05,173.76$ & $3 / 07 / 1222: 36$ & 6.2 & 241 & 3,4 \\
Seddon & $-41.60,174.32$ & $21 / 07 / 1317: 08$ & 6.6 & 16 & 3,4 \\
Grassmere & $-41.73,174.15$ & $16 / 08 / 1314: 31$ & 6.6 & 8 & 3,4 \\
Eketahuna & $-40.62,175.86$ & $20 / 01 / 1414: 52$ & 6.3 & 34 & 3,4 \\
Kaikoura & $-42.69,173.02$ & $13 / 11 / 1623: 02$ & 7.8 & 15 & 2,4 \\
\hline
\end{tabular}

Although aftershocks of some of the large-magnitude earthquakes were themselves quite large $\left(M_{\mathrm{w}}>5.4\right)$, aquifer systems were commonly still re-equilibrating to the main shock weeks after the event. Therefore, aftershock sequences were ignored and responses were presumed to be solely attributed to the main shock. Numerous offshore large magnitude earthquakes occurred in the Puysegur, Hikurangi and Kermadec trenches between 2008 and 2018, far from the groundwater monitoring networks. These 
earthquakes were not considered in this thesis, although they may have caused aquifer changes. In future work an offshore decadal catalogue should be collated comprising these earthquakes.

GeoNet operates and maintains continuously recording seismographs and strong motion instruments. Seismograms were compiled from all over New Zealand that recorded the earthquakes, from 306 strong motion and broadband seismic stations.

The hydrological monitoring infrastructure in New Zealand is both dense and widespread. The monitoring infrastructure is not evenly distributed spatially, as the majority of groundwater tends to be monitored and extracted from the most permeable aquifers, commonly gravel and sandstone aquifers. However, monitoring wells are also screened in a range of other rock types including basalt, volcanics, schist and cataclasite. Groundwater-levels are recorded by vented/non-vented piezometers, floatactivated recorders in the monitoring wells at intervals ranging from four seconds to three months, with 15 minutes being the most common sampling frequency. Equipment used vary between regional councils, however, the resolution of the sampling measurements is typically on the order of $\pm 3 \mathrm{~mm}$. Water-levels are also manually checked quarterly by regional councils to correct for drift, offset and slippage of the suspension system. Considering the scale of changes measured after earthquakes, the sampling resolution is sufficient.

Groundwater level data between 2008 and 2017 were obtained from regional councils who manage and maintain networks of monitoring wells. A total of 495 monitoring well water-level time-series were gathered. New Zealand-wide climate data from 2008 to 2017 was collected from the National Institute for Water and Atmospheric Research (https://cliflo.niwa.co.nz), who manage $65+$ climate stations. Sea-level data was collected from Land Information New Zealand (https://www.linz.govt.nz) who oversee 15 tidal gauges around the New Zealand coastline (Figure 2.13). 


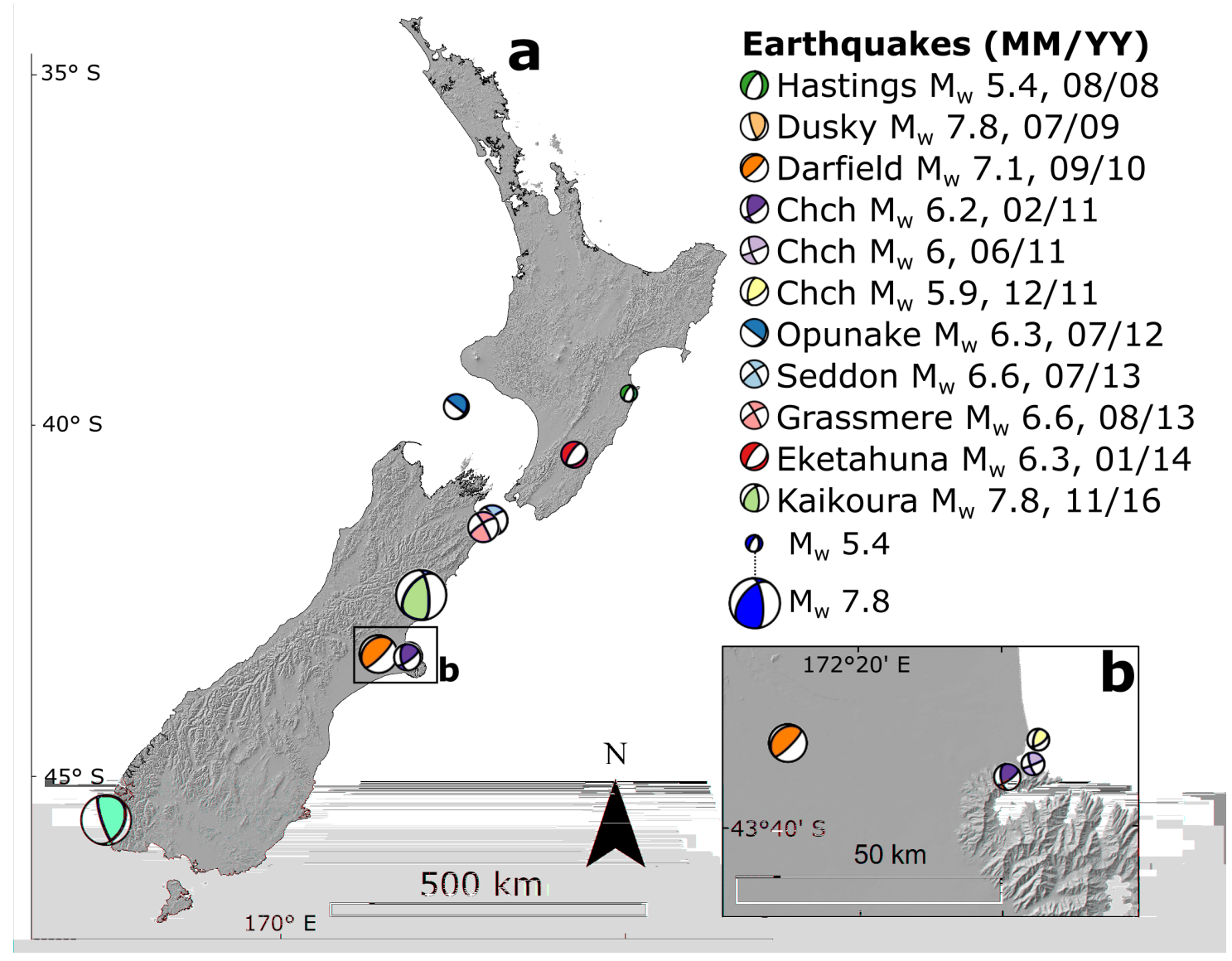

Figure 2.12: Spatial distribution of the 11 earthquakes that predominantly caused the greatest intensity of shaking to the New Zealand landmass over a period of a decade (2008 to 2018), that have been studied in this thesis. (a - Centre left) New Zealandwide earthquakes. (b - Bottom right) Expanded view of the Christchurch region and the four major events in 2010 and 2011 of the Canterbury earthquake sequence, plotted at the same scale. 

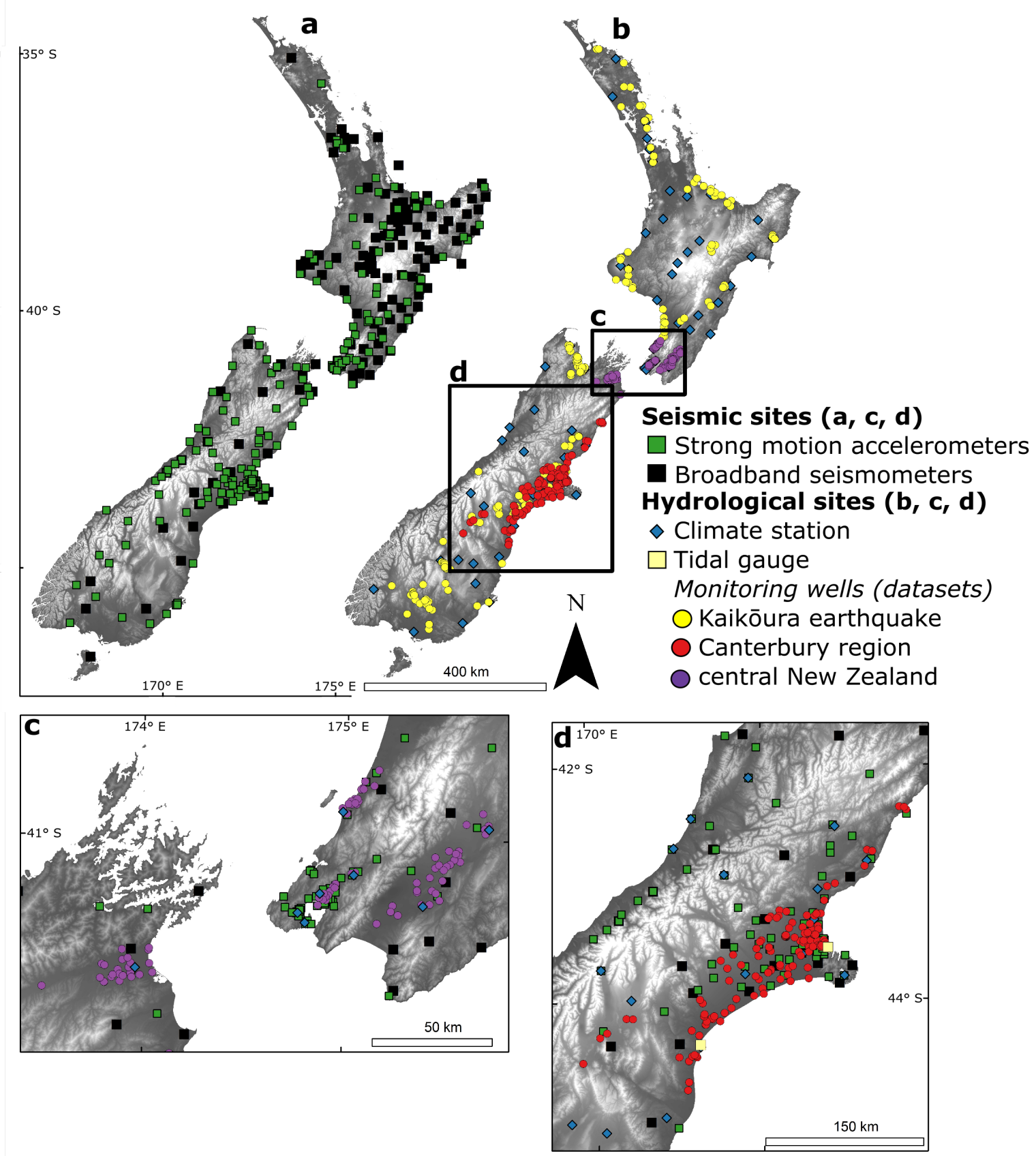

Figure 2.13: Spatial distribution of the seismic and hydrological datasets used in this thesis. (a - Top left) Seismic stations (strong motion accelerometers and broadband seismometers) that recorded the earthquakes, (b - Top right) New Zealand-wide hydrological sites, (c - Bottom left) Seismic and hydrological sites in central New Zealand, (d - Bottom right) Seismic and hydrological sites in Canterbury, New Zealand. 


\subsection{Scientific approach}

Earthquake hydrology can be studied using a variety of approaches, such as with field observations, laboratory tests and numerical modelling. Field observations are fundamental to understand the governing mechanisms and have been analysed in two ways: the effect of a singular earthquakes on several sites (e.g. Cox et al., 2012) or the influence of several earthquakes on one site (e.g. Lee et al., 2012; Weingarten and Ge, 2014, Figure 2.14). In recent years, the effect of multiple earthquakes on a hydrological network have been studied in New Zealand (e.g. O'Brien et al., 2016) and overseas (e.g. Shi et al., 2015b). Laboratory simulations provide an opportunity to study hydrological responses in a controlled environment. Investigations have studied the effect of varying frequencies and amplitudes of transient stresses on rock permeability (e.g. Roberts, 2005; Manga et al., 2012; Elkhoury et al., 2011). Numerical modelling has further facilitated the study of earthquake-induced hydrological changes (e.g. Elkhoury et al., 2006; Dudley Ward, 2015; Nespoli et al., 2016).

Table 2.3: Table comparing datasets of international studies, specifically with respect to number of earthquakes, wells, lithologies and distance from epicentre

\begin{tabular}{|c|c|c|c|c|}
\hline Study & $\begin{array}{c}\text { No of } \\
\text { earthquakes }\end{array}$ & $\begin{array}{l}\text { No. of } \\
\text { wells }\end{array}$ & Lithology & $\begin{array}{c}\text { Near-/Intermediate-/Far- } \\
\text { field }\end{array}$ \\
\hline Chapter 3 & 1 & 433 & Varied & Near, Intermediate \\
\hline Chapter 4 & 9 & 161 & Unconsolidated & Near, Intermediate \\
\hline Chapter 5 & 11 & 495 & Varied & Near, Intermediate \\
\hline Cox et al. (2012) & 1 & 171 & Varied & Near, Intermediate \\
\hline Gulley et al. (2013) & 4 & 161 & Unconsolidated & Near \\
\hline Cox et al. (2015) & 3 & 1 & Schist & Intermediate \\
\hline Rutter et al. (2016) & 1 & 84 & Unconsolidated & Near \\
\hline O'Brien et al. (2016) & 11 & 22 & Schist & Intermediate \\
\hline Roeloffs (1998) & 8 & 1 & Unconsolidated & Intermediate \\
\hline Matsumoto et al. (2003) & 28 & 1 & Sandstone & Intermediate, Far \\
\hline Wang and Chia (2008) & 1 & 247 & Unconsolidated & Near, Intermediate \\
\hline Chia et al. (2008) & 1 & 209 & Unconsolidated & Near, Intermediate \\
\hline Shi et al. (2013b) & 1 & 17 & - & Intermediate \\
\hline Yan et al. (2014) & 1 & 216 & Varied & Intermediate, Far \\
\hline Weingarten and Ge (2014) & 219 & 1 & Carbonate & Far \\
\hline Shi and Wang (2014) & 13 & 1 & Limestone & Intermediate, Far \\
\hline Shi et al. (2014) & 2 & 12 & Varied & Intermediate \\
\hline Shi et al. (2015a) & 1 & 197 & Varied & Near, Intermediate, Far \\
\hline Shi et al. (2015b) & 4 & 245 & Varied & Intermediate, Far \\
\hline Shi and Wang (2015) & 1 & 3 & Unconsolidated & Intermediate \\
\hline
\end{tabular}




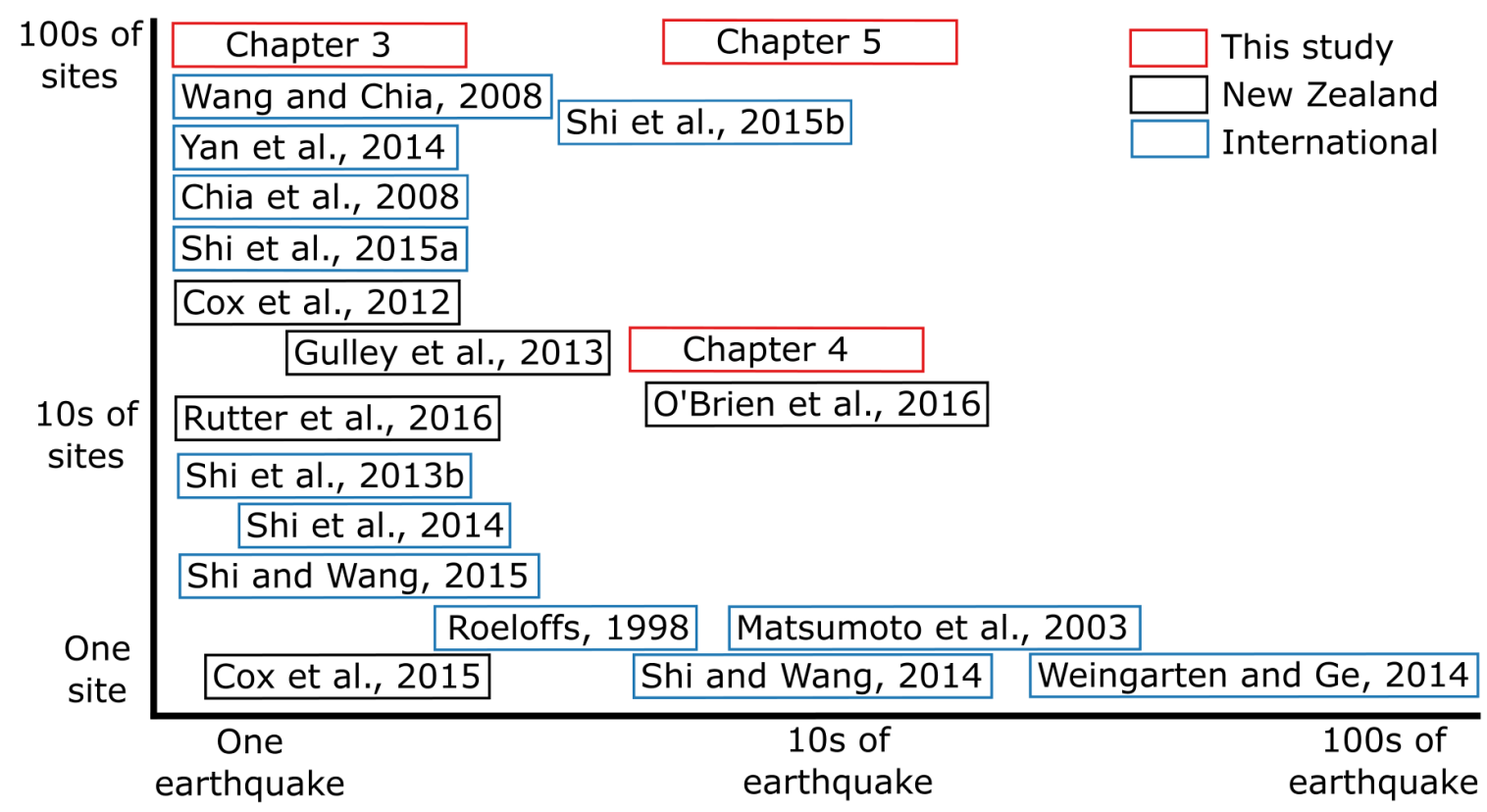

Figure 2.14: Schematic comparison of datasets between international studies. Previous studies commonly have investigated the effect of a singular earthquake on multiple sites, or the effect of multiple earthquakes on a single site. Chapter 3 is a singular earthquake study with a internationally significant number of responses analysed in the near- and intermediate-field. Chapter 4 is a multi-site multi-earthquake study in gravel aquifers assessing water-level and tidal behaviour changes. Chapter 5 is an internationally signficant contribution investigating regional-scale multi-site multiearthquake responses.

The key difference and contribution of this thesis is that it is a regional-scale multisite multi-earthquake study (Table 2.3), that includes the occurrence and absence of responses, over a decade of seismic shaking. The advantage of this approach is that responses can be examined in a range of aquifers, rock types and hydrogeological settings. Furthermore, responses can be recorded in the near- and intermediate-field at the same site, induced by a range of shaking intensities. As a result, site effects and shaking characteristics can be normalised/calibrated. This then enables the precise identification of responses and mechanisms that are anomalous or merely local aberrations, from those that underpin region-wide processes and are likely to be applicable and significant internationally. 


\section{Seismological and hydrogeological controls on New Zealand-wide groundwater-level changes induced by the $2016 \mathrm{M}_{\mathrm{w}} 7.8$ Kaikōura earthquake}

\section{$3.1 \quad$ Abstract}

The $2016 \mathrm{M}_{\mathrm{w}} 7.8$ Kaikōura earthquake induced groundwater-level changes throughout New Zealand. Water-level changes were recorded at 433 sites in compositionally diverse, young shallow aquifers, at distances of between 4 and $850 \mathrm{~km}$ from the earthquake epicentre. Water-level changes are inconsistent with static stress changes, but do correlate with peak ground acceleration (PGA). At PGAs exceeding $\sim 2 \mathrm{~m} / \mathrm{s}^{2}$, water-level changes were predominantly persistent increases. At lower PGAs, there were approximately equal numbers of persistent water-level increases and decreases. Shear-induced consolidation is interpreted to be the predominant mechanism causing groundwater changes at accelerations exceeding $\sim 2 \mathrm{~m} / \mathrm{s}^{2}$, whereas permeability enhancement is interpreted to predominate at lower levels of ground acceleration. Water-level changes occur more frequently north of the epicentre, as a result of the fault rupture propagating northward and northward directivity. Local hydrogeological conditions also contributed to the observed responses, with larger water-level changes occurring in deeper wells and in well-consolidated rocks at equivalent PGA levels.

This chapter has been submitted as a research manuscript for consideration in the international journal Geofluids (May 2018). Co-authors contributed to the making of this manuscript. S. C. Cox and J. Townend provided conceptual discussion, research design, reviewed the manuscript and obtained funding. H. Rutter assisted with collecting data and reviewing the manuscript. I. Hamling calculated static stress changes and reviewed the manuscript. C. Holden reviewed seismic calculations and the manuscript. 


\subsection{Introduction}

Central New Zealand has experienced several moment magnitude $\left(\mathrm{M}_{\mathrm{w}}\right) 7$ or larger earthquake ruptures in the last 200 years, the largest of which were the $1848 \mathrm{M}_{\mathrm{w}}$ 7.4-7.7 Awatere earthquake (Grapes et al., 1998; Mason and Little, 2006), the $1855 \mathrm{M}_{\mathrm{w}}$ 8.1+ Wairarapa earthquake (Rodgers and Little, 2006), and the $1888 \mathrm{M}_{\mathrm{w}} 7-7.3$ Hope earthquake (Cowan, 1991). The most recent $M_{w} 7+$ event in the region was the $M_{w}$ 7.8 Kaikoura earthquake, which occurred on the 14th November 2016 at 00:02:56 (New Zealand Daylight Time, NZDT). The earthquake was the largest in almost a decade of seismic disruption in New Zealand (Kaiser et al., 2017), following four decades of relative quiescence (Downes and Dowrick, 2015; Nicol et al., 2016). The Kaikōura earthquake followed the 2010-2011 Canterbury earthquake sequence, which included the devastating $\mathrm{M}_{\mathrm{w}} 6.2$ aftershock of 22 February 2011 (Gledhill et al., 2011; Kaiser et al., 2012a), and the Cook Strait earthquakes of 2013 (Holden et al., 2013a; Hamling et al., 2014).

The Kaikoura earthquake initiated in the Waiau Plains in northern Canterbury, New Zealand, on an oblique thrust at a depth of $\sim 15 \mathrm{~km}$. It propagated upwards and northwards, forming a complex rupture along a $\sim 180 \mathrm{~km}$ zone that involved at least 21 faults (Langridge et al., 2016; Holden et al., 2017), producing widespread shaking reaching maximum Modified Mercalli Intensity of IX. The maximum horizontal surface displacement was c. $10 \mathrm{~m}$ in a dextral sense (Stirling et al., 2017; Hamling et al., 2017) and vertical displacements were highly variable, causing widespread coastal uplift/subsidence between +6.5 and $-2.5 \mathrm{~m}$ (Clark et al., 2017). The rupture took over two minutes (Kaiser et al., 2017), and ground acceleration exceeded $\sim 1 \mathrm{~g}$ in the nearsource region (Bradley et al., 2017b).

Earthquakes are speculated to induce groundwater-level changes with varying amplitude, duration, and polarity of response (e.g. Esposito et al., 2009; Petitta et al., 2018; Tranfaglia et al., 2011). Earthquake-induced static and dynamic stresses (e.g. Kinoshita et al., 2015), and local hydrogeological factors (Besedina et al., 2017) influence groundwater-level responses. In this first report on the Kaikoura earthquake's hydrogeological effects, we document an extensive data-set of groundwater-level responses in order to assess the level to which earthquake-driven and local hydrogeological factors contributed to the national-scale groundwater level response. This earthquake hydrology data-set is the most extensive compiled in New Zealand, surpassing that compiled by Cox et al. (2012) following the $\mathrm{M}_{\mathrm{w}} 7.1$ Darfield (Canterbury) earthquake, and is of comparable size to data-sets compiled following the $1999 \mathrm{M}_{\mathrm{w}} 7.5$ Chi-Chi earthquake in Taiwan (Wang et al., 2004a; Wong and Wang, 2007). In comparison to other case studies, the Kaikoura earthquake data-set is also significant as it includes groundwater level responses collated from a variety of hydrogeological settings. 


\subsection{New Zealand hydrogeology}

There are a wide variety of compositionally diverse aquifers in New Zealand that were formed in a range of depositional environments, mainly during the Tertiary and Quaternary geological periods. Sedimentary aquifers were formed from terrestrial (e.g. glacial, aeolian), shallow (e.g. deltaic, carbonate) and deep marine sedimentary deposits, with mixed clast composition reflecting the varied source rock geology (White, 2001). Transgression/regression sequences created overlaps of terrestrial and marine deposits in coastal areas (Taylor et al., 1989), resulting in large variations in vertical and horizontal permeability and storage capacity (Bal, 1996). There are also volcanic aquifers of ignimbrite and scoriaceous deposits formed in the central North Island from Taupo Volcanic Zone caldera eruptions and basalt flows respectively. Groundwater is also stored in Mesozoic-Cretaceous metamorphic bedrock that forms mountain ranges in both North and South Islands, but is seldom utilised for water supplies due to the low permeability and yield of the bedrock (White, 2001).

\subsection{Hydrological and seismic data}

The hydrological monitoring infrastructure in New Zealand is extensive due to the country's heavy reliance on groundwater for agriculture (White, 2001). Regional councils manage and maintain networks of boreholes instrumented by data loggers and pressure sensors that measure groundwater levels, representing piezometric levels. The monitoring infrastructure is not evenly distributed as groundwater tends to be extracted from the most permeable areas, predominantly gravel aquifers, and pumping test data are not readily available. Where repeated pumping test data are available, the inferred transmissivities are ambiguous (Rutter et al., 2016), highly variable (Dann et al., 2008) and catchment dependent (Pedretti et al., 2016).

We collected groundwater level time-series data spanning the Kaikoura earthquake from 433 open or closed monitoring wells distributed throughout New Zealand (Figure 3.1). Groundwater levels are sampled at intervals ranging from one minute to three hours, with 15 minutes being the most common. The majority of wells are less than $100 \mathrm{~m}$ deep, which are shallow in comparison with those considered in international studies (e.g. Kitagawa et al., 2006; Shi et al., 2014). Screens typically range from 1 to $10 \mathrm{~m}$ in length, and well diameters generally vary from 50 to $300 \mathrm{~mm}$, but overall the construction method and well-completion does not vary appreciably across the regions, resulting in similar style of earthquake-induced responses. The aquifers mostly occur in young sedimentary deposits that have varying levels of consolidation, with few aquifers in igneous or metamorphic rocks. A notable exception are the geoengineered schist landslides in Cromwell Gorge (O'Brien et al., 2016), which have fracture permeability 
and water tables that have been displaced from their natural condition by drainage tunnels. In contrast to these examples from New Zealand, many international studies of earthquake hydrology provide datasets on aquifers in well-consolidated and crystalline rocks (e.g. Elkhoury et al., 2006; Shi and Wang, 2014; Shi et al., 2015a).

We gathered rainfall and atmospheric pressure data from 65 climate stations, which are managed and maintained by the National Institute for Water and Atmospheric Research. Barometric corrections were applied where necessary using data from the nearest climate station, leaving monitoring well water-level data relative to waterlevel only. Rainfall data were qualitatively compared to groundwater-level data before, during, and after the Kaikōura earthquake, to assess any effect on observed water-level changes.

Earthquake-induced water level changes can be split into co-seismic and postseismic components relative to the period of shaking at the monitoring site. The primary responses observed in this study were post-seismic, as most of the records were collected at 15 minute intervals, the first occurring after the shaking had stopped. Water-level changes were classified as either having no response, responding transiently and returning to pre-earthquake levels within two hours, or responding persistently (increasing or decreasing) and re-equilibrating at a new post-earthquake level lasting several days or longer (Figure 3.2). For each water-level change, the polarity, amplitude, and duration until re-equilibrated or returned to pre-earthquake levels were recorded. The amplitude of persistent water-level changes was estimated from the difference between the re-equilibrated and pre-earthquake groundwater level. Waterlevel time-series were removed from the analysis in cases in which earthquake-induced damage to the well compromised or prevented the recording of water-level.

The following general terms have been adopted for monitoring wells with respect to earthquakes (Wang and Manga, 2010a): "near-field" denotes wells within one rupture fault length and "intermediate-field" represents wells from one to ten rupture fault lengths away. Considering the Kaikōura earthquake rupture zone extends $\sim 180 \mathrm{~km}$ north east of the epicentre (Figure 3.1), the near-field region extends $\sim 360 \mathrm{~km}$ to the north and $\sim 180 \mathrm{~km}$ to the south of the epicentre (Figure 3.2).

We compiled all available New Zealand seismic recordings of the Kaikōura earthquake from 306 strong motion and broadband seismic stations. The seismic stations are part of the National Seismograph Network and Strong Motion Network (http://geonet.org.nz). Instrument responses were corrected, and a band-pass filter with transition bands of $0.10-0.25 \mathrm{~Hz}$ and $24.50-25.50 \mathrm{~Hz}$ was applied. Shaking parameters, peak ground velocity (PGV) and acceleration (PGA), were calculated at each seismic station and interpolated to the monitoring wells using the nearest neighbour interpolation method (Ebdon, 1985). We make an implicit assumption that surface shaking observed at the seismograph sites, interpolated locally as parameters at the well site, is applicable over the depth of the wells since they are mostly shallow. 


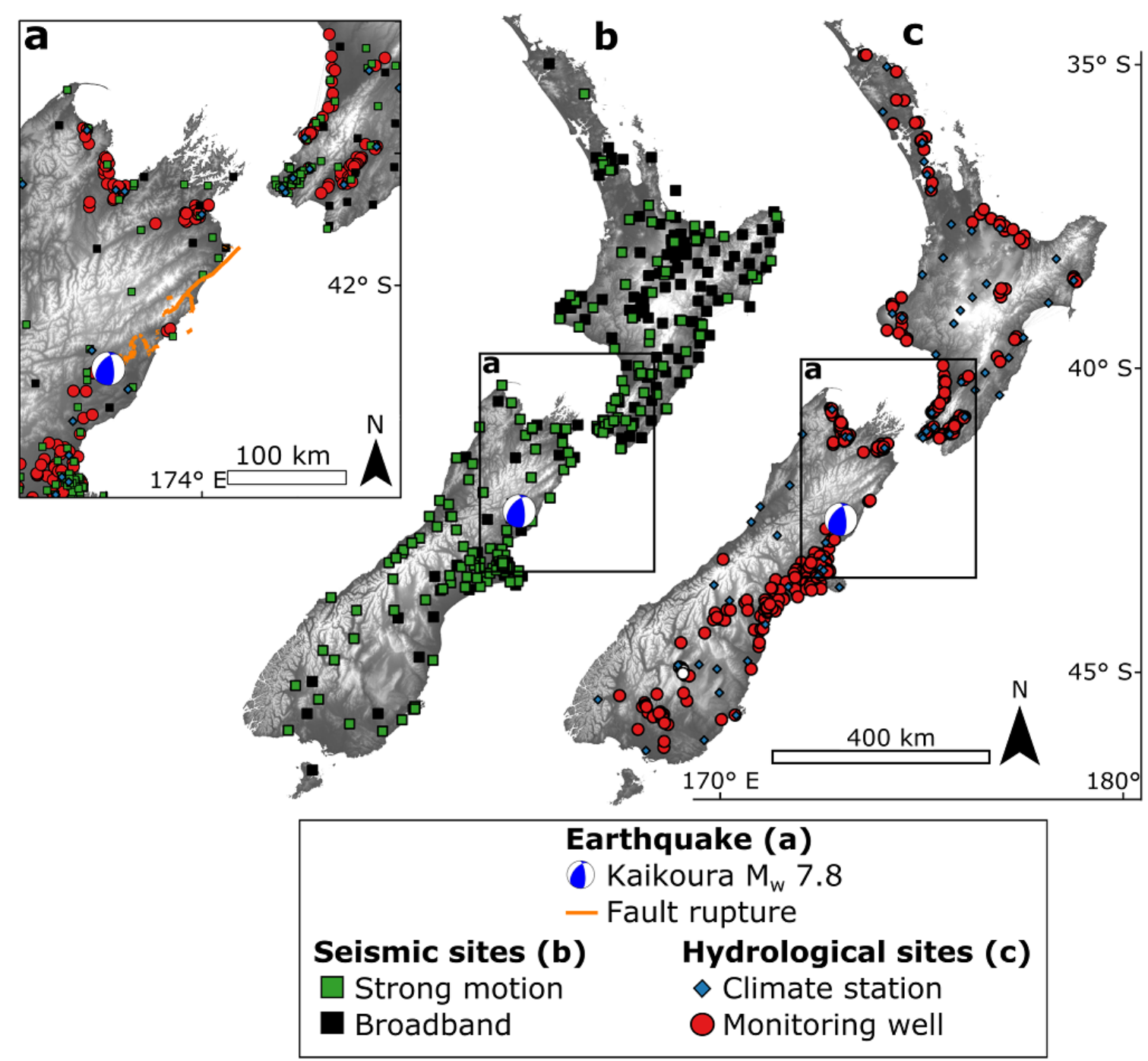

Figure 3.1: Spatial distribution of the hydrological and seismic data-set that recorded the $2016 \mathrm{M}_{\mathrm{w}} 7.8$ Kaikōura earthquake: (a - Top left) Kaikōura earthquake focal mechanism (Kaiser et al., 2017) and surface rupture zone (Langridge et al., 2016). (b - Centre left) 306 seismic stations (strong motion and broadband) recorded the Kaikoura earthquake. (c - Centre right) Water-level data were collected from 433 monitoring wells, and rainfall and atmospheric pressure were collected from 65 climate stations, which spanned the earthquake interval. Monitoring wells in Cromwell Gorge are highlighted differently. 


\subsection{Groundwater-level changes induced by the Kaikōura earthquake}

The Kaikōura earthquake induced groundwater level changes across New Zealand in the near- and intermediate-field (Figure 3.2). Water-levels were recorded at 433 sites from 4 to $850 \mathrm{~km}$ from the earthquake epicentre, at seismic energy densities (Wang, 2007) ranging between $10^{-2}$ to $10^{5} \mathrm{~J} / \mathrm{m}^{3}$ (Figure 3.3). Although the relationship of seismic energy density, magnitude and epicentral distance was derived from earthquakes in southern California (Cua, 2004), the term is accepted internationally and used for seismo-hydrological phenomena (e.g. Cox et al., 2015). Of the well waterlevels observed, 146 showed a persistent increase, 91 exhibited a persistent decrease, and 69 displayed a transient change. At 127 wells there was no observed change. In the near-field, approximately two-thirds of the persistent water-level changes observed were increases. In the intermediate-field, changes were roughly equally split between increases and decreases. The largest persistent water-level increase was $\sim 3.5 \mathrm{~m}$ and the largest decrease was $\sim 3.3 \mathrm{~m}$, both of which were observed in Cromwell Gorge. In simple terms, water-level changes in the near-field had larger amplitudes than in the intermediate-field. The time taken for water-levels to re-equilibrate at new postearthquake levels generally ranged from 10 minutes to two hours, with a median time of 65 minutes and longest time of $100+$ days (Cromwell Gorge).

\subsection{The influence of earthquake driven factors on water-level changes}

\section{Earthquake-induced static stress changes}

Static stress changes are permanent and decay rapidly with distance $(r)$ at $\sim 1 / \mathrm{r}^{3}$, meaning that they are most significant in the near-field (Figure 3.4 Lay and Wallace, 1995; Manga and Wang, 2007). Earthquake-induced static stress changes imposed on the surrounding crust cause volumetric strain changes within aquifer systems. Studies have suggested that volumetric strain changes cause water-level changes (e.g. Wakita, 1975; Quilty and Roeloffs, 1997; Jónsson et al., 2003; Akita and Matsumoto, 2004). The contractional and dilatational volumetric strain changes are inferred to increase and decrease water-levels respectively, with predictable amplitudes (e.g. Roeloffs, 1996). However, several fault lengths away from the epicentre, water-level changes are commonly larger in amplitude and inconsistent in water-level change polarity (increase/decrease) with model predictions (Koizumi et al., 1996; Shi and Wang, 2015; Wang and Manga, 2010a). 


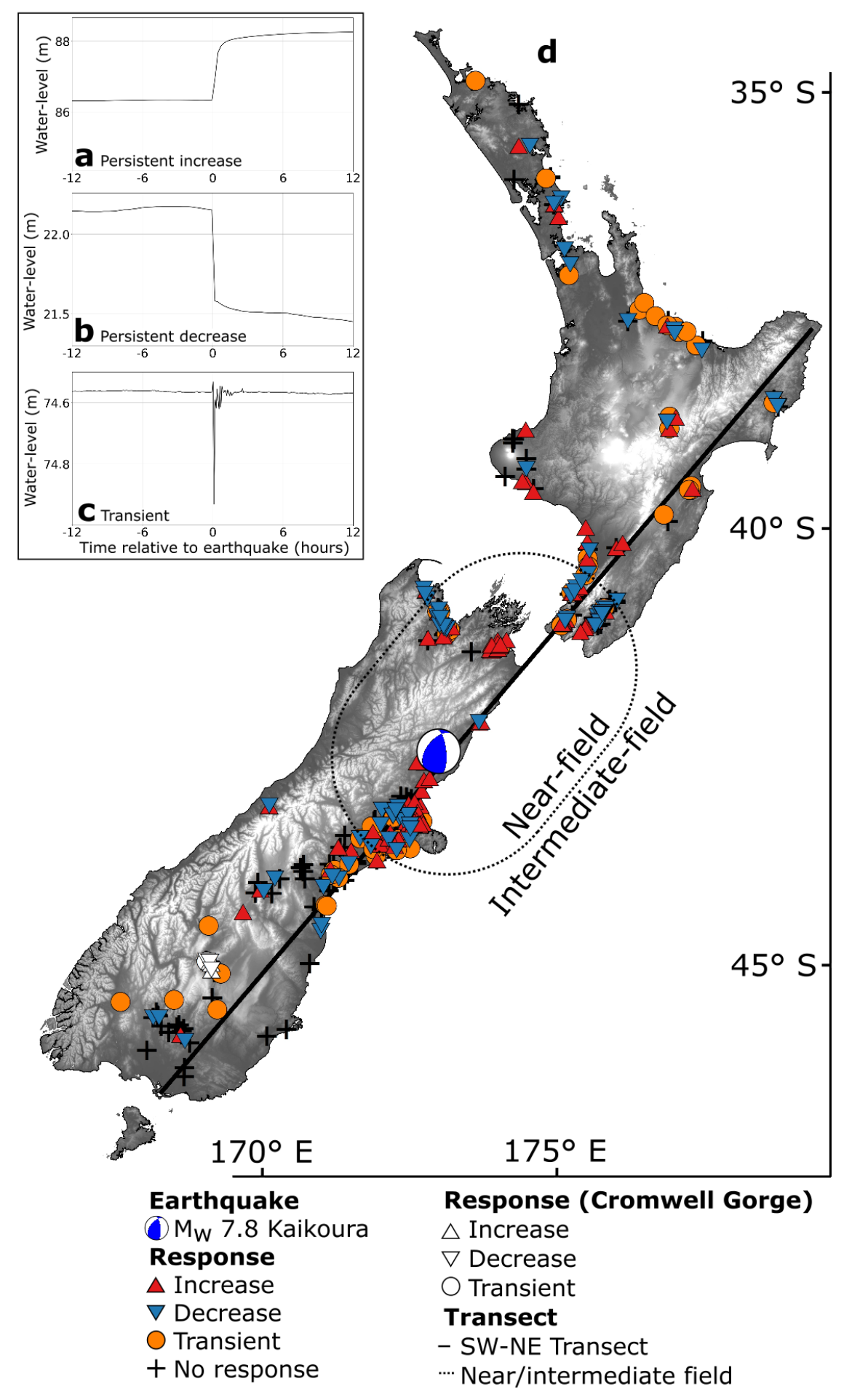

Figure 3.2: Three examples of earthquake-induced groundwater-level responses characterised, and the spatial distribution of water-level changes induced by the $2016 \mathrm{M}_{\mathrm{w}} 7.8$ Kaikōura earthquake. (a - Top left) Persistent water-level increase, (b - Middle left) persistent water-level decrease, (c - Bottom left) transient water-level change, and (d - Centre right) spatial distribution. Sampling intervals are 15 minutes (a and b) and 5 minutes (c). Responses in Cromwell Gorge are highlighted separately. The thick black line shows a transect approximately parallel to the long axis of the surface rupture zone; see Figure 3.8 for water-level changes along this transect. 


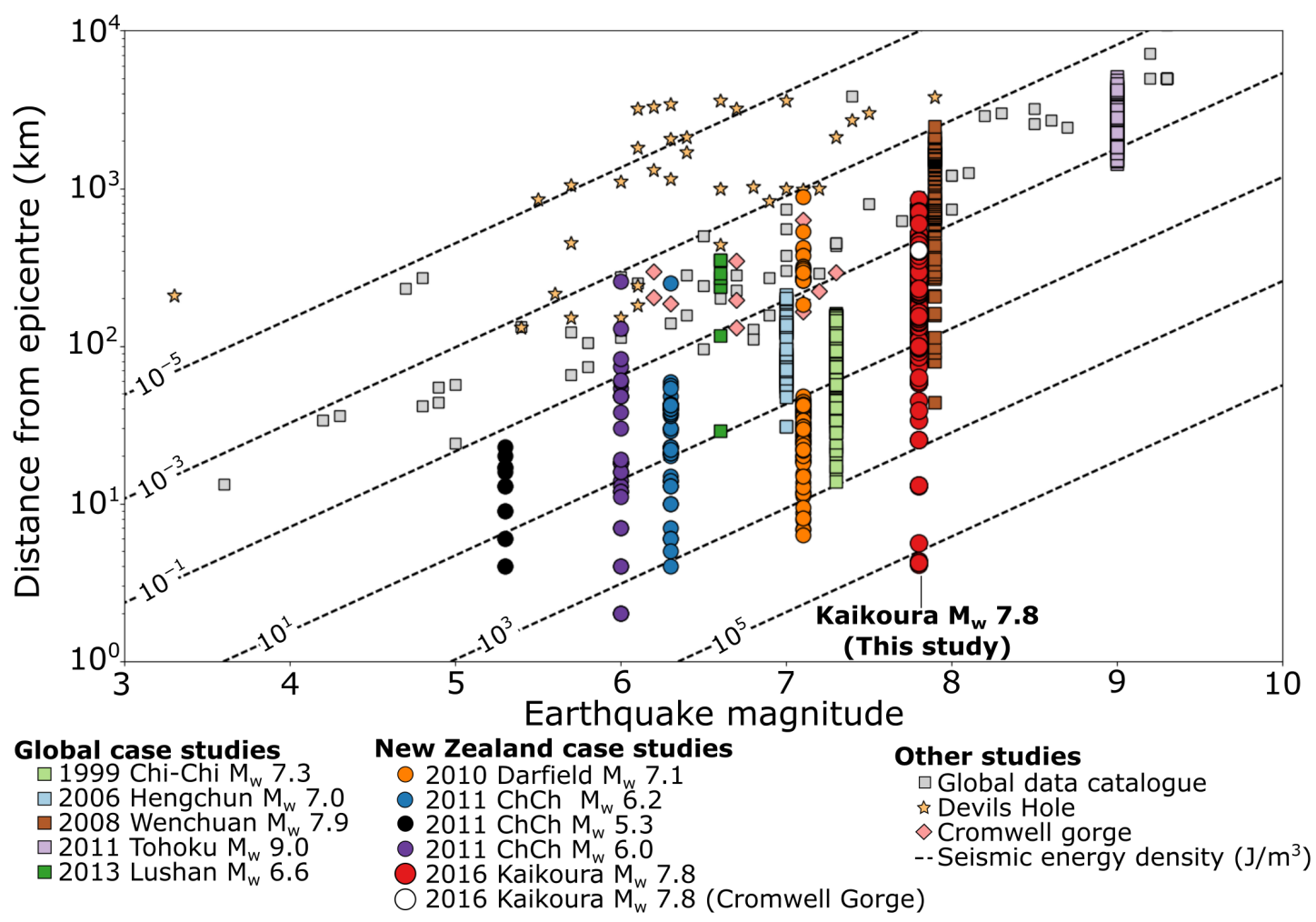

Figure 3.3: Earthquake magnitude as a function of distance from epicentre, where a groundwater level response was observed. We collated New Zealand and global case studies. New Zealand studies include: 2010 Darfield $\mathrm{M}_{\mathrm{w}} 7.1$ (Cox et al., 2012); 2011 Christchurch $\mathrm{M}_{\mathrm{w}}$ 6.2, 5.3, 6.0 (Gulley et al., 2013); and Cromwell Gorge (O’Brien et al., 2016). International studies include: 1999 Chi-Chi $\mathrm{M}_{\mathrm{w}} 7.3$ and 2006 Hengchun $\mathrm{M}_{\mathrm{w}} 7.0$ (Chia et al., 2008); 2008 Wenchuan $\mathrm{M}_{\mathrm{w}} 7.9$ (Shi et al., 2013b, 2015a); 2011 Tohoku $\mathrm{M}_{\mathrm{w}} 9.0$ (Yan et al., 2014); 2013 Lushan $\mathrm{M}_{\mathrm{w}} 6.6$ (Shi et al., 2014). Also included is a worldwide compilation of groundwater responses (Wang and Chia, 2008); responses from the extremely sensitive Devils Hole (Weingarten and Ge, 2014); and seismic energy density contours in $\mathrm{J} / \mathrm{m}^{3}$ (Wang, 2007). ChCh $=$ Christchurch.

To calculate the mean static stress changes $\left(\sigma_{\mathrm{kk}}\right)$, we used the slip distribution of Clark et al. (2017) to calculate the internal strain field based on the formulation of Okada (1992) at $500 \mathrm{~m}$ depth across the epicentral region. Using a Poisson's ratio of 0.25 and a shear modulus of $30 \mathrm{GPa}$, we then convert the strain to stress at $500 \mathrm{~m}$ depth. Modelled fault slip geometries for the 21 ruptured faults, were based on the surface rupture field (Stirling et al., 2017) and geodetic data. Positive $\sigma_{\mathrm{kk}}$ indicates tensional stress changes, and negative $\sigma_{\mathrm{kk}}$ indicates compressional stress changes.

As expected, $\sigma_{\mathrm{kk}}$ was most significant in the near-field (Figure 3.4 and 3.8). In total 386 wells were in areas of contraction, where $\sigma_{\mathrm{kk}}$ ranged from -0.2 to $-18,800 \mathrm{kPa} .47$ wells were in areas of dilatation, where $\sigma_{\mathrm{kk}}$ ranged from 0.7 to $120 \mathrm{kPa}$ (Figure 3.5). Static stress-induced compressional changes larger than $-10^{1} \mathrm{kPa}$ occurred predomi- 
nantly with water-level increases $(\mathrm{n}=98)$, and static stress-induced tensional changes between $10^{1}$ and $10^{2} \mathrm{kPa}$ occurred generally with water-level decreases $(\mathrm{n}=13)$. Compressional changes smaller than $-10^{1} \mathrm{kPa}$ occurred more frequently with decreases in water-level $(\mathrm{n}=53)$ than increases $(\mathrm{n}=39)$, although the larger amplitudes were mostly increases. At lower than $\pm 10^{2} \mathrm{kPa}$ regardless of the sign of $\sigma_{\mathrm{kk}}$, some water-levels did not respond. Significant $(>1 \mathrm{~m})$ water-level changes were observed in Cromwell Gorge, where $\sigma_{\mathrm{kk}}$ was less than $-10^{0} \mathrm{kPa}$ (Figure 3.5).

\section{Earthquake \\ Mw 7.8 Kaikoura \\ Response \\ $\triangle$ Increase \\ $\nabla$ Decrease \\ Transient \\ + No change \\ Transect \\ - SW-NE Transect \\ Mean static \\ stress change $\left(\sigma_{k k}\right)$}
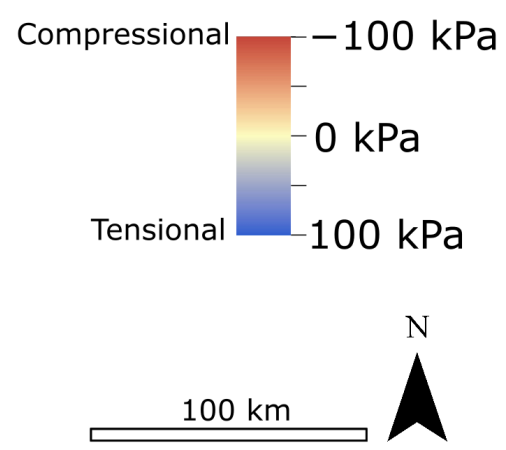

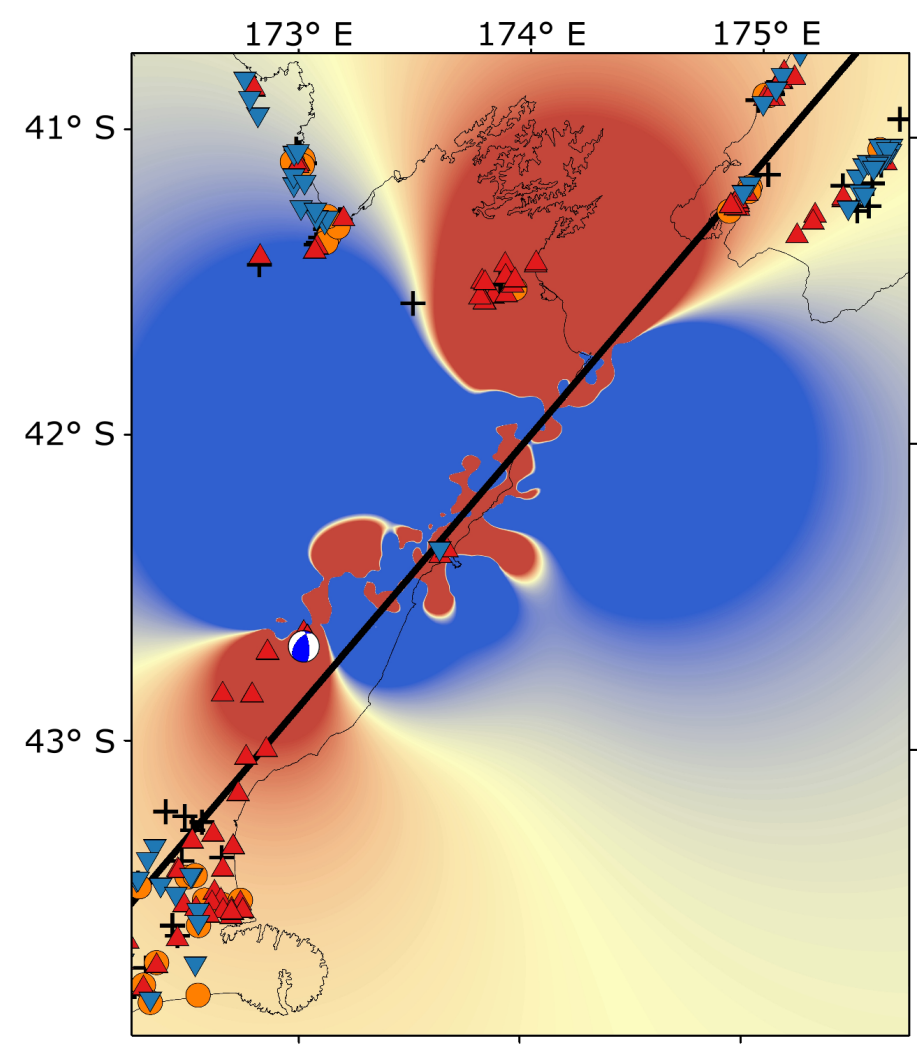

Figure 3.4: Spatial distribution of water-level changes and mean static stress changes $\left(\sigma_{\mathrm{kk}}\right)$ induced by the Kaikoura earthquake. Red colours indicate contraction, blue colours indicate dilatation. A transect through the surface rupture zone and the majority of monitoring wells is shown in Figure 3.8. 

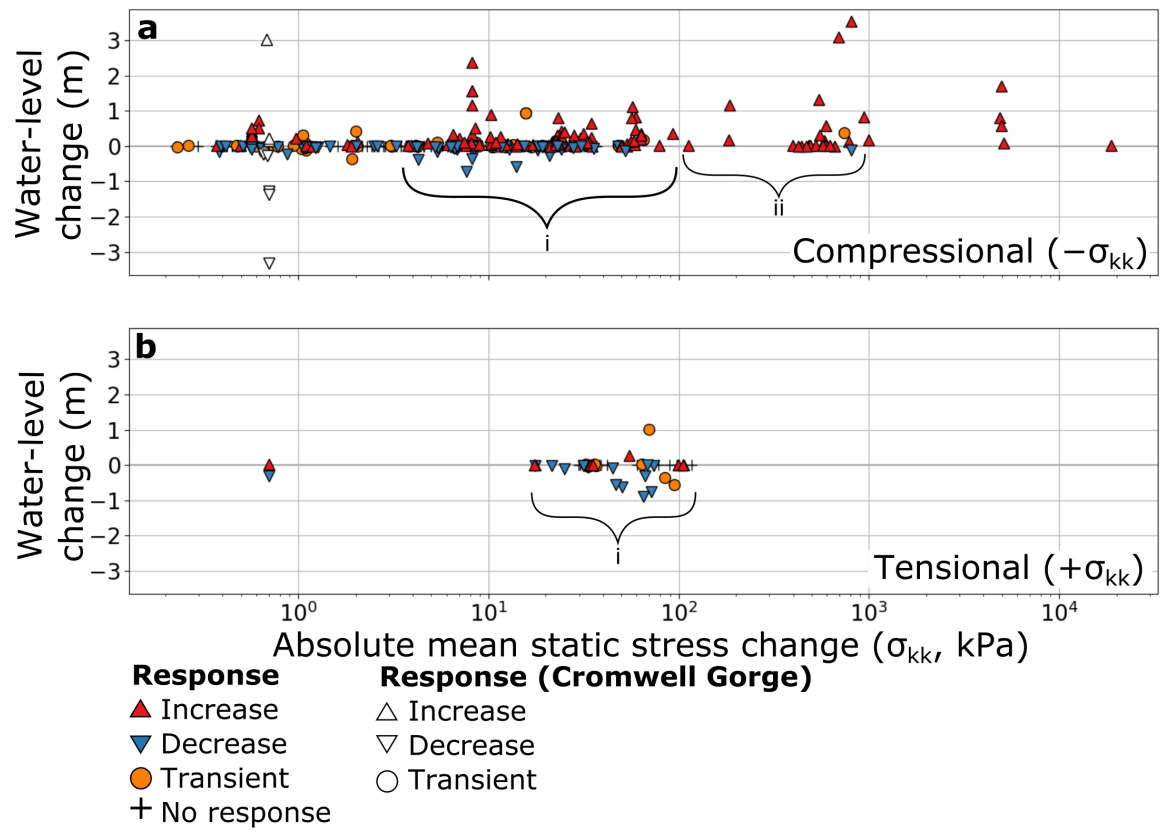

Figure 3.5: The relationship between earthquake-induced mean static stress changes $\left(\sigma_{\mathrm{kk}}\right)$ and water-level changes. (a - Top) Static stress-induced compressional stress changes. High areas of compressional stress changes include (i) Wellington and Canterbury, and (ii) Marlborough. (b - Bottom) Static stress-induced tensional stress changes. High areas of tensional stress changes include (i) Tasman.

\section{Earthquake-induced dynamic shaking}

Dynamic stress changes caused by the passage of seismic waves, are short-lived, and decay at $\sim 1 / r^{1.66}$, meaning that they can be significant from the near- to far-field (Lay and Wallace, 1995; Manga and Wang, 2007). Dynamic stress-induced deformation depends on loading rates and cycles of inertial forces (Manga and Wang, 2007), and is influenced by rupture directivity and radiation patterns (Wang, 2007).

Peak ground velocity (PGV) reflects the majority of energy in seismic ground motion (Wang, 2007) and is easily measurable. PGV can be related to the Modified Mercalli Intensity scale (e.g. Gerstenberger et al., 2007), and is a potential indicator for engineers in seismic assessment methods (e.g. Akkar and Özen, 2005). PGV has been compared to water-level changes (e.g. Elkhoury et al., 2006; Shi et al., 2015a) and is related to peak dynamic stress, which has been utilised in permeability enhancement experiments (e.g. Roberts, 2005; Elkhoury et al., 2011). Dynamic stresses are thought to control the incidence of shear-induced consolidation and dilatation (Luong, 1980; Dobry et al., 1982; Vucetic, 1994), vertical (e.g. Wang et al., 2004b; Wang, 2007; Wang et al., 2016) and horizontal (e.g. Brodsky et al., 2003) enhancement of permeability. 
Peak dynamic stress $\left(\sigma_{\mathrm{D}}, \mathrm{GPa}\right)$ can be expressed (Jaeger and Cook, 1979) as:

$$
\sigma_{\mathrm{D}} \sim \mu_{\mathrm{s}} \mathrm{PGV} / \mathrm{v}_{\mathrm{s}}
$$

in terms of the shear modulus $\left(\mu_{\mathrm{s}}, \mathrm{GPa}\right)$, shear-wave velocity at the monitoring well $\left(\mathrm{v}_{\mathrm{s}}, \mathrm{m} / \mathrm{s}\right)$, and maximum peak ground velocity $(\mathrm{PGV}, \mathrm{m} / \mathrm{s})$. The maximum PGV of horizontal and vertical motions have been used here as a proxy for dynamic stress (Equation 3.1 Love, 1927; Brodsky et al., 2003; Kano and Yanagidani, 2006).

The assessment of liquefaction, an earthquake-induced hydrogeological response (e.g. Wang, 2007), utilises a stress-based approach which uses the horizontal (geometric mean) peak ground acceleration (PGA New Zealand Geotechnical Society, 2010; Bradley and Hughes, 2012). We compared the horizontal (geometric mean) PGA to groundwater-level changes. Comparing both PGV and PGA to groundwater-level changes, allowed an assessment of whether velocity or acceleration was the best indicator for determining the polarity, amplitude and/or duration of water-level change.

The assessment of liquefaction, an earthquake-induced hydrogeological response (e.g. Wang, 2007), is typically based on considerations of changes in stress and uses the horizontal (geometric mean) peak ground acceleration (PGA) (New Zealand Geotechnical Society, 2010; Bradley and Hughes, 2012). PGA also correlates with the amplitude and occurrence of groundwater-level changes (Lai et al., 2004, 2010). We compared the horizontal (geometric mean) PGA to groundwater-level changes. Comparing both PGV and PGA to groundwater-level changes allowed an assessment of whether velocity or acceleration was the better indicator for determining the polarity, amplitude and/or duration of water-level change. 


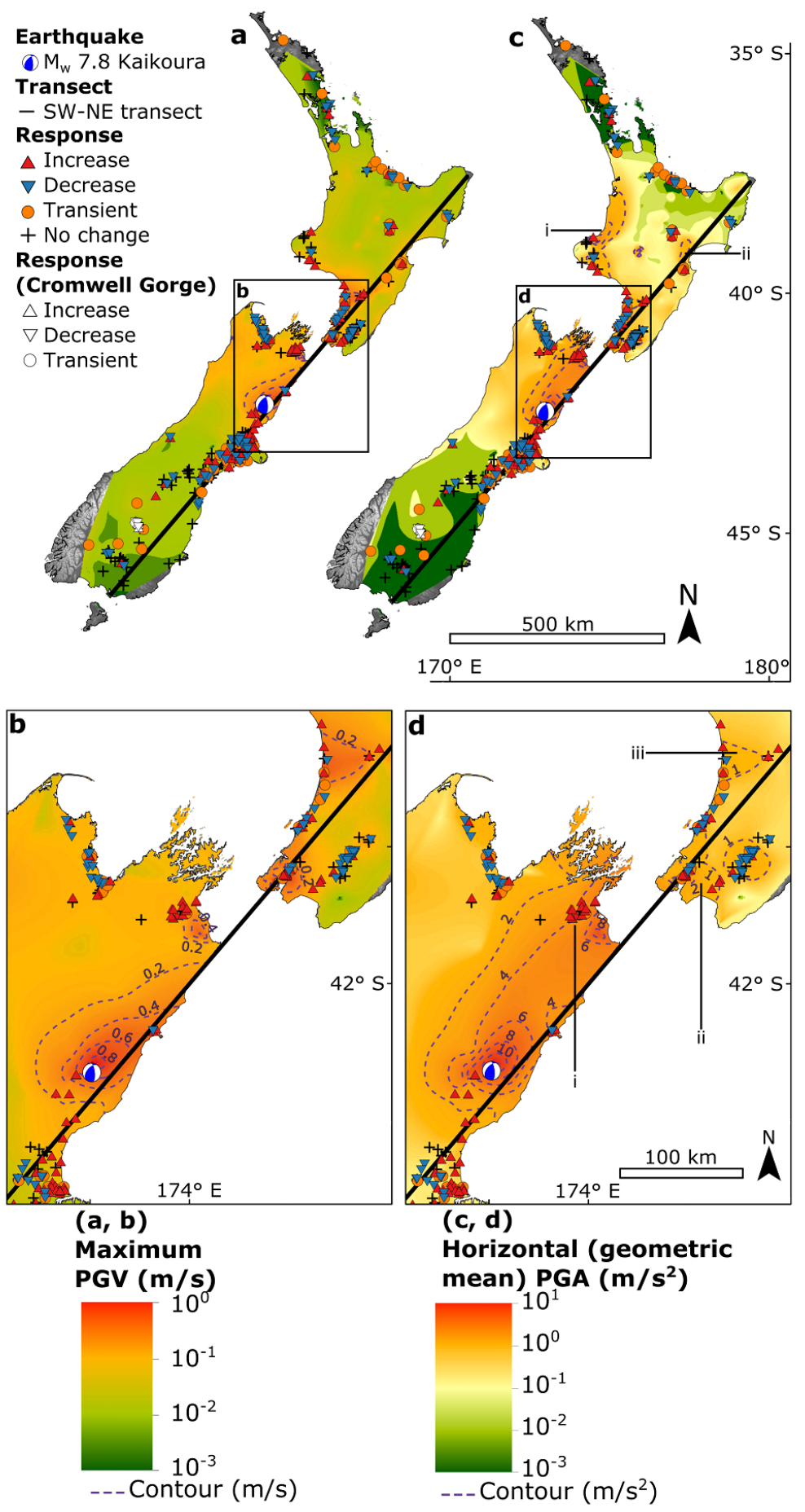

Figure 3.6: Spatial distribution of water-level changes, maximum PGV and horizontal (geometric mean) PGA, induced by the $2016 \mathrm{M}_{\mathrm{w}} 7.8$ Kaikōura earthquake. Spatial distribution of the water-level changes on a national-scale compared to PGV (a - Top left) and PGA (c -Top right). Notably high levels of shaking occurred in the (i) Taranaki, and (ii) Hawkes Bay regions. Spatial distribution of water-level changes in central New Zealand as a function of PGV (c - Bottom left) and PGA (d - Bottom right). Notably high levels of shaking occurred in the (i) Marlborough, (ii) Wellington, and (iii) Manawatu-Wanganui regions. Red colours indicate high levels of PGV and PGA, green colours represent low levels of PGV and PGA. A transect through the surface rupture zone and the majority of monitoring wells is shown in Figure 3.8. 
PGV and PGA were highest in the near-field, adjacent to the fault rupture, and notably high in areas of the Marlborough, Wellington, Manawatu-Wanganui, Taranaki and Hawkes Bay regions. The extent of the fault rupture to the north of the epicentre and the northward rupture directivity of the earthquake, resulted in a slower decay of PGV and PGA north of the epicentre, and a more rapid decay of PGV and PGA south of the epicentre. The higher PGV and PGA north of the epicentre correlate with a higher percentage of wells exhibiting changes. North of the epicentre, $60 \%$ of water-levels changed persistently, while south of the epicentre $48 \%$ of water-levels changed persistently (Figure 3.6 and 3.8).

At monitoring wells, the PGV ranged from 0.002 to $0.9 \mathrm{~m} / \mathrm{s}$ and the PGA ranged from 0.01 to $11.8 \mathrm{~m} / \mathrm{s}^{2}$. Above a PGV of $\sim 0.3 \mathrm{~m} / \mathrm{s}$ and a PGA of $\sim 2 \mathrm{~m} / \mathrm{s}^{2}$ the majority of persistent water-level changes were increases, and the median response reequilibration times were 1455 and 585 minutes respectively. Below a PGV of $\sim 0.3 \mathrm{~m} / \mathrm{s}$ and a PGA of $\sim 2 \mathrm{~m} / \mathrm{s}^{2}$ there was no preferred polarity, and the median response reequilibration time was 75 minutes below both thresholds. PGA differentiates polarity behaviour more clearly than PGV, with 32 persistent water-level increases above $\sim 2$ $\mathrm{m} / \mathrm{s}^{2}$, compared to 11 persistent water-level increases above $\sim 0.3 \mathrm{~m} / \mathrm{s}$. Some monitoring wells that experienced low levels of shaking, showed a larger water-level change than wells that experienced high levels of shaking, such as wells in Cromwell Gorge (Figure 3.7). This may be due to local hydrogeological conditions that partly contribute to the characteristics of water-level changes. 

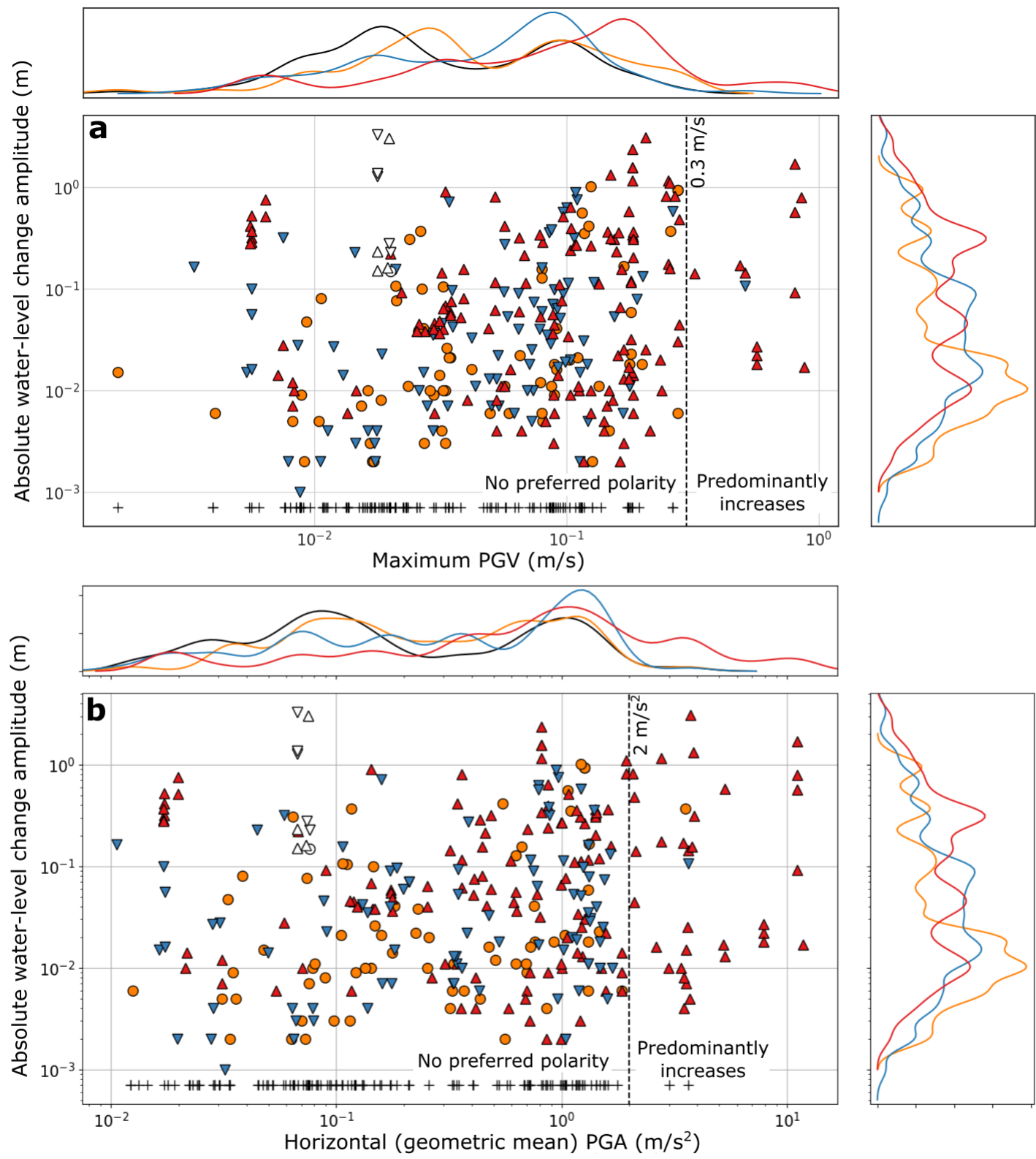

$\begin{array}{lll}\text { Response } & \text { Response (Cromwell Gorge) } & \text { Kernel density } \\ \Delta \text { Increase } & \triangle \text { Increase } & \text { - Increase } \\ \nabla \text { Decrease } & \nabla \text { Decrease } & \text { - Decrease } \\ \text { OTransient } & \bigcirc \text { Transient } & \text { - Transient } \\ + \text { No change } & & \text { - No change }\end{array}$

Figure 3.7: Absolute water-level change amplitude as a function of (a - Top) maximum PGV, and (b - Bottom) horizontal (geometric mean) PGA. Above a PGV of $\sim 0.3 \mathrm{~m} / \mathrm{s}$ and a PGA of $\sim 2 \mathrm{~m} / \mathrm{s}^{2}$, water-level changes were predominantly increases. 

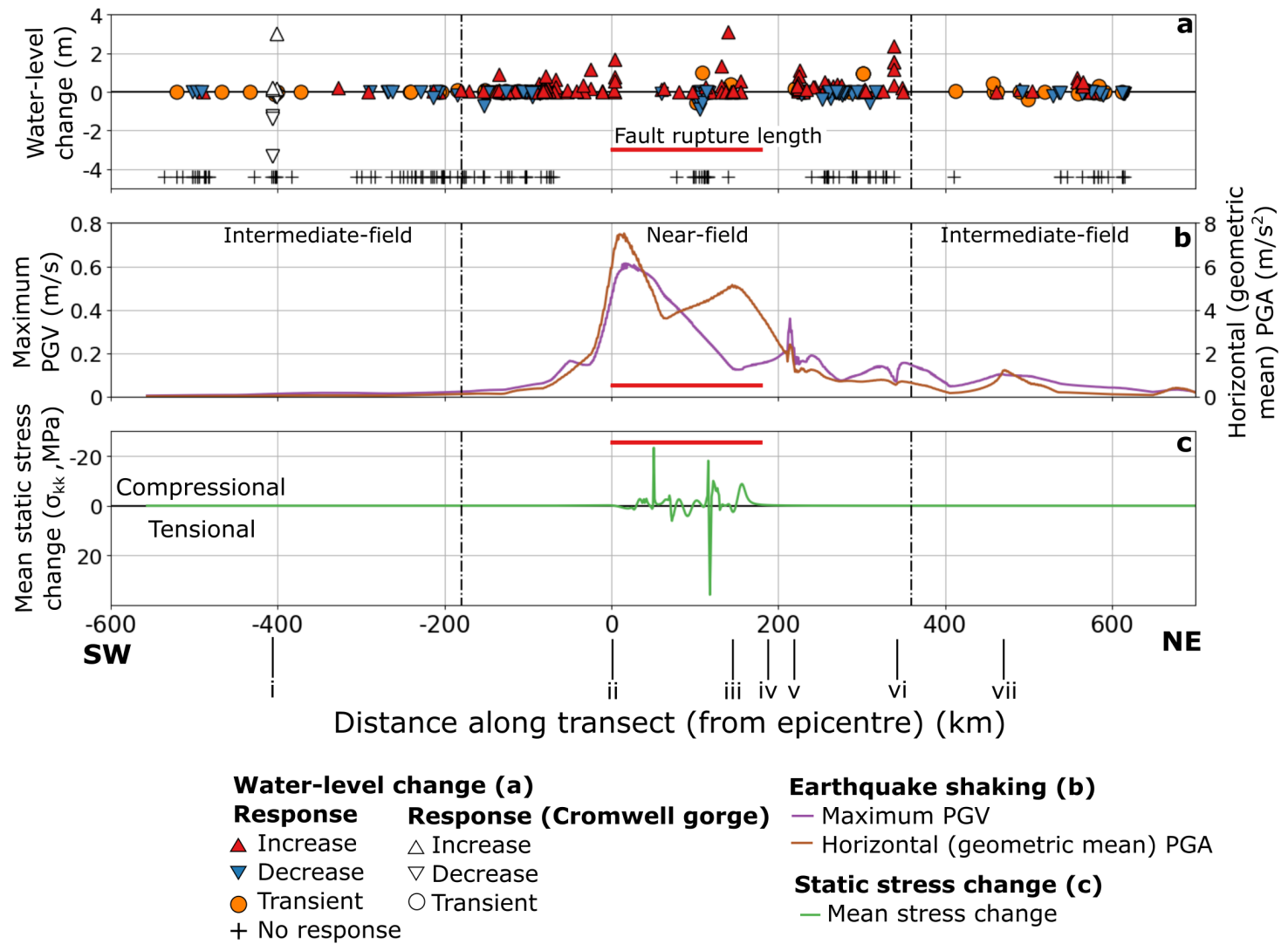

Earthquake shaking (b)

- Maximum PGV

- Horizontal (geometric mean) PGA

Static stress change (c)

- Mean stress change

Figure 3.8: A transect of the Kaikoura earthquake-induced (a - Top) groundwater-level changes, (b - Middle) maximum PGV and horizontal (geometric mean) PGA, and (cBottom) mean static stress changes $\left(\sigma_{\mathrm{kk}}\right)$. Locations of interest are: (i) Cromwell gorge monitoring wells, (ii) earthquake epicentre, (iii) Marlborough region, (iv) Cook Strait, (v) Wellington, (vi) Manawatu-Wanganui, and (vii) Hawkes Bay regions. The crosssection goes through the Kaikoura surface rupture zone and the majority of monitoring wells.

\subsection{The influence of local hydrogeological factors on water-level changes}

Although distance from the epicentre provides a rough approximation of how a monitoring well may respond to an earthquake, some monitoring wells respond with larger amplitudes of water-level change than others at the same epicentral distance. Aquifer properties are likely to partly control earthquake-induced water-level changes. The higher the transmissivity of the formation, the more reflective the well water-level change is of the formation pressure change, with the time taken for water-levels to reequilibrate or return to pre-earthquake levels being governed by flow properties (Faoro et al., 2012). 
Since PGA differentiates polarity behaviour more clearly than PGV (Figure 3.7), and because earthquake induced dynamic shaking occurred at all monitoring wells, we scaled the absolute water-level change amplitudes (WLC, m) to the horizontal (geometric mean) PGA $\left(\mathrm{m} / \mathrm{s}^{2}\right)$ experienced at each monitoring well (WLC/PGA, $\mathrm{s}^{2}$ ). To further understand the local hydrogeological factors in contributing to water-level changes we compared WLC/PGA to depth of monitoring well and to the average shear wave velocity between 0 and $30 \mathrm{~m}$ depth as a representation of degree of confinement and expected dynamic rock-strength behaviour at each site.

\section{Depth}

Earthquake-induced water-level changes vary with degree of confinement in aquifer formations. Water-level changes in unconfined aquifers are generally smaller than in confined/semi-confined aquifers (Roeloffs, 1996), as a result of the specific yield of unconfined aquifers being higher than the storativity of confined aquifers (Freeze and Cherry, 1979). Changes in monitoring well water-levels in unconfined aquifers reflect the (de)watering process of pore spaces above/below the water table, which forms the aquifer's upper boundary. Changes are also influenced by well storage effects, the impact of which increases with decreasing transmissivity (Roeloffs, 1996). Assuming undrained conditions (Kano and Yanagidani, 2006), changes in confined aquifer pore pressure $(\mathrm{p}, \mathrm{GPa})$, given by $\mathrm{p}=-\mathrm{B} \sigma_{\mathrm{kk}} / 3$, are proportional to mean stress $\left(\sigma_{\mathrm{kk}}, \mathrm{GPa}\right)$, and the magnitude of pore pressure change is governed by Skempton's coefficient (B Roeloffs, 1996).

We used the depth of each monitoring well ( $4 \mathrm{~m}$ to $1.4 \mathrm{~km}$ ) as a first-order proxy for the degree of confinement of the aquifers studied. The monitoring wells are generally shallow with the median depth being $24 \mathrm{~m}$. At any depth, WLC/PGA typically varies by two orders of magnitude. Generally, the deeper the monitoring well, the more sensitive the well was to water-level change. A similar observation was recorded by Rutter et al. (2016), who found that water-level changes occurred more consistently in wells of greater than $80 \mathrm{~m}$ depth, compared to shallower wells. At depths less than 10 metres, WLC/PGA broadly ranged from $\sim 10^{-3}$ to $10^{-1} \mathrm{~s}^{2}$. At depths between 10 and 100 metres, WLC/PGA mostly varied from $\sim 10^{-2}$ to $10^{0} \mathrm{~s}^{2}$. Deeper than 100 metres, WLC/PGA largely fluctuated from $\sim 10^{-1}$ to $10^{1} \mathrm{~s}^{2}$. All types of water-level changes were observed over the entire depth range as shown by the kernel density estimate. Monitoring wells in Cromwell Gorge geoengineered landslides were generally the most sensitive (Figure 3.9). 


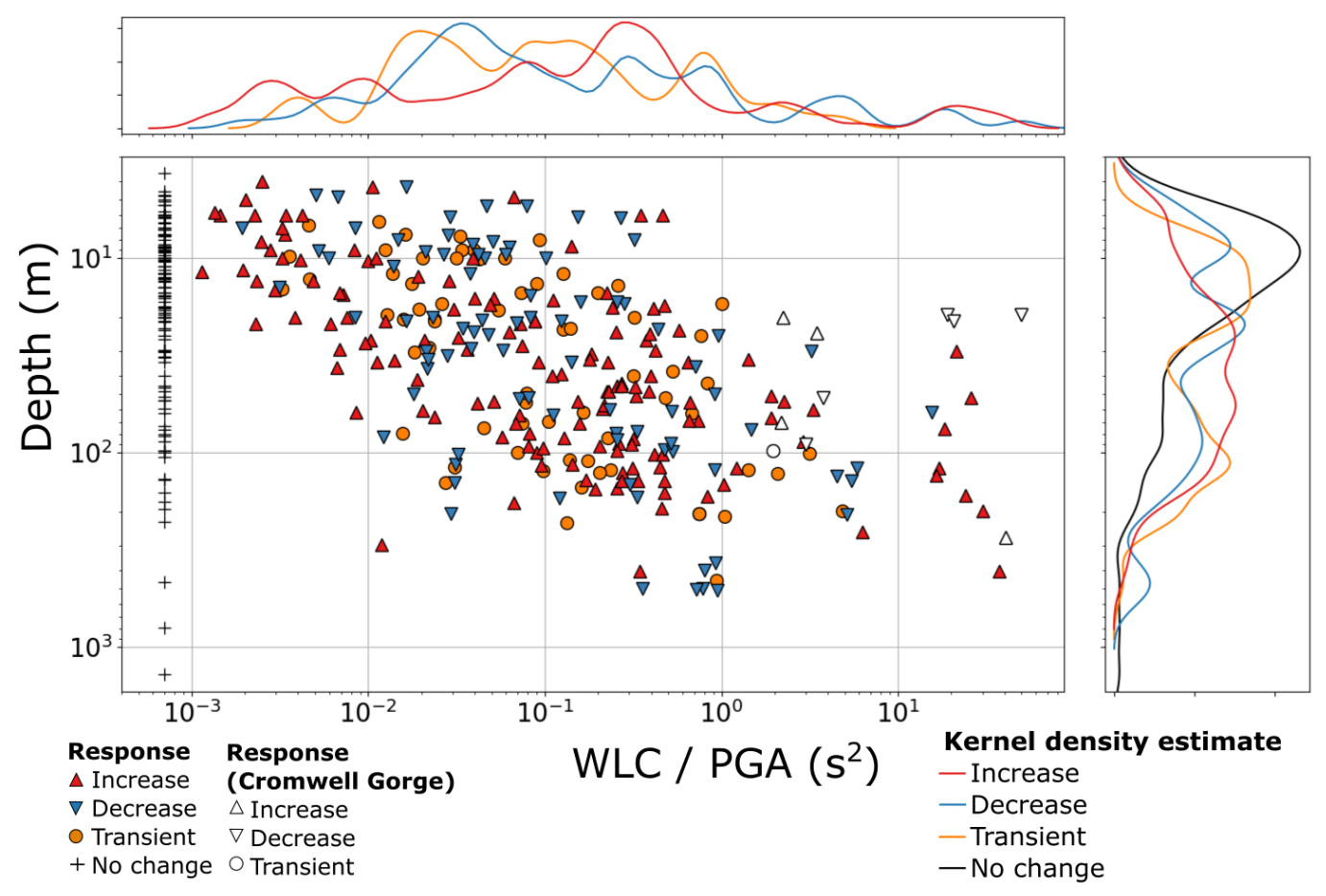

Figure 3.9: WLC/PGA as a function of monitoring well depth. The deeper the monitoring well, the more sensitive the well was to water-level change. All types of water-level changes were observed over the entire depth range.

\section{Shear wave velocity}

Seismic waves attenuate differently in different rock types (Wang and Manga, 2010a), and it is therefore unsurprising that hydrogeological factors partly control earthquakeinduced groundwater-level changes. Site effects and varying crustal structures have differing efficiencies of dynamic shaking (Wang, 2007). Saturated unconsolidated media damp high-frequency motions, while amplifying lower frequencies (Popescu, 2002; Wong and Wang, 2007; Youd and Carter, 2005). In contrast, consolidated/crystalline aquifer material amplify high-frequency shaking more than low frequency shaking (Bradley, 2013). Sensitive hydrological sites screened in well consolidated or crystalline rocks can respond to teleseismic earthquakes over $1000 \mathrm{~km}$ away, and typically do so with hydroseismograms (e.g. Brodsky et al., 2003; Kitagawa et al., 2006; Shi and Wang, 2014; Weingarten and Ge, 2014; Zhang et al., 2015). Where static and dynamic stresses are insignificant, hydrogeological factors must partly control the hydrological response. The geoengineered schist landslides of Cromwell gorge respond hydrologically with large amplitude, although static and dynamic stresses are insignificant (Figure 3.8).Where static and dynamic stresses are significant, hydrogeological factors may influence hydrological responses but are probably less substantial. In the near-field responses are not entirely consistent with the magnitude of static or dynamic stresses (Figure 3.8). 
To reflect the varied hydrogeological conditions of the aquifers studied, we used site-average shear-wave velocity $\left(\mathrm{Vs}_{30}, \mathrm{~m} / \mathrm{s}\right.$ ) over depths between 0 and $30 \mathrm{~m}$ (Horspool et al., 2015) at each monitoring well. Shear wave velocities range from 40 to $1040 \mathrm{~m} / \mathrm{s}$, representing very soft soil to weak rock respectively (Destegul et al., 2008). The $\mathrm{Vs}_{30}$ is typically towards the lower end of this range, the median $\mathrm{Vs}_{30}$ being 225 $\mathrm{m} / \mathrm{s}$, representative of deep soil. At any $\mathrm{Vs}_{30}$, WLC/PGA varied over three orders of magnitude. Broadly, as the $\mathrm{Vs}_{30}$ increases, WLC/PGA increases. When $\mathrm{Vs}_{30}$ ranged between 0 and $270 \mathrm{~m} / \mathrm{s}$, WLC/PGA typically ranged from $\sim 10^{-3}$ to $10^{0} \mathrm{~s}^{2}$. When $\mathrm{Vs}_{30}$ was close to $1000 \mathrm{~m} / \mathrm{s}$, WLC/PGA was mostly between $\sim 10^{-2}$ to $10^{1} \mathrm{~s}^{2}$. There is no correlation between polarity of water-level change and $\mathrm{Vs}_{30}$ at any depth. Monitoring wells in Cromwell Gorge were particularly sensitive in deep soil and weak rock site classifications. There are also numerous sites that did not respond to the earthquake at a variety of $\mathrm{Vs}_{30}$ values (Figure 3.10). 


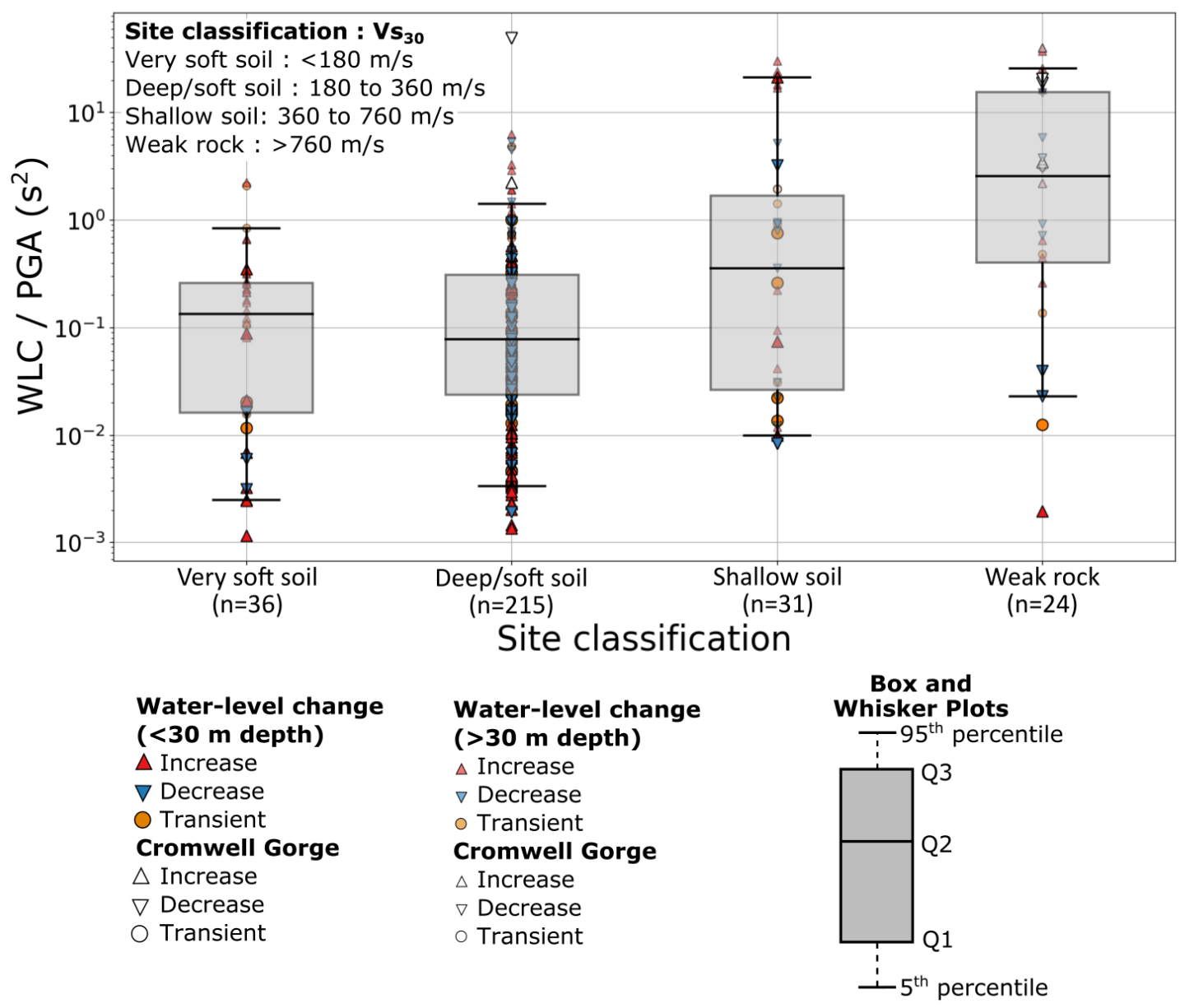

Figure 3.10: WLC/PGA as a function of site classification (Destegul et al., 2008). Site classifications are converted from $\mathrm{Vs}_{30}$ (Horspool et al., 2015). Monitoring well depths shallower than $30 \mathrm{~m}$ have larger opaque symbols as the $\mathrm{Vs}_{30}$ is representative. Monitoring well depths deeper than $30 \mathrm{~m}$ have smaller transparent symbols as the $\mathrm{Vs}_{30}$ is less representative. 


\subsection{Discussion}

\section{Earthquake-induced static stress changes}

Static stress changes induced by the Kaikoura earthquake were only significant in the near-field (Figure 3.8), and were variable in polarity and amplitude as a result of the complex rupture zone (Figure 3.4). Mean static stress change $\left(\sigma_{\mathrm{kk}}\right)$, used in this study, can be converted into volumetric strain change $\left(\epsilon_{\mathrm{kk}}\right), \epsilon_{\mathrm{kk}}=\sigma_{\mathrm{kk}} / \mathrm{K}$, with Bulk modulus ( $K, \mathrm{GPa})$ of the lithology. For Bulk modulus, an arithmetic mean of $6.6 \mathrm{GPa}$ for sands and gravels was used (Hart and Wang, 1995). $\epsilon_{\mathrm{kk}}$ has the relationship with pore-pressure change $(p)$ in a monitoring well, $\mathrm{p}=-(2 \mathrm{~GB} / 3)\left[\left(1+\mathrm{v}_{\mathrm{u}}\right) /\left(1-2 \mathrm{v}_{\mathrm{u}}\right)\right] \epsilon_{\mathrm{kk}}$ (e.g. Roeloffs, 1996). To obtain a first-order estimate of the static strain changes and corresponding water-level changes in this investigation, arithmetic means of shear modulus $(G, 5.6 \mathrm{GPa})$, Skempton coefficient $(B, 0.62)$, and undrained poisson ratio $\left(\mathrm{v}_{\mathrm{u}}\right.$, 0.33 ) of sands and gravels were used (Hart and Wang, 1995), resulting in a coefficient $\left((2 \mathrm{~GB} / 3)\left[\left(1+\mathrm{v}_{\mathrm{u}}\right) /\left(1-2 \mathrm{v}_{\mathrm{u}}\right)\right]\right)$ value of $\sim 9$ GPa. Therefore, a $\sigma_{\mathrm{kk}}$ of $\pm 10^{0}$ and $\pm 10^{1}$ $\mathrm{kPa}$ predicts a $\sim 10 \mathrm{~cm}$ and $\sim 1 \mathrm{~m}$ water-level change respectively. However, most wells with a $\sigma_{\mathrm{kk}}$ of $< \pm 10^{0} \mathrm{kPa}$ had a larger water-level change than predicted, even in cases of wells that had a consistent polarity with static stress changes. Only wells with $\sigma_{\mathrm{kk}}$ larger than $\pm 10^{0} \mathrm{kPa}$ had smaller water-level changes than predicted, although the polarities were generally consistent with static stress changes exceeding $\pm 10^{1} \mathrm{kPa}$ (Figure 3.5).

Considering water-level change polarity or amplitude was inconsistent with static stress change predictions, static stress changes did not contribute to water-level changes in the near-field. Furthermore, groundwater level changes are not necessarily good indicators of co-seismic static strain change, similar to Roeloffs et al. (2015). In the intermediate-field, water-level changes are larger than static stress change prediction, notably monitoring wells in Cromwell Gorge (Figure 3.5), which is consistent with other studies (Igarashi and Wakita, 1995; Itaba and Koizumi, 2007; Manga and Wang, 2007; Wang and Manga, 2010a; Shi and Wang, 2015). These results are dissimilar to findings in other studies where static stress changes correlate with water-level change amplitude and polarity (Wakita, 1975; Roeloffs, 1996; Quilty and Roeloffs, 1997; Jónsson et al., 2003; Akita and Matsumoto, 2004; Chia et al., 2008). High model uncertainty resulting from variable slip geometries and magnitudes between different models, may partly account for poor fit between static stress and groundwater level changes. 


\section{Earthquake-induced dynamic shaking}

If dynamic stress-induced cyclic shear strains in unconsolidated deposits greatly exceed a threshold of $\sim 10^{-4}$ (Luong, 1980), shear-induced dilatation occurs (Wang et al., 2001). Groundwater-levels can decrease persistently as a result of the decrease in pore pressure and increase in porosity (Wang and Chia, 2008). Shear-induced dilatation may have occurred in proximity to the Kaikoura earthquake fault rupture. However, as a result of the numerous landslides (Dellow et al., 2017), and limited number of monitoring wells adjacent to the fault rupture, it is unclear to what extent shearinduced dilatation may or may not have occurred.

Shear-induced consolidation and liquefaction (Wang et al., 2001; Wang, 2007) occur at lower cyclic shear strains, still exceeding $\sim 10^{-4}$ (Dobry et al., 1982; Vucetic, 1994). Shear-induced consolidation predicts that water-levels increase persistently as a result of dynamic shaking, due to consolidating the sediment within an aquifer and decreasing porosity (Wang et al., 2001). The threshold at which persistent water-level increases predominantly occurred was at a horizontal (geometric mean) peak ground acceleration (PGA) of $\sim 2 \mathrm{~m} / \mathrm{s}^{2}$ and a maximum peak ground velocity $(\mathrm{PGV})$ of $0.3 \mathrm{~m} / \mathrm{s}$. PGA differentiated persistent water-level increases from other response types more clearly than PGV (Figure 3.7). Dynamic shaking also caused liquefaction to occur in the Marlborough (Davies et al., 2017; Stringer et al., 2017) and Wellington (Bradley et al., 2017c; Cubrinovski et al., 2017; Orense et al., 2017) regions. These areas experienced a PGA exceeding $\sim 2 \mathrm{~m} / \mathrm{s}^{2}$ and had predominantly persistent water-level increases.

At low thresholds of dynamic shaking, earthquake-induced flow velocities may be strong enough to dislodge colloidal particles (Wang et al., 2009). It has been postulated that dislodging of colloidal particles from preferential flow pathways may enhance horizontal permeability (Matsumoto et al., 2003; Brodsky et al., 2003; Wang and Chia, 2008; Rutter et al., 2016). The change in water-level may originate in proximity to a local pressure source, which could be produced by liquefaction (Roeloffs, 1998), or elevated hydraulic heads (Rojstaczer et al., 1995). Earthquake-induced flow velocities may be strong enough to dislodge colloidal particles (Wang et al., 2009). Laboratory experiments on pore unclogging (Liu and Manga, 2009; Elkhoury et al., 2011) and groundwater colour changes (Prior and Lohmann, 2003) support permeability enhancement by dislodging colloids. The location of permeability enhancement could occur either up- or down-hydraulic head gradient of a monitoring well. If enhancement occurs up-hydraulic head gradient of a monitoring well, water-level in the well would increase, as more flow is directed towards the well. If enhancement occurs downhydraulic head gradient, water-level in the well would decrease, as flow is directed away from the well. Therefore, if a sufficiently large number of observations are made, the permeability enhancement model would predict a statistically random occurrence in the polarity of the water-level change (Wang and Chia, 2008). In this study, there 
was roughly an equal number of persistent water-level increases and decreases at accelerations lower than PGA of $\sim 2 \mathrm{~m} / \mathrm{s}^{2}$, with water-level change amplitudes generally less than $1 \mathrm{~m}$. This is consistent with the model of enhanced permeability. Persistent water-level changes may have occurred above a PGA of $\sim 2 \mathrm{~m} / \mathrm{s}^{2}$ as a result of enhanced permeability, but may be concealed by larger amplitude changes caused by shear-induced consolidation (Wang and Manga, 2010a).

Water-level changes caused by dislodging colloidal particles may be described as gradual sustained changes, because the response re-equilibration time to new postearthquake levels depends on the distance between the source of the blockage and the monitoring well (Roeloffs, 1998; Brodsky et al., 2003). Water-level changes caused by consolidation are more likely to be described as abrupt changes, because immediate changes in pore pressure occur as a result of an undrained volumetric change around the well (Wang and Manga, 2010a). In this study, the median persistent response reequilibration time for monitoring wells that experienced a PGA above $\sim 2 \mathrm{~m} / \mathrm{s}^{2}(\mathrm{n}=33$ ) was 585 minutes, while below a PGA of $\sim 2 \mathrm{~m} / \mathrm{s}^{2}(\mathrm{n}=204)$ was 75 minutes. The two populations of response times were statistically different. Shear-induced consolidation, may occur on a large-scale (km; Wang et al., 2001), as the threshold of shaking is likely to be exceeded over a wide area near the earthquake epicentre. However, permeability enhancement caused by dislodging of colloids, may occur more frequently on a small-scale (m; Brodsky et al., 2003) in preferential flow pathways. The response time may reflect the scale at which these processes occur at, but should not be considered definitive.

International case-studies have shown that undrained consolidation/dilatation is the dominant mechanism in the near-field, with enhanced permeability being dominant in the intermediate-field (Wang and Manga, 2010a). In the field, seismic energy densities larger than $\sim 10^{1} \mathrm{~J} / \mathrm{m}^{3}$ are above the threshold for undrained consolidation, with sensitive sites experiencing consolidation above $\sim 10^{-1} \mathrm{~J} / \mathrm{m}^{3}$ (Hazirbaba and Rathje, 2004; Wang and Manga, 2010a). For the Chi-Chi and Hengchun earthquakes, the transition from consolidation to enhanced permeability was inferred at $\sim 10^{1} \mathrm{~J} / \mathrm{m}^{3}$ (Wang and Chia, 2008). In this investigation, that equates to an epicentral distance of $100 \mathrm{~km}$ (near-field), where water-level changes were still predominantly increasing (Figure 3.8). The terms seismic energy density (Wang, 2007), near- and intermediate-field (Wang and Manga, 2010a), and one fault rupture length (Wells and Coppersmith, 1994), do not take into account directivity of an earthquake. The occurrence of water-level changes broadly correlated with the spatially asymmetric distribution of PGA (Figure 3.8). Water-levels changed persistently in $60 \%$ of the monitoring wells north of the epicentre, whereas south of the epicentre water-levels changed persistently only in 48 $\%$ of monitoring wells. Therefore, considering the northward rupturing nature of the Kaikoura earthquake, and for systematic comparison with other studies, we find that the transition between shear-induced consolidation and enhanced permeability occurs 
at a PGA of $\sim 2 \mathrm{~m} / \mathrm{s}^{2}$. This is not a definitive threshold and therefore, should be compared to other earthquakes and monitoring sites.

At low levels of dynamic shaking, dynamic volumetric stresses cause pore spaces to dilate and compress, which can lead to transient pulses of pore pressure (Roeloffs, 1998) and poro-elastic deformation (e.g. Kano and Yanagidani, 2006). In this case study, transient water-level changes occurred mainly below a PGA of $\sim 2 \mathrm{~m} / \mathrm{s}^{2}$ with small amplitudes of water-level changes, (Figure 3.7), and are likely to be a result of poro-elastic deformation (e.g. Roeloffs, 1998; Kano and Yanagidani, 2006).

\section{Local hydrogeological factors}

Shear-induced consolidation and enhancement of permeability are likely to have partly contributed to the polarity and occurrence of water-level changes (Figure 3.7). Some monitoring wells were more sensitive to water-level changes than others at similar ground accelerations, which may be partially a result of hydrogeological factors. 400 $\mathrm{km}$ south of the epicentre (Figure 3.8), monitoring wells in Cromwell Gorge screened in schist rock exhibited water-level changes of $\pm 3 \mathrm{~m}$. Yet, monitoring wells within $200 \mathrm{~km}$ of Cromwell Gorge, mainly screened in unconsolidated deposits, responded persistently with small amplitudes of less than $1 \mathrm{~m}$. Cromwell Gorge monitoring wells are known to be sensitive to hydrological change from multiple earthquakes. Cromwell Gorge groundwater levels are depressed below equilibrium levels by pumping and gravity drainage due to infrastructure, and the sensitivity may in-part reflect anthropogenic modification of the groundwater regime (O’Brien et al., 2016). The Devils Hole, Nevada, is another example of a site that is sensitive to change, with responses occurring at low seismic energy densities of $10^{-6} \mathrm{~J} / \mathrm{m}^{3}$ (Weingarten and Ge, 2014). Since there is a disparity between the global dataset (Wang and Chia, 2008) and case studies (Figure 3.3 ), it is possible that response thresholds vary widely as a result of hydrogeological factors. Different catchment responses may also affect the hydrological response to the earthquakes (e.g. Pedretti et al., 2016).

Depth is positively correlated with WLC/PGA (Figure 3.9), which concurs with studies that observed pronounced earthquake-induced water-level changes in deeper confined aquifers compared to shallow unconfined aquifers (Stearns, 1928; Eaton and Takasaki, 1959; Roeloffs, 1996; Rutter et al., 2016). This is because the specific yield of unconfined aquifers is higher than the storativity of confined aquifers (Freeze and Cherry, 1979). Seismic acceleration generally decreases significantly with depth (e.g. Theodoulidis et al., 2018) which might increase the correlation between depth and WLC/PGA.

WLC/PGA is positively correlated with $\mathrm{Vs}_{30}$ (Figure 3.10), which is consistent with sites screened in well consolidated or crystalline rocks responding hydrologically to teleseismic earthquakes (Brodsky et al., 2003; Shi et al., 2014; Weingarten and Ge, 
2014; Zhang et al., 2015). Therefore, regardless of the magnitude of the earthquake, it appears that monitoring wells may have a predisposition to show water-level changes of certain amplitude relative to dynamic shaking, based on the strength of the rock they are screened in. This concept was adopted by O’Brien et al. (2016) who concluded that aquifer systems have the ability to resist and recover from dynamic shaking which is consistent between earthquakes. WLC/PGA varies over several orders of magnitude at any given depth or $\mathrm{Vs}_{30}$. This large variation of WLC/PGA may result from variable permeabilities or well-aquifer coupling which may partly contribute to amplitudes of water-level changes (Manga and Wang, 2007; Wang et al., 2009; O'Brien et al., 2016).

The fact that 127 monitoring wells that experienced different levels of shaking, did not exhibit water-level changes, further demonstrates that hydrogeological factors do contribute to a monitoring wells capacity to exhibit a water-level change. The well and monitoring system and/or the aquifer properties may result in some wells being unresponsive. A large noise-to-signal ratio and/or a low sampling resolution could result in low resolution measurements of the water-level and any changes that occur. Monitoring well site conditions may also influence response recordings with pumping, precipitation or large seasonal variations having an effect on water levels. Aquifers with high storage capacities and/or low transmissivity may prevent responses being recorded at the monitoring wells. This in-turn may have resulted in a higher shaking threshold required for a water-level change. Understanding why sites did not respond should be investigated in future work.

The characteristics of dynamic shaking are influenced by geological conditions (Wang, 2007). The amplification of seismic shaking is larger over sediments than bedrock (Bard and Riepl-Thomas, 2000), shown by high levels of shaking in parts of the Marlborough, Wellington, Manawatu-Wanganui, Taranaki and Hawkes Bay regions (Figure 3.6 and 3.8). Seismic wave attenuation and velocity are also affected by degree of saturation, and the spatial distribution of fluids within the crust (Li et al., 2001). Although we evaluated seismic and hydrogeological factors separately, we acknowledge that a non-linear relationship exists (Beresnev and Wen, 1996) between them.

\subsection{Conclusion}

We quantify groundwater-level changes in 433 monitoring wells across New Zealand to the $2016 \mathrm{M}_{\mathrm{w}} 7.8$ Kaikōura earthquake. We compare water-level changes to earthquake driven characteristics such as mean static stress changes $\left(\sigma_{\mathrm{kk}}\right)$, maximum peak ground velocity (PGV), and horizontal (geometric mean) peak ground acceleration (PGA). We also compare scaled water-level changes (WLC/PGA) to local hydrogeological factors, depth and site average shear wave velocity $\left(\mathrm{Vs}_{30}\right)$.

The Kaikoura earthquake-induced static stress changes were only significant in the 
near-field. The amplitude and polarity of water-level changes observed in monitoring wells in the near-field do not generally correlate with the modelled $\sigma_{\mathrm{kk}}$. However, above a PGA of $\sim 2 \mathrm{~m} / \mathrm{s}^{2}$, persistent water-level changes predominantly increased. This is consistent with the hypothesis of shear-induced consolidation (Wang et al., 2001).

For wells that experienced a PGA lower than $\sim 2 \mathrm{~m} / \mathrm{s}^{2}$, there was approximately an equal number of water-level increases and decreases. The statistically random polarity of water-level change is consistent with the hypothesis of enhanced permeability by dislodging colloids (Brodsky et al., 2003), as the polarity of the water-level change depends on the location of the monitoring well relative to the location of the permeability change (up- or down-hydraulic head gradient; Wang and Chia, 2008).

The fault rupture extending to the north of the epicentre and northward directivity of the Kaikōura earthquake (Kaiser et al., 2017) resulted in a spatially asymmetric distribution of PGA. Water-levels changed persistently in $60 \%$ of the monitoring wells north of the epicentre, whereas south of the epicentre water-levels changed persistently only in $48 \%$ of monitoring wells. Considering the northward directivity, and that both enhanced permeability and shear-induced consolidation are primarily controlled by dynamic shaking, we find that the transition between shear-induced consolidation and enhanced permeability occurs at a PGA of $\sim 2 \mathrm{~m} / \mathrm{s}^{2}$. This threshold should be confirmed in future studies.

Hydrogeological factors depth and $\mathrm{Vs}_{30}$ positively correlate with WLC/PGA. Regardless of the magnitude of the earthquake, monitoring wells may have a predisposition to have water-level changes of certain amplitudes relative to PGA, based on the degree of confinement and the strength of the rock surrounding the screen. Additional work should also include changes in spring discharge and other earthquake hydrological responses to the Kaikōura earthquake, at local and catchment scales.

This immediate report examines the effect of a single earthquake on multiple hydrological sites. To provide an informative map of aquifer susceptibility to earthquakes, a multi-earthquake, multi-site dataset, composed of individual case studies such as this one, must be developed. These data-sets should collectively span significant decadal time periods, and record the lack of responses as well as responses. Their analysis will distinguish the role of extrinsic (earthquake-related) and intrinsic (local geology and hydrogeology) factors and potentially could be utilised to inform practitioners on seismic risk to aquifers and water supplies. 


\subsection{Acknowledgements}

We would like to thank many organisations and people for providing data for this study: Northland Regional Council (Sandrine Le Gars, Alan Bee, Susie Osbaliston); Auckland Council (Nicholas Holwerda); Bay of Plenty Regional Council (Diane Harvey, Brent Hutchby); Gisborne District Council (Matthew McGill-Brown, Peter Hancock, Murry Cave); Hawkes Bay Regional Council (Simon Harper); Waikato Regional Council (John Hughey); Taranaki Regional Council (Jane Harvey, Fiona Jansma, Regan Phipps); Horizons Regional Council (Stephen Collins, Brent Watson); Greater Wellington Regional Council (Sheree Tidswell, Doug Mzila, Mike Thompson); Marlborough District Council (Peter Davidson); Tasman District Council (Joseph Thomas, Monique Harvey); Environment Canterbury (Shaun Thomsen); Otago Regional Council (Andrew Egan, Nineva Vaitupu); Environment Southland (Michael Killick); Watercare (Andrew Lester); GNS Science (Abigail Lovett, Grant O’Brien); Contact Energy (Neil Whitford); Golder Associates (Eric van Nieuwkerk); Aqualinc Research Ltd (Ross Hector); Wairakei estate (Nic Conland); Manfeild (Steve Easthope); Victoria University of Wellington (Rupert Sutherland); and the National Institute of Water and Atmospheric Research. We also wish to thank colleagues Mai-Linh Doan, Nick Perrin, and Guðjón Eggertsson for their discussion and helpful comments. We acknowledge the New Zealand GeoNet project and its sponsors EQC, GNS Science and LINZ, for providing data used in this study. This study was funded under the Royal Society of New Zealand Marsden Fund [2012-GNS-003]. The authors declare that there is no conflict of interest regarding the publication of this paper. The data supporting the results reported can be found in the Electronic appendix 1. 


\section{Tidal behaviour and water-level changes in gravel aquifers in response to multiple earthquakes: A case study from New Zealand}

\subsection{Abstract}

Earthquakes have been inferred to induce hydrological changes in aquifers on the basis of either changes to well water-level or tidal behaviour, but the relationship between these changes remains unclear. Here, changes to tidal behaviour and water-levels were quantified in a hydrological network monitoring gravel aquifers in Canterbury, New Zealand, in response to nine earthquakes (from $\mathrm{M}_{\mathrm{w}} 5.4$ to 7.8 ) that occurred between 2008 and 2015. Out of the 161 wells analysed, only 35 wells contain water-level fluctuations associated with earth (7) or ocean (28) tides. Permeability reduction manifest as changes in tidal behaviour, and increased water-level in the near-field of the Canterbury earthquake sequence of 2010 and 2011, support the hypothesis of shear-induced consolidation. However, tidal behaviour and water-level changes rarely occurred simultaneously $(\sim 2 \%)$. Water-level changes that occurred with no change in tidal behaviour re-equilibrated at a new post-seismic level faster (on timescales of $\sim 50$ mins), than when a change in tidal behaviour occurred ( $\sim 240$ mins to 10 days). Water-level changes were more than likely to occur above $\sim 50 \mathrm{kPa}$, and were more than likely to not occur below $\sim 10 \mathrm{kPa}$. The minimum peak dynamic stress required for a tidal behaviour change to occur was $\sim 0.2$ to $100 \mathrm{kPa}$.

This chapter has been submitted as a research manuscript for consideration in the international journal Water Resources Research (February 2018). Co-authors contributed to the making of this manuscript. M. L-. Doan assisted with tidal analysis methodology, analysis of results, and research design. S. C. Cox and J. Townend provided conceptual discussion, research design, reviewed the manuscript and obtaining funding. C. Holden reviewed seismic calculations and the manuscript. 


\subsection{Introduction}

The ability of a material to transmit fluid, referred to as permeability, plays a critical role in a broad range of geological processes. In addition to its essential hydrogeological significance, permeability has in recent years been recognized as a control on hydrocarbon migration (Gluyas and Swarbrick, 2013), the longevity of geological carbon sequestration (Gleeson and Ingebritsen, 2016), and the advection of heat and solutes in response to earthquakes (Cox et al., 2015). There is growing evidence that fluids are mechanically involved in all stages of the earthquake cycle (Sibson, 1994), and that permeability fluctuations play a key role in the rupture-reactivation-cementation cycle (Boulton et al., 2017; Dempsey et al., 2014; Sutherland et al., 2012). Permeability is considered to be dynamically self-regulating (Townend and Zoback, 2000; Weis et al., 2012). The self-regulating nature of permeability is achieved through competing processes that increase and decrease connectivity and volume of voids and fractures (Rojstaczer et al., 1995). Permeability changes can be induced by earthquakes, both locally and distally, directly or indirectly through changes in static and dynamic stress (Wang and Manga, 2010a).

Measurements of permeability are important in understanding tectonic and hydrogeological processes. Pumping tests are one way of estimating aquifer permeability. However, such tests represent a single point in time and space, are affected by well construction and completion, and are typically expensive. Tidal analysis, on the other hand, provides a means of estimating permeability on a continuous basis and in a non-invasive, relatively inexpensive manner (Merritt, 2004). By inferring permeability continuously, it is possible to detect earthquake-induced permeability changes. A pioneering study by Elkhoury et al. (2006), observed earthquake-induced dynamic permeability changes with the use of groundwater-level fluctuations caused by earth tides. Many research papers have since adopted this approach (e.g. Lai et al., 2014; Liao et al., 2015; Yan et al., 2014).

Earthquake-induced water-level changes are often attributed to changes in permeability (Wang and Manga, 2010a). The polarity of the water-level change (increase/ decrease) in a well may be influenced by permeability changing either up or down head-gradient of that well (Wang and Chia, 2008), with almost instantaneous responses occurring in the vicinity of the well (Shi and Wang, 2015). A higher pre-existing permeability may cause a larger water-level change and shorter decay time (Shi et al., 2013b). An unresolved issue is the relationship between earthquake-induced waterlevel and tidal behaviour changes (Elkhoury et al., 2006), which recent studies suggest seldom occur simultaneously (e.g. Shi and Wang, 2015; Shi et al., 2015b; Yan et al., 2014). 
Enhancement of permeability takes many forms that can involve either physical or chemical processes. The removal of colloidal blockages in heterogeneous aquifers (Brodsky et al., 2003), may alter flow pathways significantly. Fracture-scale permeability enhancement, both sub-vertical (Wang, 2007; Wang et al., 2016) and sub-horizontal (O’Brien et al., 2016), may connect hydraulically isolated pore pressure zones. Shearinduced dilation (Wang et al., 2001) may occur if cyclic shear strain exceeds $\sim 10^{-4}$ (Vucetic, 1994).

Permeability reduction is mainly documented in the inter-seismic environment involving chemical processes such as clay alteration (Menzies et al., 2016), fault healing (Aben et al., 2017; Gratier and Gueydan, 2007), and cementation (Dempsey et al., 2014). Co-seismic reduction of permeability has been observed in the field as a result of clogging of fractures (Shi et al., 2018; Yan et al., 2016), and can be associated with processes requiring a high level of shaking (Vucetic, 1994): typically shear-induced consolidation (Rutter et al., 2016; Wang et al., 2001) or liquefaction (Wang, 2007).

In this contribution, tidal analysis was performed on data from 161 wells in the Canterbury hydrological network, New Zealand, that have been affected by nine $\mathrm{M}_{\mathrm{w}}$ 5.4 or larger earthquakes between 2008 and 2015. A comparison of earthquake-induced tidal behaviour and water-level changes was undertaken in order to discern the underlying processes and the scale at which they occurred. An estimate of the dynamic stress perturbations required to induce changes was also calculated.

\section{Tectonics and hydrogeological setting}

Oblique-convergent collision between the Australia and Pacific plates in southwest New Zealand occurs at $~ 38 \mathrm{~mm} /$ year (DeMets et al., 2010) and earthquakes occur throughout the country along the plate boundary zone. In the central South Island, the majority of Late Quaternary plate motion has been accommodated by slip on the Alpine Fault (Norris and Cooper, 2001). The Alpine and Marlborough faults connect two subduction zones of opposite dip: the Puysegur trench to the South; and the Hikurangi trough to the North (Berryman et al., 1992). A damaging sequence of earthquakes in Canterbury from 2010 to 2011, was associated with distributed deformation east of the Alpine Fault (Quigley et al., 2016).

The Canterbury region is composed of Permian-Jurassic Torlesse greywacke bedrock, overlain by Paleogene-Pleistocene sedimentary sequences, and late Quaternary gravel alluvium (Brown, 2001). The gravel alluvium was sourced from tectonic uplift of the Southern Alps, and have been entrained and transported eastwards by glacial meltwaters (Forsyth et al., 2008). At the coast, sea-level fluctuations during glacial and inter-glacial sequences have resulted in inter-layering of fine marine and estuarine sediments with coarse-grained gravels. The finer-grained sediment thickens eastward and coastward (Brown and Weeber, 1992), forming a zone of coastal confined aquifers (Tal- 
bot et al., 1985). The coastal artesian aquifers are hydrologically heterogeneous, with variable permeability and thickness of aquitards (Bal, 1996). Commonly, large proportions of groundwater flow $(\sim 98 \%)$ occur through a very small proportion of the aquifers $(\sim 1 \%)$, via highly-permeable open-framework gravels (OFGs; Dann et al., 2008).

\subsection{Data}

\section{Seismic data}

We selected nine $\mathrm{M}_{\mathrm{w}} 5.4$ or larger earthquakes that occurred in New Zealand between 2008 and 2015 (Figure 4.1); each was felt throughout both the North and South islands Table 4.2). Seismic stations in the New Zealand National Seismograph Network and Strong Motion Network are operated by GeoNet (geonet.org.nz). In this study, we acquired seismic data for each of the nine earthquakes from broadband and strong motion seismographs. The seismic data have a sampling frequency ranging between 100 and $200 \mathrm{~Hz}$. We applied instrument response corrections and a band-pass filter with transition bands of 0.10 to $0.25 \mathrm{~Hz}$ and 24.50 to $25.50 \mathrm{~Hz}$. We then calculated site specific shaking parameters described below.

\section{Hydrological data}

Groundwater in the gravel aquifers of Canterbury is continuously monitored in 161 wells by Environment Canterbury (Figure 4.1). Water-levels are recorded every 15 minutes by either vented or non-vented pressure transducers. There are seven clusters of two or three wells, where the monitoring sites contain multi-level piezometers or are in proximity to each other $(<20 \mathrm{~m}$; see Supplementary data). Barometric pressure sensors are located throughout the region and installed in monitoring well casings just below ground level. We apply barometric corrections to the non-vented pressure data so that the dataset analysed reflects changes in water pressure only. The correction process uses barometric pressure data from the nearest site, usually within a $20 \mathrm{~km}$ distance and $300 \mathrm{~m}$ elevation of the respective well.

Sea-level monitoring in the Canterbury region is undertaken by The National Institute for Water and Atmospheric Research (NIWA). These sites are located in Christchurch, and Timaru (Figure 4.1; see Supplementary data). Data are recorded at 15 minute intervals by pressure transducers and provide information on the time and amplitude of ocean tide fluctuation. 


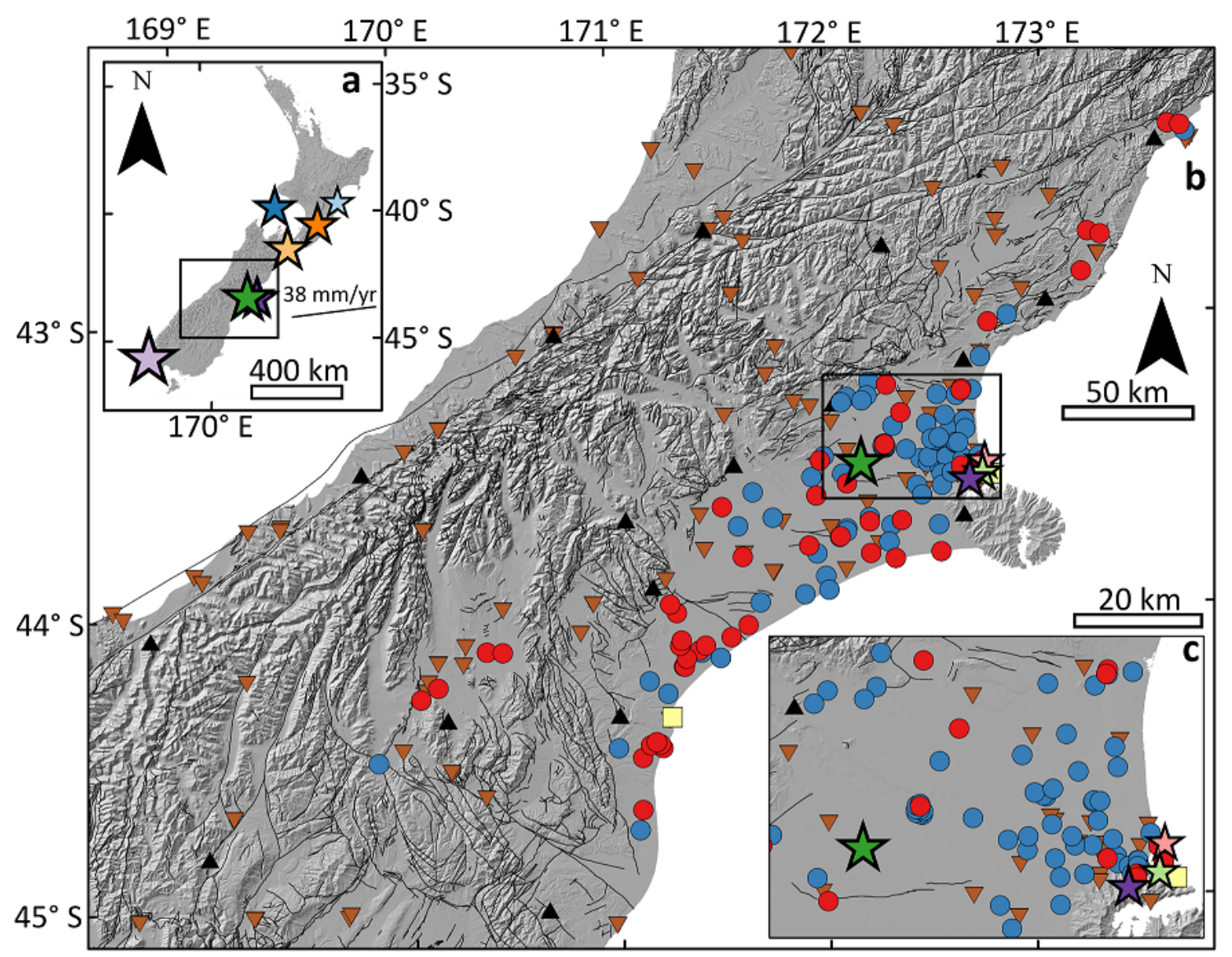

\begin{tabular}{|c|c|}
\hline 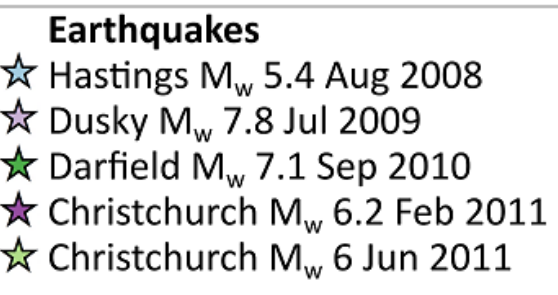 & 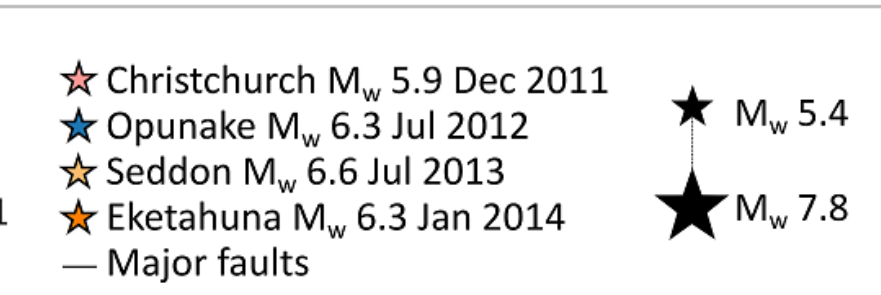 \\
\hline $\begin{array}{l}\text { Monitoring sites } \\
\text { B Broadband seismograph } \\
\nabla \text { Strong motion seismograph }\end{array}$ & $\begin{array}{l}\text { Monitoring well (no water-level or tidal change) } \\
\text { O Monitoring well (water-level and/or tidal change) } \\
\square \text { Tidal gauge }\end{array}$ \\
\hline
\end{tabular}

Figure 4.1: Seismic and hydrological monitoring in Canterbury, New Zealand. (a - Top left) Summary map showing the epicentres of the nine $\mathrm{M}_{\mathrm{w}} 5.4$ or larger earthquakes that occurred between 2008 and 2015. (b - Centre) Seismic and hydrological monitoring sites in the central South Island of New Zealand. (c - Bottom right) Expanded view of the Christchurch region and the four major events in 2010 and 2011 of the Canterbury earthquake sequence. 
Table 4.1: Table of the nine $\mathrm{M}_{\mathrm{w}} 5.4$ or larger earthquakes that occurred between 2008 and 2015. $\mathrm{M}_{\mathrm{w}}=$ Moment magnitude. The average distance is the average of all the individual monitoring well epicentral distances for each earthquake.

\begin{tabular}{ccccccc}
\hline No. & $\begin{array}{c}\text { Earthquake } \\
\text { Location }\end{array}$ & $\begin{array}{c}\text { Epicentre } \\
\text { (Latitude, } \\
\text { Longitude) }\end{array}$ & $\begin{array}{c}\text { Time, Date (NZST) } \\
\text { HH:MM } \\
\text { dd / mm/yyyy }\end{array}$ & $\mathbf{M}_{\mathbf{w}}$ & $\begin{array}{c}\text { Depth } \\
(\mathbf{k m})\end{array}$ & $\begin{array}{c}\text { Average } \\
\text { distance }\end{array}$ \\
\hline 1 & Hastings & $-39.72,176.85$ & $23: 2525 / 08 / 2008$ & 5.4 & 32 & 587 \\
2 & Dusky Sound & $-45.77,166.59$ & $21: 2215 / 07 / 2009$ & 7.8 & 12 & 500 \\
3 & Darfield & $-43.53,172.17$ & $4: 354 / 09 / 2010$ & 7.1 & 11 & 55 \\
4 & Christchurch & $-43.58,172.68$ & $11: 5122 / 02 / 2011$ & 6.2 & 5 & 60 \\
5 & Christchurch & $-43.57,172.74$ & $14: 1213 / 06 / 2011$ & 6 & 7 & 63 \\
6 & Christchurch & $-43.52,172.75$ & $15: 1823 / 12 / 2011$ & 5.9 & 7 & 64 \\
7 & Opunake & $-40.05,173.76$ & $22: 363 / 07 / 2012$ & 6.2 & 241 & 430 \\
8 & Seddon & $-41.60,174.32$ & $17: 0821 / 07 / 2013$ & 6.6 & 16 & 291 \\
9 & Eketahuna & $-40.62,175.86$ & $14: 5220 / 01 / 2014$ & 6.3 & 34 & 456 \\
\hline
\end{tabular}

\subsection{Material and methods}

\section{Tidal computation}

We quantify the responses of aquifers to tidal strains predicted from astronomical laws in order to model the temporal evolution of hydraulic and poroelastic parameters (Bower and Heaton, 1978; Bredehoeft, 1967; Hsieh et al., 1987). The gravitational effects on the Earth of celestial bodies induce Earth deformation and produce tidal potential energies. The resulting tidal potential spectrum $(W)$ is the sum of a large number of components $(k)$ :

$$
W=\sum_{k} W_{k}
$$

The combination of solar and lunar forcing produces two main groups of components, semi-diurnal (2 cycles per day; $2 \mathrm{cpd}$ ) and diurnal (1 cpd): $\mathrm{O}_{1}(0.9295 \mathrm{cpd}) ; \mathrm{S}_{1}$ (1 cpd); $\mathrm{K}_{1}(1.0027 \mathrm{cpd}) ; \mathrm{M}_{2}$ (1.9323 cpd); $\mathrm{S}_{2}$ (2 cpd); and $\mathrm{K}_{2}$ (2.0055 cpd; Wilhelm et al., 1997). Each tidal potential component $\left(W_{k}\right)$ has a corresponding frequency $\left(\omega_{k}\right)$ and can be expressed with respect to complex coefficients $\left(a_{k}\right)$ :

$$
W_{k}=a_{k} e^{i \omega_{k} t}
$$

Frequency-domain analysis enables different components of the tidal spectrum to be identified in water-level time-series from monitoring wells (see Supplementary data). Wells exhibiting water-level fluctuations caused predominantly by $\mathrm{S}_{1}, \mathrm{~S}_{2}, \mathrm{~K}_{1}$ or $\mathrm{K}_{2}$ tend to be dominated by barometric- and thermal-effects (Doan and Brodsky, 2006). Only water-level fluctuations caused by the $\mathrm{M}_{2}$ and $\mathrm{O}_{1}$ components have a low sensitivity to thermal and anthropogenic disturbances. Typical amplitudes of the $\mathrm{M}_{2}$ component are larger than the $\mathrm{O}_{1}$ component (Wilhelm et al., 1997). Also the sea-level sites in 
Canterbury exhibit a larger ocean tide amplitude of the $\mathrm{M}_{2}$ component $(\sim 763 \mathrm{~mm})$ than the $\mathrm{O}_{1}(\sim 28 \mathrm{~mm})$ component (see Supplementary data). As a result, only waterlevel fluctuations caused by the $\mathrm{M}_{2}$ component were considered in the analysis.

We have used the software package Baytap08, modified for application to highfrequency data, to decompose the observed water-level data $(h)$ into constituent tidal signals $\left(h_{k}\right)$. Baytap08 uses a time-domain Bayesian modelling procedure (Tamura and Agnew, 2008) to estimate a series of complex coefficients $\left(c_{k}=A_{k} e^{i \phi_{l a g}}\right)$ such that:

$$
h=\sum_{k} h_{k}=\sum_{k} c_{k} \cdot \frac{W_{k}}{g R}
$$

with gravitational acceleration $\left(g, 9.81 \mathrm{~m} / \mathrm{s}^{2}\right)$ and radius of the Earth $(R, \sim 6371$ $\mathrm{km})$. The $c_{k}$ coefficients are related to the expected poroelastic response of the aquifer, relative to the tidal strain. For each tidal component, in the first-order geometrical expansion of the Earth there is a volumetric strain contribution $\left(\epsilon_{k}\right)$ (Doan and Brodsky, 2006):

$$
\epsilon_{k}=\frac{1-2 \nu}{1-\nu}[2 l-6 s] \frac{W_{k}}{g R}
$$

that depends on Love $(l, 0.606)$ and Shida parameters $(s, 0.0840)$. Of the rock types for which poroelastic moduli have been systematically collated (Wang, 2000), down-scaled in the laboratory environment, sandstone appears to be the most comparable to the Canterbury gravel aquifers at depth, in both poroelastic and architectural (sedimentary facies) terms. Therefore, we assume the Poisson's ratio to be an average of the sandstone Poisson's ratio compiled by Wang (2000), to represent the Canterbury gravel aquifers at depth $(\nu, 0.3)$. In an undrained porous medium, a change in strain $(\epsilon)$ would induce a change in pore pressure, $p=B K_{u} \epsilon$ governed by Skempton's coefficient (B, dimensionless) and the undrained bulk modulus $\left(K_{u}, \mathrm{GPa}\right)$. As $p_{k}=\rho g h_{k}$ :

$$
c_{k}=\frac{\frac{1-2 \nu}{1-\nu}[2 l-6 s]}{\rho g} B K_{u}
$$

We term the $B K_{u}$ an apparent $B K_{u}$, as we assumed here that the tidal variations in pore pressure were dominated by the poroelastic response to tides. If this assumption is wrong, the computed value of $B K_{u}$ would exceed poroelastic predictions and not be representative. 


\section{Water-level fluctuations caused by earth and ocean tides}

The tides that cause water-level fluctuations in wells analysed here have two origins, which we consider below: (1) the poroelastic response to strain variation by earth tides, and (2) the effect of ocean tides by the pore pressure diffusion throughout the aquifer or direct mechanical loading.

Tidal loading imposes volumetric strain on the Earth (Agnew, 2005). The resultant dilation and contraction of the Earth causes pore pressure variations throughout groundwater aquifers. However, for shallow unconfined aquifers, this pore pressure fluctuation may be rapidly dissipated by vertical pore pressure diffusion to the surface (Roeloffs, 1996).

Solar and lunar gravitational loading also produce water level fluctuations in the ocean, the oceanic tides (Merritt, 2004). Whereas the hydraulic response to earth tides is typically of the scale of several tens of centimetres, the amplitudes of oceanic tides can exceed several meters. Ocean tides can induce direct mechanical loading at the coast. Software like SPOTL (Agnew, 2012) predicts this mechanical loading from global or regional models of oceanic tides. If ocean tidal gauge time-series data are available, the loading can by analytically computed from the Boussinesq equation (Doan, 2005). Pressure changes associated to ocean tides can also be diffused inland by direct hydraulic connection between the ocean and coastal aquifers. This induces water-level fluctuations in wells (Ferris, 1951). Analytical solutions (Van der Kamp, 1972) show that oceanic tides can in some situations propagate tens of kilometres inland (Merritt, 2004), but not always.

There are three states of coupling between monitoring wells and aquifers that control the recording of pore pressure variations in wells caused by earth and ocean tides in aquifers (Doan, 2005; Hsieh et al., 1987):

1. Coupled - Permeability is large and/or pore pressure fluctuations are slow, so that the water-level in monitoring wells perfectly correlates the pore pressure variation in aquifers.

2. Uncoupled - Permeability is small and/or pore pressure fluctuations are fast, so that the pore pressure variation in aquifers are not observed in monitoring wells.

3. Transitional - In an intermediate case, the water-level in monitoring wells partly reflects the pore pressure in aquifers. The phase lag $\left(\phi_{\text {lag }}\right)$ describes the partial coupling and is dependent on the hydraulic properties around monitoring wells. In this case, well hydraulic properties can be monitored.

There are cases where both earth and ocean tides contribute to water-level fluctuations in monitoring wells (Doan, 2005, e.g.). There are multiple aquifer configurations and tidal models with respect to coastal aquifers (Merritt, 2004). These include: aquifer 
and overlying confining layers cropping out at or near the coastline (Jacob, 1950; Ferris, 1951); a completely confined aquifer extending under the sea (Van der Kamp, 1972); a leaky contained aquifer system extending under the sea for a distance (Li et al., 2001). Therefore, classification between earth and ocean tides is not entirely strict, as expected amplitudes are dependent on individual site conditions. A quantitative assessment was adopted to distinguish between monitoring well water-level fluctuations that result from earth tide, earth and ocean tides, and contaminated/no tide:

1. The first criterion was based on the raw amplitude of the $\mathrm{M}_{2}$ component, which differentiated between the tidally-sensitive and tidally-insensitive wells. Any wells with a tidal $\mathrm{M}_{2}$ amplitude $<1 \mathrm{~mm}$ were classified as having no tides as fluctuations were lower than measurement uncertainties. Furthermore, wells exhibiting fluctuations caused predominantly by $\mathrm{S}_{1}, \mathrm{~S}_{2}, \mathrm{~K}_{1}$, or $\mathrm{K}_{2}$ were classified as having contaminated/no tide.

2. The second criterion was based on the magnitude of the apparent $B K_{u}$, considering only the wells that were classified as tidally-sensitive wells, according to the previous criterion. In the wells studied, there are variable lithologies from gravels, to sandstones with varying degrees of compaction, therefore, an average of the sandstone $B K_{u}$ values was taken as the maximum acceptable $B K_{u}$ for the Canterbury Plains aquifer system (12 GPa Wang, 2000) as sandstone is the most comparable in both poroelastic and architectural (sedimentary facies) terms. The $B K_{u}$ value was only used to discriminate between wells containing fluctuations associated with (1) earth + ocean and (2) ocean tides and not taken definitively. Pressuremeter tests were deemed not suitable for assessment of poroelastic moduli as interpretation methods can lead to large differences in parameters obtained (Mair and Wood, 2013). Water-levels that predominantly responded poro-elastically to tides, have an apparent $B K_{u}<12 \mathrm{GPa}$. When apparent $B K_{u}>12 \mathrm{GPa}$, water-levels most likely responded to ocean tides as the apparent $B K_{u}$ exceeds poroelastic predictions.

3. A qualitative assessment on the water-level fluctuations also assisted classification, where earth tide fluctuations contain proportionately larger $\mathrm{O}_{1}$ amplitudes than $\mathrm{M}_{2}$ amplitudes, compared to earth and ocean tide fluctuation (see Supplementary data). 


\section{Earthquake-induced tidal behaviour changes}

The $\phi_{\text {lag }}$ was computed in 30 day windows shifted in 7.5 day increments. The 30 day window analysis was computed in 10 separate analyses between January 2008 and January 2015. Each of the 10 analyses corresponds to an inter-seismic period (Table 4.2). The tidal analyses started one day after and stopped one day before each earthquake. The time of the earthquakes were never included in the analyses, to avoid abnormal water-level changes adversely affecting the calculation of tidal effects. The phase lag is generally negative and should range between -80 and 0 degrees, corresponding with horizontal permeability (Hsieh et al., 1987). However, positive phase lag can occur for multiple reasons: ocean tides; anisotropy (fracture orientation; Bower, 1983); lateral boundaries; and changes in cavity and topography (e.g. Harrison, 1976). Attenuation of tidal amplitude and decrease in phase lag also occurs with decreased confinement and increased leakage (Roeloffs, 1996). In this study, $\phi_{\text {lag }}$ decreases and $\phi_{\text {lag }}$ increases have been interpreted as horizontal permeability increases and decreases respectively, as in previous studies (Elkhoury et al., 2006; Roeloffs et al., 2003; Xue et al., 2013). We do not constrain the true phase lag values with sophisticated models of the wells and aquifers, as this study is not well specific, and pumping tests and bore logs are not readily available. This is a multi-site, multi-earthquake study that investigates the absolute change in phase lag induced by earthquakes.

\section{Earthquake-induced water-level changes}

Earthquake-induced water-level changes can be split into co-seismic and post-seismic components. Studies have defined water-level changes during and after earthquake shaking as purely co-seismic (e.g. Shi et al., 2015a) while others use the term co-seismic when groundwater is sampled hourly (e.g. Wang et al., 2004a). To save confusion and for a more accurate use of the terms, in this study we have defined co-seismic as water-level changes that occur during earthquake shaking and post-seismic as waterlevel changes that occur after earthquake shaking has ceased. Since monitoring well water-levels were sampled every quarter-hour, observed changes were considered postseismic and not co-seismic. The amplitude, polarity and duration of these post-seismic water-level changes were recorded. Water-level changes were also classified as either transient (returning to pre-earthquake levels within two hours) or persistent (lasting several days).

To perform a systematic comparison between water-level and tidal behaviour changes, the comparison must take place on a similar time scale of response time, as response longevity is partly-determined by the induced processes. Considering tidal behaviour changes in this study were observed over 7.5 day increments in 30 day windows (a minimal analysis duration to ensure good separation between the $\mathrm{M}_{2}$ and $\mathrm{S}_{2}$ tidal com- 
ponents), only persistent water-level changes have been examined. A series of short earthquake-induced fluctuations that returned to background levels within two hours, are termed transient and recorded as "no change" as they represent transitory changes which tidal analysis was unable to detect.

\section{Stress changes}

Earthquake-induced stress changes can be of static or dynamic sources, and varyingly decrease with distance from the earthquake (Manga and Brodsky, 2006). The distance $r$ from the epicentre can be summarized as follows: near-field representing distances within $\sim$ one ruptured fault length, far-field representing distances multiple times greater than the fault length, and intermediate-field for distances in between (Wang and Manga, 2010a). Static stress changes decay at $\sim 1 / r^{3}$ and are most significant in the near-field (Lay and Wallace, 1995; Manga and Wang, 2007). Dynamic stress changes are of a higher magnitude than static stress changes and decrease at $\sim 1 / r^{1.66}$ (Lay and Wallace, 1995). Dynamic stress changes dominate at intermediate to far-field distances (Wang and Manga, 2010a).

Wakita (1975) proposed that persistent water-level responses reflect earthquakeinduced static strain perturbations, reinforced by subsequent studies (Akita and Matsumoto, 2004; Chia et al., 2008; Jónsson et al., 2003; Quilty and Roeloffs, 1997; Roeloffs, 1996). However, the magnitude of water-level responses in the intermediate- and farfield are often larger than predicted by poroelastic theory (Manga and Wang, 2007). The spatial distribution of hydrological responses induced by the Darfield earthquake ( $\sim 55 \mathrm{~km}$ average distance), is inconsistent with static stress change calculations (Zhan et al., 2011) and has been interpreted as a consequence of dynamic stresses (Cox et al., 2012; Rutter et al., 2016). Most of the wells considered here are in the intermediate- or far-field with respect to the earthquake sources, therefore, only dynamic stress changes have been considered. The peak dynamic stress (PDS) change $\left(\sigma_{D}, \mathrm{GPa}\right)$ were calculated (Jaeger and Cook, 1979):

$$
\sigma_{D} \sim \frac{\mu_{S} u_{D}}{v_{s}}
$$

with maximum peak ground velocity $\left(\mathrm{PGV} ; u_{D}, \mathrm{~m} / \mathrm{s}\right)$, shear modulus $\left(\mu_{S}, \mathrm{GPa}\right)$ and shear-wave velocity at the monitoring well $\left(v_{s}, \mathrm{~m} / \mathrm{s}\right)$. In this study, maximum PGV was calculated at seismic stations and interpolated to wells using the nearest neighbour method (Ebdon, 1985). The small-strain shear modulus is a function of the void ratio and the effective mean confining stress (Clayton, 2011; Hardin and Drnevich, 1972). Considering the monitoring wells are generally shallow $(<100 \mathrm{~m})$, a shear modulus value of $0.14 \mathrm{GPa}$ was used, an arithmetic mean of the small-strain shear modulus for unconsolidated gravels (Chen et al., 2018). Although the shear modulus is influenced by 
the gravel content, the shear modulus only varies over $\pm 0.2 \mathrm{MPa}$. Shear-wave velocities were based on geological site classification (Horspool et al., 2015). Uncertainties in shear-wave velocity $( \pm 30 \mathrm{~m} / \mathrm{s})$, peak ground velocity $( \pm 1 \mathrm{~mm} / \mathrm{sec})$, shear modulus $( \pm 0.2 \mathrm{MPa})$, and the simple relationship employed for estimating PDS, require us to use PDS only as an approximation, as error margins can be over $\sim 10 \%$ of calculated values.

\section{Uncertainties and assumptions}

Tidal behaviour and water-level changes were observed after seismic events, and it is assumed the largest magnitude event was the cause of the perturbation. In this study, secondary events are assumed to not induce a hydrological change. There is a possibility, however, that perturbations could alternatively have been the result of, or enhanced by, smaller magnitude aftershocks or near-field earthquakes.

There have been attempts to assess the potential for tidal behaviour and waterlevel changes to reflect precursory seismic processes (Liu et al., 2013). Considering the heterogeneity of the Canterbury aquifer system (Dann et al., 2008), seasonal changes in hydraulic head are expected to cause a deviation in mechanical and hydraulic properties (Miller and Shirzaei, 2015). With such variability, small precursory earthquake signals are unlikely to be detected, but we assume they are small and/or rare, and so have been ignored.

Many wells incurred damage as a result of the Canterbury earthquake sequence. The elevation of several monitoring well heads changed, as a result of buoyant rise of casing and/or ground subsidence, which affected the measurement of water levels, so necessitated re-surveying. Elsewhere, damaged logger equipment and screens were replaced and re-pumped. New elevations were used where re-surveying was completed, otherwise it was assumed any anthropogenic influence on the data or data-quality were either minor or easily identified and corrected.

Absolute ground-water levels are generally known to $\pm 50 \mathrm{~cm}$ relative to sea-level, once corrected for barometric pressure variations and surveying uncertainty. Relative ground-water level changes are known much more precisely, with changes induced by earthquakes and or tides occurring on scales of $\pm 1 \mathrm{~cm}$. 


\subsection{Results}

\section{Identification of the origin of the tides}

Water-level fluctuations caused by earth and ocean tides contain similar components of the tidal spectrum, even though different processes produce them. It is important to identify water-level fluctuations caused by earth and ocean tides and determine which cyclic phenomenon is predominantly responsible.

Earth tide monitoring wells are generally far from the shore and at depths exceeding $60 \mathrm{~m}$, whereas monitoring wells containing a combination of earth and ocean tides are generally close to the shore (within $6 \mathrm{~km}$ of the coast) and of shallow depths (Figure $4.2,4.3,4.4)$. The water-level fluctuations caused by ocean tides had amplitudes up to $460 \mathrm{~mm}$, significantly larger than that of water-level fluctuations caused by earth tides $(<19 \mathrm{~mm})$. The water-level fluctuations caused by ocean tides were of the same order of magnitude as the sea-level gauge amplitude ( $763 \mathrm{~mm}$, see Supplementary data). Monitoring wells insensitive to tides may be too shallow to be influenced by earth or ocean tides (Figure 4.2, 4.3).

Of the 161 wells, only 35 (22\%) were considered sensitive to tides (Figure 4.2). Of the 35 wells sensitive to tides, seven ( $\sim 4 \%$ of the original wells) are sensitive to earth tides, and $28(\sim 17 \%)$ sensitive to earth and ocean tides. 

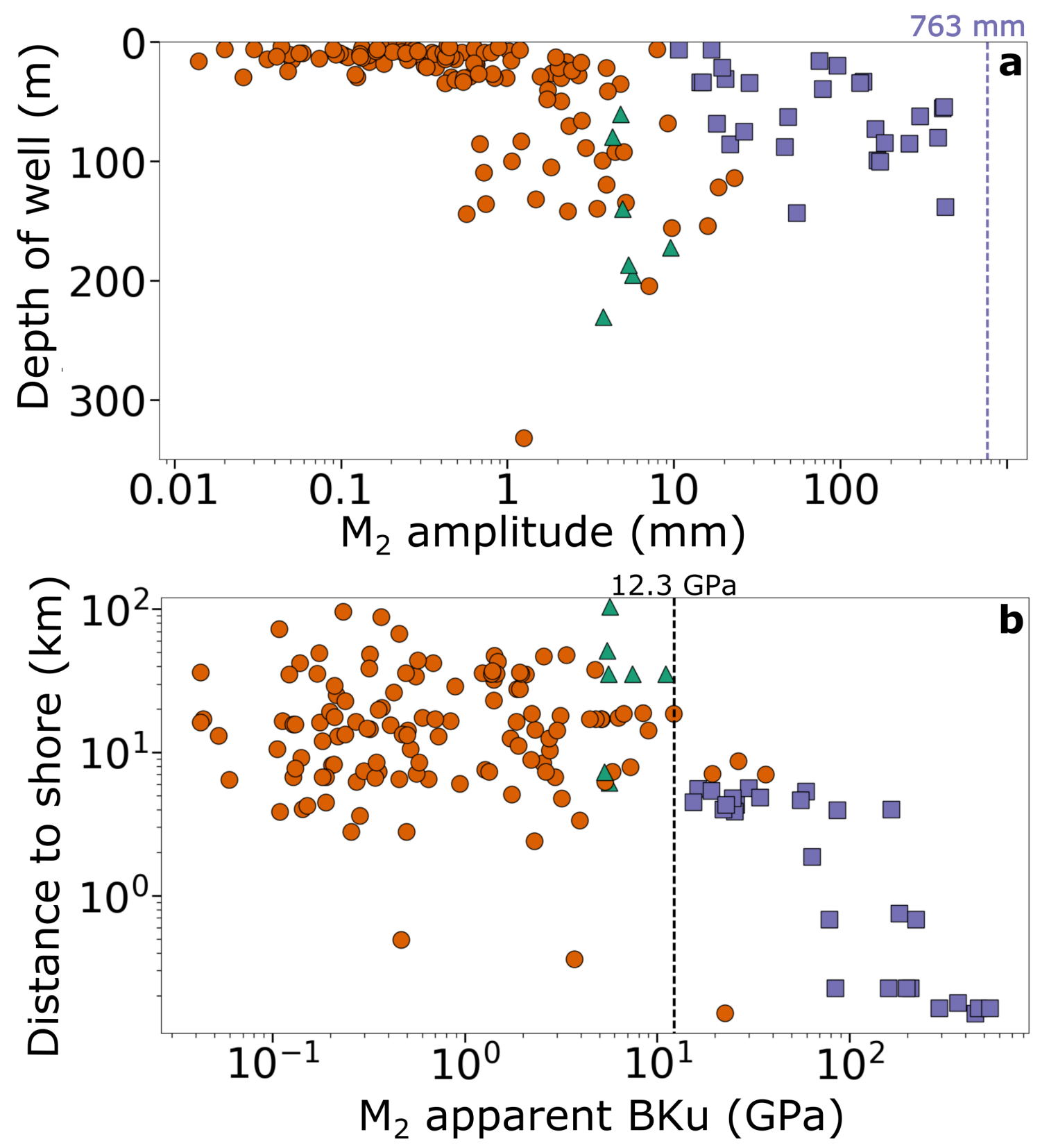

Well tide
None
$\triangle$ Earth + Ocean
Ocean

Figure 4.2: Monitoring well tides were characterised by the overall $\mathrm{M}_{2}$ amplitude and $B K_{u}$ from 2008 to 2012. (a - Top) $\mathrm{M}_{2}$ amplitude as a function of well depth. (b Bottom) $\mathrm{M}_{2} B K_{u}$ plotted against distance to shore. The Canterbury region $\mathrm{M}_{2}$ ocean tidal amplitude, and the average $B K_{u}$ for sandstones from Wang (2000), are included for reference. 


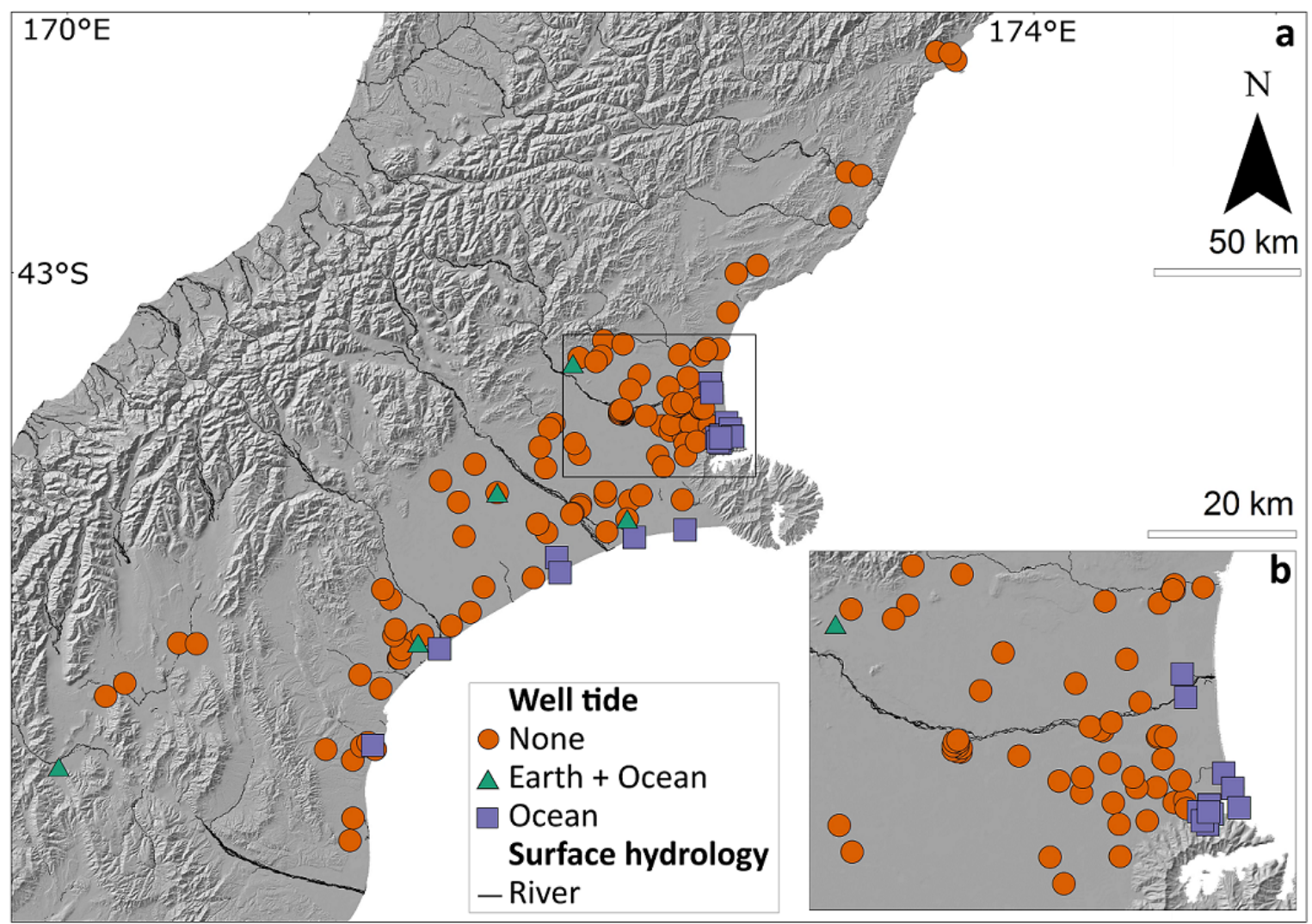

Figure 4.3: (A - Centre left) Distribution of monitoring wells in Canterbury, identified by the pre-dominant tide that caused water-level fluctuations. (B - Bottom Right) Expanded view of the Christchurch region. The major river networks are included for reference.

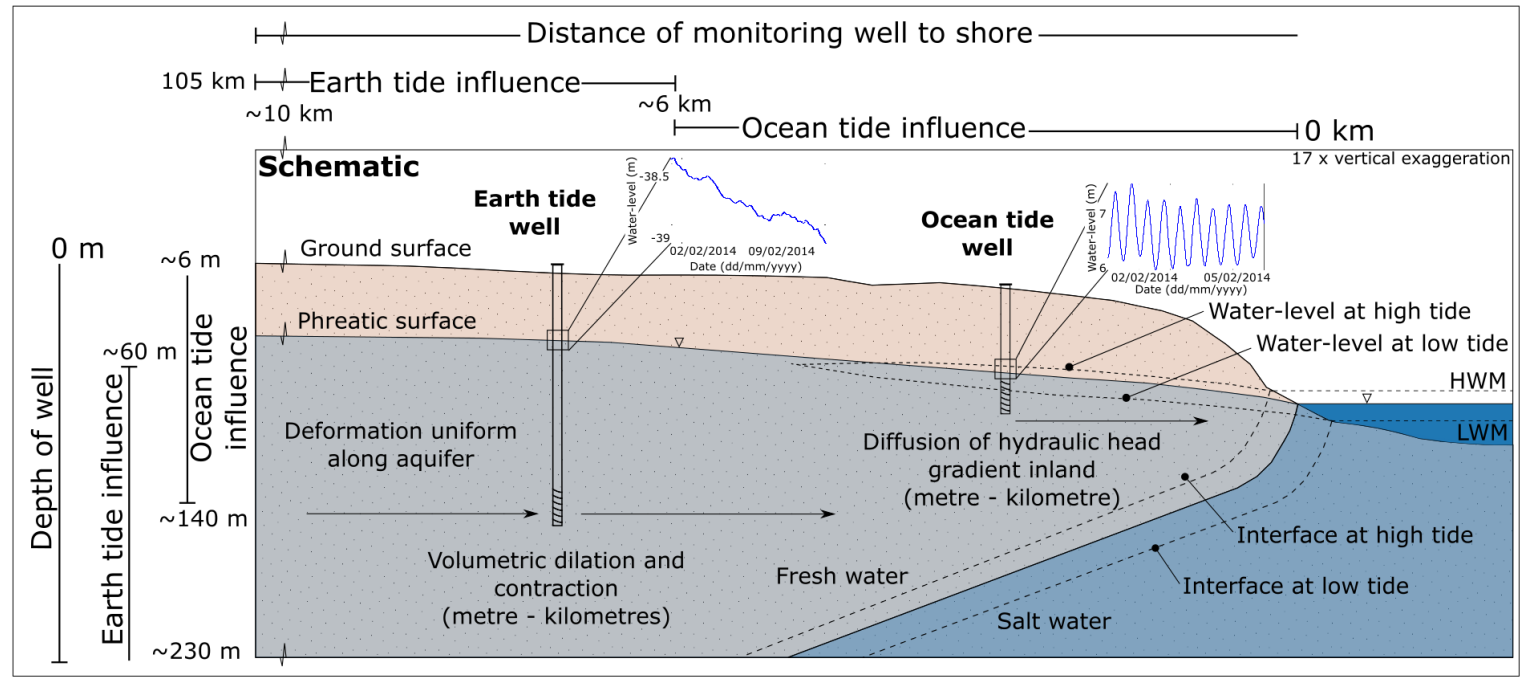

Figure 4.4: A schematic of the coastal Canterbury plains aquifer system. The schematic shows the zone of influence for water-level fluctuations caused by earth and ocean tides. 


\section{Earthquake-induced tidal behaviour changes}

We focus on the time evolution of the tide-sensitive wells. We investigate the change in the $\mathrm{M}_{2} \phi_{\text {lag }}$ induced on these wells by any of the 9 earthquakes studied (Table 4.4). The $\mathrm{M}_{2} \phi_{\text {lag }}$ was compared in the inter-seismic period before and after each earthquake (Figure 4.5). If the absolute change in $\mathrm{M}_{2} \phi_{\text {lag }}$ after each earthquake was larger than the $\mathrm{M}_{2} \phi_{\text {lag }}$ natural variation, the polarity and amplitude of change was recorded.

In the 35 monitoring wells, nine responses of $\mathrm{M}_{2} \phi_{\text {lag }}$ occurred. Earthquake-induced tidal behaviour changes occurred as a result of the Darfield $\left(\mathrm{M}_{\mathrm{w}} 7.1\right)$, Christchurch $\left(\mathrm{M}_{\mathrm{w}} 6.2,6.0,5.9\right)$ and Opunake $\left(\mathrm{M}_{\mathrm{w}} 6.2\right)$ earthquakes. There were seven cases of $\phi_{\text {lag }}$ decreasing and two cases of $\phi_{\text {lag }}$ increasing. The largest $\phi_{\text {lag }}$ increase was $26^{\circ}$ and $\phi_{\text {lag }}$ decrease was $57^{\circ} \cdot \mathrm{M}_{2} \phi_{\text {lag }}$ change occurred four times in only one monitoring well that displayed earth tides: H39/0148 (Figure 4.5 and 4.6). The lowest PDS (peak dynamic stress) required for an earth tide behaviour change in H39/0148 was $\sim 0.2 \mathrm{kPa}$ (Figure 4.7). In H39/0148 which has a large variation in seasonal hydraulic head (Figure 4.5), tidal behaviour may be influenced by changes in boundary conditions. $\mathrm{M}_{2} \phi_{\text {lag }}$ change occurred five times in monitoring wells that displayed ocean tides. The five changes occurred once in three wells and twice in one well (Figure 4.6). The lowest PDS required for an ocean tide behaviour change was $\sim 2 \mathrm{kPa}$. In the clustered wells sub-set, only two wells responded to an earthquake with a tidal behaviour change (Figure 4.6). There is no clear statistical difference between no tidal behaviour change and tidal behaviour change, based on PDS, in these gravel aquifers (Figure 4.7).

Table 4.3: Table of the $\mathrm{M}_{2} \phi_{\text {lag }}$ response types that occurred as a result of the nine $\mathrm{M}_{\mathrm{w}}$ 5.4 or larger earthquakes in the 35 tidally sensitive monitoring wells. In 90 instances, monitoring wells lacked water-level data before and/or after the earthquake of interest and no change in tidal phase behaviour could be detected. In 234 cases, no earthquakeinduced change in tidal phase behaviour were observed.

\begin{tabular}{cccccc}
\hline Earthquake & Total & No data & No response & $\phi_{\text {lag }}$ decrease & $\phi_{\text {lag }}$ increase \\
\hline Hastings & 35 & 6 & 29 & 0 & 0 \\
Dusky Sound & 35 & 4 & 31 & 0 & 0 \\
Darfield & 35 & 8 & 25 & 1 & 1 \\
Christchurch (Feb) & 35 & 15 & 18 & 1 & 1 \\
Christchurch (Jun) & 35 & 14 & 20 & 1 & 0 \\
Christchurch (Dec) & 35 & 10 & 24 & 1 & 0 \\
Opunake & 35 & 12 & 20 & 3 & 0 \\
Seddon & 35 & 11 & 24 & 0 & 0 \\
Eketahuna & 35 & 9 & 26 & 0 & 0 \\
\hline Total & 315 & 89 & 217 & 7 & 2 \\
\hline
\end{tabular}




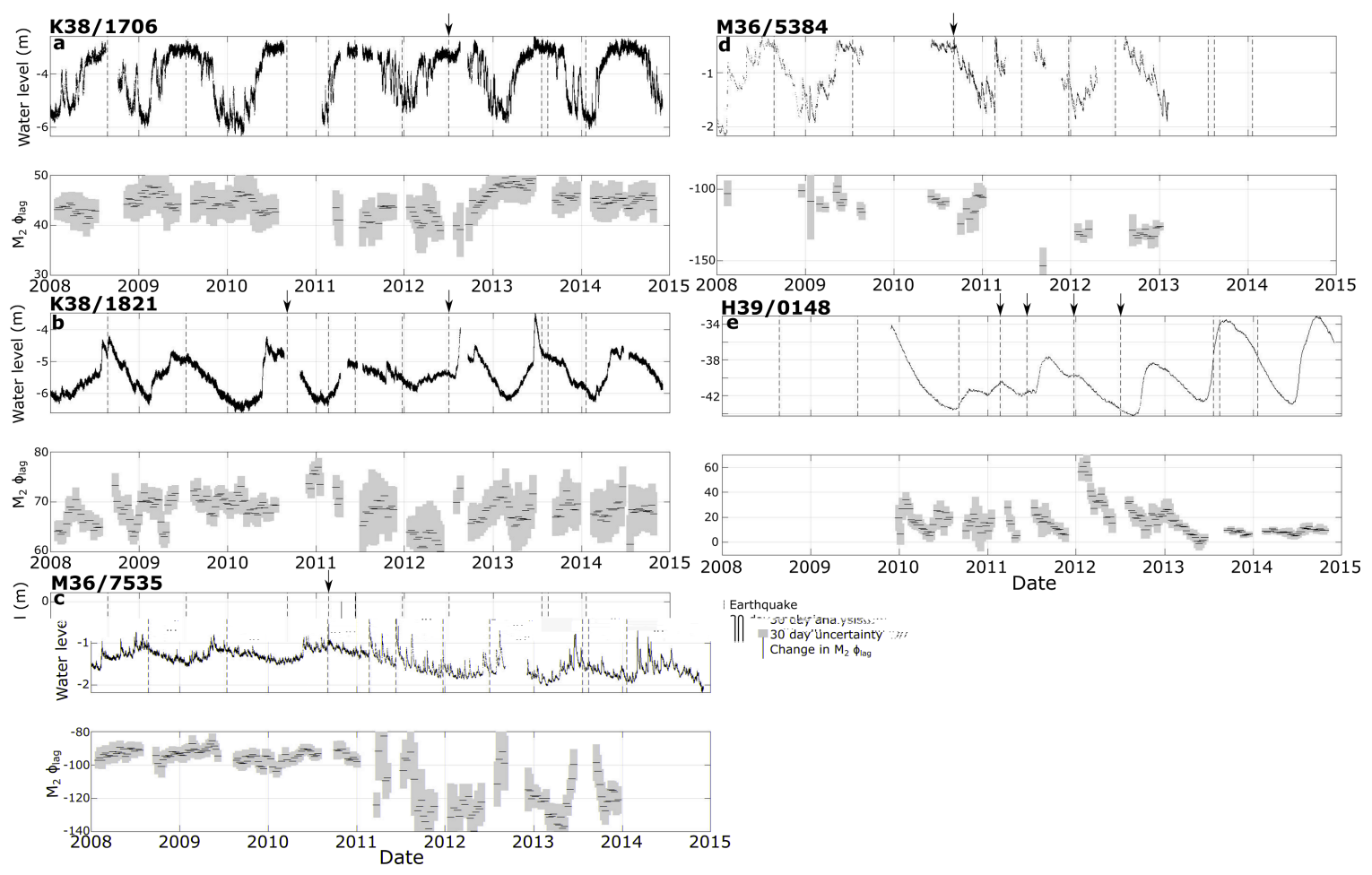

Figure 4.5: Water-level and $\mathrm{M}_{2} \phi_{\text {lag }}$ time-series for the five monitoring wells that showed a tidal change. The graphs are ordered in terms of distance from shore $(\mathrm{a}-$ Top left) K38/1706; (b - Middle left) K38/1821; (c - Bottom left) M36/7535; (d - Top right) M36/5384; and (e - Middle right) H39/0148. The occurrence of the nine $\mathrm{M}_{\mathrm{w}}$ 5.4 or larger earthquakes are displayed with dashed black lines. Tidal phase behaviour changes identified are highlighted in Figure 4.6.

\section{Earthquake-induced water-level changes}

Within the 161 wells monitored during the nine earthquakes, there were a total of 203 water-level changes, with 122 increases and 81 decreases (Table 4.6). The waterlevel changes ranged from -94 to $240 \mathrm{~cm}$. The Hastings $\left(M_{w} 5.4\right)$ earthquake did not produce persistent changes (Table 4.6). The different earthquakes generally produced water-level changes of different polarities in each monitoring well. In $\sim 38 \%$ (earth tide subset), $\sim 22 \%$ (ocean tide subset) and $\sim 19 \%$ (no tide subset) of instances, a waterlevel change occurred (Figure 4.7). In the earth and ocean tide subsets, the maximum number of changes observed in an individual well was four times. Nine wells had no response to any of the nine earthquakes. In the individual well clusters, in the rare case that water-level changes occurred in all wells in response to a particular earthquake, water-level change polarity was inconsistent (Figure 4.6). For PDS values $<\sim 10 \mathrm{kPa}$, it is more than likely that no water-level change will occur. For PDS values $>\sim 50$ $\mathrm{kPa}$, it is more than likely that a water-level change will occur. Between $\sim 10 \mathrm{kPa}$ and $\sim 50 \mathrm{kPa}$, there is a transition from no water-level change to a water-level change 
(Figure 4.7). An increased sensitivity to rainfall after the February 2011 earthquake in M36/7535 (Figure 4.5), may suggest a change in the level of confinement.

Table 4.5: Table of the post-seismic water-level changes that occurred as a result of the nine $\mathrm{M}_{\mathrm{w}} 5.4$ or larger earthquakes in the 161 monitoring wells. In 308 instances, monitoring wells lacked water-level data before and/or after the earthquake of interest, therefore, a water-level change could not be deduced. In 866 cases no earthquakeinduced water-level change was observed, while a response was observed in 203 cases.

\begin{tabular}{cccccc}
\hline Earthquake & Total & No data & No change & Increase & Decrease \\
\hline Hastings & 161 & 55 & 106 & 0 & 0 \\
Dusky Sound & 161 & 35 & 98 & 7 & 21 \\
Darfield & 161 & 23 & 48 & 62 & 28 \\
Christchurch (Feb) & 161 & 48 & 75 & 33 & 5 \\
Christchurch (Jun) & 161 & 45 & 87 & 11 & 18 \\
Christchurch (Dec) & 161 & 34 & 119 & 4 & 4 \\
Opunake & 161 & 44 & 115 & 2 & 0 \\
Seddon & 161 & 53 & 101 & 2 & 5 \\
Eketahuna & 161 & 43 & 117 & 1 & 0 \\
\hline Total & 1449 & 308 & 866 & 122 & 81 \\
\hline
\end{tabular}

\section{Comparison of tidal behaviour and water-level changes}

For the most part, tidal behaviour and water-level changes occurred independently (Figure 4.8). There were four tidal behaviour changes, and 53 water-level changes that occurred independently. Only in four cases did tidal behaviour and water-level changes occur simultaneously. Of these four cases, two included a $\phi_{\text {lag }}$ decrease and two included a $\phi_{\text {lag }}$ increase (Table 4.8). In the well clusters, only one tidal behaviour change occurred with a water-level change (M36/5384, Darfield earthquake; Figure 4.6). In most other cases, water-level changes occurred independently either in one or two wells within each cluster. Water-level changes that occurred without tidal behaviour changes, generally equilibrated sooner ( $\sim 50$ mins) than those with tidal behaviour changes $(\sim 240$ mins to $\sim 10$ days; Figure 4.9$)$. 
Table 4.7: Combination tally of tidal behaviour and water-level changes that occurred in each monitoring well in response to the nine $\mathrm{M}_{\mathrm{w}} 5.4$ or larger earthquakes.

\begin{tabular}{cccc}
\hline Tidal change behaviour & No data & No change & Change \\
\hline No data & 82 & 4 & 2 \\
No response & 19 & 153 & 45 \\
$\phi_{\text {lag }}$ decrease & 1 & 4 & 2 \\
$\phi_{\text {lag }}$ increase & 0 & 0 & 2 \\
\hline
\end{tabular}

a

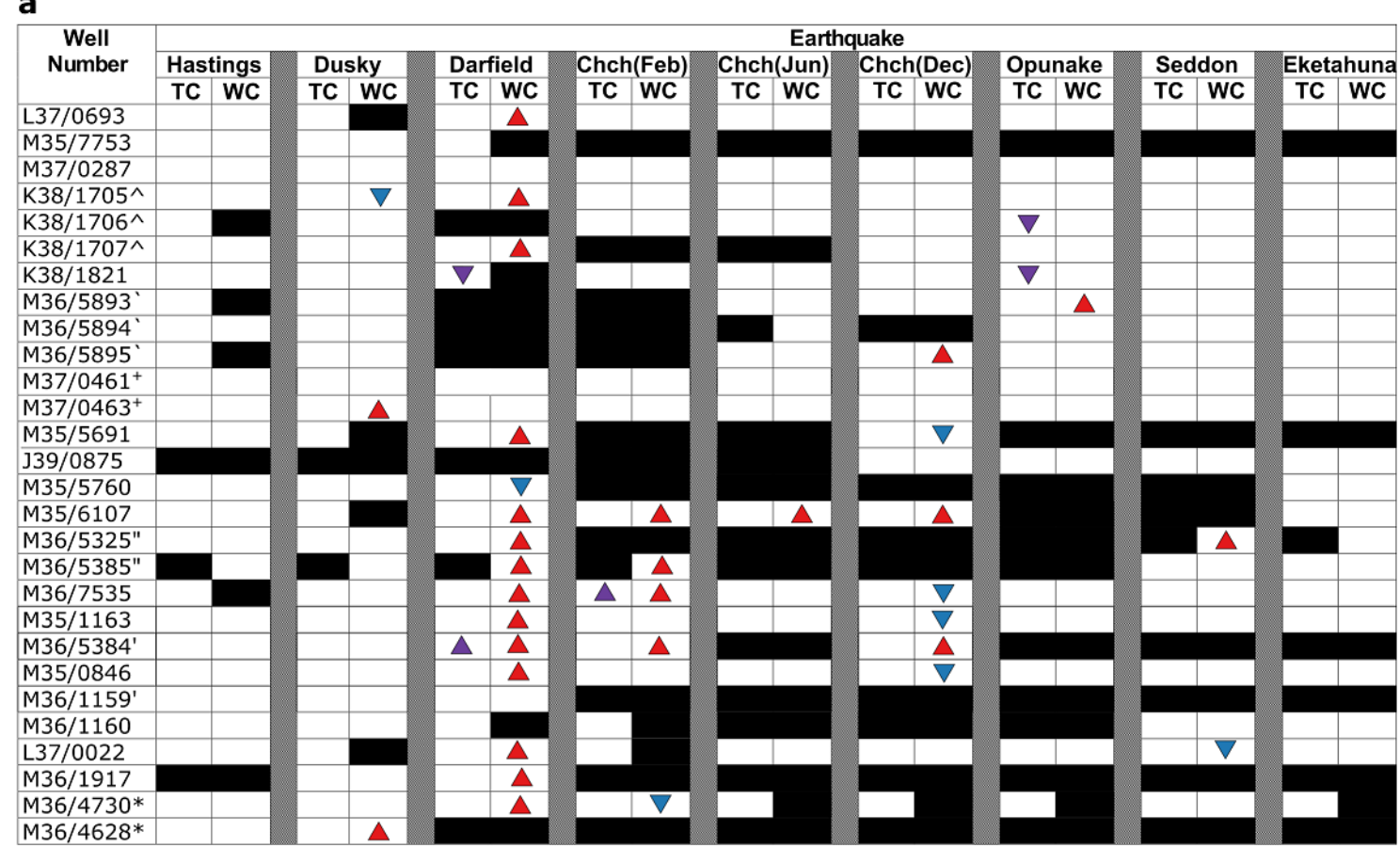

b

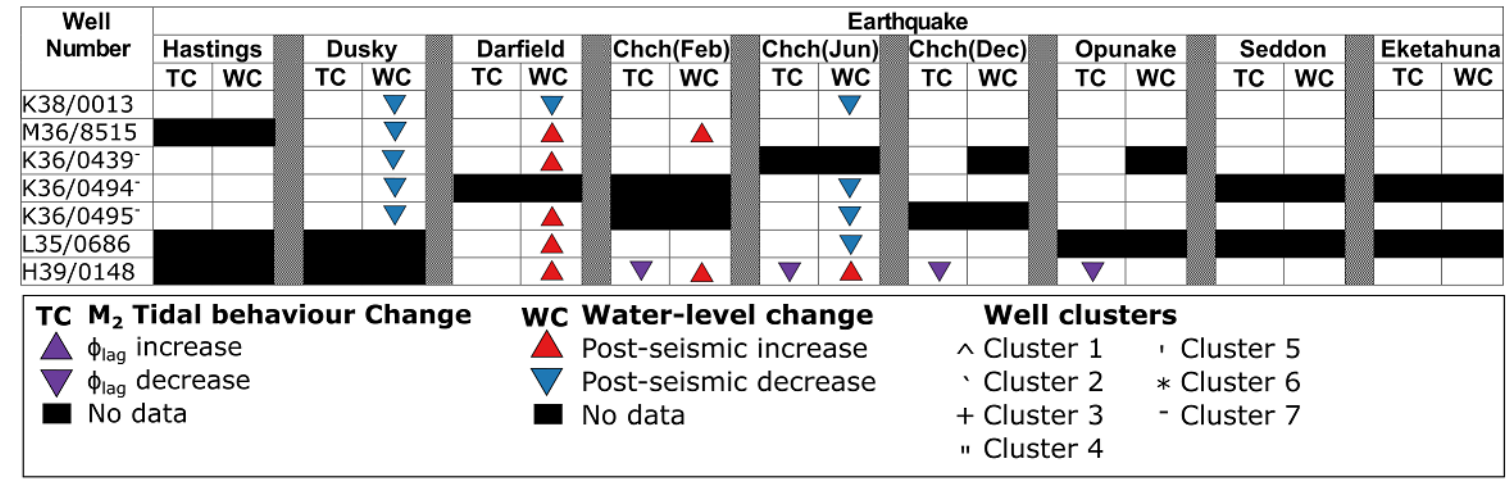

Figure 4.6: The tidal behaviour and water-level changes that occurred in the 35 monitoring wells in response to the nine $\mathrm{M}_{\mathrm{w}} 5.4$ or larger earthquakes. The tables are ordered in terms of distance to shore (see Supplementary data). Well clusters represented are wells that are in proximity to each other $(<20 \mathrm{~m}$; see Supplementary figures). (a Top) A table of the earth and ocean tide monitoring well response history. ( $\mathrm{b}$ - Bottom) A table of the earth tide monitoring well response history. Earthquake numbers refer to Table 1. 


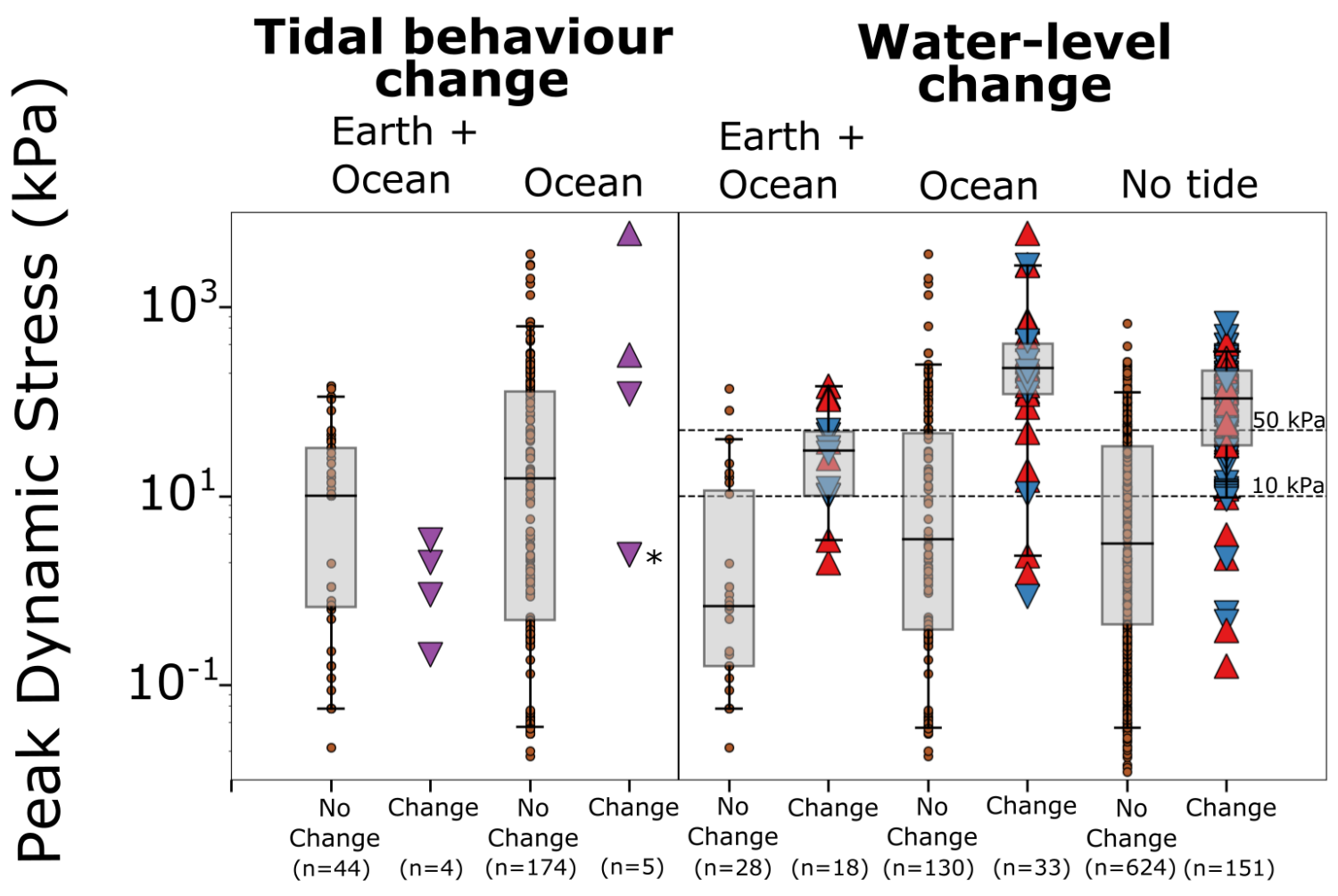

\begin{tabular}{|c|c|}
\hline $\begin{aligned} & \mathbf{M}_{\mathbf{2}} \text { Tidal behaviour change } \\
& \text { - } \text { No response } \\
& \Delta \phi_{\text {lag }} \text { increase } \\
& \nabla \text { laq decrease }\end{aligned}$ & $\begin{array}{l}\text { Box and } \\
\text { Whisker Plots } \\
95^{\text {th }} \text { percentile }\end{array}$ \\
\hline $\begin{array}{l}\text { Water-level change } \\
\text { - No change } \\
\Delta \text { Post-seismic increase } \\
\nabla \text { Post-seismic decrease }\end{array}$ & \begin{tabular}{|l} 
\\
\\
\\
\end{tabular} $5^{\text {th } 1}$ percentile \\
\hline
\end{tabular}

Figure 4.7: Interpolated peak dynamic stress produced by the nine $\mathrm{M}_{\mathrm{w}} 5.4$ or larger earthquakes and tidal behaviour and water-level changes. $*=\phi_{\text {lag }}$ decreases occurred after the $2012 \mathrm{M}_{\mathrm{w}} 6.2$ Opunake earthquake in two monitoring wells (K38/1821, K38/1706) that are close to each other $(<3 \mathrm{~m}$ horizontal separation) and have identical peak dynamic stresses. 


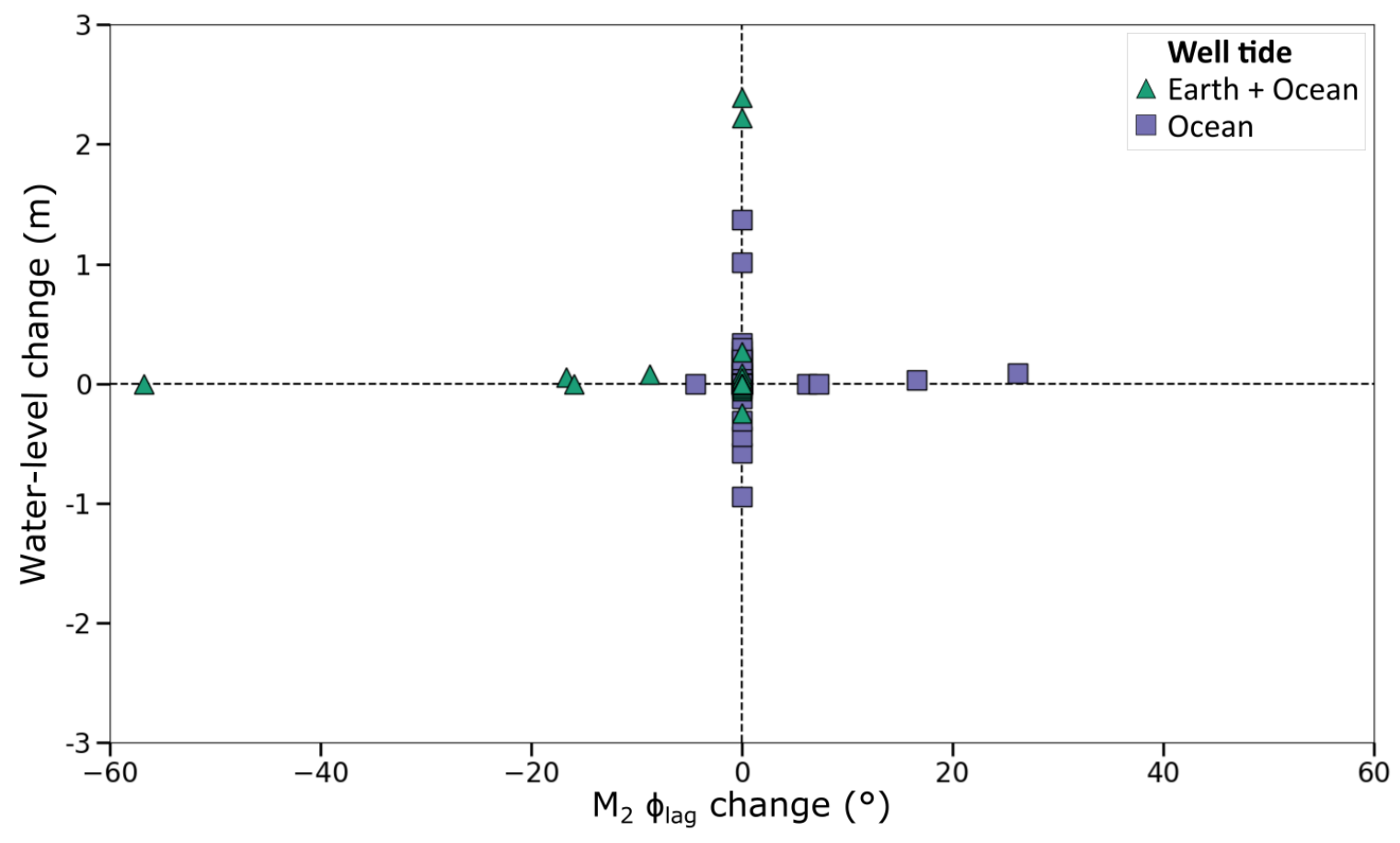

Figure 4.8: Cross-plots comparing water-level and $\mathrm{M}_{2} \phi_{\text {lag }}$ changes. Monitoring wells are distinguished by tide type. This figure illustrates that at individual sites, earthquake-induced changes in water-level were generally independent of tidal behaviour changes.

\subsection{Discussion}

\section{Mechanisms for water-level and tidal behaviour change}

Numerous mechanisms may cause changes in water-level and tidal behaviour following earthquakes. Shear-induced dilation in unconsolidated deposits (Wang et al., 2001) occurs when cyclic shear strains exceed a threshold of $\sim 10^{-4}$ (Luong, 1980). An increase in porosity, and a decrease in pore pressure leads to consistent earthquake induced water-level decreases (Wang and Chia, 2008). At a lower cyclic shear strain, still exceeding $\sim 10^{-4}$ (Dobry et al., 1982; Vucetic, 1994), shear-induced consolidation and liquefaction occurs (Wang et al., 2001; Wang, 2007), resulting in consistent earthquake induced water-level increases (Wang and Chia, 2008). In this study, the Canterbury earthquakes of 2010 and 2011 induced seismic shaking that exceeded the threshold for liquefaction $\left(\sim 0.1 \mathrm{~J} / \mathrm{m}^{3}\right.$ Wang et al., 2006) at the majority of monitoring wells. The $2010 \mathrm{M}_{\mathrm{w}} 7.1$ Darfield and the $2011 \mathrm{M}_{\mathrm{w}}$ 6.2 Christchurch earthquake both induced a tidal behaviour change in two separate monitoring wells, probably related to a decrease in permeability. A simultaneous increase in water-level was observed at these wells. Furthermore, the $2010 \mathrm{M}_{\mathrm{w}} 7.1$ Darfield earthquake induced post-seismic persistent water-level increases in the near-field (see Supplementary data). These observations 


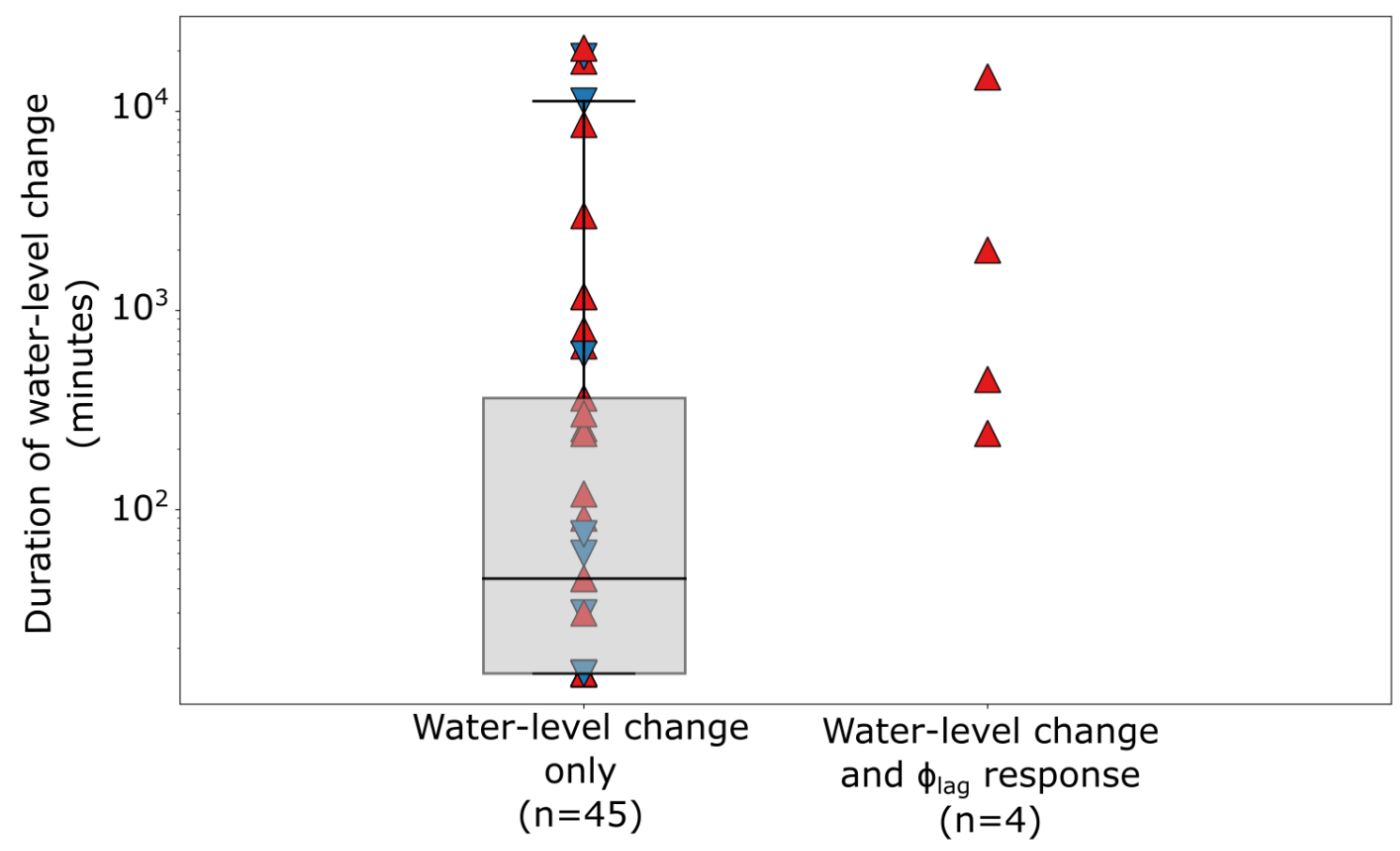

Water-level change

$\Delta$ Post-seismic increase

$\nabla$ Post-seismic decrease

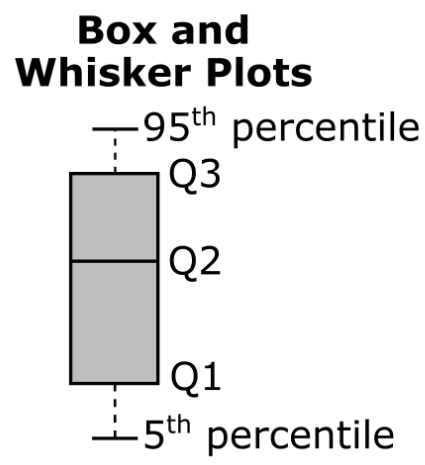

Figure 4.9: Box plots showing the duration of water-level changes when occurring independently and simultaneously with an $\mathrm{M}_{2} \phi_{\text {lag }}$ response. This figure shows that water-level changes which occur simultaneously with tidal behaviour changes had generally longer durations ( $\sim 240$ minutes to 10 days $)$ than those that occurred without tidal behaviour changes ( $\sim 15$ to 350 minutes).

are consistent with reductions in permeability measured by step-drawdown tests in the vicinity of the Darfield epicenter, three years after the event (Rutter et al., 2016), and shear-induced consolidation.

High levels of seismic shaking can also cause breaching of aquitards and enhancement of vertical permeability (Wang et al., 2016). Considering the Canterbury aquifer system at depth is artesian, any enhancement of vertical permeability would result in the upward movement of groundwater. The $2010 \mathrm{M}_{\mathrm{w}} 7.1$ Darfield and the 2011 $\mathrm{M}_{\mathrm{w}} 6.2$ Christchurch earthquakes induced water-level decreases in confined aquifers and water-level increases in unconfined aquifers, indicative of upward movement of groundwater (Gulley et al., 2013). In Taiwan, Wang et al. (2016) studied clustered well responses to the $1999 \mathrm{M}_{\mathrm{w}}$ 7.6 Chi-Chi earthquake and interpreted the convergence 
of water-levels in stratified aquifers and post-seismic phase response similarity in confined and unconfined aquifers, to be evidence of vertical enhancement of permeability and upward movement of groundwater. In the seven clusters studied here, water-level changes occur independently most of the time. Only two instances of tidal behaviour change occurred, one decrease in permeability (above the liquefaction threshold) and one increase in permeability in the intermediate-field, in response to the $2012 \mathrm{M}_{\mathrm{w}} 6.2$ Opunake earthquake. The clustered wells in the data-set studied here show no substantial evidence for enhancement of vertical permeability. Unfortunately, monitoring wells with earth and/or ocean tides in the Canterbury Plains are scarce, and thus significantly reduce the data-set for assessing this hypothesis.

At lower levels of shaking, horizontal permeability can be enhanced or reduced by the re-distribution of colloidal particles. Seismically induced groundwater flow velocities (Wang et al., 2009) have the potential to dislodge colloids from flow pathways and enhance permeability (Brodsky et al., 2003; Matsumoto et al., 2003; Wang and Chia, 2008). Seismic shaking may also mobilize sediment that further blocks these flow pathways (Rutter et al., 2016). The dislodging of colloids may result in random polarity of resultant water-level changes (Wang and Chia, 2008). Controlled experiments of pore unclogging (Elkhoury et al., 2011; Liu and Manga, 2009) and earthquake induced groundwater color changes (Prior and Lohmann, 2003) support the hypothesis of permeability enhancement via colloidal dislodgement. Considering the Canterbury gravel aquifer system is made up of highly permeable open framework gravels that accommodate $\sim 98 \%$ of flow through $\sim 1 \%$ of the aquifer (Dann et al., 2008), it is perhaps possible to induce substantial permeability change by colloidal re-distribution in preferential flow pathways. Such changes could also occur in the immediate surroundings of a monitoring well (Shi et al., 2015b) or at flow boundaries. Water-level changes, both increases and decreases, and tidal changes which occurred below the liquefaction threshold may have resulted from colloidal re-distribution, either enhancing or reducing permeability.

\section{Peak dynamic stress}

We compare the peak dynamic stress (PDS) required to induce water-level and tidal behaviour changes in the Canterbury gravel aquifers. Permeability reduction detected by tidal behaviour changes in the $2010 \mathrm{M}_{\mathrm{w}}$ 7.1 Darfield and the $2011 \mathrm{M}_{\mathrm{w}} 6.2$ Christchurch earthquake, required a PDS of $\sim 200 \mathrm{kPa}$ (Figure 4.7 ). We suspect the permeability reduction coupled with post-seismic water-level increases is a result of shear-induced consolidation which requires a high level of shaking (Vucetic, 1994).

The minimum PDS required for permeability increase in the Canterbury gravel aquifers is $\sim 0.2$ to $100 \mathrm{kPa}$ (Figure 4.7). However, owing to an insufficient number of tidal responses, there is no clear distinction between the presence and absence of tidal 
behaviour changes based on PDS. Water-level changes are more than likely to occur above $\sim 50 \mathrm{kPa}$ and more than likely to not occur below $\sim 10 \mathrm{kPa}$ (Figure 4.7 ).

Although the hypotheses may provide explanations for water-level and tidal behaviour changes observed in this study, in the vast majority of instances monitoring wells that experience a PDS from $\sim 10^{-1}$ to $10^{3} \mathrm{kPa}$ did not respond to the earthquakes with persistent tidal behaviour and/or water-level changes. The monitoring wells that didn't respond may be screened in aquifers that have high storage capacities or have poor permeability. This in-turn may result in a higher shaking threshold required for a change to be observed as the monitoring well and aquifer are uncoupled (Doan and Brodsky, 2006; Hsieh et al., 1987). The low bulk modulus of unconsolidated gravels may also contribute to monitoring wells not responding with water-level or tidal behaviour changes (Roeloffs, 1998). Other shaking (source factors) and/or hydrogeological (receptor factors) parameters may also control the threshold for tidal behaviour and water-level changes.

\section{Comparison of tidal behaviour and water-level changes}

The results here show significant inconsistency between tidal behaviour and water-level changes. Only $\sim 2 \%$ of the cases had a water-level change that occurred simultaneously with a tidal behaviour change (cf. $33 \%$, 43\% Shi et al., 2015b; Yan et al., 2014). Water-level changes that occurred without tidal behaviour changes took a median of $\sim 50$ minutes to re-equilibrate at the new post-seismic water-level (Figure 4.9). The fast re-equilibration time may be a result of high permeability and good coupling between the monitoring well and aquifer (Doan and Brodsky, 2006; Hsieh et al., 1987). Furthermore, the water-level changes may have returned to pre-earthquake levels sooner than 30 days after the earthquake, possibly resulting in no small tidal behaviour change being detected. Tidal changes may also not have been observed in these cases, possibly due to the unconsolidated gravels having a relatively low bulk modulus (Roeloffs, 1998), and thus being less sensitive to tidal behaviour changes than other rock types. It should also be considered that these water-level changes may represent permeability changes in the local surroundings, hence the short re-equilibration time. The small-scale (m) nature of these permeability changes may be too small to alter tidal behaviour (Shi et al., 2015b).

In each monitoring well, the different earthquakes generally produced water-level changes of different polarity, which is in contrast with some previous observations (e.g. Roeloffs, 1998; Wang and Chia, 2008). This is not surprising considering the variety in shaking amplitude, duration, and frequency experienced across the earthquake intervals. Monitoring wells were not consistently in the near- or intermediate-field for the data-set, thus were subject to variable shaking intensities. Furthermore, aquifer susceptibility to earthquake-induced process may have changed through each successive 
earthquake (Elkhoury et al., 2006; Xue et al., 2013), although there does not appear to be any significant change in ground strength following the Canterbury earthquake sequence (Lees et al., 2015; Orense et al., 2012).

Water-level changes that occurred with tidal behaviour changes took from $\sim 240$ mins to $\sim 10$ days to re-equilibrate at the new post-seismic water-level (Figure 4.9). The re-equilibration time was larger than for independent water-level changes. Tidal behaviour changes indicated an equal number of permeability increases and decreases. These water-level and tidal behaviour changes may reflect transitional coupling between the monitoring well and aquifer due to lower permeability (Doan and Brodsky, 2006; Hsieh et al., 1987). The permeability changes may occur on a larger scale than permeability changes detected by independent water-level changes, as water-level changes also occurred in nearby wells where present (see Supplementary figures).

There are instances where tidal behaviour changes occur without water-level changes, requiring a new explanation. We hypothesize that perhaps low permeability resulted in an uncoupled state between monitoring wells and aquifers. Under these conditions permeability changes in aquifers might not be observed in monitoring wells on the time-scale that water-level changes are identified (days), but may still be detected on the time-scale of tidal behaviour changes (30 days). Low signal to noise ratio may also prevent water-level changes being recorded.

\subsection{Conclusion}

1. In the near-field of the Canterbury earthquake sequence of 2010 and 2011, permeability reduction and increased water-level support the hypothesis of shearinduced consolidation. The hydrological responses to the earthquakes north and south of Canterbury included variable water-level change polarity and rare tidal behaviour change, suggesting permeability enhancement or reduction in the local aquifer.

2. Water-level changes that occurred without tidal behaviour changes took $\sim 50$ minutes to re-equilibrate at a new post-seismic water-level, while those that occurred with tidal behaviour changes took from $\sim 240$ minutes to $\sim 10$ days to re-equilibrate. The fast re-equilibration time of independent water-level changes may be due to a high permeability and good coupling between the well and the aquifer, and/or small permeability changes in the local aquifer. Tidal behaviour changes may have also not been observed due to the low bulk modulus of the gravels. Water-level changes that occurred with tidal behaviour changes may occur on a larger scale than independent water-level changes, as water-level changes also occurred in nearby wells where present. 
3. The minimum peak dynamic stress required for a tidal behaviour change in the Canterbury gravel aquifers was $\sim 0.2 \mathrm{kPa}$ for wells containing earth tides and $\sim 2$ $\mathrm{kPa}$ for well containing ocean tides. Water-level changes were more than likely to occur above $\sim 50 \mathrm{kPa}$ and were more than likely to not occur below $\sim 10 \mathrm{kPa}$. However, there was no clear distinction between the presence and absence of tidal behaviour and water-level changes based on peak dynamic stress.

\subsection{Acknowledgments}

This study was funded by the Royal Society of New Zealand Marsden Fund (2012-GNS003). Hydrological data was provided by Shaun Thomsen of Environment Canterbury, and seismic data was provided by GeoNet. Valuable feedback was provided by Helen Rutter, Chi-Yuen Wang, Xin Liao, Zeb Etheridge, Sung Soo Koh. The data supporting the conclusions of this study can be found in the supporting information. 


\section{$5 \quad$ Aquifer susceptibility to earthquake-induced persistent groundwater- level changes}

\section{$5.1 \quad$ Abstract}

A probabilistic model for earthquake-induced groundwater response as a function of Modified Mercalli (MM) shaking intensity has been constructed using an internationally significant catalogue of monitoring well observations during earthquakes. The study constitutes a regional-scale multi-site multi-earthquake investigation encompassing the occurrence and absence of responses, over a decade of seismic shaking. Persistent groundwater-level changes, or absence of change, have been quantified in 495 monitoring wells in response to one or more of 11 recent New Zealand earthquakes larger than $\mathrm{M}_{\mathrm{w}} 5.4$ between 2008 and 2017. A binary logistic regression model with random effects has been applied to the dataset using three predictors: earthquake shaking (peak ground velocity), degree of confinement (monitoring well depth) and rock strength (site average shear-wave velocity). Random effects were included as a partial proxy for variations in monitoring wells' susceptibilities to earthquake-induced persistent water-level change. Marginal probabilities have been calculated as a function of PGV and MM intensity, and the likelihood of persistent water-level changes computed for MM intensities II to VIII. This study is the first attempt at incorporating both seismic and hydrogeological factors into a probabilistic framework for earthquake-induced groundwater level changes. The framework is a novel and more generalizable approach to quantifying responses than alternative metrics based on epicentral distance, magnitude and seismic energy density. It has potential to enable better comparison of international studies and to inform practitioners making decisions around investment

This chapter has been written as a research manuscript and has been submitted for consideration in the international journal Bulletin of the Seismological Society of America in October 2018. Coauthors contributed to the making of this manuscript. R. Arnold assisted with research design, analysis of results and reviewed the manuscript. J. Townend and S. C. Cox provided conceptual discussion, reviewed the manuscript and obtained funding. 
to mitigate risk and increase the resilience of water supply infrastructure.

\subsection{Introduction}

Deriving a deeper understanding of what causes earthquakes to induce hydrological responses in aquifers is important as it can give insight into crustal hydromechanics, support infrastructural decision-making in seismically active regions, and assist with the quantification and mitigation of natural hazards. For example, crustal fluids are mechanically involved within all stages of the earthquake cycle and play a key role in the rupture-reactivation-cementation cycle (Dempsey et al., 2014; Sutherland et al., 2012; Boulton et al., 2017). Seismicity and associated groundwater flow may also compromise the longevity of $\mathrm{CO}_{2}$ (Zoback and Gorelick, 2012; Gleeson and Ingebritsen, 2016), waste-water (Keranen et al., 2014) and nuclear waste (Carrigan et al., 1991) storage. The intensity of shaking may further cause damage to water-supply infrastructure (Roeloffs et al., 1995; Zemansky et al., 2012). Earthquake-induced groundwater changes can have potentially diverse and large impacts within the urban environment, whether by contributing to floods by rising springs (Chen and Wang, 2009), increasing groundwater-fed stream discharge (e.g. Manga, 2001, 2003), or by changing groundwater chemistry and quality (e.g. Prior and Lohmann, 2003; Cox et al., 2015). As these responses can be both wide-reaching (e.g. Weingarten and Ge, 2014) and long-lasting (e.g. Rutter et al., 2016), a susceptibility analysis of earthquake-induced groundwaterlevel changes will benefit hazard assessment during future earthquakes.

\section{Previous studies}

Earthquakes are inferred to induce groundwater-level changes of different amplitudes, durations, and polarity of response in several ways (Wang and Manga, 2010a). These include for example: static-stress-induced volumetric strain changes (e.g. Wakita, 1975; Jónsson et al., 2003); shear-induced consolidation and dilatation (Wang et al., 2001); enhancement of permeability by removal of colloidal blockages (Brodsky et al., 2003); and the enhancement of fracture permeability sub-horizontally (O'Brien et al., 2016) and sub-vertically (Wang et al., 2016).

A general reference used to study groundwater-level changes is the magnitude of the earthquake and the epicentral distance of the hydrological response. The use of this metric is particularly useful due to its applicability to the many historic documentations of responses that lack any other hydrological or seismological characteristics (Wang and Manga, 2010b). A comparable parameter is seismic energy density $\left(e, \mathrm{~J} / \mathrm{m}^{3}\right)$, which is computed based on an empirical relationship between magnitude $(M)$ and epicentral 
distance $(r, \mathrm{~km}$; Wang, 2007):

$$
M=2.7+0.69 \log (e)+2.1 \log (r)
$$

Although this relationship was originally derived in southern California, seismic energy density has been utilised to study many types of hydrological responses worldwide (Wang and Manga, 2010b). However, the empirical relationship between magnitude, energy, and epicentral distance does not incorporate the effect of either rupture directivity or site-specific hydrogeological factors (Wang and Manga, 2010a). Hydrogeological factors such as degree of confinement (Roeloffs, 1996) or flow properties (e.g. Faoro et al., 2012; Manga and Wang, 2007) do contribute to a monitoring well's capacity to exhibit a water-level change. Moreover, the characteristics and distribution of seismic energy vary with rock type (Bard and Riepl-Thomas, 2000; Wang, 2007; Wang and Manga, 2010a), and thus potentially from one region to another.

Although hydrologic responses are common and often experienced at great distances from an earthquake source, not all monitoring wells will exhibit groundwater-level changes. It is not uncommon for wells to experience high levels of seismic shaking with no discernible hydrologic response, while neighbouring wells do respond (e.g. Cox et al., 2012). Unresponsive wells may result from the aquifer and/or the well and monitoring system. Aquifers with low transmissivity and/or high storage capacities may prevent responses being recorded at the monitoring wells. A low sampling resolution and/or a large noise to signal ratio could result in low resolution measurements of the waterlevel and any changes that occur. Monitoring well site conditions may also influence response recordings with precipitation, pumping or large seasonal variations having an effect on water levels. Although numerous studies have documented a range of waterlevel changes in response to different earthquakes and widely variable shaking intensities (e.g. Shi et al., 2014, 2015b), monitoring wells that do not respond are generally ignored, meaning that the occurrence/non-occurrence threshold for groundwater-level changes has not been studied in detail.

Binary logistic regression is a commonly used statistical method in environmental research and permits the simultaneous use of categorical and continuous variables as predictors of a binary outcome (Hosmer and Lemeshow, 1989). Logistic regression has been used in a variety of natural hazard studies, including studies of earthquaketriggered landslide susceptibility (García-Rodríguez et al., 2008; Lee and Pradhan, 2007; Bai et al., 2010), aquifer vulnerability to contaminants (Twarakavi and Kaluarachchi, 2005; Winkel et al., 2008), and earthquake-induced streamflow responses (Mohr et al., 2018). In this study, we used binary logistic regression to assess the earthquake-induced threshold between persistent and non-persistent groundwater-level changes in New Zealand aquifers. The susceptibility assessment tested the contributions of seismic and hydrogeological factors to this threshold. 
The main aims of this study were to (a) determine the relationships of seismic and hydrogeological factors to the occurrence and non-occurrence of earthquake-induced groundwater-level changes, and to (b) supplement the environmental response criteria of the New Zealand MM scale, with groundwater-level changes in a probabilistic framework. The dataset collated is the most extensive multi-earthquake multi-site dataset compiled in New Zealand (cf. O'Brien et al., 2016) and of a scale comparable with the world-wide catalogue of events (Wang and Manga, 2010a), and this study represents the first attempt at incorporating both seismic and hydrogeological factors into a probabilistic framework for earthquake-induced groundwater-level changes. The implications for earthquake-induced groundwater-level changes for seismic hazard assessments in New Zealand are briefly discussed within the context of the New Zealand MM scale.

\subsection{New Zealand tectonics and hydrogeology}

New Zealand's basement rocks were formed by plutonism on the margin of Gondwana, and terrane accretion during the Paleozoic (Western Province) and Mesozoic (Eastern Province; Landis and Coombs, 1967; Coombs et al., 1976). Late-Cretaceous Gondwana rifting and break-up later ensued, followed by Eocene-Quaternary evolution of the stillactive plate boundary (Cox and Sutherland, 2007). The basement rocks are collectively termed the Austral Superprovince, and the late-Cretaceous-Holocene Zealandia cover is termed the Zealandia Megasequence (Mortimer et al., 2014).

In New Zealand, there are a variety of compositionally diverse aquifers that were formed mainly during the Tertiary and Quaternary geological periods. Sedimentary aquifers are formed within shallow marine (e.g. deltaic, carbonate) and deep marine, and terrestrial (e.g. glacial, aeolian) sedimentary deposits. The mixed clast composition reflects the varied source rock geology (White, 2001). In central New Zealand (Marlborough and Greater Wellington regions) and the Canterbury region, the sedimentary cover depositional sequences are a result of tectonic movement and eustatic sea-level change in the Quaternary geological period (Forsyth et al., 2008). The shallow water-bearing stratigraphy consists of sequences of coarse alluvial deposits and fine marine sediments (Jones and Baker, 2005). Transgression/regression sequences created the inter-bedded deposits in coastal areas (e.g. Taylor et al., 1989), resulting in large variations in permeability and storage capacity (e.g. Bal, 1996). Volcanic aquifers of scoriaceous and ignimbrite deposits formed in the central North Island from volcanic activity within the Taupo Volcanic Zone. Fractured Mesozoic-Cretaceous metamorphic bedrock also stores groundwater, but is unsuitable for water supplies due to low yield and permeability (White, 2001). Wells from these different aquifer settings are represented in the dataset. 


\subsection{Seismic and hydrological monitoring, and the classification of data}

In this study, we analysed the responses to 11 earthquakes larger than $\mathrm{M}_{\mathrm{w}} 5.4$ that occurred in New Zealand between 2008 and 2017 (Figure 5.1, Table 5.1). We compiled seismograms from all over New Zealand, from 306 strong motion and broadband seismic stations that recorded the earthquakes. The seismic stations are part of the National Seismograph and Strong Motion Network. Instrument responses were corrected, and a band-pass filter with transition bands at $0.10-0.25 \mathrm{~Hz}$ and $24.50-25.50 \mathrm{~Hz}$ was applied. Shaking parameters were calculated at each seismic station and interpolated to nearby monitoring wells using nearest neighbour interpolation (Ebdon, 1985). We made an implicit assumption that surface shaking observed at the seismograph sites, interpolated locally as parameters at the well site, is applicable over the depth of the wells since they are mostly shallow $(<100 \mathrm{~m})$.

Water-level data is sampled at intervals of between one minute and three hours, with 15 minutes being the most common interval in aquifers throughout New Zealand (Figure 5.1). Data are available from various regional councils charged with environmental monitoring. We compiled New Zealand-wide earthquake-induced water-level observations made during and after the $2016 \mathrm{M}_{\mathrm{w}} 7.8$ Kaikōura earthquake, and water level changes that occurred in the Canterbury region and central New Zealand associated with earthquakes larger than $\mathrm{M}_{\mathrm{w}} 5.4$ between 2008 and 2015 (Figure 5.1). In total, water-level data from 495 monitoring wells were collated in time periods spanning one or more of the 11 earthquakes.

Atmospheric pressure data recorded in 2008-2017 throughout New Zealand by the National Institute for Water and Atmospheric Research were used, with up to 65 sites operational and recording immediately before, during and after the earthquakes. Barometric corrections were applied to groundwater-level monitoring sites with non-vented transducers using the nearest climate station, so that all groundwater measurements could be assessed in a standard format measured as a water-level relative to a well-head measuring point elevation.

Some wells incurred damage during the Canterbury earthquake sequence (Zemansky et al., 2012). The elevation of several monitoring well-heads changed, as a result of ground subsidence and/or buoyant rising of casing, which affected water level measurements. Therefore, re-surveying was necessary. In other instances, damaged screens and logger equipment were removed and replaced. It was assumed any anthropogenic influence (including nearby pumping) on the data or data-quality were either minor or easily identified and corrected.

Groundwater level data were assessed for both the presence and absence of observable earthquake-induced water-level changes, classifying sites into Response or No 
Response categories. Earthquake-induced water-level changes are commonly split into co-seismic and post-seismic components (e.g. Wang et al., 2009; Yan et al., 2016). As the sampling interval is typically at 15 minute intervals for New Zealand sites, with most shaking occurring between two successive measurements, we consider responses in this study to be entirely post-seismic.

Where there were unambiguous water-level responses, these were assessed as either being persistent (Response) or non-persistent (No Response), depending on the duration over which the earthquake-induced changes could be clearly observed. Persistent water-level changes increased or decreased, re-equilibrating at a new post-earthquake level that then lasted several days or longer. Non-persistent water-level changes included both those that were transient, returning to pre-earthquake levels within two hours, and those for which there was no observable water-level response at all.

Table 5.1: Table of the $11 \mathrm{M}_{\mathrm{w}} 5.4$ or larger earthquakes that occurred between 2008 and 2017. $\mathrm{M}_{\mathrm{w}}=$ Moment magnitude. Focal mechanisms are shown in Figure 5.1.

\begin{tabular}{ccccccc}
$\begin{array}{c}\text { Earthquake } \\
\text { location }\end{array}$ & $\begin{array}{c}\text { Epicentre } \\
\text { latitude } \\
\text { longitude } \\
\text { (degrees) }\end{array}$ & $\begin{array}{c}\text { Time and date } \\
\text { (NZST) } \\
\text { HH:MM }\end{array}$ & $\mathbf{M}_{\mathbf{w}}$ & $\begin{array}{c}\text { Depth } \\
\mathbf{\text { ddmm }} \mathbf{\text { mmyyy }}\end{array}$ & $\begin{array}{c}\text { Number } \\
\text { of } \\
\text { wells }\end{array}$ & $\begin{array}{c}\text { Data } \\
\text { available }\end{array}$ \\
\hline Hastings & $-39.72,176.85$ & $25 / 08 / 200823: 25$ & 5.4 & 32 & 268 & 188 \\
Dusky Sound & $-45.77,166.59$ & $15 / 07 / 200921: 22$ & 7.8 & 12 & 268 & 221 \\
Darfield & $-43.53,172.17$ & $4 / 09 / 20104: 35$ & 7.1 & 11 & 268 & 229 \\
Christchurch & $-43.58,172.68$ & $22 / 02 / 201111: 51$ & 6.2 & 5 & 268 & 211 \\
Christchurch & $-43.57,172.74$ & $13 / 06 / 201114: 12$ & 6 & 7 & 268 & 213 \\
Christchurch & $-43.52,172.75$ & $23 / 12 / 201115: 18$ & 5.9 & 7 & 268 & 220 \\
Opunake & $-40.05,173.76$ & $3 / 07 / 201222: 36$ & 6.2 & 241 & 268 & 222 \\
Seddon & $-41.60,174.32$ & $21 / 07 / 201317: 08$ & 6.6 & 16 & 268 & 208 \\
Grassmere & $-41.73,174.15$ & $16 / 08 / 201314: 31$ & 6.6 & 8 & 268 & 205 \\
Eketahuna & $-40.62,175.86$ & $20 / 01 / 201414: 52$ & 6.3 & 34 & 268 & 220 \\
Kaikoura & $-42.69,173.02$ & $13 / 11 / 201623: 02$ & 7.8 & 15 & 426 & 426 \\
\hline & & & & & Total & 2563
\end{tabular}




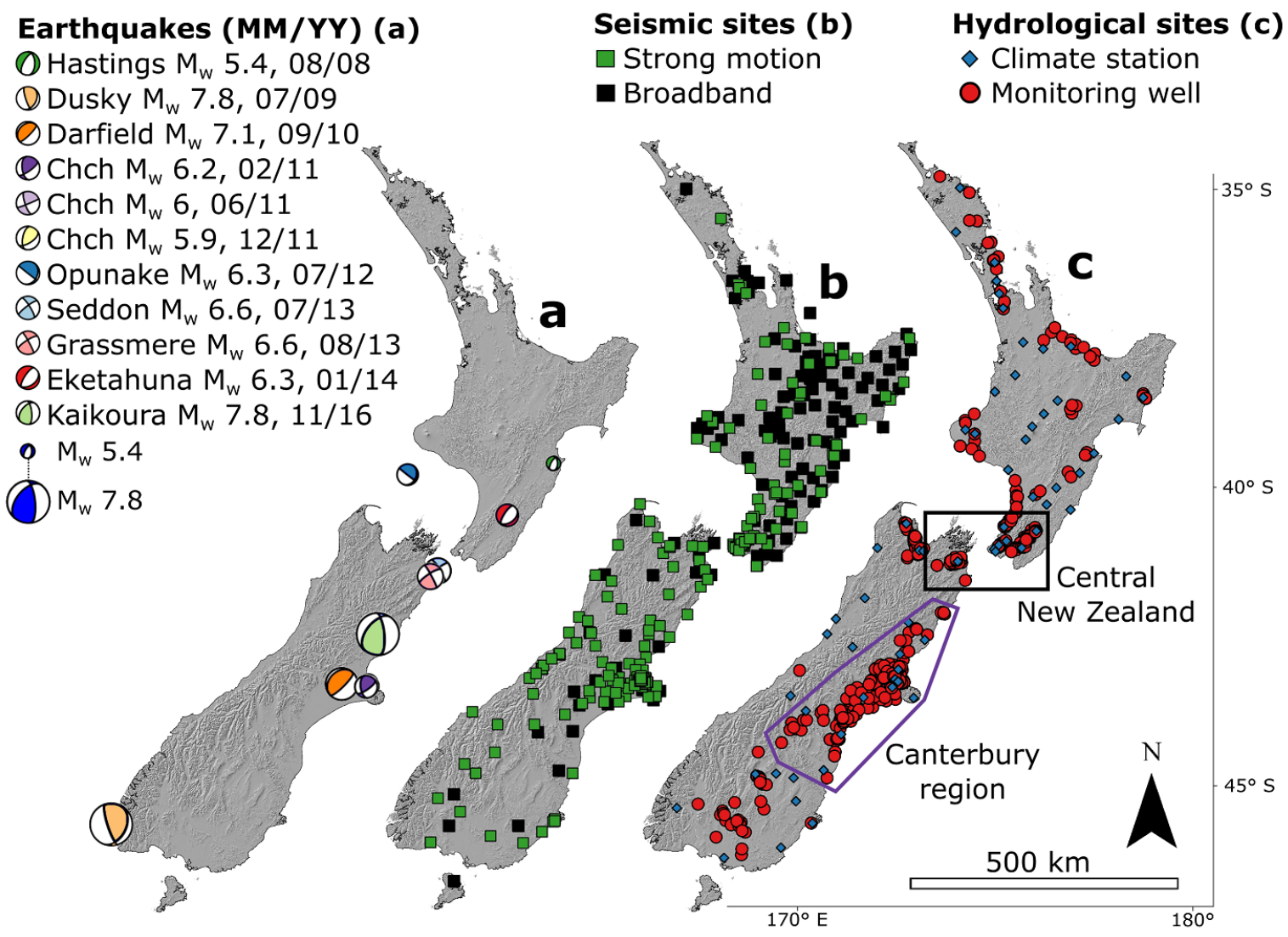

Figure 5.1: Spatial distribution of earthquakes, and seismic and hydrological sites: (a - Left) 11 earthquakes larger than $\mathrm{M}_{\mathrm{w}} 5.4$ between 2008 and 2017. At the scale of this map the Christchurch $\mathrm{M}_{\mathrm{w}} 6$ and 5.9 earthquakes are hidden beneath the $\mathrm{M}_{\mathrm{w}}$ 6.2 focal mechanisms stereonet. (b - Centre) 306 seismic stations (strong motion and broadband). (c - Right) 495 monitoring wells that recorded water-level data. 65 climate stations recorded atmospheric pressure. The Canterbury Region and Central New Zealand dataset monitoring wells are highlights. Chch $=$ Christchurch.

The monitoring wells were also classified with respect to their location relative to earthquake epicentres using the term "near-field" to denote wells within approximately one rupture fault length, and "intermediate-field" to reflect wells between one and ten rupture fault lengths away (cf. Wang and Manga, 2010a). The boundary between nearand intermediate-field generally occurs at a seismic energy density of around $10 \mathrm{~J} / \mathrm{m}^{3}$. Since the earthquake epicentres span much of the New Zealand plate boundary (Figure 5.1a), and monitoring wells are dispersed throughout the country, two proximity subsets were created: the Near-Field and the Intermediate-Field datasets. Monitoring well observations were also extracted in two regional subsets: Canterbury Region, and Central New Zealand (Table 5.2, Figure 5.1c). The dataset is available in the electronic supplement to this article. 
Table 5.2: Table of the responses and no responses observed in the All Data, Canterbury Region, Central New Zealand, Near-Field and Intermediate-Field datasets. The number of earthquakes and monitoring wells in each dataset are also included.

\begin{tabular}{cccccc} 
Datasets & Responses & No responses & Total & Earthquakes & Wells \\
\hline All Data & 1945 & 618 & 2563 & 11 & 495 \\
Canterbury Region & 1039 & 302 & 1341 & 11 & 224 \\
Central New Zealand & 814 & 224 & 1038 & 11 & 106 \\
Near-Field & 78 & 184 & 262 & 7 & 158 \\
Intermediate-Field & 1867 & 434 & 2301 & 11 & 468
\end{tabular}

\subsection{Methods}

\section{Logistic regression analysis}

Logistic regression models the probability of an event occurring, given a calibration dataset of binary occurrences of the event and predictors that influence the outcome. Logistic regression, models $\log$ (odds), where odds are defined as the ratio of the probability of an event occurring to the probability that it fails to occur, as a linear combination of a set of predictors (Kleinbaum and Klein, 2002). Logistic regression with random effects (LRRE) extends the standard logistic regression model by adding a set of random effects/disturbances on top of the fixed effects present in the standard model.

Here we define the probability $(P)$ of a persistent water-level change occurring or not $\left(Y_{i}=1\right.$ or 0 , respectively) with a number of independent predictors influencing the outcome. For the logistic regression model, let $i=1, \ldots, N$ be Bernoulli variables with probability distribution:

$$
P\left(Y_{i}=1 \mid \eta_{i}\right)=\frac{e^{\eta_{i}}}{1+e^{\eta_{i}}}, \quad \quad \eta_{i}=\overrightarrow{x_{i}} \vec{\beta}+z_{i} u
$$

where $\overrightarrow{x_{i}} \vec{\beta}$ are the fixed terms and $z_{i} u$ are the random effect terms. $\vec{\beta}$ are the fixed effects parameters associated with the predictors, $\overrightarrow{x_{i}}$. The $p$-vector $\overrightarrow{x_{i}}$ is the $i$ th row of the $\mathrm{N} \times p$ design matrix $\mathrm{X}$ which contains the predictor values. The $r$-vector $u$ contains the random effects, which follow a multivariate normal distribution with mean 0 and variance matrix $\sum$, and $z_{i}$ is the $i$ th row of the $\mathrm{N} \times r$ design matrix $Z$ which contains the predictors associated with the random effects. The random effects play the role of unmeasured covariates, modelling heterogeneity which is otherwise unexplained (Larsen et al., 2000). In this study, seismic and hydrogeological predictors, known for their association with the occurrence and/or the characteristics of water-level changes, were input into the LRRE model. The random effects represented the variable monitoring well susceptibility to persistent groundwater-level change. Predictors that 
had effects that were insignificantly different from zero ( $p$-value $>0.05$ ) were removed from the model. The models presented here are fit to the data by Maximum Likelihood Estimation.

These data could be modelled using an ordinal logistic regression with an outcome variable with a three-level classification of water-level change, distinguishing no change, increasing and decreasing persistent water-level responses. This approach was however deemed unsuitable because the majority of monitoring wells in the dataset were in the intermediate-field (Table 5.2), where permeability enhancement by dislodging colloids is thought to be predominate (Brodsky et al., 2003). At these epicentral distances, the polarity (increase/decrease) is purely random because permeability enhancement could occur up or down the hydraulic head gradient of the well (Wang and Chia, 2008). An alternative three-level classification would distinguish no change, transient and persistent responses. However, the distinction between persistent and transient water-level changes in this dataset was only observed at high levels of shaking. Thus, classification as a function of duration was also considered inappropriate. Although ordinal logistic regression is suitable in other hydrogeological disciplines (e.g. Twarakavi and Kaluarachchi, 2005), further research beyond the scope of this study is required to determine its suitability in the modelling of earthquake-induced water-level changes.

\section{Predictor selection}

The fixed effect predictors used in the logistic regression model can each be categorised as either seismic or hydrogeological. Five seismic and two hydrogeological predictors were included in the regression model.

Maximum peak ground velocity (PGV), was used as it represents the majority of energy in seismic ground motion (Wang, 2007), and is related to peak dynamic stress (Jaeger and Cook, 1979). Peak dynamic stress is suggested to control the incidence of processes that may cause water-level changes: shear-induced dilatation and consolidation (Luong, 1980; Dobry et al., 1982; Vucetic, 1994), and enhancement of vertical (e.g. Wang, 2007) and horizontal (e.g. Brodsky et al., 2003) permeability.

Horizontal (geometric mean) peak ground acceleration (PGA) was determined as it is used in the prediction of liquefaction (New Zealand Geotechnical Society, 2010; Bradley and Hughes, 2012), which can affect water-levels in surrounding aquifers (Roeloffs, 1998; Wang and Chia, 2008).

The maximum frequency of shaking was computed as low-frequency ground motions have been shown to be correlated with the occurrence of coseismic water-level changes and liquefaction, unlike high-frequency ground motions which show no correlation (Wong and Wang, 2007).

Seismic energy density was computed from magnitude and epicentral distance, as it may be compared to laboratory studies on the energy required for pore pressure 
change and liquefaction (Wang and Manga, 2010b). Furthermore, numerous international studies use seismic energy density to compare water-level responses between earthquakes (e.g. Shi et al., 2015b).

The epicentral distance was also calculated, as this parameter can be calculated even when no seismic shaking data are available. Although epicentral distance is not strictly a seismic parameter, it is a partial proxy for shaking intensity. Therefore, we referred to epicentral distance as a seismic predictor for simplicity and grouped it with the seismic shaking variables.

The amplitudes of water-level changes at intermediate-field distances are commonly larger than predicted by poroelastic theory (Manga and Wang, 2007). Furthermore, static stress changes induced by the two largest-magnitude earthquakes in the NearField dataset, the $2016 \mathrm{M}_{\mathrm{w}} 7.8$ Kaikoura earthquake, and the $2010 \mathrm{M}_{\mathrm{w}} 7.1$ Darfield earthquake (Zhan et al., 2011), have poor fits with observed water-level changes (Cox et al., 2012; Rutter et al., 2016). Therefore, we did not implement earthquake-induced static stress change as a predictor in the logistic regression model.

For each monitoring well analysed, the depth was included in the analysis as a proxy for the degree of aquifer confinement. Earthquake-induced water-level changes are more frequent and generally larger in confined aquifers compared to unconfined aquifers (Freeze and Cherry, 1979; Roeloffs, 1996; Gulley et al., 2013), and thus confinement is expected to partly control the occurrence/absence of persistent water-level changes.

Seismic waves filter and attenuate differently in different rock types (Wang and Manga, 2010a), with correspondingly varying efficiencies of dynamic shaking (Wang, 2007). Consolidated/crystalline lithologies amplify high-frequency shaking (Bradley, 2013), while unconsolidated media amplify low-frequency shaking (Wong and Wang, 2007; Youd and Carter, 2005). Considering that monitoring wells screened in consolidated/crystalline rocks respond to teleseismic earthquakes, at epicentral distance for which static and dynamic stress are insignificant, hydrogeological factors must partly control the occurrence of water-level changes. Therefore, at each monitoring well the site average shear-wave velocity between 0 and $30 \mathrm{~m}$ depth $\left(\mathrm{Vs}_{30}\right)$ was obtained (Horspool et al., 2015). We make an implicit assumption that $\mathrm{Vs}_{30}$ is an adequate proxy for rock strength at the monitoring well screen, as the depth of wells are generally shallow $(<100 \mathrm{~m})$ with a median depth of $\sim 22 \mathrm{~m}$. 


\section{Jackknife variance estimation}

Jackknife estimation provides a means of estimating the bias and variance of parameter estimates in situations where the assumptions of standard statistical theory may not hold (Tukey, 1958). The jackknife estimates a parameter of a population of interest from a random sample of data from the population. A sample estimate of the parameter can be formed from a function of the $N$ observations in the sample:

$$
T=f\left(Y_{1}, \ldots, Y_{i}, \ldots, Y_{N}\right)
$$

In jackknife estimation, each element is, in turn, dropped from the dataset and the parameter is re-estimated from the smaller sample size. An estimate of the parameter without the $i$ th observations is the $i$ th partial estimate $\left(T_{-i}\right)$ :

$$
T_{-i}=f\left(Y_{1}, \ldots, Y_{i-1}, Y_{i+1}, \ldots, Y_{N}\right)
$$

The jackknife estimate of $\theta\left(T^{*}\right)$ and its standard error $\left(\hat{\sigma} T^{*}\right)$, are defined as:

$$
\begin{gathered}
T^{*}=N T-(N-1) \bar{T} . \\
\hat{\sigma} T^{*}=(N-1) \frac{\hat{\sigma} T .}{\sqrt{N}}
\end{gathered}
$$

where $\bar{T}$. and $\hat{\sigma} T$. are respectively the mean and standard deviation of the set of $N$ partial estimates. The jackknife assumes that each observation is drawn independently and identically from the same distribution and the estimation function is linear in the data. Where observations are not independent, the jackknife is implemented by deleting complete groups of dependent observations in forming the partial estimates, and $N$ is replaced by the number of independent groups in the formulae above. We utilise the jackknife estimates to approximate the variability in the predictor coefficients of the LRRE models, when determined from a random sample of data from the datasets. 


\subsection{Results}

The All Data dataset contains a total of 2563 water-level time-series from 495 monitoring wells, recorded at epicentral distances of 1 to $913 \mathrm{~km}$ at the times of 11 earthquakes. Persistent water-level changes occurred in 618 instances, and non-persistent water-level changes occurred 1945 times (Figure 5.2, Table 5.2). Monitoring well depths range from 3 to $510 \mathrm{~m}$, with $\mathrm{Vs}_{30}$ spanning 40 to $1040 \mathrm{~m} / \mathrm{s}$. At the monitoring wells, PGV broadly varied from $10^{-5}$ to $10^{0} \mathrm{~m} / \mathrm{s}$, and PGA roughly varied from $10^{-5}$ to $10^{1} \mathrm{~m} / \mathrm{s}^{2}$. The maximum frequency of shaking occurred between 0.2 and $26 \mathrm{~Hz}$. Seismic energy density varied by ten orders of magnitude from $10^{-5}$ to $10^{5} \mathrm{~J} / \mathrm{m}^{3}$ (Figure 5.2).

There is poorer distinction between persistent and non-persistent responses as a function of the hydrogeological predictors, compared to the seismic predictors (Figure 5.2). Therefore, we assessed hydrogeological variation not described by depth and $\mathrm{Vs}_{30}$, by analysing pairs of closely wells (Table 5.3). For each monitoring well, we analysed data from all neighbouring wells within $100 \mathrm{~m}, 500 \mathrm{~m}$ and $1000 \mathrm{~m}$ radius that had a Vs 30 within $\pm 100 \mathrm{~m} / \mathrm{s}$ and depth within $\pm 10 \mathrm{~m}$ to the well of interest. At these small separations, and for similar depth and $\mathrm{Vs}_{30}$ conditions, seismic predictors could reasonably be assumed to be similar, and it is therefore reasonable to expect similar responses. For each pair of wells, the behaviour in response to each earthquake recorded in both wells was collected. The behaviour for each pair in each earthquake were grouped into three possible combinations.

Below the threshold of shaking required for a response $(\mathrm{PGV}<0.0064 \mathrm{~m} / \mathrm{s})$, all well pairs typically exhibited the same no response - no response combination. This is purely a function of insufficient seismic energy input and not hydrogeological consistency. Therefore, all pair behaviours below this threshold were removed from the subsequent analysis. In total, the consistency of responses to earthquakes in the remaining pairs of wells was high, being $90.2 \%$ for pairs within $100 \mathrm{~m}$ of each other, 89.1 $\%$ for pairs within $500 \mathrm{~m}$, and $81.1 \%$ for pairs within $1000 \mathrm{~m}$. We conclude from this that the depth and $\mathrm{Vs}_{30}$ are appropriate hydrogeological predictors of response. 


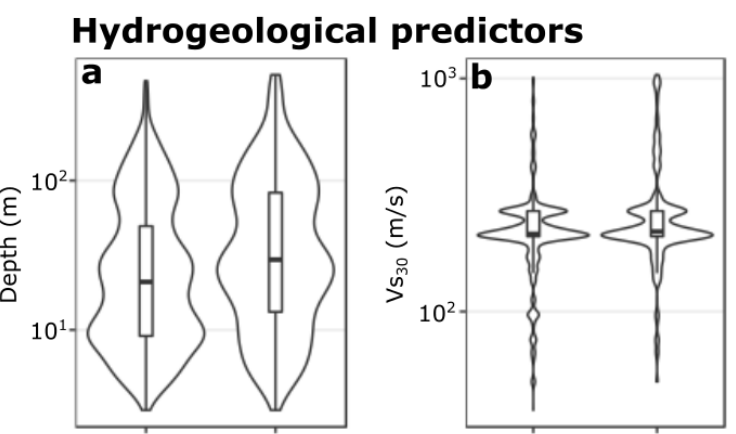

\section{Seismic predictors}
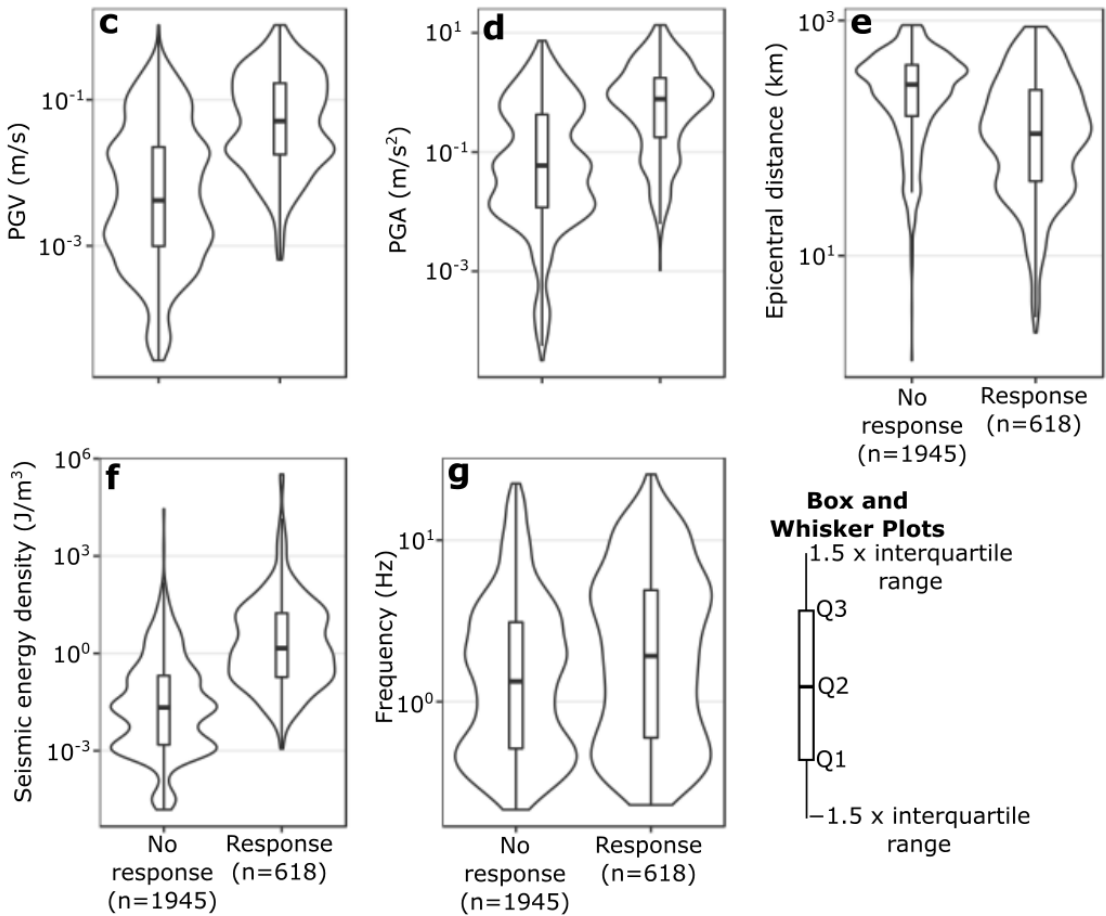

Figure 5.2: Violin plots of predictors when persistent and non-persistent water-level changes occurred, for the All Data dataset. Whisker limits are defined by Tukey (1977). ( $\mathrm{a}$ and b - Top) Hydrogeological predictors, (c, d, e, f, g - Middle-bottom) Seismic predictors. The violin plots contain vertically oriented kernel density plots showing the full distribution of the data, as well as box and whisker summaries.

Table 5.3: Pair analysis response combinations at a radius of $100 \mathrm{~m}, 500 \mathrm{~m}$ and 1000 m. Any Non-persistent - Non-persistent combinations were removed when maximum peak ground velocity $<0.0064 \mathrm{~m} / \mathrm{s}$, the threshold required for a persistent water-level change.

\begin{tabular}{cccccc}
$\begin{array}{c}\text { Radius } \\
(\mathbf{m})\end{array}$ & $\begin{array}{c}\text { Response } \\
\text { Response }\end{array}$ & $\begin{array}{c}\text { No Response } \\
\text { Response }\end{array}$ & $\begin{array}{c}\text { No Response } \\
\text { No Response }\end{array}$ & $\begin{array}{c}\text { Total } \\
\text { Consistency } \\
(\%)\end{array}$ \\
\hline 100 & 18 & 6 & 37 & 61 & 90.2 \\
500 & 32 & 14 & 82 & 128 & 89.1 \\
1000 & 51 & 43 & 134 & 228 & 81.1
\end{tabular}




\section{All seismic predictor model}

A logistic regression model with random effects was fitted to all five datasets (Table 5.2 ), with the five seismic and two hydrogeological predictors. As the predictors did not clearly distinguish between persistent and non-persistent responses (Figure 5.2), we introduced a random effect to account for each monitoring well's susceptibility to a persistent groundwater-level change. We refer to this model as the all seismic predictor model (ASPM; Table 5.4). All five datasets had at least one predictor that was insignificant.

Depth, $\mathrm{Vs}_{30}, \mathrm{PGV}, \mathrm{PGA}$, and seismic energy density each yielded positive coefficients, meaning that the larger the predictor value, the more likely a persistent waterlevel change would occur. As expected, epicentral distance generally had a negative coefficient, implying that the smaller the epicentral distance, the larger the likelihood of a persistent water-level change. However, in the Near-Field dataset, the epicentral distance coefficient was positive. Frequency had a positive coefficient in the Central New Zealand and Intermediate-Field datasets, but a negative coefficient in the Canterbury Region dataset. PGV was the only seismic predictor that was significant in all five datasets. The hydrogeological variables, depth and $\mathrm{Vs}_{30}$, were insignificant in at least one dataset (Table 5.4).

\section{One seismic predictor model}

For fair comparison between datasets, we created a second logistic regression model with random effects with the one seismic predictor that was significant in all datasets, PGV. We refer to this model as the one seismic predictor model (OSPM; Table 5.5). We also included depth and $\mathrm{Vs}_{30}$ as hydrogeological predictors, and random effects for each monitoring well's susceptibility to a persistent groundwater-level change. All three predictors had positive coefficients in all five datasets in the OSPM. PGV consistently had the largest coefficient, followed by depth and then $\mathrm{Vs}_{30}$. Depth and $\mathrm{Vs}_{30}$ were insignificant for the same datasets in the OSPM as previously observed in the ASPM (Table 5.4 and 5.5).

The Hosmer-Lemeshow test (Hosmer and Lemeshow, 2000) assesses the goodness of fit of a logistic regression model by comparing the predictive accuracy within dataset sub-populations. The Hosmer-Lemeshow test was carried out for all five datasets in the ASPM and OSPM. The p-values were $<0.05$ for all five datasets in the ASPM and OSPM indicating the model was a poor fit, except for the case of the Canterbury Region in the ASPM, and the Near-Field in the ASPM and OSPM (Table 5.4 and 5.5). 
Table 5.4: Mixed effects logistic regression results from the all seismic predictor model (ASPM) in the five data-sets. Fixed effect coefficient values and their corresponding p-values and standard errors are provided. Predictors that are insignificant $(\mathrm{p}>0.05)$ are identified by grey squares. These predictors were removed from the model and the results from the refitted models are shown here. The random effects standard deviation and Hosmer \& Lemeshow goodness of fit test are also provided. Coeff. = coefficient, SE $=$ standard error, St. Dev $=$ standard deviation, $\mathrm{df}=$ degrees of freedom, Sig. $=$ p-value.

\begin{tabular}{|c|c|c|c|c|c|c|c|c|c|c|c|c|c|c|c|c|}
\hline \multirow[b]{2}{*}{ Effects } & \multirow[b]{2}{*}{ Variable } & \multicolumn{3}{|c|}{ All Data } & \multicolumn{3}{|c|}{ Canterbury Region } & \multicolumn{3}{|c|}{ Central New Zealand } & \multicolumn{3}{|c|}{ Near-Field } & \multicolumn{3}{|c|}{ Intermediate-Field } \\
\hline & & Coeff. & p-value & SE & Coeff. & p-value & SE & Coeff. & p-value & $\mathbf{S E}$ & Coeff. & p-value & SE & Coeff. & p-value & SE \\
\hline \multirow{8}{*}{ 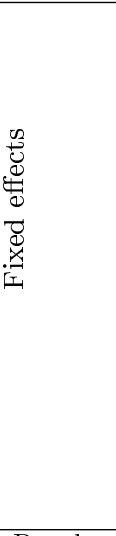 } & \multirow{2}{*}{$\begin{array}{l}\text { Intercept } \\
\text { Depth } \\
\text { (m) }\end{array}$} & -2.0002 & $<0.001$ & 0.1675 & -1.3154 & $<0.001$ & 0.2129 & -3.097 & $<0.001$ & 0.5123 & -1.3778 & 0.0047 & 0.4872 & -3.5247 & $<0.001$ & 0.1975 \\
\hline & & 0.0049 & $<0.001$ & 0.0011 & 0.0087 & $<0.001$ & 0.0016 & & & & 0.0096 & 0.0071 & 0.0036 & 0.0049 & $<0.001$ & 0.0013 \\
\hline & \multirow{6}{*}{$\begin{array}{l}\mathrm{Vs}_{30} \\
(\mathrm{~m} / \mathrm{s}) \\
\mathrm{PGV} \\
(\mathrm{m} / \mathrm{s}) \\
\mathrm{PGA} \\
\left(\mathrm{m} / \mathrm{s}^{2}\right) \\
\text { Epicentral } \\
\text { distance }(\mathrm{km}) \\
\text { Seismic energy } \\
\text { density }\left(\mathrm{J} / \mathrm{m}^{3}\right) \\
\text { Frequency } \\
(\mathrm{Hz})\end{array}$} & 0.0033 & $<0.001$ & 0.0005 & & & & 0.0041 & 0.0013 & 0.0013 & & & & 0.0035 & $<0.001$ & 0.0005 \\
\hline & & 7.7886 & $<0.001$ & 0.7029 & 7.7237 & $<0.001$ & 0.9829 & 15.3049 & $<0.001$ & 2.5634 & 5.4822 & $<0.001$ & 1.2846 & 7.8796 & $<0.001$ & 1.0527 \\
\hline & & & & & & & & 0.7897 & $<0.001$ & 0.2113 & & & & & & \\
\hline & & -0.0027 & $<0.001$ & 0.0003 & -0.0033 & $<0.001$ & 0.0006 & -0.0032 & 0.0017 & 0.001 & 0.0156 & 0.0031 & 0.0053 & & & \\
\hline & & & & & & & & 0.1621 & $<0.001$ & 0.0424 & & & & 0.3073 & $<0.001$ & 0.035 \\
\hline & & & & & -0.1315 & 0.0006 & 0.0384 & 0.0843 & $<0.001$ & 0.0235 & & & & 0.0904 & $<0.001$ & 0.0157 \\
\hline \multicolumn{2}{|c|}{ Random effects: St. Dev } & \multicolumn{3}{|c|}{0.8076} & \multicolumn{3}{|c|}{0.5386} & \multicolumn{3}{|c|}{1.1522} & \multicolumn{3}{|c|}{$4.008 \mathrm{E}-14$} & \multicolumn{3}{|c|}{1.0716} \\
\hline \multicolumn{2}{|c|}{ Lemeshow test } & $\begin{array}{c}\chi^{2} \\
75.69\end{array}$ & $\begin{array}{c}\mathrm{df} \\
8\end{array}$ & $\begin{array}{l}\text { Sig. } \\
<0.001\end{array}$ & $\begin{array}{c}\chi^{2} \\
16.5\end{array}$ & $\begin{array}{c}\mathrm{df} \\
8\end{array}$ & $\begin{array}{l}\text { Sig. } \\
0.0357\end{array}$ & $\begin{array}{c}\chi^{2} \\
29.56\end{array}$ & $\begin{array}{c}\mathrm{df} \\
8\end{array}$ & $\begin{array}{l}\text { Sig. } \\
<0.001\end{array}$ & $\begin{array}{c}\chi^{2} \\
6.84\end{array}$ & $\begin{array}{c}\mathrm{df} \\
8\end{array}$ & $\begin{array}{l}\text { Sig. } \\
0.5544\end{array}$ & $\begin{array}{c}\chi^{2} \\
80.45\end{array}$ & $\begin{array}{c}\mathrm{df} \\
8\end{array}$ & $\begin{array}{c}\text { Sig. } \\
<0.001\end{array}$ \\
\hline
\end{tabular}


Table 5.5: Mixed effects logistic regression results from the one seismic predictor model (OSPM) in the five data-sets. Fixed effect coefficient values and their corresponding p-values and standard errors are provided. Predictors that are insignificant $(\mathrm{p}>0.05)$ are identified by grey squares. These predictors were removed from the model and the results from the refitted models are shown here. The random effects standard deviation and Hosmer \& Lemeshow goodness of fit test are also provided. Coeff. $=$ coefficient, SE $=$ standard error, St. Dev $=$ standard deviation, $\mathrm{df}=$ degrees of freedom, Sig. $=\mathrm{p}$-value.

\begin{tabular}{|c|c|c|c|c|c|c|c|c|c|c|c|c|c|c|c|c|}
\hline \multirow[b]{2}{*}{ Effects } & \multirow[b]{2}{*}{ Variable } & \multirow{2}{*}{\multicolumn{2}{|c|}{$\begin{array}{c}\text { All Data } \\
\text { p-value }\end{array}$}} & \multirow[b]{2}{*}{ SE } & \multicolumn{3}{|c|}{ Canterbury Region } & \multicolumn{3}{|c|}{ Central New Zealand } & \multicolumn{3}{|c|}{ Near-Field } & \multicolumn{3}{|c|}{ Intermediate-Field } \\
\hline & & & & & Coeff. & p-value & SE & Coeff. & p-value & SE & Coeff. & p-value & SE & Coeff. & p-value & SE \\
\hline \multirow{4}{*}{ Fixed } & \multirow{4}{*}{$\begin{array}{l}\text { Intercept } \\
\text { Depth } \\
(\mathrm{m}) \\
\text { Vs30 } \\
(\mathrm{m} / \mathrm{s}) \\
\mathrm{PGV} \\
(\mathrm{m} / \mathrm{s}) \\
\end{array}$} & -2.6032 & $<0.001$ & 0.1453 & -2.4214 & $<0.001$ & 0.135 & -2.5207 & $<0.001$ & 0.2616 & -0.2031 & 0.4504 & 0.2691 & -2.866 & $<0.001$ & 0.1644 \\
\hline & & 0.0043 & $<0.001$ & 0.001 & 0.008 & $<0.001$ & 0.0015 & & & & 0.0086 & 0.0136 & 0.0035 & 0.0043 & $<0.001$ & 0.0012 \\
\hline & & 0.0026 & $<0.001$ & 0.0004 & & & & 0.0031 & 0.0012 & 0.001 & & & & 0.003 & $<0.001$ & 0.0005 \\
\hline & & 10.1689 & $<0.001$ & 0.6532 & 9.6359 & $<0.001$ & 0.7323 & 17.8762 & $<0.001$ & 2.026 & 3.2938 & $<0.001$ & 0.9308 & 10.0498 & $<0.001$ & 0.9713 \\
\hline \multirow{2}{*}{\multicolumn{2}{|c|}{$\begin{array}{c}\text { Random: St.Dev } \\
\text { Hosmer \& }\end{array}$}} & \multicolumn{3}{|c|}{0.7235} & \multicolumn{3}{|c|}{0.4485} & \multicolumn{3}{|c|}{0.7582} & \multicolumn{3}{|c|}{0} & \multicolumn{3}{|c|}{0.919} \\
\hline & & $\begin{array}{c}\chi^{2} \\
119.09\end{array}$ & $\begin{array}{l}\mathrm{df} \\
8\end{array}$ & $\begin{array}{c}\text { Sig. } \\
<0.001\end{array}$ & $\begin{array}{c}\chi^{2} \\
39.67\end{array}$ & $\begin{array}{l}\mathrm{df} \\
8\end{array}$ & $\begin{array}{c}\text { Sig. } \\
<0.001\end{array}$ & $\begin{array}{c}\chi^{2} \\
54.64\end{array}$ & $\begin{array}{c}\mathrm{df} \\
8\end{array}$ & $\begin{array}{c}\text { Sig. } \\
<0.001\end{array}$ & $\begin{array}{c}\chi^{2} \\
11.43\end{array}$ & $\begin{array}{l}\mathrm{df} \\
8\end{array}$ & $\begin{array}{c}\text { Sig. } \\
0.1784\end{array}$ & $\begin{array}{c}\chi^{2} \\
10854\end{array}$ & $\begin{array}{l}\mathrm{df} \\
8\end{array}$ & Sig. \\
\hline
\end{tabular}


The Akaike Information Criterion (AIC; Burnham and Anderson, 2004) is a relative measure of model fit, with a lower value indicating a better model. The AIC allows comparison between different models estimated on the same dataset, and was computed for all five datasets in the ASPM and OSPM. The AIC was better for the ASPM, compared to the OSPM, for all five datasets. The more predictors removed when transferring from the ASPM to the OSPM, the worse the AIC became (Table 5.8).

The receiver operating characteristic curve (ROC) is a graphical diagnostic test which examines a model's ability to discriminate between binary outputs at all classification thresholds (e.g. Peres and Cancelliere, 2014). The area under the ROC curve (AUC) is a cumulative measure of performance across all classification thresholds. An AUC value of 1 indicates perfect classification, whereas an AUC of 0.5 indicates a classification performing no better than chance. The ROC and the associated AUC value were calculated for the OSPM (Figure 5.3) for all five datasets. Based on the AUC, the OSPM applied to the Intermediate-Field dataset had the best overall ability to discriminate between the presence and absence of persistent water-level changes (AUC 0.87). The second-best performance of the OSPM was with the All Data dataset, followed by Central New Zealand and Canterbury Region (Figure 5.3). The OSPM performed significantly worse in the Near-Field than in any of the other datasets (AUC 0.667).

We considered whether our results could be biased by the statistically small number of earthquakes, and that the parameter estimates might be dependent on which events were included. Therefore, to test the robustness of the coefficient estimates derived from the OSPM, we computed two sets of jackknife estimates of the model parameters for each dataset. The first set of jackknife estimates were calculated by removing all observations associated with each earthquake in turn (Table 5.6), and the second set by removing all observations associated with each monitoring well in turn (Table 5.7). As might be expected, the removal of individual earthquakes had a much larger effect than the removal of individual wells: the derived biases and standard errors were larger in the earthquake removal estimates than in the well removal estimates. Generally, there was little variation in the distribution of the partial estimates. 


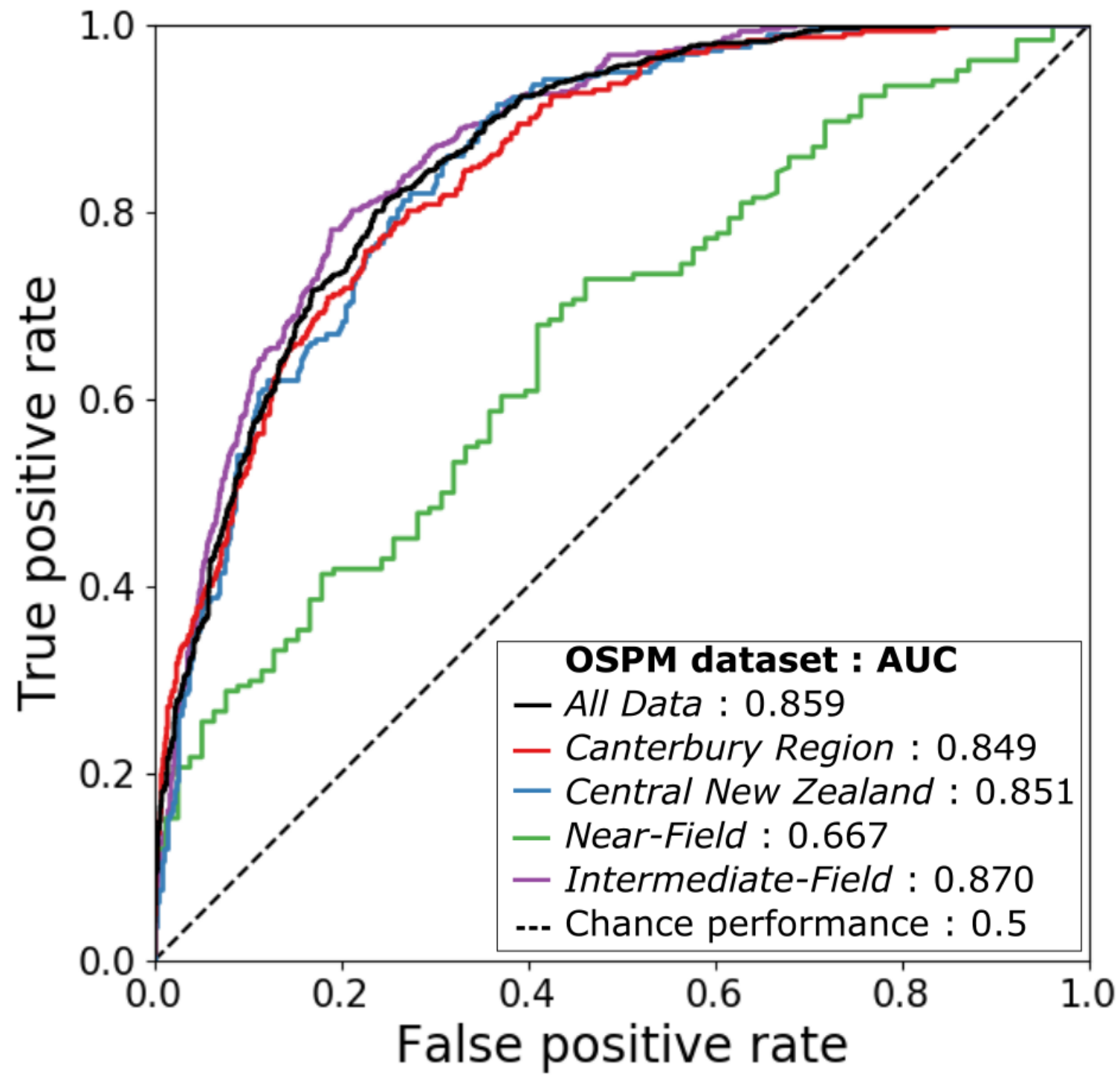

Figure 5.3: The receiver operating characteristic curve (ROC) for the five datasets in the one seismic predictor model (OSPM). The area under the ROC curve (AUC) is shown in the legend. The Intermediate-Field dataset has the best overall ability to discriminate between the presence and absence of persistent water-level changes. All datasets lie significantly above the chance performance line, suggesting the use of seismic and hydrogeological predictors in the OSPM are beneficial. 
Table 5.6: Jackknife estimates by the removal of earthquakes, from the one seismic predictor model (OSPM) in the five data-sets. Predictors that are insignificant $(\mathrm{p}>0.05)$ are identified by grey squares and don't have a jackknife estimate. J est. = jackknife estimate of coefficient, Bias $=$ OSPM coefficient - jackknife estimate of coefficient, J SE = jackknife estimate standard error.

\begin{tabular}{|c|c|c|c|c|c|c|c|c|c|c|c|c|c|c|c|}
\hline \multirow[b]{2}{*}{ Variable } & \multicolumn{3}{|c|}{ All Data } & \multicolumn{3}{|c|}{ Canterbury Region } & \multicolumn{3}{|c|}{ Central New Zealand } & \multicolumn{3}{|c|}{ Near-Field } & \multicolumn{3}{|c|}{ Intermediate-Field } \\
\hline & J est. & Bias & J SE & J est. & Bias & J SE & J est. & Bias & J SE & J est. & Bias & J SE & J est. & Bias & J SE \\
\hline Intercept & -2.6031 & -0.0001 & 0.3842 & -2.2563 & 0.1651 & .5701 & -2.5859 & 0.0652 & 0.3248 & .0010 & -0.2041 & 0.58 & -2.964 & 0.0980 & 0.2644 \\
\hline Dep & 0.0047 & -0.0003 & 0.0008 & 0.008 & 0 & 0.0012 & & & & 0.0086 & 0 & 0.0069 & 0.0052 & -0 . & 0.0009 \\
\hline $\mathrm{Vs}_{3}$ & 0.0029 & -0.0002 & 0.0002 & & & & & -0.0 & & & & & 0.0033 & -0.0003 & 0.0002 \\
\hline $\operatorname{PGV}(\mathrm{m} / \mathrm{s})$ & 10.6551 & -0.4862 & 2.0414 & 9.4077 & 0.2283 & 2.8028 & 15.6220 & 2.2542 & 6.1973 & 2.7512 & 0.5425 & 1.6353 & 12.4982 & -2.4484 & 5.5924 \\
\hline
\end{tabular}

Table 5.7: Jackknife estimates by the removal of monitoring wells, from the one seismic predictor model (OSPM) in the five data-sets. Predictors that are insignificant $(\mathrm{p}>0.05)$ are identified by grey squares and don't have a jackknife estimate. J est. = jackknife estimate of coefficient, Bias $=$ OSPM coefficient - jackknife estimate of coefficient, J SE $=$ jackknife estimate standard error.

\begin{tabular}{|c|c|c|c|c|c|c|c|c|c|c|c|c|c|c|c|}
\hline \multirow[b]{2}{*}{ Variable } & \multicolumn{3}{|c|}{ All Data } & \multicolumn{3}{|c|}{ Canterbury Region } & \multicolumn{3}{|c|}{ Central New Zealand } & \multicolumn{3}{|c|}{ Near-Field } & \multicolumn{3}{|c|}{ Intermediate-Field } \\
\hline & J est. & Bias & J SE & J est. & Bias & J SE & J est. & Bias & J SE & J est. & Bias & J SE & J est. & Bias & J SE \\
\hline Intercept & -2.5915 & -0.0117 & 0.1385 & -2.4065 & -0.0149 & 0.1266 & -2.4563 & -0.0644 & 0.3339 & -0.1417 & -0.0614 & 0.4428 & -2.7658 & -0.1002 & 0.0972 \\
\hline Dep & 0.0043 & 0 & 0.0009 & 0.0079 & 0.0001 & 0.0015 & & & & 0.0067 & 0.0019 & 0.0062 & 0.004 & 0.0003 & 0.0006 \\
\hline $\mathrm{Vs}$ & 26 & 0 & 004 & & & & & & & & & & 0.0029 & 0.0001 & 0.0003 \\
\hline $\mathrm{PGV}(\mathrm{m} / \mathrm{s})$ & 10.1109 & 0.0580 & 0.8271 & 9.5577 & .0783 & 0.8912 & 17.6086 & 0.2676 & 2.333 & 3.1303 & 0.1634 & 1.2523 & 9.5225 & 0.5273 & 0.8938 \\
\hline
\end{tabular}




\subsection{Discussion}

The multi-earthquake multi-site data compiled in this study included a wide range of earthquakes (Table 5.1), seismic shaking characteristics, and hydrogeological conditions (Figure 5.2). In addition, the data was split by proximity to earthquake epicentre (Near-Field and Intermediate-Field), and by region (Canterbury Region and Central New Zealand; Table 5.2).

Pair analysis (Table 5.3) showed that responses were generally consistent for similar degrees of confinement and rock type. This suggested that the hydrogeological variables depth and $\mathrm{Vs}_{30}$, are appropriate predictors of the local hydrogeological factors that partly contribute to the occurrence of persistent water-level change.

\section{All seismic predictor model}

The significance of the seismic predictors and the value of the associated coefficients in the ASPM varied between the five datasets, likely because each earthquake had unique shaking characteristics. PGV, PGA and seismic energy density had positive coefficients, meaning as anticipated that higher shaking intensities result in more frequent, larger-amplitude, persistent water-level changes (Manga and Wang, 2007). Epicentral distance had negative coefficients for most of the datasets as expected (Wang and Manga, 2010b). However, in the Near-Field dataset the epicentral distance coefficient was positive, perhaps reflecting the small range in values in this data. Frequency had both positive and negative coefficients, consistent and inconsistent with observations found by Wong and Wang (2007).

$\mathrm{Vs}_{30}$ had a positive coefficient (Table 4), suggesting that the stronger the rock, the more likely a persistent water-level change would occur. This is consistent with the observation that sites screened in crystalline or well-consolidated rocks can incur water-level changes in response to even teleseismic earthquakes (Brodsky et al., 2003; Shi et al., 2014; Weingarten and Ge, 2014; Zhang et al., 2015). Vsso may not have had a significant coefficient in the Canterbury Region dataset due to a limited range of rock types present in the alluvial-gravel dominated Canterbury region, in comparison to central New Zealand and regions characterised in the $2016 \mathrm{M}_{\mathrm{w}} 7.8$ Kaikōura earthquake. $\mathrm{Vs}_{30}$ may also have not been a significant coefficient in the Near-Field dataset as seismic shaking levels were high enough that rock type became irrelevant. Depth had a positive coefficient (Table 5.4), indicating that monitoring wells screened in deeper confined aquifers had a larger probability of having a persistent water-level change than shallow unconfined aquifers. This concurs with observations of larger water-level change in more confined aquifers (Stearns, 1928; Eaton and Takasaki, 1959; Roeloffs, 1996; Gulley et al., 2013) and is unsurprising given that the storativity of confined aquifers is lower than that of unconfined aquifers (Freeze and Cherry, 1979). 


\section{One seismic predictor model}

PGV, depth and $\mathrm{Vs}_{30}$ had positive coefficients in the OSPM, consistent with the ASPM and were significant in the same datasets (Table 5.5). In the All Data and IntermediateField dataset, where all predictors were significant, the largest coefficient was PGV, followed by depth, then $\mathrm{Vs}_{30}$. This suggested that the level of shaking is the most influential factor in determining whether a persistent water-level change occurs, followed by degree of confinement, then rock strength.

The ROC and AUC analysis (Figure 5.3) identifies the Near-Field dataset OSPM as the poorest model in discriminating between the presence and absence of persistent water-level changes. This is likely due to the small dataset available (Table 5.2), which in part reflects the high levels of shaking in the near-field that damaged monitoring well infrastructure (Zemansky et al., 2012). The ROC and AUC analysis shows that the remaining four datasets have a similar ability to discriminate between the presence and absence of persistent water-level changes, with the Intermediate-Field dataset performing the best.

The jackknife estimates demonstrated that the predictor coefficients vary minimally with the removal of individual earthquakes and monitoring wells (Table 5.6 and 5.7). This suggests there is no highly discordant earthquakes or monitoring wells. The jackknife estimates vary more with removal of earthquakes than monitoring wells, partly due to the removal of more data with each iteration. The All Data OSPM generally had the best jackknife estimates on the basis of having the largest dataset. Furthermore, the Hosmer-Lemeshow test suggested the OSPM poorly fit the datasets (Table $5.5)$.

\section{Marginal probabilities}

Although the OSPM did not fully account for the presence/absence of earthquakeinduced persistent water-level changes, it is the most parsimonious model developed here that accounts for both the occurrence and non-occurrence of groundwater-level changes within the logistic regression framework. The marginal probabilities of persistent water-level changes occurring were calculated using the OSPM (Equation 5.5, Table 5.5), taking into consideration evenly spaced samples of PGV within the range experienced. The interquartile range was determined by the original variation of depth and $\mathrm{Vs}_{30}$ within the datasets and their corresponding OSPM coefficients, with the lower bound defined by shallow unconfined aquifers in weak rock, and the higher bound defined by deeper confined aquifers in hard rock (Figure 5.4).

Considering the jackknife estimation determined the All Data OSPM to have the most stable predictor coefficients (Table 5.6 and 5.7), we mapped the associated marginal probability PGV values to the empirical MM scale (Gerstenberger et al., 2007). The 
marginal probabilities of persistent water-level changes occurring at a range of intensities on the New Zealand MM scale, and at sites with differing hydrogeological characteristics, are included in Table 5.9. For each MM intensity probability, we adopted verbal likelihood terms from Budescu et al. (2014). The terms are: Virtually certain (>99\%), Very likely (>90\%), Likely (>66\%), About as likely as not $(33 \%-66 \%)$, Unlikely $(<33 \%)$, Very unlikely $(<10 \%)$, Exceptionally unlikely $(<1 \%)$. The range of likelihoods of persistent water-level changes were calculated for MM II to VIII. At MM V and below, water-level changes are very unlikely to about as likely as not. At MM VI, water-level changes are unlikely to about as likely as not. At MM VII, waterlevel changes are unlikely to likely. At MM VIII, the likelihood rises to very likely to virtually certain. As the water-level changes become more frequent, the severity of the response increases in terms of amplitude and duration. At MM VII and below, water-level changes may only occur in sensitive monitoring wells, have small amplitudes $(<1 \mathrm{~m})$ and persist for days. At MM VIII and above, water-level changes may have large amplitudes $(>1 \mathrm{~m})$, and persist for weeks to months. Changes may represent permanent aquifer change (Rutter et al., 2016), and damage may occur to water infrastructure (Zemansky et al., 2012). In the same manner as Hancox et al. (2002), who incorporated earthquake-induced landslides into the New Zealand MM scale, we propose further additions to the environmental response criteria (Table 5.9).

The additional environmental response criteria may assist seismic hazard assessment during future earthquakes. The probabilistic framework could inform practitioners in decision-making processes for increasing the resilience of water supply infrastructure to earthquake-induced shaking, aquifer pollution, turbidity increases, and geochemical changes (e.g. Roeloffs et al., 1995; Zemansky et al., 2012). As site effects were included within the assessment, GIS could be used to predict how susceptible different parts of New Zealand are to groundwater-level changes. This would be the first step towards formulating a groundwater-level change susceptibility model for common earthquake events in New Zealand, akin to models for landslides (Smith et al., 2001). The additional environmental criteria could also provide MM reporting in areas where few buildings are present (Hancox et al., 2002).

Classification of earthquake effects according to the degree of shaking intensity facilitates comparison of the effects of multiple earthquakes (Eiby, 1966). A number of changes have been made to the New Zealand Modified Mercalli (MM) scale (Eiby, 1966), the first of which was making the scale more appropriate for modern earthquake resistant construction (Smith et al., 1992). Later on, revisions improved the structural damage criteria (Dowrick, 1996). Environmental response criteria were considered in detail in subsequent studies, with the inclusion of landsliding- and liquefaction-related ground damage (Hancox et al., 1997). Because there are few international papers on MM intensity and earthquake-induced groundwater-level changes (Cox et al., 2012), groundwater level changes have yet to be established in the New Zealand or other MM 
scales.

This study was the first attempt we are aware that incorporates both seismic and hydrogeological factors into a probabilistic framework for earthquake-induced groundwater level changes in the context of the MM scale. The key difference and contribution of this study is that it is a regional-scale multi-site multi-earthquake investigation that includes the occurrence and absence of responses, over a decade of seismic shaking. The advantage of this approach is that responses can be examined in a range of aquifers, rock types and hydrogeological settings. Furthermore, responses can be recorded in the near- and intermediate-field at the same site, induced by a range of shaking intensities. As a result, site effects and shaking characteristics can be normalised/calibrated. This then enables the precise identification of responses and mechanisms that are anomalous or merely local aberrations, from those that underpin region-wide processes and are likely to be applicable and significant internationally.

Although the predictor coefficients may have inaccuracies due to uniqueness of earthquakes and monitoring wells, the study highlights that shaking intensity, degree of confinement and rock strength are important. The inclusion of shaking and site effects within the framework is a novel and more generalizable approach to quantifying responses than previous metrics using epicentral distance, magnitude and seismic energy density (Wang and Manga, 2010b). It has potential to enable better comparison of international studies and inform practitioners making decisions around investment to mitigate risk to, and to increase the resilience of, water supply infrastructure. 

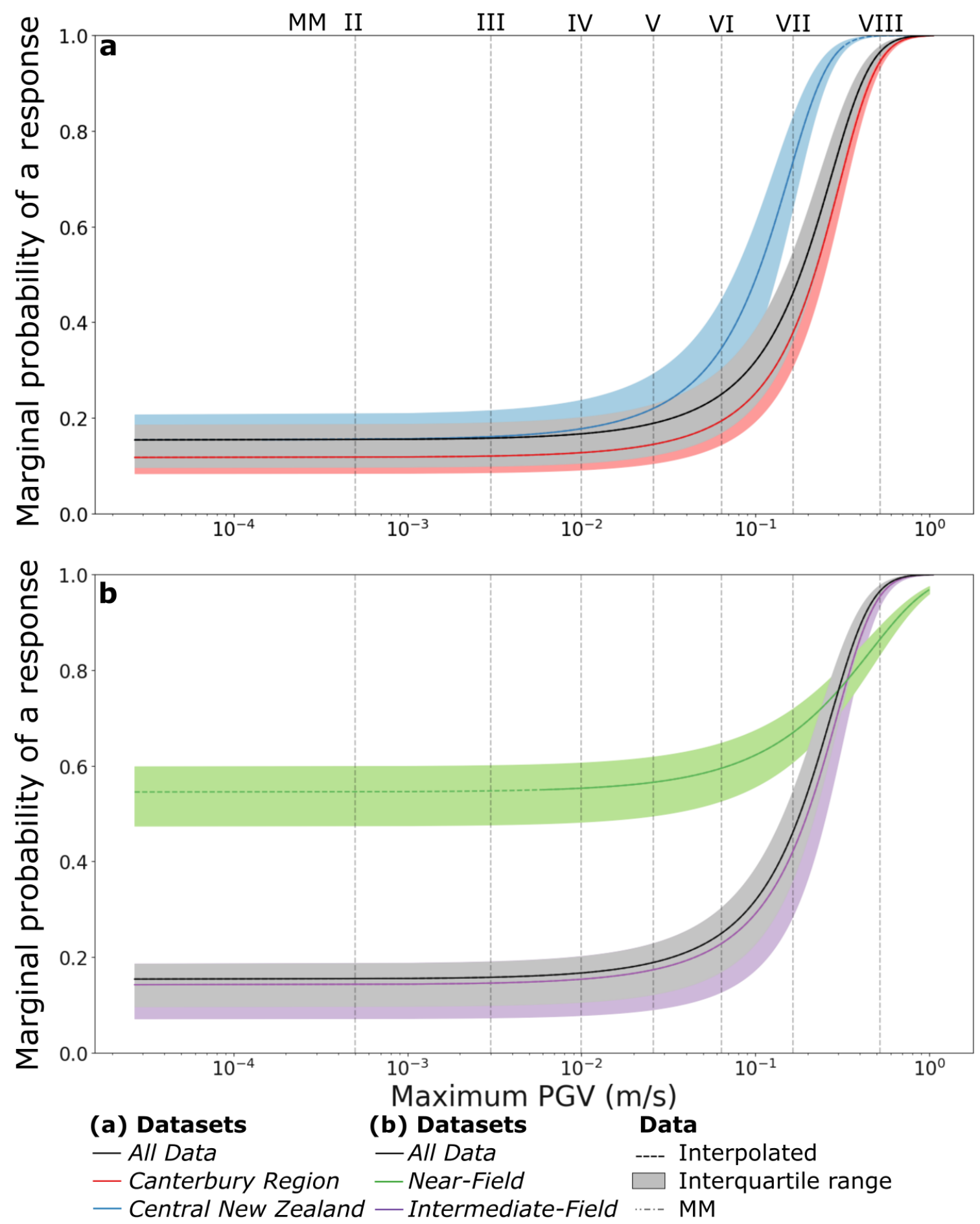

Figure 5.4: Marginal probabilities of persistent water-level changes given maximum $\mathrm{PGV}$, depth and $\mathrm{Vs}_{30}$, for all five datasets. Coefficients for the predictors are from the one seismic predictor model (OSPM; Table 5.5). The Modified Mercalli scale (MM) is converted from PGV for reference (Gerstenberger et al., 2007). (a - Top) All Data, Canterbury Region and Central New Zealand datasets. (b - Bottom) All Data, NearField and Intermediate-Field datasets. 


\section{Future work}

A comparison of the OSPM predictor coefficients in the Near-Field and IntermediateField datasets should allow an assessment of the thresholds for the different processes thought to occur in the near- and intermediate-field (Wang and Manga, 2010a). However, the limited Near-Field dataset available at this stage precludes a thorough analysis. The collection of additional near-field data would yield a more robust comparison. Comparison of the OSPM predictor coefficients in the Canterbury Region and Central New Zealand datasets were problematic as the distribution of earthquake epicentres relative to the two regions differed. The Canterbury Region dataset had more near-field earthquakes, due to the proximity of the Canterbury earthquake sequence of 2010-2011. The only near-field earthquakes in the Central New Zealand dataset were those of the Cook Strait earthquake sequence of 2013. The predictor coefficients may thus have varied significantly as a result of changing seismic inputs. Nonetheless, we emphasise that future datasets may elucidate regional influences on water-level changes (e.g. Shi et al., 2015a), and thus permit the construction of local groundwater-level change susceptibility models.

The New Zealand dataset presented here may not be representative of other seismic settings elsewhere. The OSPM developed here does not convey all of the signal within the dataset, but we anticipate its improvement by building and integrating international catalogues. More detailed studies of earthquakes are needed to refine the proposed environmental response criteria. Comprehensive studies have been undertaken elsewhere (e.g. Shi et al., 2015a), yet the degree to which such studies have consistently recorded the non-occurrence of water-level changes is not well known. The seismic and hydrogeological diversity of international studies will improve the accuracy of the predictor coefficients and provide a more representative probability range at varying shaking intensities. The incorporation of lower-magnitude earthquakes is critical in the development of the criteria. In an ideal model, the probability of a response occurring at a PGV of $0 \mathrm{~m} / \mathrm{s}$ should be zero. Due to the paucity of low-magnitude earthquakes in this study, the probability is finite (Figure 5.4). With the addition of lower-magnitude earthquakes in further work, the probability of a response occurring at low seismic shaking intensities will tend towards zero, and predictor coefficients will

Table 5.8: Akaike Information Criterion (AIC) for the all seismic predictor model (ASPM) and the one seismic predictor model (OSPM) within the logistic regression with random effects (LRRE).

\begin{tabular}{cccccc} 
LRRE & $\begin{array}{c}\text { All } \\
\text { model }\end{array}$ & $\begin{array}{c}\text { Canterbury } \\
\text { Data }\end{array}$ & $\begin{array}{c}\text { Central } \\
\text { Region }\end{array}$ & $\begin{array}{c}\text { Near- } \\
\text { New Zealand }\end{array}$ & $\begin{array}{c}\text { Field } \\
\text { Intermediate- } \\
\text { Field }\end{array}$ \\
\hline ASPM & 2319 & 1106 & 802 & 297 & 1873 \\
OSPM & 2386 & 1146 & 956 & 305 & 1992
\end{tabular}


Table 5.9: Susceptibility assessment showing the range of likelihoods for persistent water-level changes at different levels of Modified Mercalli scales (MM) and PGV. Mean probabilities are calculated from the OSPM for the All data dataset. Likelihood terms are adopted from Budescu et al. (2014). perc. = percentile.

\begin{tabular}{cl|lll|c|} 
& & \multicolumn{2}{|c|}{ Likelihood of response } & \\
MM & $\begin{array}{c}\mathbf{P G V} \\
\mathbf{( m / s )}\end{array}$ & $\begin{array}{c}\mathbf{5}^{\text {th }} \\
\text { perc. }\end{array}$ & Mean & $\begin{array}{l}\text { (th } \\
\text { perc. }\end{array}$ & Verbal likelihood term \\
\hline II & 0.0005 & 7.1 & 15.5 & 33.5 & very unlikely -about as likely as not \\
III & 0.003 & 7.2 & 15.8 & 34.1 & very unlikely -about as likely as not \\
IV & 0.01 & 7.7 & 16.7 & 35.7 & very unlikely -about as likely as not \\
V & 0.026 & 9.0 & 18.9 & 39.6 & very unlikely -about as likely as not \\
VI & 0.064 & 12.7 & 25 & 49.1 & unlikely -about as likely as not \\
VII & 0.165 & 28.8 & 46.2 & 72.9 & unlikely -likely \\
VIII & 0.522 & 93.9 & 96.6 & 99.0 & very likely - virtually certain
\end{tabular}

become increasingly accurate.

\subsection{Conclusions}

A probabilistic model has been constructed for groundwater response as a function of PGV and hence the Modified Mercalli (MM) intensity, by quantifying the occurrence and absence of persistent groundwater-level changes in 495 monitoring wells to one or more of 11 New Zealand earthquakes larger than $M_{w}$ 5.4, between 2008 and 2017. The key difference and contribution of this study is that it is a regional-scale multi-site multi-earthquake investigation that includes the occurrence and absence of responses, over a long period of time. The approach has enabled responses to be examined in a range of aquifers, rock types and hydrogeological settings. Furthermore, responses can be recorded in the near- and intermediate-field at the same site, subjected to a range of shaking intensities. In addition to examining an All Data dataset, the methodology was applied to four data subsets, defined by region and proximity to earthquakes: Canterbury Region; Central New Zealand; Near-Field; and Intermediate-Field.

We first applied a binary logistic regression model with random effects (LRRE) to five subsets of the data with seven seismic and hydrogeological predictors, in a model referred to as the all seismic predictor model (ASPM). Random effects were included as a partial proxy for variations in monitoring wells' susceptibilities to earthquake-induced persistent water-level change. The significance of the predictors and the values of the associated coefficients in the ASPM varied between the five datasets, likely because each earthquake had distinct shaking properties.

A second and preferred model, referred to as the one seismic predictor model (OSPM), was computed with three predictors: PGV, depth and $\mathrm{Vs}_{30}$. Post-hoc analysis reveals that the models of our datasets were generally capable of discriminating the occurrence or absence of water-level changes. Jackknife estimates suggest that the pre- 
dictor coefficients were not highly dependent on either the earthquakes or monitoring wells included in the datasets.

Marginal probabilities of the OSPM were calculated and presented as a function of PGV. The interquartile range was taken into account by variation of depth and $\mathrm{Vs}_{30}$ within the dataset and the model. In view of the jackknife analysis, the All Data OSPM is judged to have the most stable coefficients, and we mapped subsequently the associated marginal probability PGV values onto the Modified Mercalli (MM) intensity scale to express the likelihood of persistent water-level changes as a function of seismic intensity.

We propose that the probabilistic framework described here provides a useful addition to the environmental response criteria of the New Zealand MM scale. The expanded criteria may assist seismic hazard assessment during future earthquakes, and the probabilistic framework could inform practitioners in decision-making processes for increasing the resilience of water supply infrastructure to earthquake-induced shaking, aquifer pollution, turbidity increases, and geochemical changes. GIS could be used to predict how susceptible different parts of New Zealand are to groundwater-level changes. This would be the first step towards formulating a groundwater-level change susceptibility model for common earthquake events in New Zealand. The additional environmental criteria could also provide MM reporting in areas where few buildings are present.

This study is the first attempt we are aware of worldwide to incorporate both seismic and hydrogeological factors into a probabilistic framework for earthquake-induced groundwater level changes. The framework is a novel and more readily generalizable approach than those based on other metrics. It has potential to enable better comparison of international studies and to inform practitioners making decisions around investment to mitigate risk and to increase the resilience of water supply infrastructure.

\subsection{Acknowledgements}

We wish to thank colleagues Mai-Linh Doan, David Harte and Lucie Janku-Capova for their discussion and helpful comments. This study was supported by the Marsden Fund of the Royal Society of New Zealand (grant number 2012-GNS-003). We acknowledge the New Zealand GeoNet project (http://www.geonet.org.nz, last accessed August, 2018), and its sponsors EQC, GNS Science and LINZ, for providing data used in this study. For a complete list of the data used, see Table S1 in the electronic supplement to this article. 


\section{$6 \quad$ Summary and directions for future research}

This thesis presents three stand-alone studies of the seismic and hydrogeological controls on earthquake-induced groundwater-level changes. The key findings obtained from these investigations within the framework of the research questions introduced in Chapter 1 are summarised here, together with thoughts on future research direction. Finally, some preliminary analyses are presented that may form the basis for subsequent work.

\subsection{Key results of each study}

\section{Chapter 3: Case study of the $2016 M_{w} 7.8$ Kaiköura earthquake}

Examining the groundwater response of New Zealand aquifers to the $2016 \mathrm{M}_{\mathrm{w}} 7.8$ Kaikoura earthquake, the contributions of earthquake induced static and dynamic stress changes and hydrogeological factors were analysed.

- Observed water-level changes are inconsistent with predictions of static stress, instead correlating to variations in dynamic stress changes. A change in mechanism is inferred at peak ground acceleration (PGA) of $\sim 2 \mathrm{~m} / \mathrm{s}^{2}$. Permeability enhancement is the dominant mechanism at slower ground motions, whereas shear-induced consolidation is the dominant mechanism for water-level changes at faster ground motions.

- The northward direction of the Kaikōura fault rupture caused a spatially asymmetric PGA distribution. Correspondingly, to the north of the epicentre waterlevel changes occurred in $60 \%$ of the monitoring wells, whereas water-level changes occurred in $48 \%$ of the monitoring wells south of the epicentre. The absolute water-level change amplitudes were scaled to the horizontal (geometric mean) PGA experienced at each monitoring well.

- Monitoring well depth and $\mathrm{Vs}_{30}$ positively correlate with scaled water-level change amplitudes. Regardless of the magnitude of the earthquake, monitoring wells may have water-level changes of certain amplitudes relative to PGA based on the degree of confinement and the strength of the rock surrounding the screen. Variations in the scaled water-level change amplitudes at any particular depth or 
$\mathrm{Vs}_{30}$ may be explained by changes in aquifer transmissivity that may be up- or down-flow of the well.

\section{Chapter 4: Tidal behaviour and water-level changes to multiple earthquakes}

Water-level and tidal behaviour changes have been quantified in multiple wells in the Canterbury Plains aquifer system in response to multiple $\mathrm{M}_{\mathrm{w}} 5.4$ or larger earthquakes between 2008 and 2015. The occurrence and dynamic shaking threshold required for the two phenomena were evaluated.

- In the near-field of the Canterbury earthquake sequence of 2010 and 2011, permeability reduction and increased water-levels in shallow aquifers suggest a shearinduced consolidation mechanism. Earthquake-induced groundwater-level changes further afield included variable water-level change polarity with rare tidal behaviour change, suggesting permeability enhancement or reduction occurred in the local aquifer.

- Post-seismic water-level re-equilibration occurred faster ( $\sim 50$ mins) at wells where tidal behaviour changes were not observed. Where changes in tidal behaviour were observed, the re-equilibration time ranged from $\sim 240$ mins to 10 days. The fast re-equilibration time of water-levels where tidal behaviour changes were not observed, may be due to a high permeability and good coupling between the well and the aquifer, and/or small permeability changes in the local aquifer. Tidal behaviour changes may not have been observed due to the low bulk modulus of the gravels. Water-level changes that occurred with tidal behaviour changes may occur on a larger scale than independent water-level changes, as water-level changes also occurred in nearby wells.

- The minimum peak dynamic stress required for a tidal behaviour change in the Canterbury gravel aquifers varies between $\sim 0.2$ and $100 \mathrm{kPa}$. Water-level changes were more likely to occur at wells where peak dynamic stress exceeded $50 \mathrm{kPa}$, but not where peak dynamic stress was below $10 \mathrm{kPa}$. However, there is no clear distinction between the presence and absence of tidal behaviour and water-level changes based on peak dynamic stress. 


\section{Chapter 5: Aquifer susceptibility to groundwater-level changes}

Using statistical methods, the first probabilistic model for groundwater responses has been constructed as a function of the Modified Mercalli (MM) intensity scale. A binary logistic regression model with random effects (LRRE) was computed with three predictors: PGV, depth and $\mathrm{Vs}_{30}$. The random effects were included as a partial proxy for variations in monitoring well susceptibility to earthquake-induced persistent water-level change. Marginal probabilities were calculated as a function of PGV, and were subsequently converted to the MM intensity scale. The likelihood of persistent water-level changes was calculated at MM intensity II to VIII.

- At MM intensity V and below, water-level changes are very unlikely to about as likely as not. At MM intensity VI, water-level changes are unlikely to about as likely as not. At MM intensity VII, water-level changes are unlikely to likely. At MM intensity VIII, the likelihood rises to very likely to virtually certain.

- We propose these probabilities of responses as further additions to the environmental response criteria of the New Zealand MM intensity scale.

\subsection{Research questions revisited}

\section{To what extent do earthquake-induced static and dynamic stress changes contribute to groundwater-level changes?}

Static stress changes induced by the $2016 \mathrm{M}_{\mathrm{w}} 7.8$ Kaikōura earthquake were only significant in the near-field. The complex nature of the rupture and damage zone is responsible for the variety in polarity and amplitude of the static stress changes (Chapter 3). Considering water-level change polarity and/or amplitude is inconsistent with volumetric strain predictions, it is unlikely that static stress changes contributed to water-level changes in the near-field during this earthquake. The result is inconsistent with international studies where static stress changes correlate with water-level change amplitude and polarity (Wakita, 1975; Roeloffs, 1996; Quilty and Roeloffs, 1997; Jónsson et al., 2003; Akita and Matsumoto, 2004; Chia et al., 2008). In the intermediatefield, observed water-level changes are larger than volumetric strain predictions, which is similar with other studies (Igarashi and Wakita, 1995; Itaba and Koizumi, 2007; Manga and Wang, 2007; Wang and Manga, 2010a; Shi and Wang, 2015).

Our research suggests that dynamic stress changes contribute to the occurrence and characteristics of groundwater-level changes. The asymmetric distribution of dynamic stress changes induced by the Kaikōura earthquake correlates with the northsouth distribution of water-level change occurrences across New Zealand (Chapter 3). 
This, coupled with the positive coefficients returned from LRRE models for dynamic stress proxies (Chapter 5), demonstrates that dynamic stress changes do contribute to groundwater-level change occurrence. This finding is complementary to the predicted occurrence of dynamic stress changes from the near- to far-field (Lay and Wallace, 1995; Manga and Wang, 2007). Dynamic stress changes are also thought to cause enhanced permeability by the dislodging of colloids (Brodsky et al., 2003) and shear-induced consolidation or dilatation (Wang et al., 2001), which result in polarity variations of water-level changes. Following the Kaikoura earthquake, areas that experienced PGAs $<2 \mathrm{~m} / \mathrm{s}^{2}$, had approximately an equal number of persistent water-level increases and decreases, with small amplitudes $(<1 \mathrm{~m}$; Chapter 3$)$. The statistically random polarity of water-level change is consistent with the hypothesis of enhanced permeability (Brodsky et al., 2003), as the polarity of the water-level change depends upon the location of the monitoring well, relative to the location of the permeability change (upor down-hydraulic head gradient; Wang and Chia, 2008).

In areas where PGA exceeded $\sim 2 \mathrm{~m} / \mathrm{s}^{2}$, water-levels predominantly increased with large amplitudes (>1 m; Chapter 3 ). In addition, water-level increases in the near-field of the Canterbury earthquake sequence of 2010 and 2011, were coupled with permeability reduction inferred from tidal behaviour changes (Chapter 4). The consistent increases in water-level and tidal behaviour changes in shallow sedimentary aquifers support the hypothesis of shear-induced consolidation.

Where significant static stress changes occur, dynamic stress changes are also significant (Chapter 3). Water-level changes may have been partially caused by static stress changes, but could also have been concealed by larger amplitude changes caused by dynamic stress changes. The numerous landslides induced by the Kaikoura earthquake, and the limited number of monitoring wells in the near-field, proved detrimental to the assessment of static stress changes in causing groundwater-level changes.

Considering most observations of near-field groundwater-level changes occurred at wells located in unconsolidated sedimentary deposits, the hypothesis of static stress induced groundwater-level changes cannot be confidently rejected. Further assessment requires more observations of near-field responses in igneous and metamorphic aquifer systems. Our results show that groundwater-level changes in sedimentary aquifers are unlikely to result predominantly from static stress changes; if static stress changes contribute to groundwater-level changes they are less significant than dynamic stress changes in these relatively soft, young sediments. 


\section{To what extent do hydrogeological factors contribute to groundwater-level changes?}

Monitoring wells have variable susceptibility to earthquake-induced groundwater-level changes, which cannot be predicted by static or dynamic stress changes alone. This is likely to be partially a result of hydrogeological factors, such as the degree of aquifer confinement, rock strength, and flow properties.

Monitoring well depth, a proxy for degree of aquifer confinement, is demonstrated to contribute to the occurrence and amplitude of groundwater-level changes (Chapter $3,5)$. The greater the degree of confinement, the more likely a persistent waterlevel change will be observed, and the larger the amplitude of response. The result is consistent with other international studies (Stearns, 1928; Eaton and Takasaki, 1959; Roeloffs, 1996; Gulley et al., 2013), and is thought to result from the specific yield of unconfined aquifers being higher than the storativity of confined aquifers (Freeze and Cherry, 1979).

It was also determined that $\mathrm{Vs}_{30}$, a proxy for rock strength, correlated to the occurrence of water-level changes as demonstrated by our LRRE model (Chapter 5), and the amplitude of water-level changes as determined by investigations on the Kaikōura earthquake (Chapter 3). The stronger the rock, the more likely a persistent water-level change is to occur, and with a larger amplitude. A logical explanation is that stronger rocks generally have lower specific yields.

The transition from matrix- to fracture-dominated flow and the presence of dual porosity may also have an effect on response characteristics. At sufficiently high shear strains, the deformation characteristics of an aquifer also depend on the consolidation state of the rock-mass. For unconsolidated deposits, shear deformation causes grains to move into pre-existing pores, reducing the porosity and volume of the deposits. Shear deformation of consolidated deposits creates new porosity, increasing the volume (Manga and Wang, 2007). However, our results show no correlation between polarity of response and rock-mass type. This is perhaps because the New Zealand dataset presently contains limited responses in well consolidated rock where shaking intensity has been high.

Well-aquifer coupling is controlled by aquifer flow properties (Hsieh et al., 1987; Doan and Brodsky, 2006) and well completion. In a well-coupled state, water-level changes can be expected as pore pressure variations in aquifers strongly correlate with monitoring well water-level (Chapter 4). However, in an uncoupled state, pore pressure changes in aquifers are not well represented in monitoring wells, thus water-level changes are absent. Therefore, flow properties generally have an impact on response occurrence (Faoro et al., 2012) with transmissivity having an effect on water-level change amplitude (Manga and Wang, 2007).

The variable susceptibility of wells to earthquake-induced water-level changes may 
also be due to heterogeneity in the local aquifer, or differences in well properties (casing material, screen length, screen type etc.). In terms of aquifer heterogeneity, certain monitoring wells may be screened within small-scale fracture networks or high permeability zones. Introducing a random effects component into LRRE models (Chapter 5) enables a partial proxy to be invoked for variable monitoring well susceptibility.

\section{Is there a more informative earthquake hydrology metric than epicentral distance and magnitude?}

A widely used metric to compare groundwater-level changes from different earthquakes and different regions is the joint use of epicentral distance, earthquake magnitude, and seismic energy density (Wang and Manga, 2010b). This metric has been used to collate datasets from around the world and is based on attenuation models for California. However, it lacks consideration of earthquake directivity and hydrogeological factors, which we demonstrate influence the occurrence and amplitude of groundwater-level changes (Chapter 3). As understanding of the mechanistic processes has developed, and as datasets have become more spatially and temporally extensive, a revised metric is feasible and necessary to advance the earthquake hydrology discipline.

This study is the first attempt at a probabilistic framework for earthquake-induced groundwater-level changes in the context of felt shaking intensity using the MM scale, rather than source magnitude. The study highlights that directivity, degree of confinement and rock strength are important. The inclusion of water-level changes within the MM framework is a fresh and more encompassing approach compared to the metric of epicentral distance, magnitude and seismic energy density. It has potential to allow the comparison of international studies to be more informative, and accessible to practitioners in the field.

\subsection{Implications for future research}

Much remains unexplored in the study of earthquake hydrology especially considering earthquakes are well known to induce a wide range of responses in surface-waters (Montgomery et al., 2003; Montgomery and Manga, 2003), and geothermal environments (Manga and Brodsky, 2006), in addition to groundwater (e.g. Roeloffs, 1998).

Deeper investigation of New Zealand well responses induced by a diverse range of future local earthquakes would allow a more rigorous study of the influence of earthquake properties, such as frequency content of ground motion, rupture directivity, faulting style, recurrence interval and fault strength on the occurrence and absence of groundwater-level changes. The following earthquakes could be used to make a more complete onshore decadal catalogue between 2008 and 2018: $2015 \mathrm{M}_{\mathrm{w}} 6$ Arthur's Pass 
earthquake; $2015 \mathrm{M}_{\mathrm{w}} 6.2 \mathrm{St}$ Arnaud earthquake; $2015 \mathrm{M}_{\mathrm{w}} 5.8$ Wanaka earthquake; $2016 \mathrm{M}_{\mathrm{w}} 5.7$ Valentine's day earthquake; and the $2016 \mathrm{M}_{\mathrm{w}} 7.1$ East Cape earthquake. Numerous offshore large magnitude earthquakes occurred in the Puysegur, Hikurangi and Kermadec trenches between 2008 and 2018 but were not considered in this thesis, although they may have caused aquifer changes. In future work an offshore decadal catalogue should be collated comprising these earthquakes. Moreover, 15 slow slip events have been detected at the Hikurangi subduction margin since 2002 (Wallace and Beavan, 2010). Studying the hydrogeological response to slow slip earthquakes may help elucidate not only fluid pressure controls on slow slip, but the role of static strain without dynamic strain.

Although New Zealand is geologically diverse, the majority of the hydrological response observations available for use in this thesis were collated from gravel aquifers, as monitoring is focused in these high permeability regions. The addition of responses that occur in a variety of hydrological regimes would further our understanding of how site effects the occurrence and characteristics of responses. Observations of responses to a variety of earthquakes in diverse hydrogeological settings could be incorporated into the probabilistic framework that we have developed in order to expand the model's application.

Increasing the resolution at which monitoring infrastructure records groundwaterlevels would be invaluable. Data with sampling intervals on the order of 1 minute record substantially more signal compared to 15 minute sampled data. Furthermore, the higher resolution data are less affected by earthquake arrival times and hydroseismograms. The additional data do not need to be a significant burden on data storage systems, considering progressive technological advancements. Additionally, if measurement protocols were made to be consistent across regional councils, future nationwide studies of hydrological systems would be more achievable for researchers, and more convenient for regional council technicians. Development of a set of consistent national protocols would enable the full potential of the New Zealand hydroseismicity dataset to be more easily utilised. 


\subsection{Discussion: New research avenues and ideas}

Over the course of this investigation, a series of related ideas and possible avenues of further research emerged, which could be addressed by future work:

\section{Hydrological responses within fault zones}

The Alpine Fault ruptures every $\sim 200$ to 400 years with $\mathrm{M}_{\mathrm{w}} 7.6$ to 8.2, and last failed in A.D. 1717 (Sutherland et al., 2007; De Pascale and Langridge, 2012). Therefore, it provides a unique opportunity to examine the conditions present in the fault zone prior to a large magnitude earthquake (Townend et al., 2009). The hanging-wall of the Alpine fault is hydrologically active, with the generation of hot springs derived from meteoric fluids circulating in the upper crust (Cox et al., 2015; Reyes et al., 2010). Hydrogeochemistry (Menzies et al., 2014, 2016) and hydraulic measurements (Sutherland et al., 2012) suggest that the hanging- and foot-wall are hydrologically distinct (Townend et al., 2017).

In the first phase of the Deep Fault Drilling Project (DFDP-1), DFDP-1A and DFDP-1B were drilled through the principal slip zone (PSZ) of the Alpine Fault to depths of $\sim 101 \mathrm{~m}$ and $\sim 151 \mathrm{~m}$ respectively (Sutherland et al., 2012). In doing so, the DFDP science team collected a set of continuous rock cores and wireline logs across the fault zone and conducted borehole hydraulic experiments (e.g. Townend et al., 2013; Boulton et al., 2014; Carpenter et al., 2014; Toy et al., 2015). Longterm monitoring of temperatures, fluid pressures, fluid chemistry and seismicity were implemented. Piezometers were installed above and below the primary principle slip zone (PSZ) in DFDP-1B, and fluid pressures were measured in four second intervals. Seismometers were installed at the surface next to DFDP-1B and above the PSZ in DFDP-1A (Sutherland et al., 2011).

The piezometers and seismometers recorded the $2016 \mathrm{M}_{\mathrm{w}} 7.8$ Kaiköura earthquake (Figure 6.1). Considering the sampling interval of the piezometers, hydroseismograms were recorded above and below the PSZ. Normalising groundwater-levels above and below the PSZ to pre-earthquake levels allowed a comparison of the earthquake responses (Figure 6.2).

Additional assessment of the DFDP hydrological response to the $2016 \mathrm{M}_{\mathrm{w}} 7.8$ Kaikōura earthquake may be valuable, and could be approached in numerous ways (e.g. Brodsky et al., 2003; Kano and Yanagidani, 2006; Weingarten and Ge, 2014). Moreover, the DFDP-1 hydrological and seismic monitoring network is unique and an assessment over multiple earthquakes could provide insight into earthquake-induced hydrological responses within fault zones, and whether they differ significantly from aquifers, for example. 

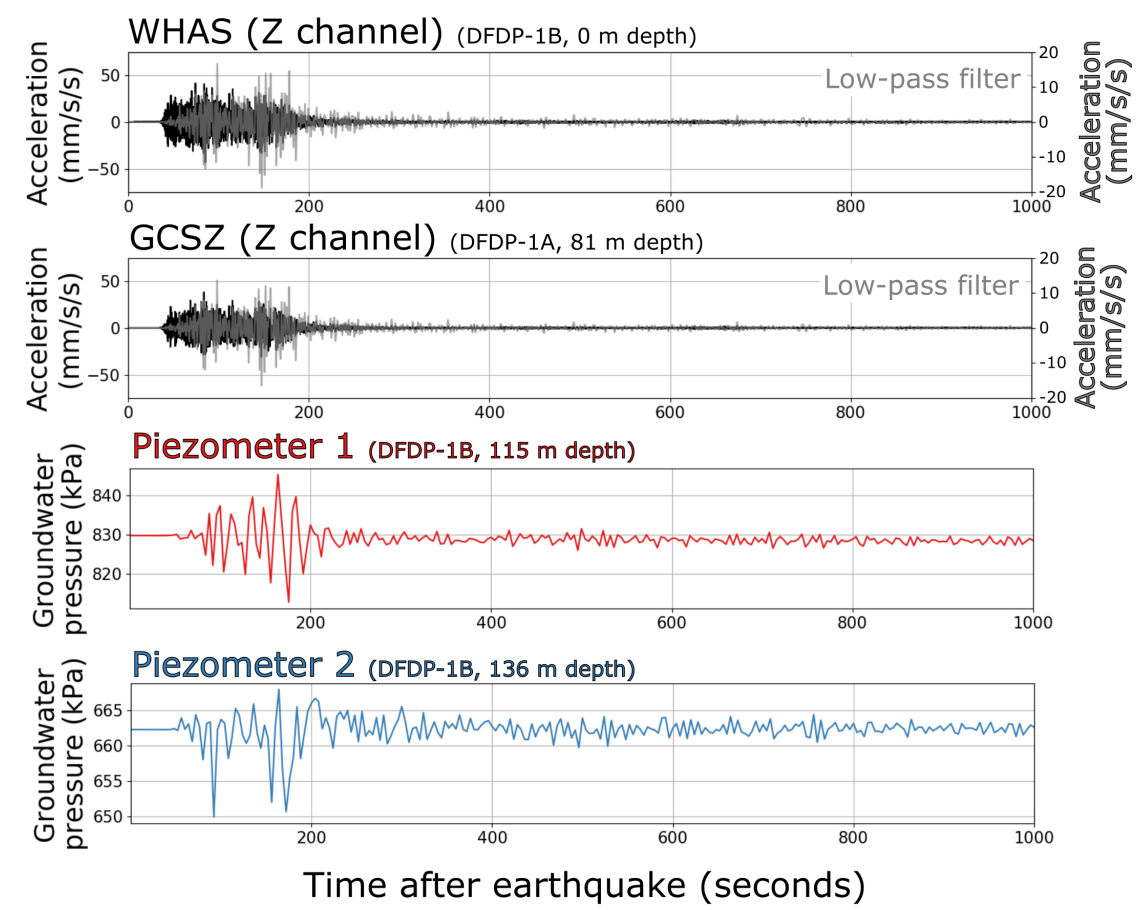

Figure 6.1: Seismic and hydrological response at DFDP-1A and DFDP-1B to the Kaiköura earthquake, in the first 1000 seconds. The time-series are ordered in terms of depth within the boreholes (Sutherland et al., 2011).

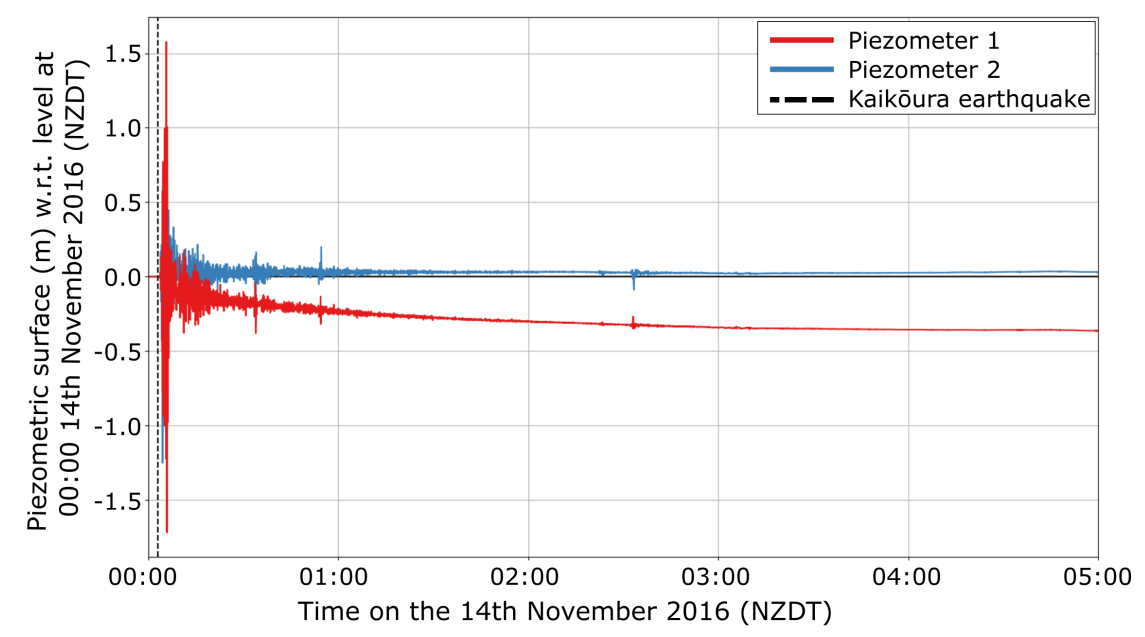

Figure 6.2: Groundwater-level response above and below the PSZ to the Kaikoura earthquake in the extensively instrumented DFDP-1B borehole. Groundwater-levels are normalised to pre-earthquake levels. The hydrological response above and below the PSZ are distinctly different, with a decrease in the piezometric surface elevation in the hanging wall, and a slight increase in the footwall in the first five hours after the earthquake. 


\section{Earthquake-induced impacts on groundwater quality}

Earthquake-induced groundwater quality changes have been reported after the $2009 \mathrm{M}_{\mathrm{w}}$ 7.8 Dusky Sound, $2010 \mathrm{M}_{\mathrm{w}} 7.1$ Darfield, and the $2016 \mathrm{M}_{\mathrm{w}} 7.8$ Kaiköura earthquakes (Cox et al., 2015; Rutter et al., 2018). These include changes in turbidity, nitrate, faecal concentrations, and water chemistry (Close et al., 2017; ECan, 2011; Water, 2017). Of particular concern is where there is evidence of contamination of aquifers by pathogens. Groundwater quality changes can also provide evidence for mixing of water from different sources, or for increased recharge from the land surface (Rutter et al., 2018).

With the examination of multiple earthquakes, the threshold at which turbidity changes occur could be elucidated, which could inform practitioners in decision-making processes for increasing the resilience of water supply infrastructure. The measuring of turbidity changes in boreholes over earthquake intervals remains infrequent and available observations are mainly anecdotal. Quantitative data of turbidity changes may provide insight into the amount of colloids that may become mobilised, the settling rate within the surrounding aquifer, and if there are implications for water treatment protocol. The time period over which these responses occur also remains unknown.

Turbidity changes induced by the $2016 \mathrm{M}_{\mathrm{w}} 7.8$ Kaiköura earthquake were explored in four municipal drinking water supply wells in Marlborough, South Island, New Zealand. Before flowing to the water treatment plant, groundwater is pumped out of the wells and the turbidity of the water is measured every minute by a nephelometer in nephelometric turbidity units (NTU). Generally, when the pumps are turned on, spikes in turbidity occur followed by an exponential decay. If the overall turbidity of the water entering the water treatment plant is above $2 \mathrm{NTU}$ for longer than three minutes, the pumps can no longer tolerate the increased turbidity (I. Hosie, personal communication, 2017), which has important ramifications for earthquake resilience.

Pumping of the wells occurred before and after the Kaikoura earthquake (Figure 6.3). The first pump initiated turbidity measurement after the earthquake was at least five times higher than the water treatment plant limit $(\sim 10 \mathrm{NTU})$. The abnormally high turbidity levels persisted with the incidence of further pumping.

Although analysis is only preliminary, spike and decay patterns stimulated by pump initiation were identified and associated decay constants were estimated (Figure 6.4). The decay constants changed transiently or persistently after the Kaiköura earthquake, and may have resulted from of change in aquifer or well conditions. Further assessment is required to understand the turbidity changes, specifically the effect of the: geometry of the wells; construction design of the turbidity monitoring infrastructure; and pumping, calibration, and maintenance schedules. 


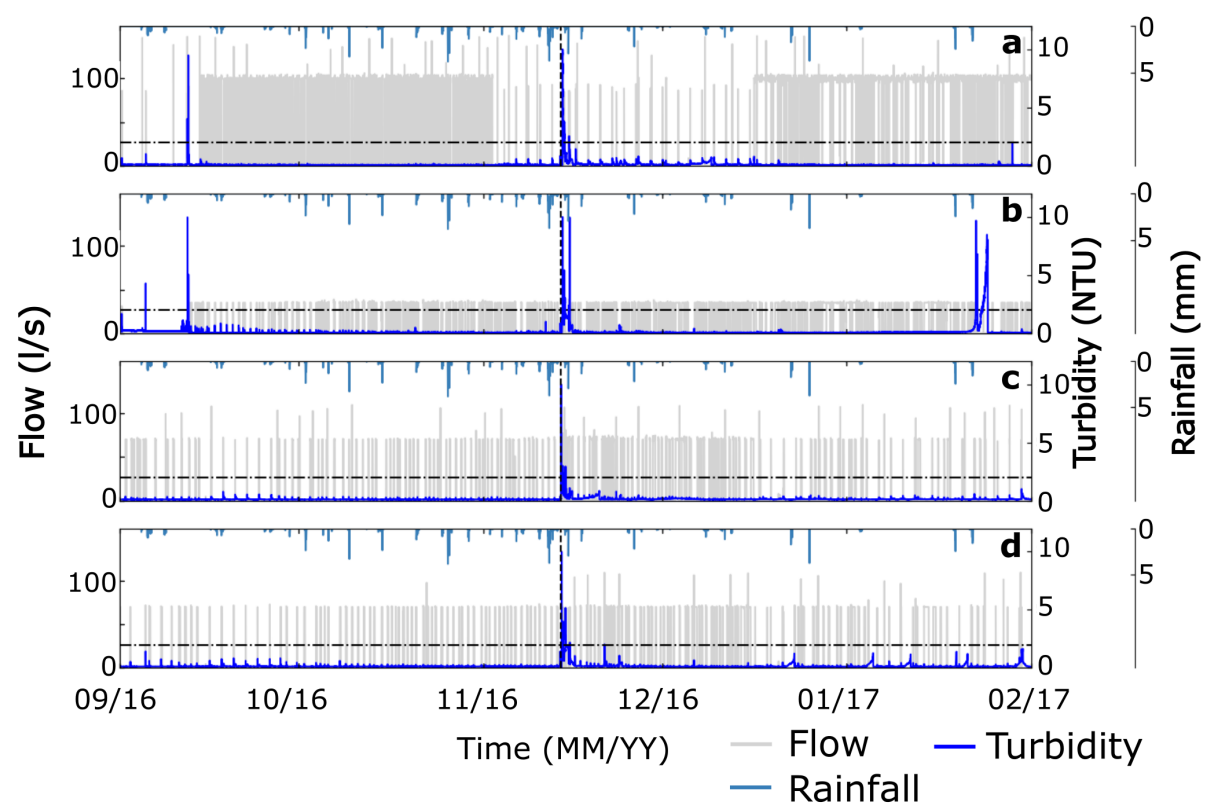

Figure 6.3: Time-series of turbidity, flow and rainfall at the municipal drinking water supply wells (Sep 2016 to Feb 2017). (a - Top) P28w0544, (b - Middle Top) P28w2993, (c - Middle Bottom) 10081, (d - Bottom) 10082.

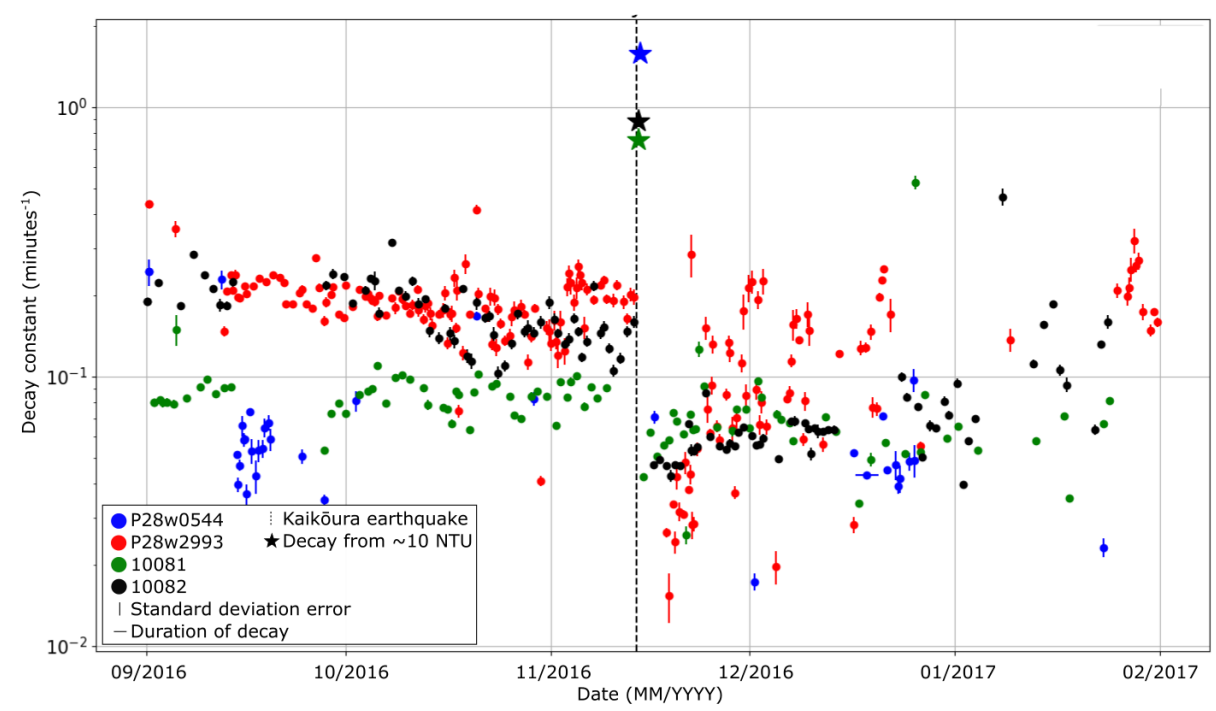

Figure 6.4: Turbidity decay constants extracted from exponential decays curves stimulated by the initiation of pumps. Decay constants were calculated for decay curves that occurred up to several months before and after the Kaikōura earthquake. The decay curves induced by the initiation of pumps immediately after the earthquake are indicated by stars. Vertical error bars represent one standard deviation errors of the decay constant. Horizontal bars, represent the length of decay time to background levels. Decay times are generally less than 12 hours. 


\section{Applications for a probabilistic model of groundwater responses}

The probabilistic framework developed in Chapter 5 has potential to inform practitioners in decision-making processes for increasing the resilience of water supply infrastructure to earthquake-induced shaking, aquifer pollution, turbidity increases, and geochemical changes. As site effects were included within the assessment, GIS data could be used to predict how susceptible different parts of New Zealand are to groundwaterlevel changes. This could be the first step towards formulating a groundwater-level change susceptibility model for common earthquake events in New Zealand.

\section{Lake Horowhenua water-level changes}

Lake Horowhenua is a shallow lake located within the Manawatu-Wanganui region (North Island, New Zealand), which is fed by small streams and discharges into the Hokio stream. Horizons Regional Council reported a significant persistent increase in the water-level of Lake Horowhenua, around the time of the $2016 \mathrm{M}_{\mathrm{w}} 7.8$ Kaikoura earthquake (S Collins, personal communication 2017) that warrant further investigation.

There are two monitoring wells ( $\sim 7 \mathrm{~m}$ in depth, 362999 and 352261$)$, that are upand down-stream of the lake respectively. Several streams drain on the Kapiti coast and are sourced from the Tararua range. There are six gauges on six separate streams upstream and to the South of Lake Horowhenau. Rainfall is monitored upstream of Lake Horowhenua and to the North in Palmerston North.

In the month prior to the Kaikoura earthquake, the lake water-level was $\sim 1.3 \mathrm{~m}$ (Figure 6.5). Over the earthquake interval, the water-level rose to $\sim 1.6 \mathrm{~m}$. The monitoring wells 362999 and 352261, both responded to the Kaikōura earthquake (Chapter 3). Between mid-2013 and mid-2017, Lake Horowhenua water-level fluctuated seasonally between $\sim 1$ and $1.4 \mathrm{~m}$. Only in two instances have water-levels exceeded $\sim 1.4 \mathrm{~m}$, in mid-2015, and around the time of the $2016 \mathrm{M}_{\mathrm{w}} 7.8$ Kaikoura earthquake.

While the temporal association of the high Lake Horowhenua water-levels with the $2016 \mathrm{M}_{\mathrm{w}} 7.8$ Kaikoura earthquake remains intriguing, at this stage the contribution of the Kaikoura earthquake to the increase in water-level cannot be deduced. This is because rainfall occurred prior to the earthquake, contributing to stream-flow and lake water-level increases. To quantify the contributions of the Kaikōura earthquake to the increased Lake Horowhenua water-levels, modelling could be implemented, similar to that used by Rutter et al. (2016). Modelling could quantify rainfall and groundwater inputs into the lake by assessing historical events and lag times for for flows reaching the lake (JJ Weir, personal communication, 2017). 

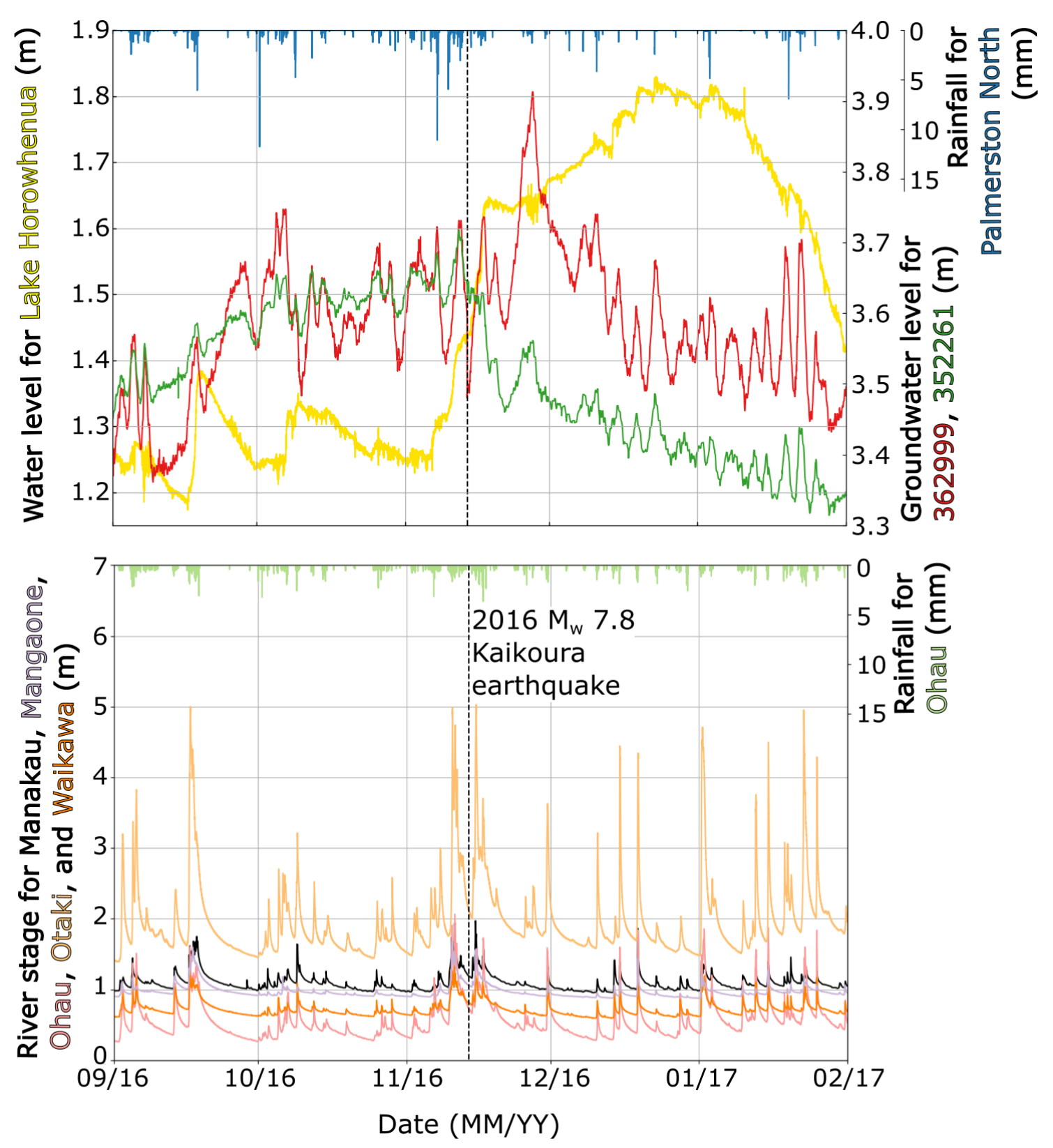

Figure 6.5: Lake Horowhenua water-level, groundwater-level, stream-flow and rainfall two months prior to and after the Kaikoura earthquake. 


\subsection{Concluding statement}

This thesis describes a regional-scale, multi-site, multi-earthquake study that includes the absence and occurrence of responses, across moderate to large magnitude earthquakes from the past decade. Earthquake-induced groundwater-level and tidal behaviour changes were examined in a range of aquifers, rock types and hydrogeological settings. Monitoring wells were in the near- and intermediate-field with respect to a variety of earthquakes that produced a range of shaking intensities. The study of seismic and hydrogeological factors in the internationally significant New Zealand "hydroseismicity" dataset culminated in the first attempt at a probabilistic framework for earthquake-induced groundwater-level changes in the context of felt shaking intensity using the MM scale. Inclusion within the MM framework is a novel and more universal approach compared to the metric of epicentral distance, magnitude and seismic energy density. It has potential to enable better comparison of international studies and inform practitioners making decisions around water supply infrastructure resilience in seismically active regions. 


\section{Appendix}




\section{A Tidal analysis: Earth and ocean tidal responses}

Table A.1 contain sea level site locations, depth and distance from shore and tidal properties. Sea level site properties were collected from Environment Canterbury and tidal properties were calculated using the methods described in the paper. Table A.2 and A.3 contain borehole locations, depth and distance from shore and tidal properties. Borehole properties were collected from Environment Canterbury and tidal properties were calculated using the methods described in the paper.

Table A.1: A table of the two sea level sites in the Canterbury region,their locations, physical and tidal properties. The tidal properties were computed for the whole time series. Chch $=$ Christchurch.

\begin{tabular}{|c|c|c|c|c|c|c|c|c|c|c|c|c|}
\hline $\begin{array}{l}\text { Sea } \\
\text { level } \\
\text { site }\end{array}$ & $\begin{array}{l}\text { Latitude, } \\
\text { Longi- } \\
\text { tude }\end{array}$ & $\begin{array}{l}\text { Time } \\
\text { series }\end{array}$ & $\begin{array}{l}\text { Depth } \\
\text { (m) }\end{array}$ & $\begin{array}{l}\text { DTS } \\
(\mathrm{km})\end{array}$ & $\begin{array}{l}\mathbf{M}_{2} \\
B K_{u}\end{array}$ & $\begin{array}{l}\mathbf{M}_{2} \\
\phi_{\text {lag }}\end{array}$ & $\begin{array}{l}\mathrm{M}_{2} \mathrm{~A} \\
(\mathrm{~mm})\end{array}$ & $\begin{array}{ll}\mathrm{S}_{2} & \mathrm{~A} \\
(\mathbf{m} \mathbf{m})\end{array}$ & $\begin{array}{l}\mathbf{K}_{2} A \\
(\mathbf{m m})\end{array}$ & $\left.\begin{array}{ll}\mathbf{O}_{1} & A \\
(\mathbf{m} & \mathbf{m}\end{array}\right)$ & $\begin{array}{ll}\mathbf{S}_{1} & A \\
(\mathbf{m} & \mathbf{m})\end{array}$ & $\begin{array}{l}\mathbf{K}_{1} A \\
(\mathbf{m m})\end{array}$ \\
\hline Chch & $\begin{array}{l}-43.57 \\
172.77\end{array}$ & $\begin{array}{l}01 / 08- \\
01 / 15\end{array}$ & 0 & 0 & 945.12 & 74.6 & 763.7 & 50.1 & 19.1 & 25.7 & 0.3 & 44.6 \\
\hline Timaru & $\begin{array}{l}-44.39 \\
171.26\end{array}$ & $\begin{array}{l}01 / 08- \\
01 / 15\end{array}$ & 0 & 0 & 946.97 & 107.2 & 762.9 & 90.4 & 32.3 & 31.3 & 0.2 & 29.4 \\
\hline
\end{tabular}

Table A.2: A table of the earth tide boreholes, their locations, physical and tidal properties. The tidal properties were computed for the whole time series. The amplitude of the $\mathrm{M}_{2}$ and $\mathrm{O}_{1}$ waveforms are included, as well as similar frequency waveforms that are contaminated with barometric- and thermal-effects. The table is ordered in terms of distance to shore (DTS).

\begin{tabular}{|c|c|c|c|c|c|c|c|c|c|c|c|c|}
\hline $\begin{array}{l}\text { Well } \\
\text { number }\end{array}$ & $\begin{array}{l}\text { Latitude, } \\
\text { Longi- } \\
\text { tude }\end{array}$ & $\begin{array}{l}\text { Time } \\
\text { series }\end{array}$ & $\begin{array}{l}\text { Depth } \\
\text { (m) }\end{array}$ & $\begin{array}{l}\text { DTS } \\
(\mathbf{k m})\end{array}$ & $\begin{array}{l}\mathbf{M}_{2} \\
B K_{u}\end{array}$ & $\begin{array}{l}\mathbf{M}_{2} \\
\phi_{\text {lag }}\end{array}$ & $\begin{array}{l}\mathrm{M}_{2} A \\
(\mathbf{m m})\end{array}$ & $\begin{array}{ll}\mathrm{S}_{2} & \mathrm{~A} \\
(\mathbf{m m})\end{array}$ & $\begin{array}{l}\mathrm{K}_{2} \mathrm{~A} \\
(\mathbf{m} \mathbf{m})\end{array}$ & $\begin{array}{ll}\mathbf{O}_{1} & A \\
(\mathbf{m} \mathbf{m})\end{array}$ & $\begin{array}{ll}\mathbf{S}_{1} & A \\
(\mathbf{m} & \mathbf{m})\end{array}$ & $\begin{array}{l}\mathbf{K}_{1} \mathbf{A} \\
(\mathbf{m} \mathbf{m})\end{array}$ \\
\hline K38/0013 & $\begin{array}{l}-44.17 \\
171.40\end{array}$ & $\begin{array}{l}01 / 08- \\
01 / 15\end{array}$ & 79 & 6.2 & 5.6 & -4.2 & 4.1 & 2.3 & 1.6 & 1.9 & 0.1 & 1.7 \\
\hline M36/8515 & $\begin{array}{l}-43.80 \\
172.30\end{array}$ & $\begin{array}{l}01 / 08- \\
01 / 15\end{array}$ & 139.4 & 7.3 & 5.3 & -1.6 & 5.1 & 3.8 & 0.7 & 2.8 & 0.4 & 3 \\
\hline $\mathrm{K} 36 / 0439$ & $\begin{array}{l}-43.72 \\
171.75\end{array}$ & $\begin{array}{l}01 / 08- \\
01 / 15\end{array}$ & 230 & 35.3 & 5.6 & 14.5 & 4.9 & 5.3 & 1 & 2.5 & 0.3 & 14.3 \\
\hline $\mathrm{K} 36 / 0494$ & $\begin{array}{l}-43.72, \\
171.75\end{array}$ & $\begin{array}{l}01 / 08- \\
11 / 12\end{array}$ & 172 & 35.3 & 11.1 & 2.7 & 7.9 & 4.9 & 0.8 & 4.6 & 0.1 & 4.6 \\
\hline K36/0495 & $\begin{array}{l}-43.72 \\
171.75\end{array}$ & $\begin{array}{l}01 / 08- \\
01 / 15\end{array}$ & 195 & 35.3 & 7.4 & -12.3 & 3.9 & 3.2 & 1.1 & 4 & 0.1 & 2.2 \\
\hline L35/0686 & $\begin{array}{l}-43.32 \\
172.08\end{array}$ & $\begin{array}{l}01 / 10- \\
01 / 12\end{array}$ & 186.5 & 51.7 & 5.5 & -2.1 & 4.8 & 2.7 & 0.2 & 1.9 & 0 & 1.8 \\
\hline Н39/0148 & $\begin{array}{l}-44.52 \\
169.85\end{array}$ & $\begin{array}{l}12 / 09- \\
01 / 15\end{array}$ & 60 & 105 & 5.7 & 2.6 & 4.6 & 4 & 0.6 & 2.3 & 0.5 & 2.8 \\
\hline
\end{tabular}


Table A.3: A table of the ocean tide boreholes, their location, physical and tidal properties. Tidal properties were computed for the whole time series. The amplitude of the $\mathrm{M}_{2}$ and $\mathrm{O}_{1}$ waveforms are included, as well as similar frequency waveforms that are contaminated with barometric- and thermal-effects. The table is ordered in terms of distance to shore (DTS).

\begin{tabular}{|c|c|c|c|c|c|c|c|c|c|c|c|c|}
\hline $\begin{array}{l}\text { Well } \\
\text { number }\end{array}$ & $\begin{array}{l}\text { Latitude, } \\
\text { Longi- } \\
\text { tude }\end{array}$ & $\begin{array}{l}\text { Time } \\
\text { series }\end{array}$ & $\begin{array}{l}\text { Depth } \\
\text { (m) }\end{array}$ & $\begin{array}{l}\text { DTS } \\
(\mathbf{k m})\end{array}$ & $\begin{array}{l}\mathbf{M}_{2} \\
B K_{u}\end{array}$ & $\begin{array}{l}\mathbf{M}_{2} \\
\phi_{\text {lag }}\end{array}$ & $\begin{array}{l}M_{2} A \\
(\mathbf{m m})\end{array}$ & $\begin{array}{ll}\mathbf{S}_{2} & \mathbf{A} \\
(\mathbf{m} & \mathbf{m})\end{array}$ & $\begin{array}{l}\mathbf{K}_{2} \\
(\mathbf{m m})\end{array}$ & $\begin{array}{ll}\mathbf{O}_{1} & A \\
(\mathbf{m ~ m})\end{array}$ & $\begin{array}{ll}S_{1} & A \\
(\mathbf{m ~ m})\end{array}$ & $\begin{array}{l}\mathbf{K}_{1} \mathbf{A} \\
(\mathbf{m m})\end{array}$ \\
\hline $\begin{array}{l}\mathrm{L} 37 / 0693 \\
\end{array}$ & $\begin{array}{l}-43.97, \\
172.01\end{array}$ & $\begin{array}{l}01 / 08- \\
01 / 15\end{array}$ & 80 & 0 & 59.3 & 73.5 & 377.5 & 44.2 & 16.3 & 17.8 & 0.3 & 20.5 \\
\hline M35/7753 & $\begin{array}{l}-43.53, \\
172.74\end{array}$ & $\begin{array}{l}01 / 08- \\
02 / 11\end{array}$ & 55 & 0.2 & 55.6 & 51.1 & 414.3 & 26.6 & 7.4 & 15.6 & 0.2 & 25.2 \\
\hline M37/0287 & $\begin{array}{l}-43.84, \\
172.54\end{array}$ & $\begin{array}{l}01 / 08- \\
01 / 15\end{array}$ & 62 & 0.2 & 25.6 & 75.4 & 306 & 35.2 & 12.2 & 12.5 & 0.1 & 11.5 \\
\hline $\mathrm{K} 38 / 1705$ & $\begin{array}{l}-44.19 \\
171.49\end{array}$ & $\begin{array}{l}01 / 08- \\
01 / 15\end{array}$ & 100 & 0.2 & 181 & 62.2 & 171.7 & 21.9 & 6.6 & 8.9 & 0.1 & 7.7 \\
\hline K38/1706 & $\begin{array}{l}-44.19 \\
171.49\end{array}$ & $\begin{array}{l}01 / 08- \\
01 / 15\end{array}$ & 72.5 & 0.2 & 25.1 & 42.9 & 160.7 & 20.1 & 6.5 & 9.2 & 0.1 & 7.8 \\
\hline $\mathrm{K} 38 / 1707$ & $\begin{array}{l}-44.19 \\
171.49\end{array}$ & $\begin{array}{l}01 / 08- \\
01 / 15\end{array}$ & 34 & 0.2 & 29.8 & 32.8 & 122.1 & 14.9 & 5.2 & 7.3 & 0.1 & 6.7 \\
\hline $\mathrm{K} 38 / 1821$ & $\begin{array}{l}-44.19 \\
171.49\end{array}$ & $\begin{array}{l}01 / 08- \\
01 / 15\end{array}$ & 19.4 & 0.2 & 16.2 & 70.6 & 83.2 & 9.6 & 3.5 & 4.1 & 0.2 & 3.7 \\
\hline M36/5893 & $\begin{array}{l}-43.55 \\
172.75\end{array}$ & $\begin{array}{l}01 / 08- \\
01 / 15\end{array}$ & 54.3 & 0.2 & 86.1 & 41.8 & 429.8 & 28 & 8.5 & 17.9 & 0.2 & 27.9 \\
\hline M36/5894 & $\begin{array}{l}-43.55 \\
172.75\end{array}$ & $\begin{array}{l}01 / 08- \\
01 / 15\end{array}$ & 84.7 & 0.2 & 164.5 & 33.7 & 272.8 & 19 & 4.9 & 15 & 0.2 & 21.7 \\
\hline M36/5895 & $\begin{array}{l}-43.55 \\
172.75\end{array}$ & $\begin{array}{l}01 / 08- \\
01 / 15\end{array}$ & 138 & 0.2 & 22 & 54.4 & 461.1 & 38.2 & 9.6 & 18 & 4.4 & 23 \\
\hline M37/0461 & $\begin{array}{l}-43.86, \\
172.33\end{array}$ & $\begin{array}{l}01 / 08- \\
01 / 15\end{array}$ & 15.5 & 0.7 & 449.8 & 59.2 & 68.6 & 8.6 & 2.9 & 3.6 & 0.4 & 2.4 \\
\hline M37/0463 & $\begin{array}{l}-43.86, \\
172.33\end{array}$ & $\begin{array}{l}01 / 08- \\
01 / 15\end{array}$ & 84 & 0.7 & 34 & 65.7 & 178 & 21.5 & 7.5 & 8 & 0.1 & 6.6 \\
\hline M35/5691 & $\begin{array}{l}-43.51 \\
172.72\end{array}$ & $\begin{array}{l}01 / 08- \\
05 / 12\end{array}$ & 98.9 & 0.8 & 15.3 & 27.1 & 162.9 & 31.8 & 4.6 & 10.7 & 0.2 & 15.9 \\
\hline J39/0875 & $\begin{array}{l}-44.49 \\
171.20\end{array}$ & $\begin{array}{l}12 / 10- \\
01 / 15\end{array}$ & 143 & 1.9 & 24.6 & 19.4 & 49.8 & 8.5 & 2.2 & 3.6 & 0 & 1.1 \\
\hline M35/5760 & $\begin{array}{l}-43.55 \\
172.70\end{array}$ & $\begin{array}{l}01 / 08- \\
01 / 15\end{array}$ & 68 & 3.9 & 363.7 & -70.9 & 19.9 & 1.1 & 0.5 & 1.3 & 6.4 & 1.7 \\
\hline M35/6107 & $\begin{array}{l}-43.55 \\
172.70\end{array}$ & $\begin{array}{l}01 / 08- \\
01 / 15\end{array}$ & 39.1 & 4 & 63.6 & -9.8 & 72.4 & 4.3 & 0.5 & 4.2 & 0.5 & 7.7 \\
\hline M36/5325 & $\begin{array}{l}-43.56 \\
172.70\end{array}$ & $\begin{array}{l}01 / 08- \\
01 / 15\end{array}$ & 33 & 4 & 207 & 0 & 126.7 & 8.4 & 2.2 & 7.8 & 0.1 & 10.8 \\
\hline M36/5385 & $\begin{array}{l}-43.56 \\
172.70\end{array}$ & $\begin{array}{l}01 / 08- \\
01 / 15\end{array}$ & 6 & 4 & 196.4 & -29.7 & 59.1 & 5 & 0.6 & 4.4 & 0.1 & 4.1 \\
\hline M36/7535 & $\begin{array}{l}-43.55 \\
172.70\end{array}$ & $\begin{array}{l}01 / 08- \\
01 / 15\end{array}$ & 20.7 & 4.3 & 158.5 & -100.7 & 14.9 & 0.3 & 0.6 & 2.6 & 0.1 & 3.7 \\
\hline M35/1163 & $\begin{array}{l}-43.42, \\
172.66\end{array}$ & $\begin{array}{l}01 / 08- \\
01 / 15\end{array}$ & 85.3 & 4.4 & 84 & 0.6 & 21.5 & 14.3 & 1.1 & 2.3 & 0.1 & 4 \\
\hline M36/5384 & $\begin{array}{l}-43.57 \\
172.70\end{array}$ & $\begin{array}{l}01 / 08- \\
02 / 13\end{array}$ & 6 & 4.5 & 434 & -111.7 & 10.7 & 0.7 & 0.4 & 1.8 & 0.4 & 3.5 \\
\hline M35/0846 & $\begin{array}{l}-43.39 \\
172.65\end{array}$ & $\begin{array}{l}01 / 08- \\
01 / 15\end{array}$ & 87.5 & 4.7 & 19 & -19.4 & 44.9 & 31.4 & 4.6 & 3.3 & 5.9 & 28.4 \\
\hline M36/1159 & $\begin{array}{l}-43.57 \\
172.70\end{array}$ & $\begin{array}{l}01 / 08- \\
02 / 12\end{array}$ & 33.8 & 4.9 & 465 & -15.2 & 28.3 & 2.7 & 0.6 & 2 & 0.1 & 3.7 \\
\hline M36/1160 & $\begin{array}{l}-43.57 \\
172.70\end{array}$ & $\begin{array}{l}01 / 08- \\
01 / 15\end{array}$ & 30.8 & 4.9 & 291.7 & -32.6 & 18.7 & 1.4 & 0.5 & 1.5 & 0.8 & 1.7 \\
\hline L37 /0022 & $\begin{array}{l}-43.92, \\
172.00\end{array}$ & $\begin{array}{l}01 / 08- \\
01 / 15\end{array}$ & 62.7 & 5.4 & 533.2 & 7.3 & 48.4 & 11.2 & 2.8 & 2.8 & 0.6 & 29.8 \\
\hline M36/1917 & $\begin{array}{l}-43.57 \\
172.69\end{array}$ & $\begin{array}{l}01 / 08- \\
02 / 11\end{array}$ & 33.4 & 5.4 & 22.6 & -20.1 & 14.7 & 5.7 & 0.9 & 3.2 & 0.1 & 6.3 \\
\hline M36/4730 & $\begin{array}{l}-43.55 \\
172.68\end{array}$ & $\begin{array}{l}01 / 08- \\
03 / 11\end{array}$ & 33.5 & 5.6 & 78.4 & -23.2 & 10.9 & 14 & 2.4 & 2.7 & 0.1 & 7.8 \\
\hline M36/4628 & $\begin{array}{l}-43.55 \\
172.68\end{array}$ & $\begin{array}{l}01 / 08- \\
02 / 11\end{array}$ & 75 & 5.7 & 219.6 & 23.5 & 26 & 0.9 & 0.3 & 1.7 & 0.1 & 5.7 \\
\hline
\end{tabular}




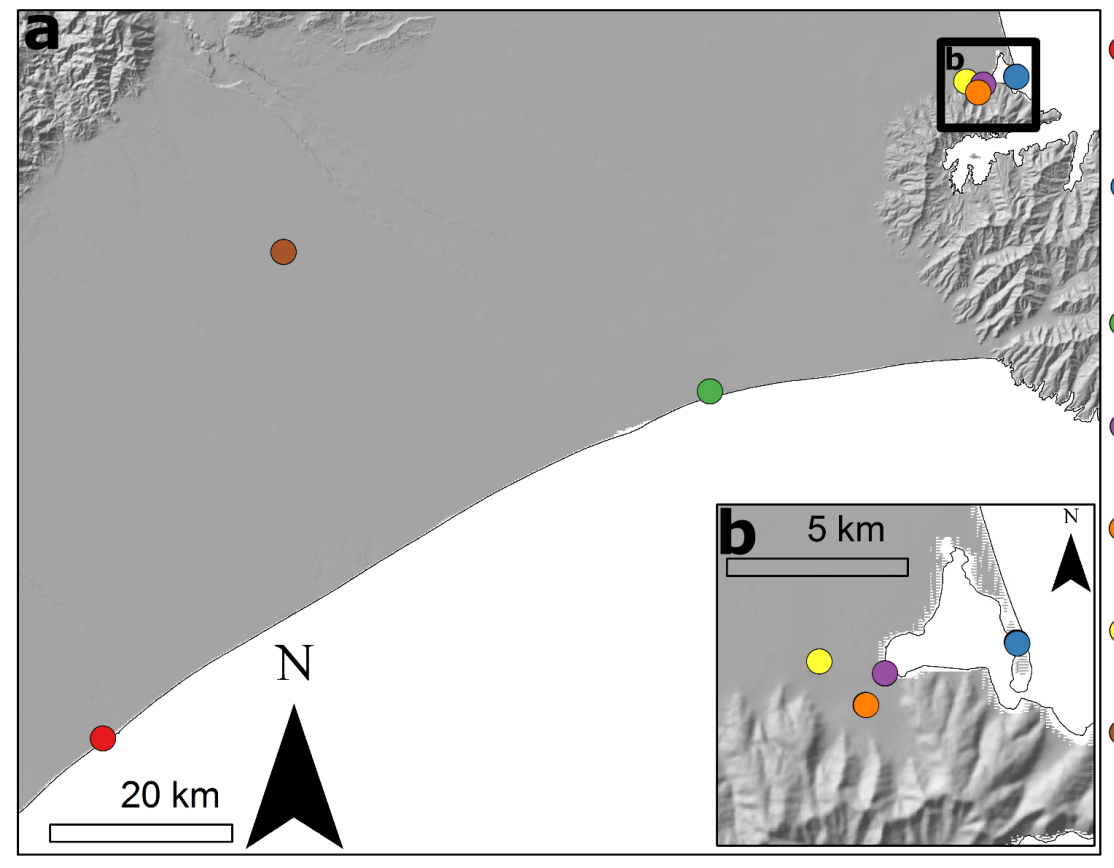

WELL NAME, DEPTH (M)

Cluster 1:

$\mathrm{K} 38 / 1705,100$

$\mathrm{K} 38 / 1706,72.5$

$\mathrm{K} 38 / 1707,34$

Cluster 2:

M36/5893, 54.3

$M 36 / 5894,84.7$

M36/5895, 138

Cluster 3:

M37/0461, 15.5

M37/0463, 84

Cluster 4:

M36/5325, 33

M36/5385, 6

Cluster 5:

M36/5384, 6

M36/1159, 33.8

Cluster 6:

M36/4730, 33.5

M36/4628, 75

Cluster 7:

K36/0439, 230

K36/0494, 172

K36/0495, 195

Figure A.1: Map showing clustered wells in the Canterbury Plains monitoring system. Cluster number is consistent with Figure 4.6. 


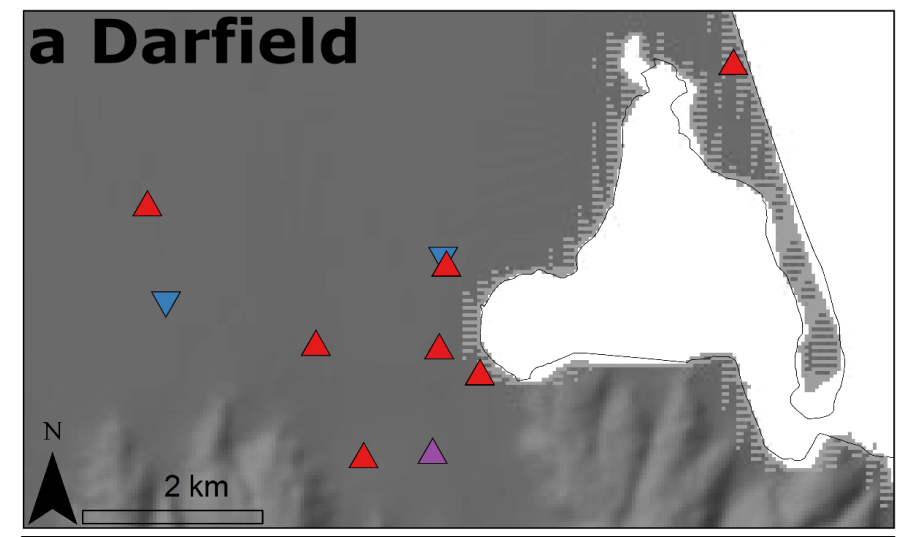

\section{Water-level change \\ $\triangle$ Increase \\ $\nabla$ Decrease}

Tidal behaviour change $\Delta \phi_{\text {lag }}$ increase

\section{Earthquakes}

$\star$ Chch (Feb) $M_{w} 6.2$

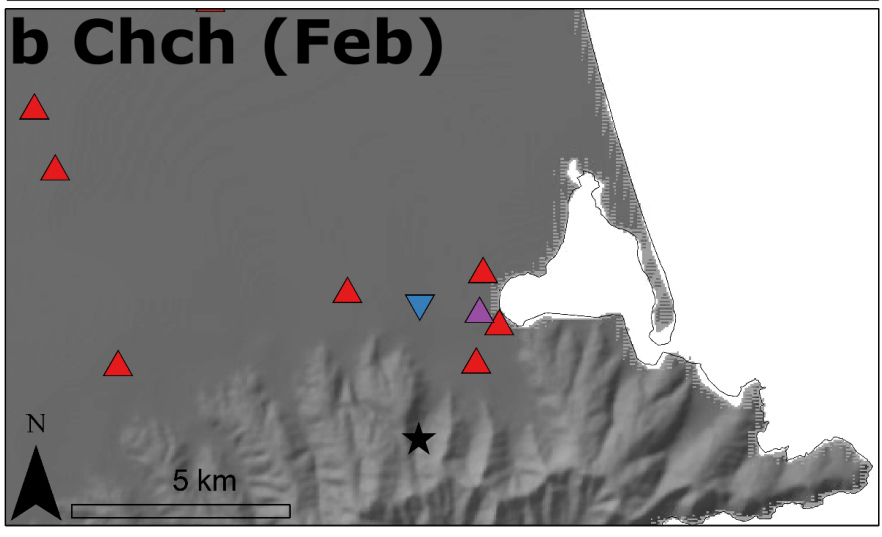

Figure A.2: Water-level changes that occurred nearby permeability changes detected by tidal behaviour changes. (a - Top) $M_{w} 7.1$ Darfield earthquake. (b - Bottom) $M_{w}$ 6.2 Christchurch (February) earthquake. 


\section{Bibliography}

Aben, F. M., Doan, M. L., Gratier, J. P., and Renard, F. (2017). Experimental postseismic recovery of fractured rocks assisted by calcite sealing. Geophysical Research Letters, 44(14):7228-7238.

Agnew, D. C. (2005). Earth tides: An introduction. University of California, San Diego, CA, USA.

Agnew, D. C. (2012). SPOTL: Some Programs for Ocean-Tide Loading. SIO Technical Report, Scripps Institution of Oceanography.

Akita, F. and Matsumoto, N. (2004). Hydrological responses induced by the Tokachioki earthquake in 2003 at hot spring wells in Hokkaido, Japan. Geophysical Research Letters, 31(16):4-7.

Akkar, S. and Özen, Ö. (2005). Effect of peak ground velocity on deformation demands for SDOF systems. Earthquake Engineering and Structural Dynamics, 34(13):15511571.

Allen, J., Ashford, S., Bowman, E., Bradley, B. A., Cox, B., Cubrinovski, M., Green, R. A., Hutchinson, T., Kavazanjian, E., Orense, R., Pender, M., Quigley, M., and Wotherspoon, L. (2010). Geotechnical Reconnaissance of the 2010 Darfield (New Zealand) Earthquake. Bulletin of the NZSEE, 43(1):243-321.

Allen, R. B., Bellingham, P. J., and Wiser, S. K. (1999). Immediate Damage by an Earthquake to a Temperate Montane Forest. Ecology, 80(2):708-714.

Alley, W. M., Healy, R. W., Labaugh, J. W., and Reilly, T. E. (2002). Flow and storage in groundwater systems. Science, 296:1985-1990.

Ambraseys, N. N. (1988). Engineering seismology. Earthquake Engineering Structural Dynamics, 17:1-105.

Bai, S. B., Wang, J., Lü, G. N., Zhou, P. G., Hou, S. S., and Xu, S. N. (2010). GIS-based logistic regression for landslide susceptibility mapping of the Zhongxian segment in the Three Gorges area, China. Geomorphology, 115(1-2):23-31.

Bal, A. a. (1996). Valley fills and coastal cliffs buried beneath an alluvial plain: Evidence from variation of permeabilities in gravel aquifers, Canterbury Plains, New Zealand. Journal of Hydrology New Zealand, 35(1):1-27. 
Bard, P. and Riepl-Thomas, J. (2000). Wave propagation in complex geological structures and their effects on strong ground motion. Wave Motion in Earthquake Engineering, pages $37-95$.

Bath, M. (1966). Earthquake Energy and Magnitude. Physics and Chemistry of the Earth, 7:115-165.

Benites, R. and Olsen, K. B. (2005). Modeling strong ground motion in the Wellington metropolitan area, New Zealand. Bulletin of the Seismological Society of America, 95(6):2180-2196.

Bense, V. F., Gleeson, T., Loveless, S. E., Bour, O., and Scibek, J. (2013). Fault zone hydrogeology. Earth-Science Reviews, 127:171-192.

Beresnev, I. a. and Wen, K.-l. (1996). Nonlinear Soil Response-A Reality ? Bulletin of the Seismological Society of America, 86(6):1964-1978.

Berrill, J. B., Mulqueen, P. C., and Ooi, E. T. C. (1994). Liquefaction at Kaiapoi in the 1901 Cheviot, New Zealand, Earthquake. Bulletin of the New Zealand Natioanl Society for Earthquake Enginnering, 27(3):178-189.

Berryman, K. R., Beanland, S., Cooper, A. F., Cutten, H. N., Norris, R. J., and Wood, P. R. (1992). The Alpine Fault, New Zealand: variation in Quaternary structural style and geomorphic expression. Annales tectonicae, 6:126-163.

Berryman, K. R., Cochran, U. A., Clark, K. J., Biasi, G. P., Langridge, R. M., and Villamor, P. (2012). Major earthquakes occur regularly on an isolated plate boundary fault. Science, 336:1690-1693.

Besedina, A., Vinogradov, E., Gorbunova, E., and Svintsov, I. (2017). Chilean Earthquakes: Aquifer responses at the Russian platform. Pure and Applied Geophysics, pages 133-144.

Bhuiyan, C. (2010). Hydrogeological factors : their association and relationship with seasonal water-table fluctuation in the composite hardrock Aravalli terrain, India. Environmental Earth Sciences, 60:733-748.

Biot, M. a. (1941). General theory of three-dimensional consolidation. Journal of Applied Physics, 12(2):155-164.

Blanchard, F. B. and Byerly, P. (1935). A study of a well gauge as a seismograph. Bulletin of the Seismological Society of America, 25(4):313-321.

Bodvarsson, G. (1970). Confined fluids as strain meters. Journal of Geophysical Research, 75(14):2711-2718. 
Bonini, M., Rudolph, M. L., and Manga, M. (2016). Long- and short-term triggering and modulation of mud volcano eruptions by earthquakes. Tectonophysics, 672673:190-211.

Borcherdt, R. D. (1994). Estimates of site-dependent response spectra for design (methodology and justification).

Boulton, C., Moore, D. E., Lockner, D. A., Toy, V. G., Townend, J., and Sutherland, R. (2014). Frictional properties of exhumed fault gouges in DFDP-1 cores, Alpine Fault, New Zealand. Geophysical Research Letters, 41:356-362.

Boulton, C., Yao, L., Faulkner, D. R., Townend, J., Toy, V. G., Sutherland, R., Ma, S., and Shimamoto, T. (2017). High-velocity frictional properties of Alpine Fault rocks: Mechanical data, microstructural analysis, and implications for rupture propagation. Journal of Structural Geology, 97:71-92.

Bower, D. R. (1983). Bedrock fracture parameters from the interpretation of well tides. Journal of Geodynamics, 88(B6):5025-5035.

Bower, D. R. and Heaton, K. C. (1978). Response of an aquifer neat Ottawa to tidal forcing and the Alaskan earthquake of 1964. Canadian Journal of Earth Sciences, $15(3): 331-340$.

Bradley, B. a. (2013). A New Zealand-specific pseudospectral acceleration groundmotion prediction equation for active shallow crustal earthquakes based on foreign models. Bulletin of the Seismological Society of America, 103(3):1801-1822.

Bradley, B. A., Bae, S. E., Polak, V., Lee, R. L., Thomson, E. M., and Tarbali, K. (2017a). Ground motion simulations of great earthquakes on the Alpine Fault: Effect of hypocentre location and comparison with empirical modelling. New Zealand Journal of Geology and Geophysics, 60(3):188-198.

Bradley, B. A. and Hughes, M. (2012). Conditional Peak Ground Accelerations in the Canterbury Earthquakes for Conventional Liquefaction Assessment. University of Canterbury, Christchurch, New Zealand.

Bradley, B. A., Razafindrakoto, H. N. T., and Nazer, M. A. (2017b). Strong ground motion observations of engineering interest from the 14 November 2016 Mw7.8 Kaikoura, New Zealand earthquake. Bulletin of the New Zealand Society for Earthquake Engineering, 50(2):85-93.

Bradley, B. A., Wotherspoon, L. M., and Kaiser, A. E. (2017c). Ground motion and site effect observations in the wellington region from the 2016 Mw7.8 Kaikoura, New Zealand earthquake. Bulletin of the New Zealand Society for Earthquake Engineering, 50(2):94-105. 
Bredehoeft, J. D. (1967). Response of Well-Aquifer Systems to Earth Tides. Journal of Geophysical Research, 72(12):3075-3087.

Brodsky, E. E., Roeloffs, E., Woodcock, D., Gall, I., and Manga, M. (2003). A mechanism for sustained groundwater pressure changes induced by distant earthquakes. Journal of Geophysical Research, 108(B8):1-10.

Brown (2001). Canterbury. In Groundwaters of New Zealand2, pages 441-459. New Zealand Hydrological Society.

Brown, L. and Weeber, J. H. (1992). Geology of the Chirstchurch urban area: scale 1:50,000. Lower Hutt, GNS Science. Institute of Geological \& Nuclear Sciences.

Budescu, D. V., Por, H. H., Broomell, S. B., and Smithson, M. (2014). The interpretation of IPCC probabilistic statements around the world. Nature Climate Change, $4(6): 508-512$.

Burley, S. D., Mullis, J., and Matter, A. (1989). Timing diagenesis in the Tartan Reservoir (UK North Sea): constraints from combined cathodoluminescence microscopy and fluid inclusion studies. Marine and Petroleum Geology, 6:98-120.

Burnham, K. P. and Anderson, D. R. (2004). Multimodel inference: Understanding AIC and BIC in model selection. Sociological Methods and Research, 33(2):261-304.

Carpenter, B. M., Kitajima, H., Sutherland, R., Townend, J., Toy, V. G., and Saffer, D. M. (2014). Hydraulic and acoustic properties of the active Alpine Fault, New Zealand: Laboratory measurements on DFDP-1 drill core. Earth and Planetary Science Letters, 390:45-51.

Carrigan, C. R., King, G. C. P., Barr, G. E., and Bixler, N. E. (1991). Potential for water-table excursions induced by seismic events at Yucca Mountain, Nevada. Geology, 19(12):1157-1160.

Chen, G., Zhou, Z., Sun, T., Wu, W., Xu, L., Khoshnevisan, S., and Ling, D. (2018). Shear Modulus and Damping Ratio of Sand-Gravel Mixtures Over a Wide Strain Range. Journal of Earthquake Engineering, 2469:1-34.

Chen, J. S. and Wang, C. Y. (2009). Rising springs along the Silk Road. Geology, $37(3): 243-246$.

Chia, Y., Chiu, J. J., Chiang, Y. H., Lee, T. P., Wu, Y. M., and Horng, M. J. (2008). Implications of coseismic groundwater level changes observed at multiple-well monitoring stations. Geophysical Journal International, 172(1):293-301. 
Clark, K. J., Nissen, E. K., Howarth, J. D., Hamling, I. J., Mountjoy, J. J., Ries, W. F., Jones, K., Goldstien, S., Cochran, U. A., Villamor, P., Hreinsdóttir, S., Litchfield, N. J., Mueller, C., Berryman, K. R., and Strong, D. T. (2017). Highly variable coastal deformation in the 2016 Mw7.8 Kaikoura earthquake reflects rupture complexity along a transpressional plate boundary. Earth and Planetary Science Letters, 474:334-344.

Clayton, C. R. I. (2011). Stiffness at small strain: research and practice. Géotechnique, $61(1): 5-37$.

Close, M., Banasiak, L., Weaver, L., van der Raaj, R., and Morgenstern, U. (2017). Waiwhetu Aquifer Investigations. ESR. Draft Report.

Coombs, D. S., Landis, C. A., Norris, R. J., Sinton, J. M., Borns, D. J., and Craw, D. (1976). The Dun Mountain ophiolite belt, New Zealand, its tectonic setting, constitution, and origin, with special reference to the southern portion. American Journal of Science, 276(5):561-603.

Cooper, H. H., Bredehoeft, J. D., Papadopulos, I. S., and Bennett, R. R. (1965). The Response of Well-Aquifer Systems to Seismic Waves. Journal of Geophysical Research, 70(16):3915-3926.

Cowan, H. A. (1991). The North Canterbury earthquake of September 1, 1888. Journal of the Royal Society of New Zealand, 21(1):1-12.

Cox, S. C., Menzies, C. D., Sutherland, R., Denys, P. H., Chamberlain, C., and Teagle, D. a. H. (2015). Changes in hot spring temperature and hydrogeology of the Alpine Fault hanging wall, New Zealand, induced by distal South Island earthquakes. Geofluids, 15(1-2):216-239.

Cox, S. C., Rutter, H. K., Sims, A., Manga, M., Weir, J. J., Ezzy, T., White, P. A., Horton, T. W., and Scott, D. (2012). Hydrological effects of the M W 7 . 1 Darfield (Canterbury) earthquake, 4 September 2010 , New Zealand. New Zealand Journal of Geology and Geophysics, pages 1-17.

Cox, S. C. and Sutherland, R. (2007). Regional Geological Framework of South Island, New Zealand, and its Significance for Understanding the Active Plate Boundary. A Continental Plate Boundary: Tectonics at South Island, New Zealand, pages 19-46.

Cua, G. B. (2004). Creating the Virtual Seismologist: Developments in ground motion characterization and seismic early warning, Ph. D. dissertation. PhD thesis, California Institue of Technology. 
Cubrinovski, M., Bray, J. D., De La Torre, C., Olsen, M. J., Bradley, B. A., Chiaro, G., Stocks, E., and Wotherspoon, L. (2017). Liquefaction effects and associated damages observed at the Wellington centreport from the 2016 Kaikoura earthquake. Bulletin of the New Zealand Society for Earthquake Engineering, 50(2):152-173.

Cubrinovski, M., Bray, J. D., Taylor, M., Giorgini, S., Bradley, B., Wotherspoon, L., and Zupan, J. (2011). Soil Liquefaction Effects in the Central Business District during the February 2011 Christchurch Earthquake. Seismological Research Letters, 82(6):893-904.

Dann, R. L., Close, M. E., Pang, L., Flintoft, M. J., and Hector, R. P. (2008). Complementary use of tracer and pumping tests to characterize a heterogeneous channelized aquifer system in New Zealand. Hydrogeology Journal, 16(6):1177-1191.

Davies, A. J., Sadashiva, V., Aghababaei, M., Barnhill, D., Costello, S. B., Fanslow, B., Headifen, D., Hughes, M., Kotze, R., Mackie, J., Ranjitkar, P., Thompson, J., Troitino, D. R., Wilson, T., Woods, S., and Wotherspoon, L. M. (2017). Transport infrastructure performance and management in the South Island of New Zealand, during the first 100 days following the $2016 \mathrm{Mw} 7.8$ "Kaikoura" earthquake. Bulletin of the New Zealand Society for Earthquake Engineering, 50(2):271-299.

De Pascale, G. P. and Langridge, R. M. (2012). New on-fault evidence for a great earthquake in A.D. 1717, central alpine fault, New Zealand. Geology, 40(9):791794.

Dellow, S., Massey, C., Cox, S., Archibald, G., Begg, J., Bruce, Z., Carey, J., Davidson, J., Della Pasqua, F., Glassey, P., Hill, M., Jones, K., Lyndsell, B., Lukovic, B., McColl, S., Rattenbury, M., Read, S., Rosser, B., Singeisen, C., Townsend, D., Villamor, P., Villeneuve, M., Godt, J., Jibson, R., Allstadt, K., Rengers, F., Wartman, J., Rathje, E., Sitar, N., Adda, A. Z., Manousakis, J., and Little, M. (2017). Landslides caused by the Mw7.8 Kaikoura earthquake and the immediate response. Bulletin of the New Zealand Society for Earthquake Engineering, 50(2):106-116.

DeMets, C., Gordon, R. G., and Argus, D. F. (2010). Geologically current plate motions. Geophysical Journal International, 181(1):1-80.

Dempsey, E. D., Holdsworth, R. E., Imber, J., Bistacchi, A., and Di Toro, G. (2014). A geological explanation for intraplate earthquake clustering complexity: The zeolitebearing fault/fracture networks in the Adamello Massif (Southern Italian Alps). Journal of Structural Geology, 66:58-74.

Destegul, U., Dellow, G., and Heron, D. W. (2008). A ground shaking amplification map for New Zealand. Engineering an earthquake resilient New Zealand: New Zealand Society for Earthquake Engineering, 11-13 Apri. 
Doan, M. L. (2005). Étude in-situ des interactions hydromécaniques entre fluides et failles. Application au Laboratoire du Rift de Corinthe. PhD thesis, PhD thesis, Institut de Physique du Globe de Paris.

Doan, M.-L. and Brodsky, E. E. (2006). Tidal analysis of borehole pressure: A tutorial. University of California, Santa Cruz, page 27 pp.

Dobry, R., Ladd, R. S., Yokel, F. Y., Chung, R. M., and Powell, D. (1982). Prediction of pore water pressure buildup and liquefaction of sands during earthquakes by the cyclic strain method, volume 138.

Downes, G. and Dowrick, D. (2015). Atlas of Isoseismal Maps of New Zealand Earthquakes, 1843-2003, Second Ed. Technical report, Institute of Geological \& Nuclear Sciences, Lower Hutt, New Zealand.

Dowrick, D. J. (1996). The Modified Mercall Earthquake Intensity Scale - Revisions arising from recent studies of New Zealand earthakes. Bulletin of the New Zealand National Society for Earthquake Engineering, 29(2):92-106.

Dowrick, D. J. and Rhoades, D. A. (2005). Revised models for attenuation of Modified Mercalli intensity in New Zealand earthquakes. Bulletin of the New Zealand Society for Earthquake Engineering, 38:185-214.

Dudley Ward, N. F. (2015). On the mechanism of earthquake induced groundwater flow. Journal of Hydrology, 530:561-567.

Dykes, R. C., Brook, M. S., and Lube, G. (2017). A major ice-calving event at Tasman Glacier terminus, Southern Alps, 22 February 2011. Journal of the Royal Society of New Zealand, 47(4):336-343.

Eaton, J. P. and Takasaki, K. J. (1959). Seismological interpretation of earthquakeinduced water-level fluctuations in wells. Bulletin of the Seismological Society of America, 49(3):227-245.

Ebdon, D. (1985). Statistics in Geography. Blackwell.

ECan (2011). Earthquake impacts on groundwater: Update \#2. Environment Canterbury, Groundwater Resources Section.

Eiby, G. A. (1966). The Modified Mercalli Scale of Earthquake Intensity and Its Use in New Zealand. New Zealand Journal of Geology and Geophysics, 9(1-2):122-129.

Elkhoury, J. E., Brodsky, E. E., and Agnew, D. C. (2006). Seismic waves increase permeability. Nature, 441(7097):1135-1138. 
Elkhoury, J. E., Niemeijer, A., Brodsky, E. E., and Marone, C. (2011). Laboratory observations of permeability enhancement by fluid pressure oscillation of in situ fractured rock. Journal of Geophysical Research: Solid Earth, 116(2):1-15.

Ellsworth, W. L. (2013). Injection-induced earthquakes. Science, 341(6142):1225942.

Esposito, E., Pece, R., Porfido, S., and Tranfaglia, G. (2009). Ground effects and hydrological changes in the southern Apennines (Italy) in response to the 23 July 1930 earthquake (Ms=6.7). Natural Hazards and Earth System Science, 9:539-550.

Faoro, I., Elsworth, D., and Marone, C. (2012). Permeability evolution during dynamic stressing of dual permeability media. Journal of Geophysical Research:, 117(B01310):1-10.

Faulkner, D., Jackson, C., Lunn, R., Schlische, R., Shipton, Z., Wibberley, C., and Withjack, M. (2010). A review of recent developments concerning the structure, mechanics and fluid flow properties of fault zones. Journal of Structural Geology, 32(11):1557-1575.

Ferris, J. G. (1951). Cyclic fluctuations of water level as a basis for determining aquifer transmissibility. Internat. Geodesy Geophysics Union, Assoc. Sci. Hydrology Gen. Assembly, Brussels, 2:148-155.

Forsyth, P. J., Barrell, D. J. A., and Jongens, R. (2008). Geology of the Christchurch area: scale 1:250,000. Lower Hutt, GNS Science. Institute of Geological \& Nuclear Sciences, page $67 \mathrm{p}$.

Freed, A. M. (2005). Earthquake triggering by static, dynamic, and postseismic stress transfer. Annual Review of Earth and Planetary Sciences, 33(1):335-367.

Freeze, R. A. and Cherry, J. A. (1979). Groundwater. Prentice-Hall, Inc. Englewood Cliffs, NJ.

Galassi, D. M., Lombardo, P., Fiasca, B., Di Cioccio, A., Di Lorenzo, T., Petitta, M., and Di Carlo, P. (2014). Earthquakes trigger the loss of groundwater biodiversity. Scientific Reports, 4(April 2009):4-11.

Galli, P. (2000). New empirical relationships between magnitude and distance for liquefaction. Tectonophysics, 324(3):169-187.

García-Rodríguez, M. J., Malpica, J. A., Benito, B., and Díaz, M. (2008). Susceptibility assessment of earthquake-triggered landslides in El Salvador using logistic regression. Geomorphology, 95(3-4):172-191.

Gerstenberger, M., McVerry, G., Rhoades, D., and Stirling, M. (2014). Seismic hazard modeling for the recovery of Christchurch. Earthquake Spectra, 30(1):17-29. 
Gerstenberger, M. C., Worden, C. B., and Wald, D. J. (2007). A Probabilistic Relationship between Ground Shaking Parameters and MMI Based on Felt Report Data. In Proc. New Zealand Society for Earthquake Engineering, Palmerston North: Performance by design, can we predict it?

Gledhill, K., Ristau, J., Reyners, M., Fry, B., and Holden, C. (2011). The Darfield (Canterbury, New Zealand) Mw 7.1 Earthquake of September 2010: A Preliminary seismological report. Seismological Research Letters, 82(3):378-386.

Gleeson, T. and Ingebritsen, S. (2016). Crustal permeability. John Wiley \& Sons.

Gluyas, J. and Swarbrick, R. (2013). Petroleum Geoscience. John Wiley \& Sons.

Grapes, R. (1988). Dogo hot spring revisited: The earthquake effect. Research School of Earth Sciences, Victoria University.

Grapes, R., Little, T., and Downes, G. (1998). Rupturing of the Awatere Fault during the 1848 October 16 Marlborough earthquake, New Zealand: Historical and present day evidence. New Zealand Journal of Geology and Geophysics, 41(4):387-399.

Gratier, J.-P. and Gueydan, F. (2007). Deformation in the presence of fluids and minerals: Effect of Fracturing and Fluid-rock Interaction on Seismic Cycles. In Tectonic Faults: Agents of Change on a Dynamic Earth, pages 319-356.

Gulley, A. K., Dudley, N. F., Cox, S. C., and Kaipio, J. P. (2013). Groundwater responses to the recent Canterbury earthquakes : a comparison. Journal of Hydrology, 504:171-181.

Hamling, I. J., D’Anastasio, E., Wallace, L. M., Ellis, S., Motagh, M., Samsonov, S., Palmer, N., and Hreinsdõttir, S. (2014). Crustal deformation and stress transfer during a propagating earthquake sequence: The 2013 Cook Strait sequence, central New Zealand. Journal of Geophysical Research: Solid Earth, 119(7):6080-6092.

Hamling, I. J., Hreinsdóttir, S., Clark, K., Elliott, J., Liang, C., Fielding, E., Litchfield, N., Villamor, P., Wallace, L., Wright, T. J., and al., E. (2017). Complex multifault rupture during the $2016 \mathrm{Mw} 7.8$ Kaikoura earthquake, New Zealand. Science, 7194(March).

Hancox, G. T., Dellow, G. D., and Perrin, N. D. (1997). Earthquake-induced landsliding in New Zealand and implications for MM intensity and seismimc hazard assessment. Institute of Geological \& Nuclear Sciences, Client Rep.

Hancox, G. T., Perrin, N. D., and Dellow, G. D. (2002). Recent studies of historical earthquake-induced landsliding, ground damage, and MM intensity in New Zealand. Bulletin of the New Zealand Society for Earthquake Engineering, 35(2):59-95. 
Hardin, B. O. and Drnevich, V. P. (1972). Shear modulus and damping in soils: design equations and curves. Journal of Soil Mechanics \& Foundations Div, 98(sm7).

Harrison, J. C. (1976). Cavity and topographic effects in tilt and strain measurement. Journal of Geophysical Research, 81(2):319-328.

Hart, D. J. and Wang, H. F. (1995). Laboratory measurements of a complete set of poroelastic moduli for Berea sandstone and Indiana limestone. Journal of Geophysical Research, 100(B9):17,741-17,751.

Hazirbaba, K. and Rathje, E. M. (2004). A comparison between in situ and laboratory measurements of pore water pressure generation. 13th World Conference on Earthquake Engineering, Vancouver:1220.

Heron, D. (2014). Geological map of New Zealand 1:250,000. GNS Science, Lower Hutt, New Zealand.

Holden, C., Kaiser, A., Van Dissen, R., and Jury, R. (2013a). Sources, ground motion and structural response characteristics in wellington of the 2013 cook strait earthquakes. Bulletin of the New Zealand Society for Earthquake Engineering, 46(4):188195.

Holden, C., Kaneko, Y., D’Anastasio, E., Benites, R., Fry, B., and Hamling, I. J. (2017). The 2016 Kaikoura Earthquake Revealed by Kinematic Source Inversion and Seismic Wavefield Simulations: Slow Rupture Propagation on a Geometrically Complex Crustal Fault Network. Geophysical Research Letters, 44(22):11,320-11,328.

Holden, C., Zhao, J., and Stirling, M. (2013b). Ground motion modelling of a large subduction interface earthquake in Wellington, New Zealand. Proceedings of the New Zealand society of earthquake engineering, annual meeting.

Holden, C. and Zhao, J. X. (2011). Preliminary broadband modelling of an Alpine Fault earthquake in Christchurch. GNS Science report, 28:15 p.

Holt, W. E. and Haines, a. J. (1995). The kinematics of northern South Island, New Zealand, determined from geologic strain rates. Journal of Geophysical Research, 100(B9):17991-18010.

Horspool, N. A., Chadwick, M., Ristau, J., Salichon, J., and Gerstenberger, M. C. (2015). ShakeMapNZ : Informing post-event decision making. NZSEE Conference, pages $369-376$.

Hosmer, D. S. and Lemeshow, S. (1989). Applied Logistic Regression. Wiley, New York. 
Hosmer, D. W. and Lemeshow, S. (2000). Applied Logistic Regression. John Wiley and Sons Inc., New York.

Howarth, J. D., Fitzsimons, S. J., Norris, R. J., and Jacobsen, G. E. (2014). Lake sediments record high intensity shaking that provides insight into the location and rupture length of large earthquakes on the Alpine Fault, New Zealand. Earth and Planetary Science Letters, 403:340-351.

Hsieh, P. a., Bredehoeft, J. D., and Farr, J. M. (1987). Determination of aquifer transmissivity from Earth tide analysis. Water Resources Research, 23(10):18241832.

Hsu, C. C. and Vucetic, M. (2004). Volumetric threshold shear strain for cyclic settlement. Journal of Geotechnical and Geoenvironmental Engineering, 130:58-70.

Igarashi, G. and Wakita, H. (1995). Geochemical and hydrological observations for earthquake prediction in Japan. Journal of Geophysical Research, 43:585-598.

Ishihara, K. (1996). Soil behaviour in earthquake geotechnics. Oxford: Clarendon Press.

Itaba, S. and Koizumi, N. (2007). Earthquake-related changes in groundwater levels at the Dogo hot spring, Japan. Pure and Applied Geophysics, 164:2397-2410.

Ito, Y., Hino, R., Kido, M., Fujimoto, H., Osada, Y., Inazu, D., Ohta, Y., Iinuma, T., Ohzono, M., Miura, S., Mishina, M., Suzuki, K., Tsuji, T., and Ashi, J. (2013). Episodic slow slip events in the Japan subduction zone before the 2011 Tohoku-Oki earthquake. Tectonophysics, 600:14-26.

Jacob, C. (1950). Flow of groundwater. In Rouse, H., editor, Engineering Hydraulics1, pages 321-386. John Wiley, New York.

Jacoby, G. C., Bunker, D. E., and Benson, B. E. (1997). Tree-ring evidence for an A.D. 1700 Cascadia earthquake in Washington and northern Oregon. Geology, 25(11):9991002.

Jaeger, J. and Cook, N. (1979). Fundamentals of rock mechanics. Chapman and Hall, London, UK, 3rd edition edition.

Johnson, A. G., Kovach, R. L., Nur, A., and Booker, J. R. (1973). Pore pressure changes during creep events on the San Andreas Fault. Journal of Geophysical Research, 78(5):851-857.

Jones, A. and Baker, T. (2005). Groundwater monitoring technical report. Greater Wellington Regional Council, page p. 142. 
Jónsson, S., Segall, P., Pedersen, R., and Björnsson, G. (2003). Post-earthquake ground movements correlated to pore-pressure transients. Nature, 424(July):179-183.

Kaiser, A., Balfour, N., Fry, B., Holden, C., Litchfield, N., Gerstenberger, M., D'Anastasio, E., Horspool, N., McVerry, G., Ristau, J., Bannister, S., Christophersen, A., Clark, K., Power, W., Rhoades, D., Massey, C., Hamling, I., Wallace, L., Mountjoy, J., Kaneko, Y., Benites, R., Van Houtte, C., Dellow, S., Wotherspoon, L., Elwood, K., and Gledhill, K. (2017). The 2016 Kaikōura, New Zealand, Earthquake: Preliminary Seismological Report. Seismological Research Letters, 88(3):727-739.

Kaiser, A., Holden, C., Beavan, J., Beetham, D., Benites, R., Celentano, A., Cousins, J., Cubrinorski, M., Dellow, G., Denys, P., Fielding, E., Fry, B., Gerstenberger, M., Langridge, R., Massey, C., Motagh, M., Pondard, N., Mcverry, G., Ristau, J., Stirling, M., Thomas, J., Uma, S. R., and Zhao, J. (2012a). The Mw 6.2 Christchurch earthquake of February 2011: preliminary report. New Zealand Journal of Geology and Geophysics, 55(1):67-90.

Kaiser, A., Holden, C., Zhao, J., McVerry, G., and Benites, R. (2012b). It's our fault: Ground motion modelling of local site effects in the Wellington region. GNS Science Consultancy Report, 172.

Kano, Y. and Yanagidani, T. (2006). Broadband hydroseismograms observed by closed borehole wells in the Kamioka mine, central Japan: Response of pore pressure to seismis waves from 0.05 to $2 \mathrm{~Hz}$. Journal of Geophysical Research: Solid Earth, 111(3):1-11.

Kato, A., Obara, K., Igarashi, T., Tsuruoka, H., Nakagawa, S., and Hirata, N. (2012). Propagation of slow slip leading up to the 2011 Mw 9.0 Tohoku-Oki earthquake. Science, 335(6069):705-708.

Keranen, K. M., Weingarten, M., Abers, G. A., Bekins, B. A., and Ge, S. (2014). Sharp increase in central Oklahoma seismicity since 2008 induced by massive wastewater injection. Science, 345(6195):448-451.

King, C.-Y., Azuma, S., Igarashi, G., Ohno, M., Saito, H., and Wakita, H. (1999). Earthquake-related water-level changes at 16 closely clustered wells in Tono, central Japan. Journal of Geophysical Research, 104(B6):13073-13082.

Kinoshita, C., Kano, Y., and Ito, H. (2015). Shallow crustal permeability enhancement in central Japan due to the 2011 Tohoku earthquake. Geophysical Research Letters, 42:773-780.

Kitagawa, Y., Koizumi, N., Takahashi, M., Matsumoto, N., and Sato, T. (2006). Changes in groundwater levels or pressures associated with the 2004 earthquake off the west coast of northern Sumatra (M9.0). Earth, Planets and Space, 58(2):173-179. 
Kleinbaum, D. G. and Klein, M. (2002). Logistic Regression: A Self-Learning Text. Springer, New York, 2nd edition.

Koizumi, N., Kano, Y., Kitagawa, Y., Sato, T., Takahashi, M., Mishimura, S., and Nishida, R. (1996). Groundwater anomalies associated with the 1995 Hyogo-ken Nanbu earthquake. Journal of Physics of the Earth, 44:373-380.

Lai, G., Ge, H., Xue, L., Brodsky, E. E., Huang, F., and Wang, W. (2014). Tidal response variation and recovery following the Wenchuan earthquake from water level data of multiple wells in the nearfield. Tectonophysics, 619-620:115-122.

Lai, W.-c., Hsu, K.-c., Shieh, C.-l., Lee, Y.-p., Chung, K.-C., Koizumi, N., and Matsumoto, N. (2010). Evaluation of the effects of ground shaking and static volumetric strain change on earthquake-related groundwater level changes in Taiwan. Earth, Planets and Space, 62:391-400.

Lai, W.-c., Koizumi, N., Matsumoto, N., Kitagawa, Y., Lin, C.-w., Shieh, C.-l., and Lee, Y.-p. (2004). Effects of seismic ground motion and geological setting on the coseismic groundwater level changes caused by the 1999 Chi-Chi earthquake, Taiwan. Earth, Planets and Space, 56:873-880.

Landis, C. A. and Coombs, D. S. (1967). Metamorphic belts and orogenesis in southern New Zealand. Tectonophysics, 4(4-6):501-518.

Langridge, R. M., Ries, W. F., Litchfield, N. J., Villamor, P., Van Dissen, R. J., Barrell, D. J., Rattenbury, M. S., Heron, D. W., Haubrock, S., Townsend, D. B., Lee, J. M., Berryman, K. R., Nicol, A., Cox, S. C., and Stirling, M. W. (2016). The New Zealand Active Faults Database. New Zealand Journal of Geology and Geophysics, 59(1):86-96.

Larsen, K., Petersen, J. H., Budtz-Jørgensen, E., and Endahl, L. (2000). Interpreting parameters in the logistic regression model with random effects. Biometrics, $56(3): 909-14$.

Lay, T. and Wallace, T. C. (1995). Modern Glocal Seismology. San Diego: Academic Press.

Lee, S. and Pradhan, B. (2007). Landslide hazard mapping at Selangor, Malaysia using frequency ratio and logistic regression models. Landslides, 4(1):33-41.

Lee, S.-H., Hamm, S.-Y., Ha, K., Ko, K.-S., and Cheong, J.-Y. (2012). Groundwater response analysis to multiple earthquakes on Jeju volcanic island. Geosciences Journal, 16(4):469-478. 
Lees, J. J., Ballagh, R. H., Orense, R. P., and Ballegooy, S. V. (2015). CPT-based analysis of liquefaction and re-liquefaction following the Canterbury earthquake sequence. Soil Dynamics and Earthquake Engineering, 79:304-314.

Li, X., Zhong, L., and Pyrak-nolte, L. J. (2001). Physics of partially saturated porous media: Residual saturation and seismic-wave propagation. Annu. Rev. Earth Planet. Sci., 29(1):419-460.

Liao, X., Wang, C. Y., and Liu, C. P. (2015). Disruption of groundwater systems by earthquakes. Geophysical Research Letters, 42(22):9758-9763.

Linde, A. T. and Sacks, I. S. (1998). Triggering of volcanic eruptions. Nature, 395:888890.

Litchfield, N. J., Van Dissen, R., Sutherland, R., Barnes, P. M., Cox, S. C., Norris, R., Beavan, R. J., Langridge, R., Villamor, P., Berryman, K., Stirling, M., Nicol, A., Nodder, S., Lamarche, G., Barrell, D. J., Pettinga, J. R., Little, T., Pondard, N., Mountjoy, J. J., and Clark, K. (2014). A model of active faulting in New Zealand. New Zealand Journal of Geology and Geophysics, 57(1):32-56.

Little, T. a. and Jones, A. (1998). Seven million years of strike-slip and related off-fault deformation, northeastern Marlborough fault system, South Island, New Zealand. Tectonics, 17(2):285-302.

Liu, C., Wang, G., Shi, Z., Xu, Y., Fang, H., and Wang, J. (2013). Tide-factor anomalies from observations of well level in the Sichuan Province prior to the great Wenchuan earthquake of 2008. Journal of Geodynamics, 63:54-61.

Liu, L.-B., Roeloffs, E., and Zheng, X.-Y. (1989). Seismically induced water level fluctuations in the Wali Well, Beijing, China. Journal of Geophysical Research, 94(B7):9453-9462.

Liu, W. and Manga, M. (2009). Changes in permeability caused by dynamic stresses in fractured sandstone. Geophysical Research Letters, 36(20):2-5.

Love, A. E. H. (1927). Elasticity. Dover, New York.

Luong, M. P. (1980). Stress-strain aspects of cohesionless soils under cyclic and transient loading. Proceedings of the International Symposium on Soils under Cyclic and Transient Loading, Rotterdam,:315-324.

Mair, R. J. and Wood, D. M. (2013). Pressuremeter testing: methods and interpretation. Elsevier. 
Manga, M. (2001). Origin of postseismic streamflow changes inferred from baseflow recession and magnitude-distance relations. Geophysical Research Letters, 28(10):2133-2136.

Manga, M. (2003). Response of streamflow to multiple earthquakes. Geophysical Research Letters, 30(5):10-13.

Manga, M., Beresnev, I., Brodsky, E. E., Elkhoury, J. E., Elsworth, D., Ingebritsen, S. E., Mays, D. C., and Wang, C.-y. (2012). Changes in Permeability Caused By Transient Stresses : Field Observations, Experiments, and Mechanisms. Reviews of Geophysics, 50(2):24 pp.

Manga, M. and Brodsky, E. (2006). Seismic triggering of eruptions in the far field: Volcanoes and Geysers. Annual Review of Earth and Planetary Sciences, 34(1):263291.

Manga, M. and Rowland, J. C. (2009). Response of Alum Rock springs to the October 30, 2007 Alum Rock earthquake and implications for the origin of increased discharge after earthquakes. Geofluids, 9(3):237-250.

Manga, M. and Wang, C. Y. (2007). Earthquake Hydrology. Treatise on Geophysics, $4: 293-320$.

Manga, M., Wang, C. Y., and Shirzaei, M. (2016). Increased stream discharge after the 3 September $2016 \mathrm{Mw} 5.8$ Pawnee, Oklahoma earthquake. Geophysical Research Letters, 43(22):11,588-11,594.

Mason, D. P. and Little, T. A. (2006). Refined slip distribution and moment magnitude of the 1848 marlborough earthquake, Awatere Fault, New Zealand. New Zealand Journal of Geology and Geophysics, 49(3):375-382.

Matsumoto, N., Kitagawa, G., and Roeloffs, E. a. (2003). Hydrological response to earthquakes in the Haibara well, central Japan - I. Groundwater level changes revealed using state space decomposition of atmospheric pressure, rainfall and tidal responses. Geophysical Journal International, 155(3):885-898.

McVerry, G. H., Zhao, J. X., Abrahamson, N. A., and Somerville, P. G. (2006). New Zealand acceleration response spectrum attenuation relations for crustal and subduction zone earthquakes. Bulletin of the New Zealand Society for Earthquake Engineering, 39(1):1-58.

Menzies, C. D., Teagle, D. A., Craw, D., Cox, S. C., Boyce, A. J., Barrie, C. D., and Roberts, S. (2014). Incursion of meteoric waters into the ductile regime in an active orogen. Earth and Planetary Science Letters, 399:1-13. 
Menzies, C. D., Teagle, D. A. H., Niedermann, S., Cox, S. C., Craw, D., Zimmer, M., Cooper, M. J., and Erzinger, J. (2016). The fluid budget of a continental plate boundary fault: Quantification from the Alpine Fault, New Zealand. Earth and Planetary Science Letters, 445:125-135.

Merritt, M. L. (2004). Estimating hydraulic properties of the Floridan aquifer system by analysis of earth-tide, ocean-tide, and barometric effects, Collier and Hendry Counties. US Department of the Interior, US Geological Survey.

Miller, M. M. and Shirzaei, M. (2015). Spatiotemporal characterization of land subsidence and uplift in Phoenix using InSAR time series and wavelet transforms. Journal of Geophysical Research: Solid Earth, 120:5822-5842.

Mohr, C. H., Manga, M., and Wald, D. (2018). Stronger Peak Ground Motion, Beyond the Threshold to Initiate a Response, Does Not Lead to Larger Stream Discharge Responses to Earthquakes. Geophysical Research Letters, 45:1-9.

Mohr, C. H., Manga, M., Wang, C. Y., Kirchner, J. W., and Bronstert, A. (2015). Shaking water out of soil. Geology, 43(3):207-210.

Montgomery, D. R., Greenberg, H. M., and Smith, D. T. (2003). Streamflow response to the Nisqually earthquake. Earth and Planetary Science Letters, 209(1-2):19-28.

Montgomery, D. R. and Manga, M. (2003). Streamflow and water well responses to earthquakes. Science (New York, N.Y.), 300:2047-2049.

Mortensen, C. E., Lee, R. C., and Burford, R. O. (1977). Changes on the Central San Andreas Fault. Bulletin of the Seismological Society of America, 67(3):641-649.

Mortimer, N., Rattenbury, M., King, P., Bland, K., Barrell, D., Bache, F., Begg, J., Campbell, H., Cox, S., Crampton, J., Edbrooke, S., Forsyth, P., Johnston, M., Jongens, R., Lee, J., Leonard, G., Raine, J., Skinner, D., Timm, C., Townsend, D., Tulloch, A., Turnbull, I., and Turnbull, R. (2014). High-level stratigraphic scheme for New Zealand rocks. New Zealand Journal of Geology and Geophysics, 57(4):402-419.

Mukherjee, S. (1996). Targeting saline aquifer by remote sensing and geophysical methods in a part of Hamirpur-Kanpur, India. Hydrology Journal, 19:53-64.

Nespoli, M., Todesco, M., Serpelloni, E., Belardinelli, M. E., Bonafede, M., Marcaccio, M., Rinaldi, A. P., Anderlini, L., and Gualandi, A. (2016). Modeling earthquake effects on groundwater levels: evidences from the 2012 Emilia earthquake (Italy). Geofluids, 16(3):452-463. 
New Zealand Geotechnical Society (2010). Geotechnical earthquake engineering practice: Module 1 - Guideline for the identification, assessment and mitigation of liquefaction hazards. page $34 \mathrm{pp}$.

Nicol, A., Van Dissen, R., Stirling, M., and Gerstenberger, M. (2016). Completeness of the paleoseismic active fault record in New Zealand. Seismological Research Letters, $86(6)$.

Norris, R. J. and Cooper, A. F. (2001). Late Quaternary slip rates and slip partitioning on the Alpine Fault, New Zealand. Journal of Structural Geology, 23(2-3):507-520.

O’Brien, G. A., Cox, S. C., and Townend, J. (2016). Spatially and temporally systematic hydrologic changes within large geoengineered landslides, Cromwell Gorge, New Zealand, induced by multiple regional earthquakes. Journal of Geophysical Research : Solid Earth, 121:1-24.

Ohno, M., Wakita, H., and Kanjo, K. (1997). A water well sensitive to seismic waves. Geophysical Research Letters, 24(6):691-694.

Okada, Y. (1992). Internal deformation due to shear and tensile faults in a half-space. Bulletin of the Seismological Society of America, 82(2):1018-1040.

Orense, R. P., Kiyota, T., Yamada, S., Cubrinovski, M., Hosono, Y., Okamura, M., and Yasuda, S. (2011). Comparison of liquefaction Features observed during the 2010 and 2011 Canterbury earthquakes. Seismological Research Letters, 82(6):905-918.

Orense, R. P., Mirjafari, Y., Asadi, S., Naghibi, M., Chen, X., Altaf, O., and Asadi, B. (2017). Ground performance in Wellington waterfront area following the 2016 Kaikōura earthquake. Bulletin of the New Zealand Society for Earthquake Engineering, 50(2):142-151.

Orense, R. P., Pender, M., and Wotherspoon, L. (2012). Orense et al 2012. Geotechnical Engineering Journal SEAGS \& AGSSEA, 43(2):8-17.

Pedretti, D., Russia, A., Sanchez-Vila, X., and Dentz, M. (2016). Scale dependence of the hydraulic properties of a fractured aquifer estimated using transfer functions. Water Resources Research, 52:5008-5024.

Peres, D. J. and Cancelliere, A. (2014). Derivation and evaluation of landslidetriggering thresholds by a Monte Carlo approach. Hydrology and Earth System Sciences, 18(12):4913-4931.

Petitta, M., Mastrorillo, L., Preziosi, E., Banzato, F., Barberio, M. D., Billi, A., Cambi, C., Luca, G. D., Carlo, G. D., Curzio, D. D., Salvo, C. D., Nanni, T., Palpacelli, S., Rusi, S., Saroli, M., Tallini, M., Tazioli, A., Valigi, D., Vivalda, P., and Doglioni, C. 
(2018). Water-table and discharge changes associated with the 2016-2017 seismic sequence in central Italy: hydrogeological data and a conceptual model for fractured carbonate aquifers. Hydrogeology Journal, 26:1009-1026.

Popescu, R. (2002). Finite element assessment of the effects of seismic loading rate on soil liquefaction. Canadian Geotechnical Journal, 39(2):331-344.

Prior, J. C. and Lohmann, P. J. (2003). Iowa's groundwater basics. Iowa Department of Natural Resources.

Quigley, M. C., Bastin, S., and Bradley, B. a. (2013). Recurrent liquefaction in Christchurch, New Zealand, during the Canterbury earthquake sequence. Geology, 41(4):419-422.

Quigley, M. C., Hughes, M. W., Bradley, B. A., van Ballegooy, S., Reid, C., Morgenroth, J., Horton, T., Duffy, B., and Pettinga, J. R. (2016). The 2010-2011 Canterbury Earthquake Sequence: Environmental effects, seismic triggering thresholds and geologic legacy. Tectonophysics, 672-673:228-274.

Quilty, E. G. and Roeloffs, E. a. (1997). Water-level changes in response to the 20 December 1994 earthquake near Parkfield, California. Bulletin of the Seismological Society of America, 87(2):310-317.

Reyes, A. G., Christenson, B. W., and Faure, K. (2010). Sources of solutes and heat in low-enthalpy mineral waters and their relation to tectonic setting, New Zealand. Journal of Volcanology and Geothermal Research, 192(3-4):117-141.

Roberts, P. M. (2005). Laboratory observations of altered porous fluid flow behavior in Berea sandstone induced by low-frequency dynamic stress stimulation. Acoustical Physics, 51(S1):S140-S148.

Rodgers, D. W. and Little, T. A. (2006). World's largest coseismic strike-slip offset: The 1855 rupture of the Wairarapa Fault, New Zealand, and implications for displacement/length scaling of continental earthquakes. Journal of Geophysical Research, 111(12):B12408.

Roeloffs, E., Danskin, W. R., Farrarr, C. D., Galloway, D. L., Hamlin, S. N., Quilty, E. G., Quinn, H. M., Schaefer, D. H., Sorey, M. L., and Woodcock, D. E. (1995). Hydrologic effects of the June 28, 1992 Landers earthquake. : U. S. Geological Survey, Open File.

Roeloffs, E. and Rudnicki, J. W. (1984). Coupled deformation-diffusion effects on water-level changes due to propagating creep events. Pure and Applied Geophysics, 122(2-4):560-582. 
Roeloffs, E., Sneed, M., Galloway, D. L., Sorey, M. L., Farrar, C. D., Howle, J. F., and Hughes, J. (2003). Water-level changes induced by local and distant earthquakes at Long Valley caldera, California. Journal of Volcanology and Geothermal Research, 127(3-4):269-303.

Roeloffs, E. a. (1996). Poroelastic techniques in the study of earthquake-related hydrology phenomenon. Advances in Geophysics, 37:135-195.

Roeloffs, E. a. (1998). Persistent water level changes in a well near Parkfield, California, due to local and distant earthquakes. Journal of Geophysical Research, 103(B1):869889.

Roeloffs, E. A., Nelms, D. L., and Sheets, R. A. (2015). Widespread groundwaterlevel offsets caused by the Mw 5.8 Mineral, Virginia, earthquake of 23 August 2011. Geological Society of America Special Papers, 509:117-136.

Roeloffs, E. A. and Rudnicki, J. W. (1986). The effect of fault plane impermeability on pore pressure changes induced by propogating creep events (abstract). Eos. Trans. $A G U, 67: 272$.

Rojstaczer, S., Wolf, S., and Michel, R. (1995). Permeability enhancement in the shallow crust as a cause of earthquake-induced hydrological changes. Nature, 373(6511):237-239.

Rowland, J. V. and Simmons, S. F. (2012). Hydrologic, magmatic, and tectonic controls on hydrothermal flow, Taupo Volcanic Zone, New Zealand: Implications for the formation of epithermal vein deposits. Economic Geology, 107(3):427-457.

Rudnicki, J. W. and Roeloffs, E. A. (1990). PLan strain shear dislocations moving steadily in linear elastic diffusive solids. Journal of Applied Mechanics, 57(1):32-39.

Rutter, H. K., Cox, S. C., Dudley Ward, N. F., and Weir, J. J. (2016). Aquifer permeability change caused by a near-field earthquake, Canterbury, New Zealand. Water Resources Research, pages 8861-8878.

Rutter, H. K., Weaver, K. C., and Mzila, D. (2018). Potential impacts on groundwater quality caused by earthquake induced vertical permeability enhancement (Abstract). 38th Hydrology and Water Resources Symposium, Sydney.

Saffer, D. M. and Wallace, L. M. (2015). The frictional, hydrologic, metamorphic and thermal habitat of shallow slow earthquakes. Nature Geoscience, 8:594-600.

Seed, H. B. (1968). Landslides during earthquakes due to soil liquefaction. Terzaghi Lectures: 1963-1972, pages 191-261. 
Seed, H. B. and Idriss, I. M. (1967). Analysis of soil liquefaction: Niigata earthquake. Journal of the Soil Mechanics and Foundation Division, 93(3):83-108.

Seed, H. B. and Lee, K. L. (1966). Liquefaction of saturated sands during cyclic loading. Journal of Soil Mechanics \& Foundations Division, 92(105-134).

Shi, Z. and Wang, G. (2014). Hydrological response to multiple large distant earthquakes in the Mile well, China. Journal of Geophysical Research: Earth Surface, pages 2448-2459.

Shi, Z. and Wang, G. (2015). Sustained groundwater level changes and permeability variation in a fault zone following the 12 May 2008, M w 7.9 Wenchuan earthquake. Hydrological Processes, 29(12):2659-2667.

Shi, Z., Wang, G., and Liu, C. (2013a). Advances in research on earthquake fluids hydrogeology in China: A review. Earthquake Science, 26(6):415-425.

Shi, Z., Wang, G., and Liu, C. (2013b). Co-Seismic Groundwater Level Changes Induced by the May 12, 2008 Wenchuan Earthquake in the Near Field. Pure and Applied Geophysics, 170(11):1773-1783.

Shi, Z., Wang, G., Manga, M., and Wang, C.-Y. (2015a). Continental-scale water-level response to a large earthquake. Geofluids, 15(1-2):310-320.

Shi, Z., Wang, G., Manga, M., and Wang, C.-Y. (2015b). Mechanism of co-seismic water level change following four great earthquakes - insights from co-seismic responses throughout the Chinese mainland. Earth and Planetary Science Letters, 430:66-74.

Shi, Z., Wang, G., Wang, C. Y., Manga, M., and Liu, C. (2014). Comparison of hydrological responses to the Wenchuan and Lushan earthquakes. Earth and Planetary Science Letters, 391:193-200.

Shi, Z., Zhang, S., Yan, R., and Wang, G. (2018). Fault Zone Permeability Decrease Following Large Earthquakes in a Hydrothermal System. Geophysical Research Letters, 45(3):1387-1394.

Sibson, R. H. (1986). Brecciation processes in fault zones: Inferences from earthquake rupturing. Pure and Applied Geophysics, 124(1-2):159-175.

Sibson, R. H. (1994). Crustal stress, faulting and fluid flow. Geological Society, London, Special Publications, 78(1):69-84.

Sibson, R. H., Moore, J. M. M., and Rankin, A. H. (1975). Seismic pumping - a hydrothermal fluid transport mechanism. Journal of the Geological Society, 131(6):653659. 
Smith, E. G. C., Andrews, A. L., Davis, R. O., Dowrick, D. J., King, A. B., Lowry, M. A., and Wood, P. R. (1992). A revision of the Modified Mercalli seismic intensity scale: report of a study group of the New Zealand Society for Earthquake Engineering. Bulletin of the New Zealand National Society for Earthquake Engineering, $25(4): 345-347$.

Smith, W., McVerry, G., Cousins, J., Hancox, G., Downes, G., McSaveney, M., and Rattenbury, M. (2001). GAPQuake NZ - New Zealand Earthquake Loss Modelling. Institute of Geological and Nuclear Sciences Ltd Client Report, 20000/109.

Stearns, H. T. (1928). Record of earthquake made by automatic recorders on wells in California. Bulletin of the Seismological Society of America, 18:9-15.

Stein, R. S., Barka, A. A., and Dieterich, J. H. (1997). Progressive failure on the North Anatolian Fault since 1939 by earthquake stress triggering. Geophysical Journal International, 128:594-604.

Stirling, M., McVerry, G., Gerstenberger, M., Litchfield, N., Van Dissen, R., Berryman, K., Barnes, P., Wallace, L., Villamor, P., Langridge, R., Lamarche, G., Nodder, S., Reyners, M., Bradley, B., Rhoades, D., Smith, W., Nicol, A., Pettinga, J., Clark, K., and Jacobs, K. (2012). National seismic hazard model for New Zealand: 2010 update. Bulletin of the Seismological Society of America, 102(4):1514-1542.

Stirling, M. W., Litchfield, N. J., Villamor, P., Van Dissen, R. J., Nicol, A., Pettinga, J., Barnes, P., Langridge, R. M., Little, T., Barrell, D. J., Mountjoy, J., Ries, W. F., Rowland, J., Fenton, C., Hamling, I., Asher, C., Barrier, A., Benson, A., Bischoff, A., Borella, J., Carne, R., Cochran, U. A., Cockroft, M., Cox, S. C., Duke, G., Fenton, F., Gasston, C., Grimshaw, C., Hale, D., Hall, B., Hao, K. X., Hatem, A., Hemphill-Haley, M., Heron, D. W., Howarth, J., Juniper, Z., Kane, T., Kearse, J., Khajavi, N., Lamarche, G., Lawson, S., Lukovic, B., Madugo, C., Manousakis, I., McColl, S., Noble, D., Pedley, K., Sauer, K., Stah, T., Strong, D. T., Townsend, D. B., Toy, V., Villeneuve, M., Wandres, A., Williams, J., Woelz, S., and Zinke, R. (2017). The Mw7.8 2016 Kaikōura earthquake: Surface fault rupture and seismic hazard context. Bulletin of the New Zealand Society for Earthquake Engineering, $50(2): 73-84$.

Stringer, M. E., Bastin, S., McGann, C. R., Cappellaro, C., El Kortbawi, M., McMahon, R., Wotherspoon, L. M., Green, R. A., Aricheta, J., Davis, R., McGlynn, L., Hargraves, S., Van Ballegooy, S., Cubrinovski, M., Bradley, B. A., Bellagamba, X., Foster, K., Lai, C., Ashfield, D., Baki, A., Zekkos, A., Lee, R., and Ntritsos, N. (2017). Geotechnical aspects of the 2016 Kaikoura earthquake on the South Island of New Zealand. Bulletin of the New Zealand Society for Earthquake Engineering, 50(2):117-141. 
Sutherland, R., Eberhart-Phillips, D., Harris, R., Stern, T., Beavan, J., Ellis, S., Henrys, S., Cox, S., Norris, R., and Berryman, K. (2007). Do great earthquakes occur on the Alpine fault in central South Island, New Zealand? In: Okaya D, Stern TA, Davey F ed. A Continental Plate Boundary: Tectonics at South Island, New Zealand, American Geophysical Union, pages 235-251.

Sutherland, R., Toy, V., Townend, J., Eccles, J., Prior, D. J., Norris, R. J., Mariani, E., Faulkner, D. R., DePascale, G., Carpenter, B. M., Boulton, C., Menzies, C. D., Cox, S., Little, T., Hasting, M., Cole-Baker, J., Langridge, R., Scott, H. R., ReidLindroos, Z. R., Fleming, B., and Wing, R. (2011). Operations and well completion report for boreholes DFDP-1A and DFDP-1B, Deep Fault Drilling Project, Alpine Fault, Gaunt Creek, New Zealand. GNS Science Report, 48:70.

Sutherland, R., Toy, V. G., Townend, J., Cox, S. C., Eccles, J. D., Faulkner, D. R., Prior, D. J., Norris, R. J., Mariani, E., Boulton, C., Carpenter, B. M., Menzies, C. D., Little, T. A., Hasting, M., De Pascale, G. P., Langridge, R. M., Scott, H. R., Reid Lindroos, Z., Fleming, B., and Kopf, A. J. (2012). Drilling reveals fluid control on architecture and rupture of the Alpine fault, New Zealand. Geology, 40(12):11431146.

Talbot, J. D., Weeber, J. H., Freeman, M. C., Mason, C. R., and Wilson, D. D. (1985). The Christchurch artesian aquifers. North Canterbury Catchment Board, 159.

Tamura, Y. and Agnew, D. C. (2008). Baytap08 User 's Manual. Scripps Institution of Oceanography, UC San Die.

Taylor, C., Wilson, D., Brown, L., Stewart, M., Burden, R., and Brailsford, G. (1989). Sources and flow of North Canterbury plains groundwater, New Zealand. Journal of Hydrology, 106(3-4):311-340.

Terzaghi, K. (1925). Principles of soil mechanics, IV - Settlement and consolidation of clay. Engineering News-Record, 3(874-878).

Theodoulidis, N., Hollender, F., Mariscal, A., Moiriat, D., Bard, P. Y., Konidaris, A., Cushing, M., Konstantinidou, K., and Roumelioti, Z. (2018). The ARGONET (Greece) seismic observatory : An accelerometric vertical array and its data. Seismological Research Letters, 89(4):1555-1565.

Townend, J., Sutherland, R., and Toy, V. (2009). Deep fault drilling project-alpine fault, New Zealand. Scientific Drilling, 8:75-82.

Townend, J., Sutherland, R., Toy, V. G., Doan, M. L., Célérier, B., Massiot, C., Coussens, J., Jeppson, T., Janku-Capova, L., Remaud, L., Upton, P., Schmitt, D. R., Pezard, P., Williams, J., Allen, M. J., Baratin, L. M., Barth, N., Becroft, L., Boese, 
C. M., Boulton, C., Broderick, N., Carpenter, B., Chamberlain, C. J., Cooper, A., Coutts, A., Cox, S. C., Craw, L., Eccles, J. D., Faulkner, D., Grieve, J., Grochowski, J., Gulley, A., Hartog, A., Henry, G., Howarth, J., Jacobs, K., Kato, N., Keys, S., Kirilova, M., Kometani, Y., Langridge, R., Lin, W., Little, T., Lukacs, A., Mallyon, D., Mariani, E., Mathewson, L., Melosh, B., Menzies, C., Moore, J., Morales, L., Mori, H., Niemeijer, A., Nishikawa, O., Nitsch, O., Paris, J., Prior, D. J., Sauer, K., Savage, M. K., Schleicher, A., Shigematsu, N., Taylor-Offord, S., Teagle, D., Tobin, H., Valdez, R., Weaver, K., Wiersberg, T., and Zimmer, M. (2017). Petrophysical, Geochemical, and Hydrological Evidence for Extensive Fracture-Mediated Fluid and Heat Transport in the Alpine Fault's Hanging-Wall Damage Zone. Geochemistry, Geophysics, Geosystems, 18:4709-4732.

Townend, J., Sutherland, R., Toy, V. G., Eccles, J. D., Boulton, C., Cox, S. C., and McNamara, D. (2013). Late-interseismic state of a continental plate-bounding fault: Petrophysical results from DFDP-1 wireline logging and core analysis, Alpine Fault, New Zealand. Geochemistry, Geophysics, Geosystems, 14(9):3801-3820.

Townend, J. and Zoback, M. D. (2000). How faulting keeps the crust strong. Geology, 28(5):399-402.

Toy, V. G., Boulton, C. J., Sutherland, R., Townend, J., Norris, R. J., Little, T. A., Prior, D. J., Mariani, E., Faulkner, D., Menzies, C. D., Scott, H., and Carpenter, B. M. (2015). Fault rock lithologies and architecture of the central Alpine fault, New Zealand, revealed by DFDP-1 drilling. Lithosphere, 7(2):155-173.

Tranfaglia, G., Esposito, E., Porfido, S., and Pece, R. (2011). The 23 July 1930 earthquake $(\mathrm{Ms}=6.7)$ in the southern Apennines (Italy): Geological and hydrological effects. Bollettino Geofisico, pages 63-86.

Tukey, J. W. (1958). Bias and confidence in not quite large samples (abstract). Annals of Mathematical Statistics, 29:614.

Tukey, J. W. (1977). Exploratory data analysis. Addisson-Wesley.

Twarakavi, N. K. C. and Kaluarachchi, J. J. (2005). Aquifer vulnerability assessment to heavy metals using ordinal logistic regression. Groundwater, 43(2):200-214.

Van der Kamp, G. (1972). Tidal fluctuations in a confined aquifer extending under the sea. International Geological Congress, 24(11):101-106.

Velasco, A. A., Hernandez, S., Parsons, T., and Pankow, K. (2008). Global ubiquity of dynamic earthquake triggering. Nature Geoscience, 1(6):375-379.

Vucetic, M. (1994). Cyclic threshold of shear strains in soils. Journal of Geotechnical Engineering, 120:2208-2228. 
Wakita, H. (1975). Water wells as possible indicators of tectonic strain. Science, 189:553-555.

Wallace, L. M. and Beavan, J. (2010). Diverse slow slip behavior at the Hikurangi subduction margin, New Zealand. Journal of Geophysical Research: Solid Earth, 115:1-20.

Walsh, F. R. and Zoback, M. D. (2015). Oklahoma's recent earthquakes and saltwater disposal. Science Advances, 1(5):1-10.

Wang, C., Manga, M., Shirzaei, M., Weingarten, M., and Wang, L. (2017). Induced seismicity in Oklahoma affects shallow groundwater. Seismological Research Letters, 88(4):956-962.

Wang, C.-Y. (2007). Liquefaction beyond the Near Field. Seismological Research Letters, 78(5):512-517.

Wang, C. Y., Cheng, L. H., Chin, C. V., and Yu, S. B. (2001). Coseismic hydrologic response of an alluvial fan to the 1999 Chi-Chi earthquake, Taiwan. Geology, 29(9):831-834.

Wang, C. Y. and Chia, Y. (2008). Mechanism of water level changes during earthquakes: Near field versus intermediate field. Geophysical Research Letters, 35(12):15.

Wang, C. Y., Chia, Y., Wang, P. L., and Dreger, D. (2009). Role of S waves and Love waves in coseismic permeability enhancement. Geophysical Research Letters, $36(9): 1-5$.

Wang, C.-Y., Liao, X., Wang, L.-P., Wang, C.-H., and Manga, M. (2016). Large earthquakes create vertical permeability by breaching aquitards. Water Resources Research, 52(8):5923-5937.

Wang, C. Y. and Manga, M. (2010a). Earthquakes and Water, volume Lecture No. Springer.

Wang, C.-Y. and Manga, M. (2010b). Hydrologic responses to earthquakes and a general metric. Geofluids, 10:206-216.

Wang, C.-Y., Wang, C.-H., and Kuo, C.-H. (2004a). Temporal change in groundwater level following the $1999(\mathrm{Mw}=7.5)$ Chi-Chi earthquake, Taiwan. Geofluids, 5:210220.

Wang, C. Y., Wang, C. H., and Manga, M. (2004b). Coseismic release of water from mountains: Evidence from the $1999(\mathrm{Mw}=7.5)$ Chi-Chi, Taiwan, earthquake. Geology, 32(9):769-772. 
Wang, C. Y., Wong, A., Dreger, D. S., and Manga, M. (2006). Liquefaction limit during earthquakes and underground explosions: Implications on ground-motion attenuation. Bulletin of the Seismological Society of America, 96(1):355-363.

Wang, H. F. (2000). Theory of linear poroelasticity: with applications to geomechanics and hydrogeology. Princeton Series in Geophysics.

Water, W. (2017). Waterloo Wellfield Water Quality Contamination Investigations. Technical report.

Weingarten, M. and Ge, S. (2014). Insights into water level response to seismic waves: A 24 year high-fidelity record of global seismicity at Devils Hole. Geophysical Research Letters, 41(1):74-80.

Weingarten, M., Ge, S., Godt, J. W., Bekins, B. A., and Rubinstein, J. L. (2015). High-rate injection is associated with the increase in U.S. mid-continent seismicity. Science, 348(6241):1336-1340.

Weis, P., Driesner, T., and Heinrich, C. A. (2012). Porphyry-copper ore shells form at stable pressure-temperature fronts within dynamic fluid plumes. Science, 338(6114):1613-1616.

Wells, D. L. and Coppersmith, K. J. (1994). New Empirical Relationships among Magnitude, Rupture Length, Rupture Width, Rupture Area, and Surface Displacement. Bulletin of the Seismological Society of America, 84(4):974-1002.

Wesson, R. L. (1981). Interpretation of Changes in Water Level Accompanying Fault Creep and Implications for Earthquake Prediction. Journal of Geophysical Research, 86(B10):9259-9267.

White, P. A. (2001). Groundwater resources in New Zealand. Groundwaters of New Zealand, pages $45-75$.

Wilhelm, H., Zürn, W., and Wenzel, H. G. (1997). Tidal Phenomena, volume 66. Springer, Berlin, Germany.

Winkel, L., Berg, M., Amini, M., Hug, S. J., and Johnson, A. A. (2008). Predicting groundwater arsenic contamination in Southeast Asia from surface parameters. Nature Geoscience, 1(8):536-542.

Wong, A. and Wang, C. Y. (2007). Field relations between the spectral composition of ground motion and hydrological effects during the 1999 Chi-Chi (Taiwan) earthquake. Journal of Geophysical Research: Solid Earth, 112(10):1-19. 
Xue, L., Li, H.-B., Brodsky, E. E., Xu, Z.-Q., Kano, Y., Wang, H., Mori, J. J., Si, J.L., Pei, J.-L., Zhang, W., Yang, G., Sun, Z.-M., and Huang, Y. (2013). Continuous permeability measurements record healing inside the Wenchuan earthquake fault zone. Science, 340:1335-1338.

Yan, R., Wang, G., and Shi, Z. (2016). Sensitivity of hydraulic properties to dynamic strain within a fault damage zone. Journal of Hydrology, 543:721-728.

Yan, R., Woith, H., and Rongjiang, W. (2014). Groundwater level changes induced by the 2011 Tohoku earthquake in China mainland. Geophysical Journal International, 199:533-548.

Youd, T. L. (1972). Compaction od sands by repeated shear straining. Journal of Soil Mechanics \& Foundations.

Youd, T. L. and Carter, B. L. (2005). Influence of Soil Softening and Liquefaction on Spectral Acceleration. Journal of Geotechnical and Geoenvironmental Engineering, 131(7):811-825.

Zemansky, G., Van Dissen, R., Cox, S., and Gusyev, M. (2012). Potential impact of a Wellington Fault movement on the Waiwhetu Aquifer. GNS Science consultancy report 2012-204, (confident.

Zhan, Z., Jin, B., Wei, S., and Graves, R. W. (2011). Coulomb Stress Change Sensitivity due to Variability in Mainshock Source Models and Receiving Fault Parameters: A Case Study of the 2010-201. Christchurch, New Zealand, Earthquakes. Seismological Research Letters, 82(6):800-814.

Zhang, P., Deng, Q., Zhang, G., Ma, J., Gan, W., Min, W., Mao, F., and Wang, Q. (2003). Active tectonic blocks and strong earthquakes in the continent of China. Science in China (Series D), 46:13-24.

Zhang, Y., Fu, L.-Y., Huang, F., and Chen, X. (2015). Coseismic water-level changes in a well induced by teleseismic waves from three large earthquakes. Tectonophysics, 651-652:232-241.

Zoback, M. D. (2010). Reservoir geomechanics. Cambridge University Press.

Zoback, M. D. and Gorelick, S. M. (2012). Earthquake triggering and large-scale geologic storage of carbon dioxide. Proceedings of the National Academy of Sciences, 109(26):10164-10168.

Zoback, M. D. and Townend, J. (2001). Implications of hydrostatic pore pressures and high crustal strength for the deformation of intraplate lithosphere. Tectonophysics, $336(1-4): 19-30$. 